\title{
NGNP High Temperature Materials White Paper
}

\author{
August 2012
}

The INL is a

U.S. Department of Energy

National Laboratory

operated by

Battelle Energy Alliance

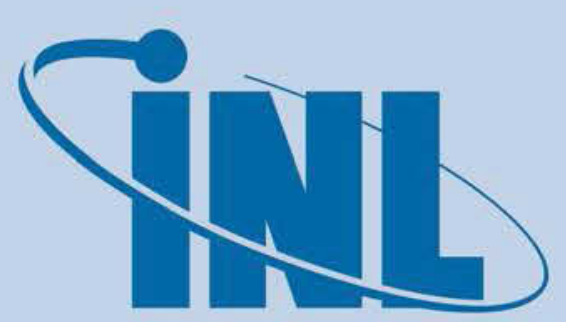

Idaho National Laboratory 


\section{DISCLAIMER}

This information was prepared as an account of work sponsored by an agency of the U.S. Government. Neither the U.S. Government nor any agency thereof, nor any of their employees, makes any warranty, expressed or implied, or assumes any legal liability or responsibility for the accuracy, completeness, or usefulness, of any information, apparatus, product, or process disclosed, or represents that its use would not infringe privately owned rights. References herein to any specific commercial product, process, or service by trade name, trade mark, manufacturer, or otherwise, does not necessarily constitute or imply its endorsement, recommendation, or favoring by the U.S. Government or any agency thereof. The views and opinions of authors expressed herein do not necessarily state or reflect those of the U.S. Government or any agency thereof. 
INL/EXT-09-17187

Revision 1

\section{NGNP High Temperature Materials White Paper}

August 2012

Idaho National Laboratory

Next Generation Nuclear Plant Project

Idaho Falls, Idaho 83415

Prepared for the

U.S. Department of Energy

Office of Nuclear Energy

Under DOE Idaho Operations Office

Contract DE-AC07-05ID14517 

Next Generation Nuclear Plant

NGNP High Temperature Materials White Paper

\author{
INL/EXT-09-17187 \\ Revision 1
}

August 2012

Approved by:

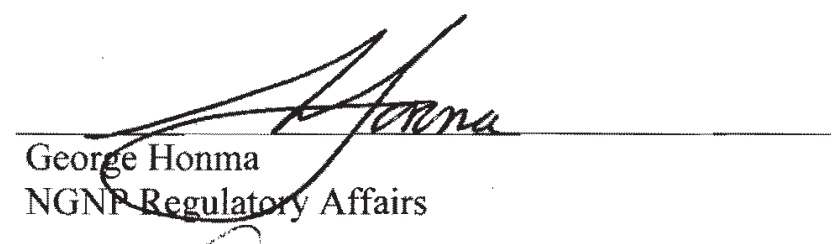

$$
\frac{8 / 1 / 12}{\text { Date }}
$$

Philip M. Mńls

$$
\frac{8 / 02 / 12}{\text { Date }}
$$

NGNP Engineering

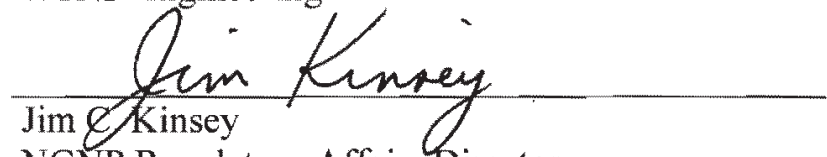

NGNP Regulatory Affairs Director

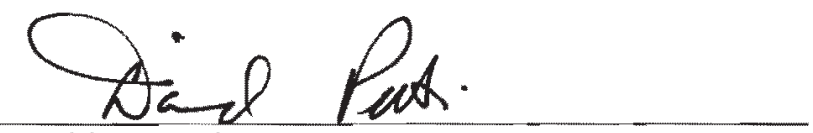

David A. Petti

VHTR TDO Director

$$
\begin{aligned}
& 8-2 / 2 \\
& 8 / 2 / 12
\end{aligned}
$$

Date 



\section{ABSTRACT}

The Next Generation Nuclear Plant (NGNP) will be a licensed commercial high temperature gas-cooled reactor (HTGR) plant capable of producing electricity and high temperature process heat for industrial markets supporting a range of end-user applications. The NGNP Project has adopted the 10 CFR 52 Combined License (COL) application process, as recommended in the Report to Congress, dated August 2008, as the foundation for the NGNP licensing strategy. Nuclear Regulatory Commission (NRC) licensing of the NGNP plant utilizing this process will demonstrate the efficacy of licensing future HTGRs for commercial industrial applications. This white paper is one in a series of submittals that will address key generic issues of the COL priority licensing topics as part of the process for establishing HTGR regulatory requirements.

The result of reviews of existing policies, regulations, and guidance associated with acceptable materials for HTGR applications is documented. It includes development of a process for high-temperature component material selection and evaluation, leading to recommendations for qualification and acceptance of HTGR components. Metallic and nonmetallic materials proposed for high-temperature service within the NGNP are identified and assessed in terms of supporting codes and standards and the existing bases for design and qualification. As part of this assessment, the processes for establishing the expected material performance requirements under operating and accident conditions are also described.

The information in this paper is intended to serve as the basis for interactions with the NRC staff. The NGNP Project wishes to obtain comments on the adequacy of the planned approach and feedback on a number of issues that have the potential to significantly impact the effort and schedule to prepare a COL application for the HTGR-based NGNP. Revision 0 of the NGNP High Temperature Materials White Paper (INL/EXT-09-17187) was submitted to the NRC on June 25, 2010, CCN 221269.

Based on a review of this white paper, NRC requested additional information and clarifications in NRC Letter No. 004, dated July 25, 2011 Request for Additional Information (RAI) Nos. 5901, 5898, 5800, 5899, and 5900. The NRC issued 108 RAIs in the areas of high temperature metals, graphite, carbon composites and ceramic insulation. These RAIs were responded to in a letter dated September 27, 2011, (CCN 225396).

In the letter dated May 9, 2012, NRC issued NGNP - Assessment of White Paper on High Temperature Materials. This letter forwards a report assessing the contents of a white paper submitted by the NGNP and responses for RAIs submitted by the NRC after preliminary review. The NRC stated that the staff will not provide a final conclusion regarding the design and qualification of any NGNP components, materials, or their use in the plant design, until an NGNP combined license or design certification application is received and reviewed.

Based on the above information, this revision (Revision 1) incorporates those changes committed to in the NGNP RAI responses and updates the sections that required further clarifications, as appropriate. The resolution of those outstanding issues raised in the NRC assessment report will be addressed during the COL or design certification application phase of the project. 


\section{CONTENTS}

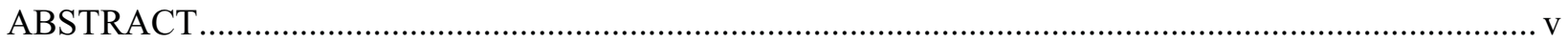

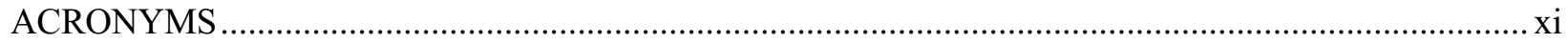

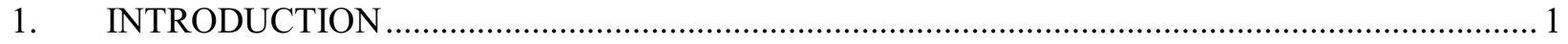

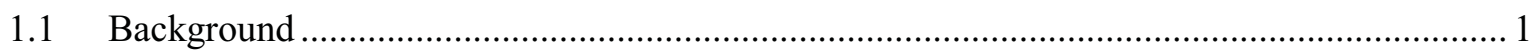

1.2 Purpose

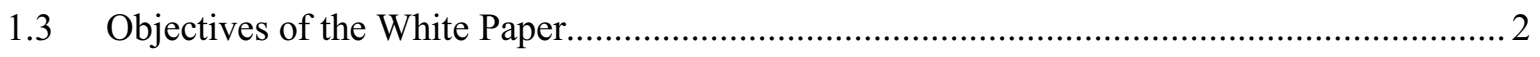

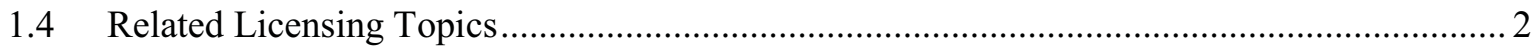

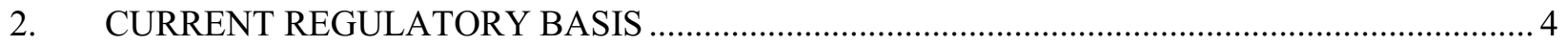

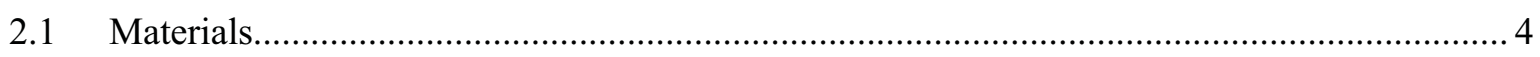

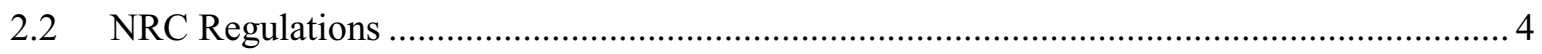

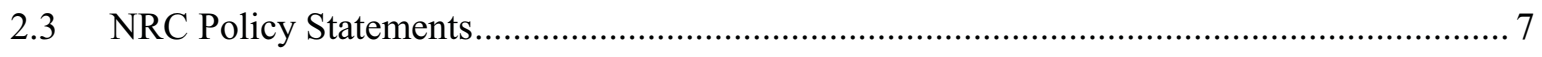

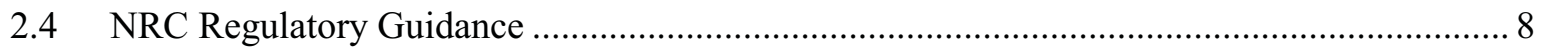

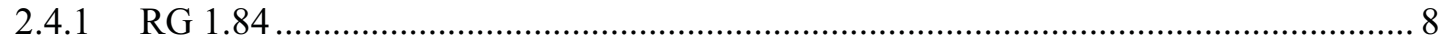

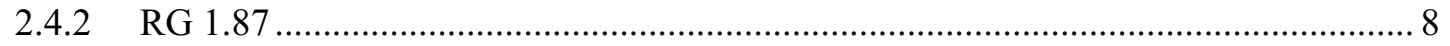

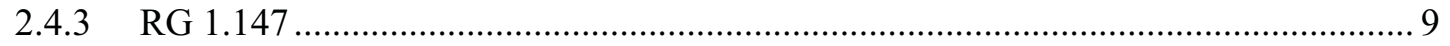

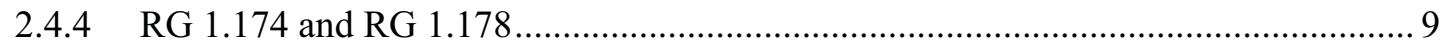

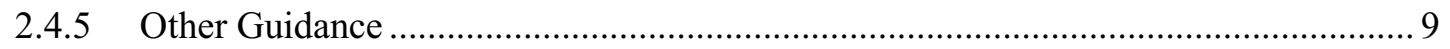

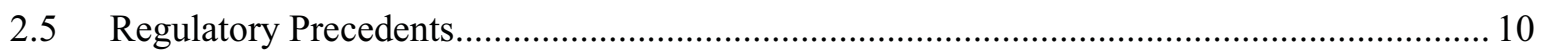

2.6 Phenomena Identification and Ranking Table Workshops ................................................ 10

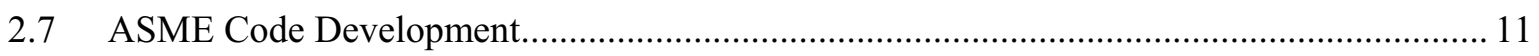

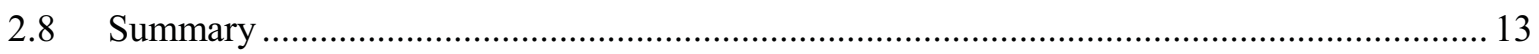

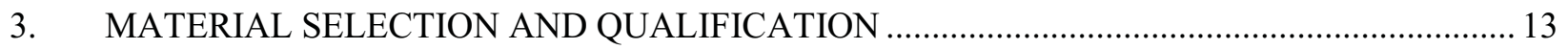

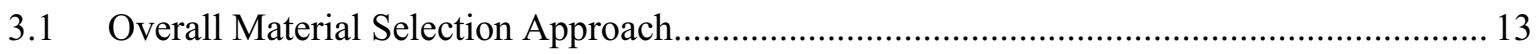

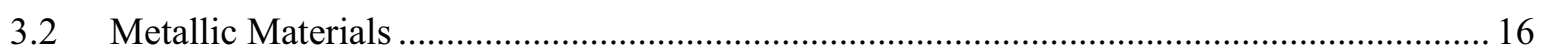

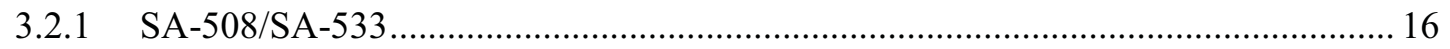

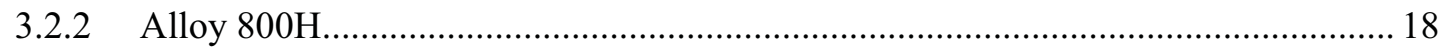

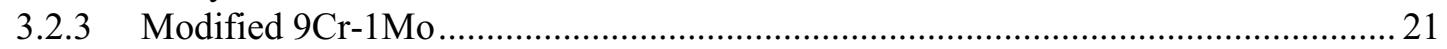

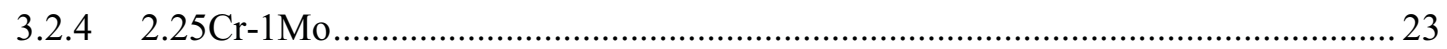

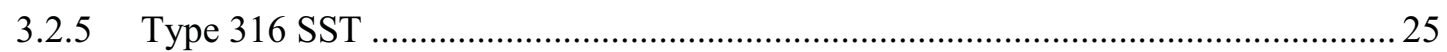

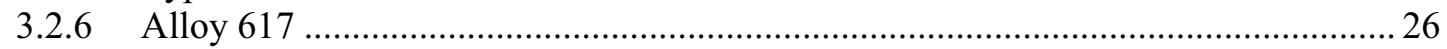

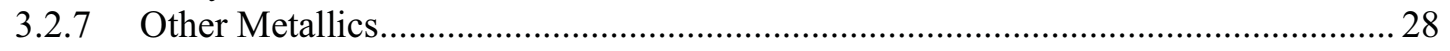

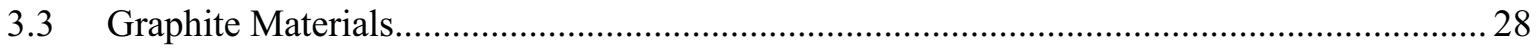

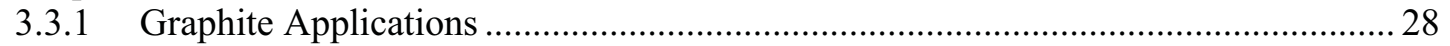

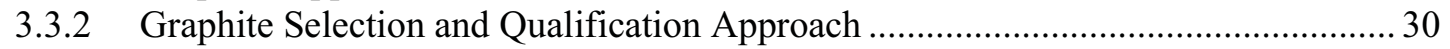

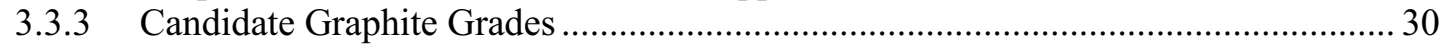

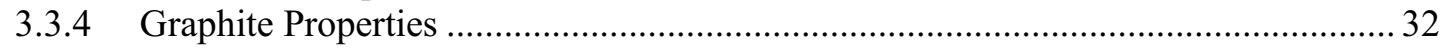

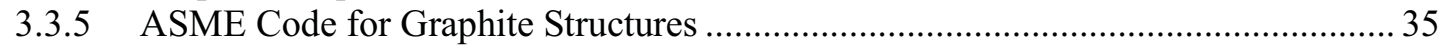

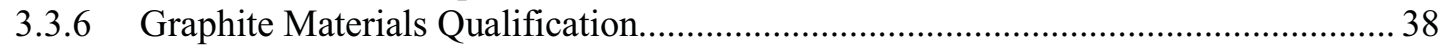

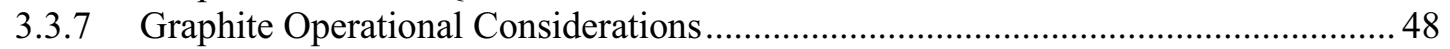

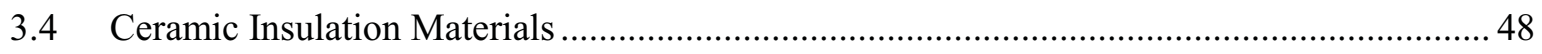

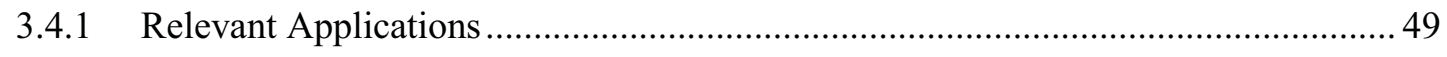




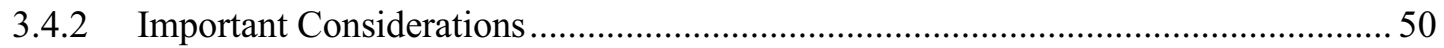

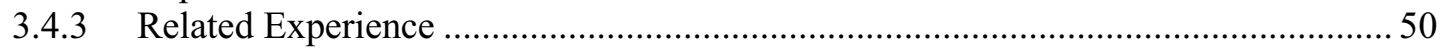

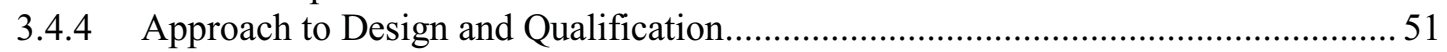

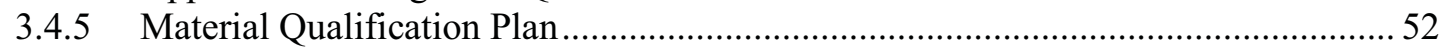

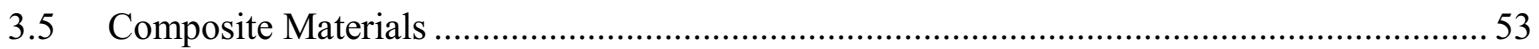

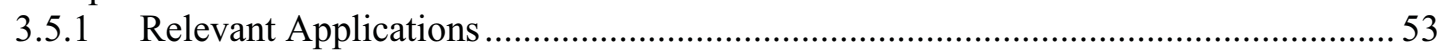

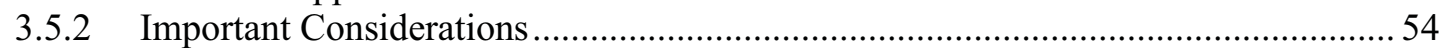

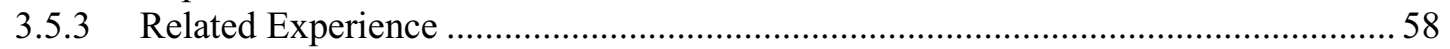

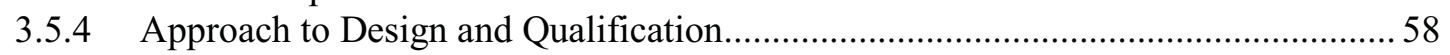

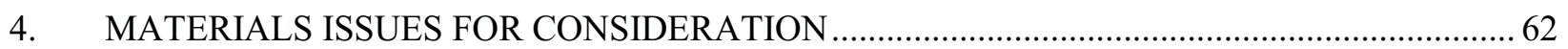

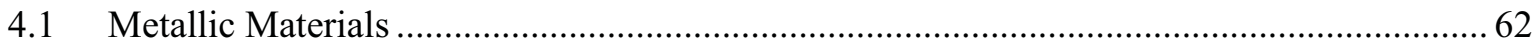

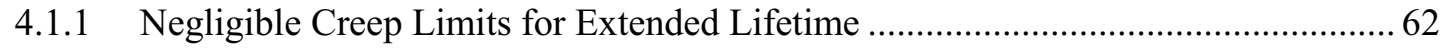

4.1.2 Application of ASME Section III, Division 5 in RPV Design..................................... 62

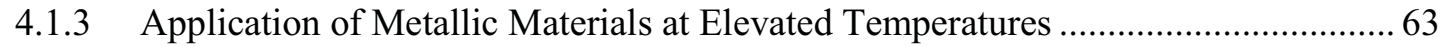

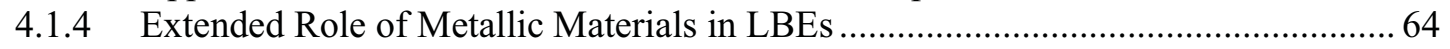

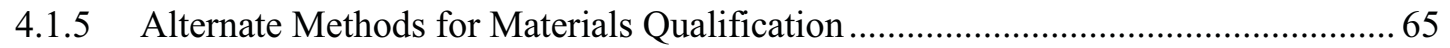

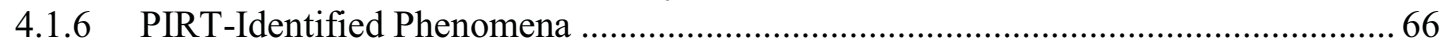

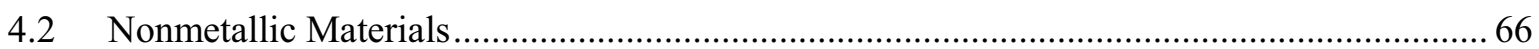

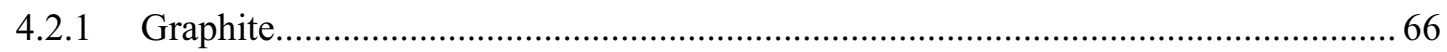

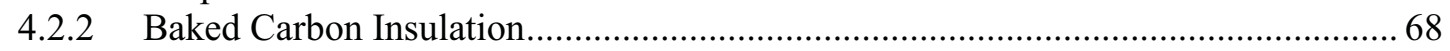

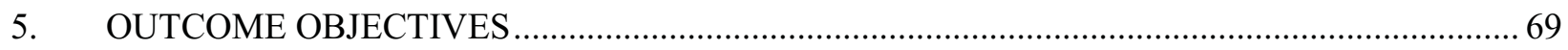

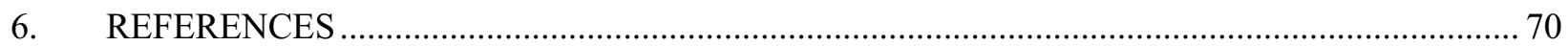

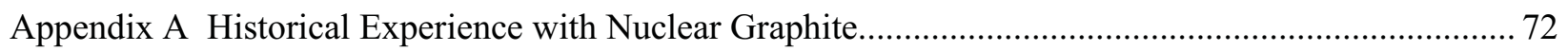

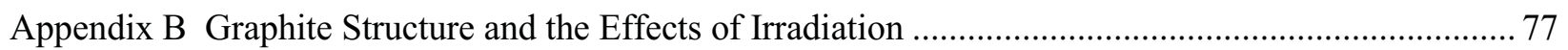

Appendix C NRC RAI Letter Number 004 (Request for Additional Information No.'s 5901,

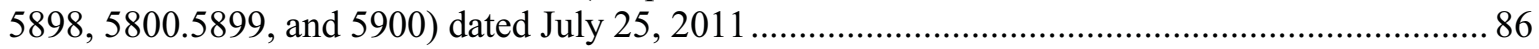

Appendix D INL Letter Number CCN 225396, NGNP Submittal - Response to NRC RAIs Letter No. 004, dated September 27, 2011.

Appendix E NRC Letter, NGNP - Assessment of White Paper on High Temperature Materials, dated May 9, 2012.

\section{FIGURES}

Figure 1. Material selection approach for HTGR components. ............................................................. 14

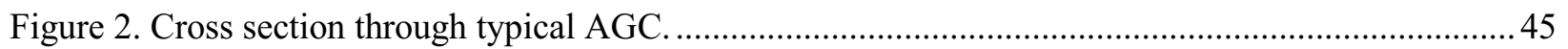

Figure 3. Planned dose and temperature distributions for the AGC experiments....................................46

Figure 4. Illustration of the fibrillar texture of a carbonized PAN fiber................................................. 55

Figure 5. Comparison of the MTR data and PBMR Demonstration Power Plant service conditions

Figure B-1. Crystal structure of graphite. .78 
Figure B-2. Neutron irradiation damage mechanism illustrating induced crystal dimensional changes.

Figure B-3. Typical irradiation-induced dimensional changes in reactor graphite, parallel direction. 80

Figure B-4. Typical irradiation-induced dimensional changes in reactor graphite, perpendicular direction. 80

Figure B-5. Typical irradiation-induced thermal conductivity changes in reactor graphite. .81

Figure B-6. Typical changes in linear coefficient of thermal expansion because of irradiation .83

Figure B-7. Typical irradiation-induced strength changes in reactor graphite. .84

Figure B-8. Typical irradiation-induced modulus changes in reactor graphite. .85

\section{TABLES}

Table 1. Candidate nuclear graphite grades for HTGR application. 30

Table 2. Typical graphite vendor properties of candidate graphite grades............................................ 32

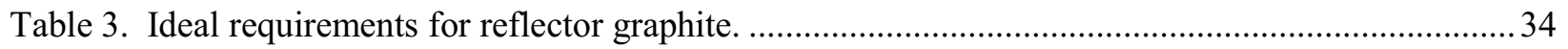

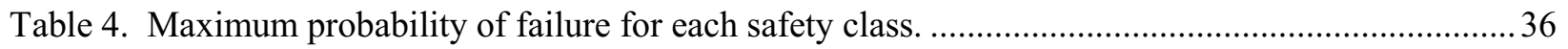

Table 4. Maximum probability of failure for each safety class. ................ Error! Bookmark not defined.

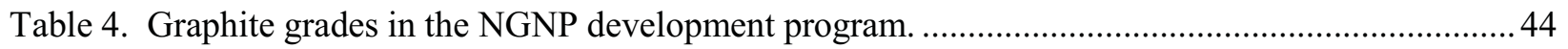

Table 5. Major graphite grades in the EU FP graphite irradiation program. ........................................ 47

Table 7. Properties of NBC-07 and ASR-0RB carbon insulation compared to the target value for

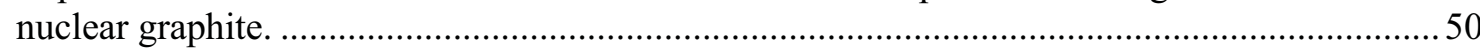

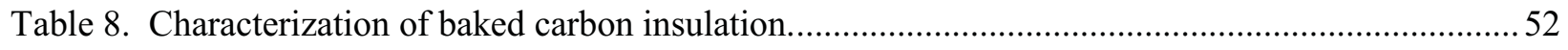

Table 9. Typical properties of graphite and CFRC materials at room temperature .................................56

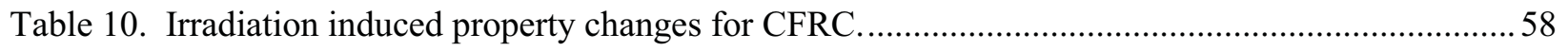

Table 6. Current ASME code limits for potential HTGR materials........................................................63

Table B-1. Stages of change in thermal conductivity because of irradiation.......................................... 81 


\section{ACRONYMS}

AGC Advanced Graphite Capsule

AGR Advanced Gas-cooled Reactor

ASME American Society of Mechanical Engineers

ASTM ASTM International

ATR

Advanced Test Reactor

AVR

Arbeitsgemeinschaft Versuchsreaktor (Germany)

$\mathrm{B} \& \mathrm{PV} \quad$ boiler and pressure vessel

CFR Code of Federal Regulations

CFRC carbon fiber reinforced carbon

COL Combined License

CSC core structure ceramic

CTE coefficient of thermal expansion

DBA Design Basis Accident

DEB Design Basis Event

DOE Department of Energy

DPP Demonstration Power Plant

EDN equivalent dido nickel

EU European Union

FSV Fort St. Vrain

GDC General Design Criteria (10 CFR 50 Appendix A)

GE General Electric

GTMHR gas turbine modular helium reactor

HTGR high temperature gas-cooled reactor

HTR high temperature reactor

HTR-10 High Temperature Test Reactor (China)

HTTR High Temperature Test Reactor (Japan)

IHX intermediate heat exchanger

INL Idaho National Laboratory

ISI in-service inspection

JAEA Japan Atomic Energy Agency

LBE Licensing Basis Event

LWR light water reactor

MHTGR modular high temperature gas-cooled reactor 


$\begin{array}{ll}\text { MQP } & \text { Materials Qualification Plan } \\ \text { MTR } & \text { Materials Test Reactor } \\ \text { NGNP } & \text { Next Generation Nuclear Plant } \\ \text { NRC } & \text { Nuclear Regulatory Commission } \\ \text { NUREG } & \text { Nuclear Regulatory Commission Report } \\ \text { ORNL } & \text { Oak Ridge National Laboratory } \\ \text { PAN } & \text { polyacrylonitrile } \\ \text { PBMR } & \text { Pebble Bed Modular Reactor } \\ \text { PGA } & \text { Pile Grade A } \\ \text { PIRT } & \text { Phenomena Identification and Ranking Table } \\ \text { PRA } & \text { Probabilistic Risk Assessment } \\ \text { RDMCI } & \text { Requirements for the Design and Manufacture of the Ceramic Internals } \\ \text { RG } & \text { Regulatory Guide } \\ \text { RIM } & \text { Reliability and Integrity Management } \\ \text { RPV } & \text { reactor pressure vessel } \\ \text { SECY } & \text { NRC Commissioner's Document } \\ \text { SRC } & \text { structural reliability class } \\ \text { SRP } & \text { Standard Review Plan } \\ \text { SSC } & \text { structures, systems, and component } \\ \text { SST } & \text { stainless steel } \\ \text { THTR } & \text { Thorium High Temperature Reactor } \\ \text { VHTR } & \text { very high temperature reactor } \\ & \end{array}$




\section{NGNP High Temperature Materials White Paper}

\section{INTRODUCTION}

\subsection{Background}

The information in this paper is intended to serve as the basis for interactions with the NRC staff. The NGNP Project wishes to obtain comments on the adequacy of the planned approach and feedback on a number of issues that have the potential to significantly impact the effort and schedule to prepare a COL application for the NGNP high temperature gas-cooled reactor (HTGR)-based. The Revision 0 of the NGNP High Temperature Materials White Paper (INL/EXT-09-17187) was submitted to the NRC on June 25, 2010, CCN 221269.

Based on review of the white paper, the NRC requested additional information and clarifications in NRC Letter Number 004, dated July 25, 2011, ("Request for Additional Information (RAI) No.'s 5901, 5898, 5800, 5899, and 5900"). The NRC issued 108 RAIs in the areas of high temperature metals, graphite, carbon composites and ceramic insulation. These RAIs were responded to in a letter dated September 27, 2011, CCN 225396.

In the letter dated May 9, 2012, the NRC issued the letter, "NGNP - Assessment of White Paper on High Temperature Materials." This letter forwards a report assessing the contents of the white paper and the RAI responses. The NRC stated that the staff will not provide a final conclusion regarding the design and qualification of any NGNP components, materials, or their use in the plant design, until an NGNP combined license or design certification application is received and reviewed.

Based on the above exchanges, this revision (Revision 1) of the white paper only incorporates those changes that were committed to in the NGNP RAI responses and updates those sections in the white paper that require further clarifications; as appropriate. The resolution of those outstanding issues raised in the NRC assessment report will be addressed during the COL or design certification application phase of the project.

\subsection{Purpose}

This paper is one in a series of white papers that addresses key generic licensing issues in preparation for the submittal of a COL application for the NGNP. The NGNP will use advanced, HTGR technologies to demonstrate the integration of a nuclear heat source, providing electricity and/or process steam, with one or more industrial applications. The purpose of these white paper submittals is to reduce the time required for COL application review by identifying and addressing key regulatory issues and obtaining agreements for achieving their resolution with the NRC.

This white paper reviews policies, regulations, and guidance associated with acceptance of materials for nuclear reactor applications and the bases for their implementation in the system components of the HTGR. Following review of the existing regulatory framework for materials, a process is developed for high temperature component material selection and evaluation, leading to recommendations for qualification and acceptance. The principal materials proposed for application in the NGNP primary system are then identified, along with the proposed approaches for establishing regulatory compliance. For those cases in which the established regulatory infrastructure for qualification and acceptance is determined to be sufficient, regulatory issues are identified along with proposed bases for their resolution. 
The design of the HTGR is in the initial conceptual design phase, so final component specification and material selection has yet to be performed. Still, typical component performance requirements and candidate materials for specific applications are evaluated to identify potential qualification and acceptance gaps.

\subsection{Objectives of the White Paper}

Development of this white paper considers applicable information from sources such as past documents and papers on high temperature materials provided in the attached references, NRC regulatory guidance, insights gained from NRC public meetings, available industry standards, Modular High Temperature Gas-cooled Reactor (MHTGR) licensing documents, ${ }^{1}$ Pebble Bed Modular Reactor (PBMR) licensing documents, ${ }^{2}$ American Society of Mechanical Engineers (ASME) Codes and Code Cases, and other gas-cooled reactor documents.

The primary objectives of this paper are to:

- Summarize existing regulatory policies and guidance that may apply to materials expected to be used in HTGRs.

- Describe an approach for selecting materials, identifying properties, qualification, and accepting materials for key gas-cooled reactor components.

- Discuss the influence that material selection and code requirements may have on licensing basis events (LBEs), including design basis accidents (DBAs).

- Discuss any needed codes and standards work, including the status and schedule for code and standards activities already in progress.

- Identify policy and technical issues that should be discussed and resolved with the NRC.

The desired outcome of this paper is to obtain NRC agreement with the recommended approach for qualification and regulatory acceptance of materials for the high temperature service conditions of the HTGR. Specific topics for which NRC feedback is requested are identified in Section 5, Outcome Objectives.

\subsection{Related Licensing Topics}

Though beyond the scope of this paper, two related licensing topics have been identified that have the potential to influence the selection and qualification of high temperature materials for service in HTGRs. These topics are summarized as follows:

- $\quad$ NRC acceptance of HTGR Licensing Basis Event (LBE) selection and categorization. LBEs are event scenarios considered in the licensing process and used to derive regulatory requirements for design certification. LBEs include normal plant operation, events anticipated to occur over the life of the plant, and off-normal events as required by 10 CFR Part 52, including infrequent Design Basis Events (DBEs) and rare events beyond the design basis.

- NRC acceptance of HTGR structures, systems, and components (SSC) classification. The classification of SSCs with respect to safety functions provides an essential input to the establishment of design and performance requirements.

The NGNP reactor design and its unique passive and inherent safety characteristics rely on key material properties to define performance during normal operation, anticipated operational occurrences, and accident conditions within the design basis. In addition to the qualification of materials properties that provide for acceptable performance during normal operation at elevated 
temperatures in a helium environment under neutron irradiation, the qualification of materials for use in the NGNP reactor must include certain material properties relied upon during accident scenarios. Further, the materials qualification basis must provide assurance that such properties stay within their design range for the life of the component.

The licensing and technical issues and the recommended resolutions associated with LBE selection and SSC classification will be discussed in separate white papers; however, the basic assumption made in this white paper is that the resolutions of these issues are such that the fundamentals of the HTGR safety case are preserved. 


\section{CURRENT REGULATORY BASIS}

\subsection{Materials}

Light water reactors (LWRs), which are the basis for current NRC commercial reactor regulations, typically use metals for their primary loop components because of the relatively low temperatures encountered in these reactors. HTGR technology requires expanding the use of primary loop component materials to include nuclear grade graphite, composite materials, and other ceramics where temperatures are higher than those allowed for metals.

All commercial nuclear power plants currently operating in the United States use water as both the heat transport medium and the neutron moderator. The HTGR concept discussed in this paper; however, uses helium as the heat transport medium and nuclear grade graphite as the neutron moderator. This represents a significant difference in reactor technology. With the exception of Fort St. Vrain (FSV) and Peach Bottom 1, no graphite-moderated gas-cooled reactors have been licensed commercially to operate within the United States. The NRC conducted preliminary safety reviews for the large gas-cooled reactors in the 1970s and for modular high temperature reactors in the 1980s and 1990s. More recently, interactions took place between the NRC and General Atomics on the MHTGR and gas turbine modular helium reactor (GTMHR) design and with Exelon and Pebble Bed Modular Reactor (Pty) Ltd. (PBMR) on the PBMR design.

Metallic components used in the primary system of an HTGR include the reactor vessel, cross vessel, piping, steam generator vessel, and/or intermediate heat exchanger (IHX), as well as components within these vessels, including the core barrel, core support structures, and steam generator tubes. In addition, nuclear grade graphite is used for HTGR fuel blocks in prismatic reactors, and for reflector blocks and core support components in all HTGRs. Baked carbon is used in conjunction with the reflector blocks in some designs to provide a higher degree of thermal insulation between the core and metallic components. Other ceramic, composite or metallic materials may be used for the cross-vessel liners, reflector supports and/or core reactivity control elements.

HTGR primary loop components operate in a different environment (helium with controlled levels of impurities) and, in many cases, at higher temperatures during both normal operation and LBEs than those applicable to LWRs. Materials needed to manufacture such HTGR components are, in general, commercially available. Some have been used in HTGRs both within and outside of the United States. This paper proposes a path for regulatory acceptance, qualification, and/or approval of these materials for use in an HTGR environment.

The sections that follow provide an assessment of NRC regulations, regulatory guidance, policy statements, standards, and past precedents that are considered relevant to materials used in nuclear reactor components. The objective is to identify regulations that may apply to or provide insights regarding the regulatory basis for qualification of materials for HTGRs.

\section{$2.2 \quad$ NRC Regulations}

This section identifies NRC regulations that may have potential relevance to materials used in HTGR primary system components. Because current regulations have been established primarily for application to LWR technologies, it is natural that most existing regulations are for metallic materials. This review did not identify regulations that refer specifically to graphite components; but some insights may be obtained from regulatory requirements applicable to metallic materials. 
The NRC regulations applicable to LWR primary system components are provided in the following Code of Federal Regulations (CFR) sections:

- 10 CFR 50.55a, "Codes and Standards"

- 10 CFR 50.34, "Contents of Applications; Technical Information," particularly Section (a)(3) addressing "Principal Design Criteria"

- 10 CFR 50.61, "Fracture Toughness Requirements for Protection Against Pressurized Thermal Shock Events"

- 10 CFR Part 50, Appendix A, “General Design Criteria (GDC),” 4, 10, 14, 15, 30, and 31

- 10 CFR Part 50, Appendix B, “Quality Assurance Criteria for Nuclear Power Plants and Fuel Reprocessing Plants"

- 10 CFR Part 50, Appendix G, "Fracture Toughness Requirements"

- 10 CFR Part 50, Appendix H, "Reactor Vessel Material Surveillance Program Requirements."

The quality assurance criteria and requirements provided in 10 CFR Part 50 Appendix A-GDC 1 and Appendix B generally apply to nuclear reactor components, irrespective of the component operating temperature. Therefore, these requirements are not discussed in this paper. Key elements of the other identified regulations are summarized below:

- 10 CFR 50.55a. Section 50.55a requires that SSCs must be designed, fabricated, erected, constructed, tested, and inspected to quality standards commensurate with the importance of the safety function to be performed. In addition, 10 CFR 50.55a requires that systems and components of boiling and pressurized water nuclear power reactors meet applicable requirements of the ASME Boiler and Pressure Vessel (B\&PV) Code.

Section 50.55a also includes a provision for the applicants to propose alternative solutions provided (a) the proposed alternatives would provide an acceptable level of quality and safety, or (b) compliance with the specified requirements of this section would result in hardship or unusual difficulty without a compensating increase in the level of quality and safety.

- $\quad 10$ CFR 50.34. Under the provisions of 10 CFR 50.34, 52.47, 52.79, 52.137, and 52.157, an application for construction permit, design certification, combined license, standard design approval, or manufacturing license, respectively, must include the principal design criteria for a proposed facility. The principal design criteria establish the necessary design, fabrication, construction, testing, and performance requirements for SSCs important to safety. It must provide reasonable assurance that the facility can be designed, constructed, and operated without undue risk to public health and safety.

- $\quad 10$ CFR 50.61 and Appendices G and H to 10 CFR Part 50. This information addresses fracture toughness and associated surveillance requirements for ferritic materials used in the pressureretaining components of the reactor coolant pressure boundary. These requirements, which pertain specifically to LWRs, are designed to provide adequate margins of safety during normal operation, including anticipated operational occurrences and system hydrostatic tests. These requirements are included in both Section III and Section XI of the ASME Code.

- 10 CFR Part 50, Appendix A, "General Design Criteria (GDC).” The GDC in 10 CFR Part 50, Appendix A establish minimum requirements for the principal design criteria for LWRs similar in design and location to plants for which construction permits have already been issued. Some GDC are generally applicable to other types of nuclear power units, except for those that are LWR technology specific. GDC that are technology specific to LWRs may, however, provide guidance in establishing the principal design criteria for non-LWR reactor technologies. 
The following GDC may be relevant to both metallic and nonmetallic materials unless specifically indicated:

- GDC 4, "Environmental and Dynamic Effects Design Bases," requires that SSCs important to safety be designed to accommodate the effects of and to be compatible with the environmental conditions associated with normal operation, maintenance, testing, and postulated accidents, including loss-of-coolant accidents. These SSCs shall be appropriately protected against dynamic effects, including the effects of missiles, pipe whipping, and discharging fluids that may result from equipment failures and events and conditions outside the nuclear power unit. However, dynamic effects associated with postulated pipe ruptures in nuclear power units may be excluded from the design basis when analyses reviewed and approved by the NRC demonstrate that the probability of fluid system piping rupture is extremely low under conditions consistent with the piping design basis.

- GDC 10, "Reactor Design," requires that the reactor core and associated coolant, control, and protection systems be designed with appropriate margin to ensure that specified acceptable fuel design limits are not exceeded during any condition of normal operation, including the effects of anticipated operational occurrences.

- GDC 14, (metals only) "Reactor Coolant Pressure Boundary," requires that the reactor coolant pressure boundary be designed, fabricated, erected, and tested so as to have an extremely low probability of abnormal leakage, rapidly propagating failure, and gross rupture.

- GDC 15, "Reactor Coolant System Design," requires that the reactor coolant system and associated auxiliary, control and protection systems be designed with sufficient margin to assure that the design conditions of the reactor coolant pressure boundary are not exceeded during any condition of normal operation, including anticipated operational occurrences.

- GDC 30, (metals only) "Quality of Reactor Coolant Pressure Boundary," requires components that are part of the reactor coolant pressure boundary to be designed, fabricated, erected, and tested to the highest quality standards practical. Means shall be provided for detecting and, to the extent practical, identifying the location of the source of reactor coolant leakage.

- GDC 31, (metals only) "Fracture Prevention of Reactor Coolant Pressure Boundary," requires that the reactor coolant pressure boundary be designed with sufficient margin to ensure that, when stressed under operating, maintenance, testing, and postulated accident conditions, (1) the boundary behaves in a nonbrittle manner, and (2) the probability of rapidly propagating fracture is minimized. The design shall reflect consideration of service temperatures and other conditions of the boundary material under operating, maintenance, testing, and postulated accident conditions and the uncertainties associated therewith in determining (1) material properties; (2) the effects of irradiation on material properties; (3) residual, steady state, and transient stresses; and (4) size of flaws.

The NRC regulations identified in this section potentially apply to high temperature components of the NGNP reactor. The interpretation and application of these current NRC regulations must consider the differences between the principal safety functions of the HTGR and the LWR technologies in addition to the inherent reactor characteristics and passive core decay heat removal capabilities of HTGRs. In addition to determining which current NRC regulations may not apply to HTGRs because of their unique characteristics, it is important to determine whether those unique characteristics create the need for additional regulatory guidance and agreements to complete the NGNP design and license application. 


\subsection{NRC Policy Statements}

The NRC has not explicitly addressed the performance of materials for HTGR components in any of its policy statements, but it has made policy statements and other official comments on advanced reactor issues that address some of the issues associated with the use and acceptance of materials used at HTGR conditions. These include:

- The Policy Statement on the Regulation of Advanced Reactors (October 2008)

- Commission vote on the NRC Commissioner's Document SECY-03-0047, "Policy Issues Related to Licensing Non-Light Water Reactor Designs"

- SECY-08-0019, "Licensing and Regulatory Research Related to Advanced Nuclear Reactors"

- SECY-10-0034, "Potential Policy, Licensing, and Key Technical Issues for Small Modular Nuclear Reactor Designs."

The Policy Statement on the Regulation of Advanced Reactors has been revised several times since its original release in 1986. The most recent revision, published in the Federal Register on October 14, 2008, does not differ substantially from previous versions in its discussion of the Commission's expectations with regard to advanced reactor features; rather, the Commission added a discussion concerning emergency preparedness and security in light of the events of September 11,2001, and subsequent new regulatory requirements for enhanced security and protection from aircraft attacks.

While the Policy Statement delineates those attributes of advanced plant designs that the Commission finds highly desirable, it does not specifically refer to the materials used to fabricate plant structures or components. However, several points can be read as being broadly applicable to the plant materials, including those used in the HTGR. These points include:

- Designs that minimize the potential for severe accidents and their consequences by providing sufficient inherent safety, reliability, redundancy, diversity, and independence in safety systems, with an emphasis on minimizing the potential for accidents over minimizing the consequences of such accidents.

- Designs that provide easily maintainable equipment and components.

- Design features that can be proven by citation of existing technology or that can be satisfactorily established by commitment to a suitable technology development program.

- Designs that incorporate the defense-in-depth philosophy by maintaining multiple barriers against radiation release and by reducing the potential for, and consequences of, severe accidents.

These attributes will be considered when selecting materials to be used in HTGR designs.

In SECY-03-0047 and the corresponding Staff Requirements Memorandum, the NRC addressed a number of key policy issues that had been identified in early discussions with the designers of and prospective license applicants for non-LWRs. One such issue is related to the potential use of international codes and standards where the U.S. codes and standards incorporated in the NRC's regulations did not adequately address non-LWR designs. The NRC's direction to the staff was to "Review international codes and standards only as part of an application or preapplication review. The staff should gain experience through review of international codes and standards during the preapplication and application reviews of non-LWRs then apply the lessons-learned from these reviews to their activities involving our domestic codes and standards committees." 


\section{$2.4 \quad$ NRC Regulatory Guidance}

The regulatory guidance for the design, fabrication, and inspection of nuclear reactor components includes Regulatory Guides (RGs) 1.84, 1.87, 1.147, 1.174 and 1.178. These guides provide additional insight into acceptable methods and criteria for nuclear primary system components in support of regulatory requirements discussed in Section 2.2.

\subsubsection{RG 1.84}

RG 1.84, Rev. 34, "Design, Fabrication, and Materials Code Case Acceptability," ASME Section III provides guidance on the acceptable uses of ASME Section III code cases applicable to materials and component design, fabrication, examination, and testing. The ASME code cases referenced in this regulatory guide for Class 1 components currently apply to LWR metallic materials only.

\subsubsection{RG 1.87}

RG 1.87, Rev. 1, "Guidance for Construction of Class 1 Components in Elevated-Temperature Reactors" (Supplement to ASME Section III Code Cases 1592, 1593, 1594, 1595 and 1596) describes five code cases that provide guidance for the construction of components subject to elevated temperature service, including HTGR components. RG 1.87 states that the service temperatures and load conditions for HTGRs are such that time-dependent phenomena such as creep and relaxation are important. It further states that Subsection NB of Section III of the ASME Code does not provide adequate guidance for construction of components subject to elevated-temperature service, thus leading to the development of the five ASME code cases as an interim step. The referenced code cases cover design, fabrication, installation, examination, testing, and protection against overpressure for such components. They reflect both time-independent and time-dependent materials properties and structural behavior (elastic and inelastic) by considering the following modes of failure:

- Ductile rupture from short-term loadings

- Creep rupture from long-term loadings

- Creep-fatigue failure

- Gross distortion caused by incremental collapse and ratcheting

- Loss of function caused by excessive deformation

- Buckling caused by short-term loadings

- Creep buckling caused by long-term loadings.

RG 1.87 also states that component designs should accommodate the required in-service inspection (ISI) and surveillance programs for material or component integrity. Finally, it states that the materials evaluations should address representative environmental factors such as compatibility with the coolant (helium) and potential contaminants in the coolant, irradiation effects that might induce ductility loss, and aging resulting from prolonged exposure to elevated temperature.

The code cases referenced within RG 1.87 were superseded by ASME Code Cases N-47 through N-51 (with numerous revisions) and, subsequently, by Section III, Subsection NH. To date, Subsection NH has attained acceptance as a basis for regulatory compliance for only one specific application. The current version of 10 CFR 50.55a(b)(1)(vi) states:

(vi) Subsection NH. The provisions in Subsection NH, "Class 1 Components in Elevated Temperature Service," 1995 Addenda through the latest edition and addenda incorporated by reference in paragraph (b)(1) of this section, 
may only be used for the design and construction of Type 316 stainless steel (SST) pressurizer heater sleeves where service conditions do not cause the component to reach temperatures exceeding $900^{\circ} \mathrm{F}$.

\subsubsection{RG 1.147}

RG 1.147, Rev. 15, "In-service Inspection Code Case Acceptability, ASME Section XI, Division 1 ," provides guidance on ASME Section XI code cases oriented to ISI programs that are generally acceptable to the NRC staff. The code cases identified in this Regulatory Guide are incorporated by reference within 10 CFR 50.55a for application to LWRs. While their use for HTGRs is not specifically addressed, many of the permitted examination and repair activities addressed by the Section XI Code cases could potentially be applied to HTGR components.

\subsubsection{RG 1.174 and RG 1.178}

NRC recently provided guidance for application of risk-informed methodologies in meeting current regulations. RG 1.174, Rev. 1, "An Approach for Using PRA in Risk-Informed Decisions on Plant-Specific Changes to the Licensing Basis," and RG 1.178, Rev. 1, "An Approach for PlantSpecific Risk-Informed Decision Making for In-service Inspection of Piping," provide an acceptable path to establish risk-informed technical specification modifications and ISI programs for LWR components and piping systems. Although these guides cannot be directly applied to HTGRs because they are linked to LWR risk metrics of core damage frequency and large release frequency, they do provide a potential path for the development of risk informed decisions that link requirements to plant-specific risk metrics.

\subsubsection{Other Guidance}

NRC report NUREG-0800, the Standard Review Plan (SRP), provides detailed guidance to the NRC staff for regulatory reviews (e.g., construction permits, operating licenses, design certifications) of LWRs. However, it is also useful to designers, applicants, and licensees, insofar as it describes the acceptance criteria that the staff applies in its reviews. SRPs may also refer to Regulatory Guides in describing acceptable methodologies. Of interest to this discussion are the SRP Sections 5.2.1.1, "Compliance with the Codes and Standards Rule"; 10 CFR 50.55a, 5.2.1.2, "Applicable Code Cases"; and 5.2.3, "Reactor Coolant Pressure Boundary Materials." Although these SRP sections do not apply directly to primary systems in HTGRs, they do indicate that material selection considerations should include the evaluation of issues such as susceptibility of the material in the reactor coolant pressure boundary to cracking and corrosion, fracture toughness, compatibility of the materials with the reactor coolant (including contaminants in the coolant), and compatibility of the materials in the reactor coolant pressure boundary with the materials in the insulation. These material selection considerations apply to the material section process for any reactor design, including HTGRs.

Furthermore, in 2003, the NRC published NUREG/Contractor Report CR-6824, "Materials Behavior in HTGR Environments," which addresses the performance of metallic components in high temperature helium-cooled reactors. This document includes information on HTGR materials properties and environmental effects on the behavior of metallic components in gas-turbine HTGR technology with a core outlet temperature range of 850 to $900^{\circ} \mathrm{C}\left(1562\right.$ to $\left.1652^{\circ} \mathrm{F}\right)$. As noted in Section 2 of that report, the selected materials should have adequate performance over long service life at temperatures in the range of 900 to $950^{\circ} \mathrm{C}\left(1652\right.$ to $\left.1742^{\circ} \mathrm{F}\right)$. 


\subsection{Regulatory Precedents}

The NRC regulatory precedents for graphite-moderated HTGRs and, more specifically, modular HTGRs were developed in two distinct time periods. Early safety reviews include those performed for Peach Bottom 1, FSV, and the large HTGR designs by General Atomics. Recent licensing interactions include preapplication reviews of the MHTGR, early preapplication reviews of the GTMHR, and two separate series (PBMR/Exelon in 2002 and PBMR (Pty) Ltd. in 2007) of early licensing interactions in support of the PBMR design.

NRC regulatory experience with these reactor concepts began with the U.S. Department of Energy (DOE)-sponsored MHTGR program. The results of the NRC's review of that concept are published in NUREG-1338, "Draft Preapplication Safety Evaluation Report for the Modular HighTemperature Gas-Cooled Reactor," which was initially issued by the NRC in 1989 and updated in 1995. NUREG-1338 notes that lower-level criteria for the design and review of the MHTGR primary system, such as those contained in the SRP, do not exist in a form approaching that for LWR primary systems. NUREG-1338 goes on to note that certain LWR criteria for primary systems are helpful and important in guiding the MHTGR conceptual design, but that significant gaps remain, particularly those related to safety issues.

During its 2001 preapplication review of PBMR, the NRC staff provided feedback on various technical, safety, and policy issues raised by Exelon for that reactor concept. With regard to a path for the NRC review and approval of materials used in the construction of HTGR components, the staff provided the following direction:

...A list should be provided of all materials used for the reactor pressure vessel and its appurtenances, core support structures, primary system boundary, connecting piping, and other components important to safety and the applicable material specifications, design stress and time at temperature and other environmental conditions. The identification of the grade or type and conditions of the materials to be placed in service would also be required. If the code approved material specifications for the intended applications are not available, relevant material specifications should be developed following the format of [ASTM International] specifications. The subject specifications should be supported by the data and information as identified in ASME Code, Section III, Appendix IV, for approval of the new materials. Additional information unique to the application in the PBMR environment and condition shall also be provided...

\subsection{Phenomena Identification and Ranking Table Workshops}

The NRC staff conducted a series of workshops in 2007 that applied the Phenomena Identification and Ranking Table (PIRT) methodology as a means of identifying and prioritizing HTGR-related issues specific to the NGNP. ${ }^{3}$ The purpose of these workshops was to assist NRC in prioritizing research and allocating available resources. High-temperature materials and graphite are among the several subjects addressed within these workshops.

A follow-on workshop was conducted in March 2009 to further assess the status of worldwide research on nuclear graphite and identify the technical gaps between the planned DOE research and the outcome of the Graphite PIRT conducted earlier.

These workshops informed the NGNP Research and Development Program Plan revisions in 2008 and 2010 and also informed the selection of technology studies (e.g., reconciliation studies of 
design data needs against PIRT findings and reactor pressure vessel [RPV] material alternatives studies) that were awarded to the HTGR design suppliers in 2008 and 2009.

\subsection{ASME Code Development}

ASME has organized a "Working Group on Nuclear High Temperature Gas-Cooled Reactors" within the framework of the B\&PV Committee on Construction of Nuclear Facility Components (Section III). The charter of the Working Group is given as follows:

The Working Group shall develop rules for the construction of Nuclear High Temperature Gas-Cooled Reactors (HTGR) within Section III Division 5 Part 1. The rules of Part 1 shall constitute the requirements for the construction of the nuclear HTGR facility components such as pressure vessels, piping, pressure retaining portions of rotating equipment including pumps, blowers, turbines and compressors, valves, heat exchangers and for core support structures, both metallic and nonmetallic, and for containment or confinement structures. The rules shall contain requirements for materials, design, fabrication, testing, examination, inspection, certification, and the preparation of reports. The Working Group shall identify research and development efforts required to support the technical development of these code rules. Coordination with BPV XI on in-service inspection (ISI) issues shall be maintained.

An important document in guiding their mission is the Roadmap to Develop ASME Code Rules the Construction of High Temperature Gas Cooled Reactors (HTGRs) that was developed by an ASME Project Team for HTGR Code Development. The effort to develop this roadmap was originally sponsored by NRC. Draft versions of this roadmap were used to determine Working Group efforts and tasks sponsored by the DOE in FY 2009 and FY 2010. The roadmap was issued in June 2010 as ASME publication STP-NU-045 by ASME Standards Technology, LLC. A revision to the roadmap is expected to be issued in 2012 to provide an update reflecting work completed to date.

Additional groups have been organized within the ASME Board on Nuclear Codes and Standards infrastructure that support the development needs of HTGRs in areas relevant to materials. The NRC participates in these B\&PV committee groups to provide regulatory perspective. These are:

- Subgroup on High Temperature Reactors. Within the B\&PV committee on Construction of Nuclear Facility Components, the Subgroup on High Temperature Reactors continues activities related to Section III with specific focus on HTGRs and liquid metal reactors. The Section III Working Groups for HTGRs and liquid metal reactors report to this subgroup. A significant accomplishment of this subgroup was the publication on November 1, 2011 of the new ASME B\&PV Code Section III Division 5, "High Temperature Reactors - Rules for Construction of Nuclear Facility Components." This new Division 5 incorporated many of the outstanding Code Cases that apply to HTGRs.

- Subgroup on Elevated Temperature Design. Within the B\&PV Committee on Construction of Nuclear Facility Components, the Subgroup on Elevated Temperature Design continues activities related to construction rules and Code Cases for materials at high temperatures. The applicability of these rules includes but is not unique to HTGRs.

- Subgroup on Graphite Core Components. The ASME Subgroup on Graphite Core Components was organized within the B\&PV Committee on Construction of Nuclear Facility Components to establish rules for materials selection, design, construction, examination, inspection, and certification of graphite core components and core assemblies. This committee's work resulted in 
the construction rules for graphite core components being published by the ASME in Section III Division 5.'For further details, see Section 3.3.5.

- Special Working Group, High Temperature Gas Cooled Reactors. The B\&PV Committee on Nuclear In-service Inspection (Section XI) has established the Special Working Group, High Temperature Gas Cooled Reactors. The initial objective of this group was to develop a rewrite of Section XI, Division 2 to address in-service inspection, evaluation, and repair/replacement activities for next generation HTGRs. A draft of the revised Section XI, Division 2 was submitted into the within the ASME committee structure in 2011, but there are currently plans to extend the scope to address all advanced reactors.

DOE has entered into a multiyear Cooperative Agreement with ASME Standards Technology, LLC for the Generation IV Reactor Materials project. The scope includes development of technical basis documents necessary to update and expand codes and standards for application in future Generation IV nuclear reactor systems that operate at elevated temperatures. The following tasks have been undertaken to date. In those cases, where reports documenting the results have been published, they are identified in the list that follows as "(STP-NU-xxx)."

Task 1 Verification of Allowable Stresses in ASME Section III, Subsection NH for Alloy (STPNU-020-2008) and Verification of Allowable Stresses in ASME Section III Subsection NH for Grade 91 Steel (STP-NU-19-1-2009)

Task 2 Regulatory Safety Issues in Structural Design Criteria of Sec III NH for VHTR \& GEN IV Reactors (STP-NU-010-2007) Task 3 Improvement of ASME Subsection NH for Grade 91 Negligible Creep and Creep Fatigue (STP-NU-013-2008)

Task 4 Updating Nuclear Code Case N-201

Task 5 Creep-Fatigue Data and Existing Evaluation Procedures for Grade 91 and Hastelloy XR (STP-NU-018-2009)

Task 6 Operating Condition Allowable Stress Values in ASME Section III Subsection NH (STP-NU-037-2010)

Task 7 ASME Code Considerations for the Intermediate Heat Exchanger (IHX) (STP-NU-0382010)

Task 8 Creep and Creep-Fatigue Crack Growth at Structural Discontinuities and Welds (STPNU-039-2011)

Task 9 Update NH - Simplified Elastic and Inelastic Methods

Task 10 Update and Improve Subsection NH - Alternative Simplified Creep-Fatigue Design Methods (STP-NU-041-2011)

Task 11 New Materials for ASME Subsection NH (STP-NU-042-2011)

Task 12 Nondestructive examination (NDE) and In-Service Inspection (ISI) Technology for High Temperature Reactors (STP-NU-044-2011)

Task 13 Recommend Allowable Stress Values for Alloy $800 \mathrm{H}$

Task 14 Corrections to Stainless Steel Allowable Stress

Task 14a Correcting Austenitic Stainless Steel Stress Values 


\subsection{Summary}

The components of the HTGR operate at higher temperatures in different environmental conditions (helium with controlled levels of impurities) and with different performance requirements than those experienced in LWRs during normal and accident conditions. The candidate materials being considered for primary HTGR components are generally commercially available and are in use in high temperature applications in other industries and, in some cases, have been used in HTGR applications in the U.S. and other countries. However, the regulatory bases for these materials in the United States are limited for metallic materials and nearly nonexistent for nonmetallic materials. This section of the white paper reviewed the current body of NRC regulations, regulatory guidance, policy statements, standards, and past precedents and identified those that are judged to be applicable to candidate HTGR materials.

It is concluded that current regulations are adequate for the licensing of the NGNP, however, gaps exist where NRC approval will be required for the specific approaches proposed as the bases for qualification and regulatory approval. This may include NRC approval for the use of specific materials and/or operating conditions. These gaps and proposed approaches will be identified as the design of the NGNP reactor continues. Further development of the regulatory infrastructure will be desirable in support of follow-on commercial plants

\section{MATERIAL SELECTION AND QUALIFICATION}

The materials for the HTGR will be selected using a rigorous approach that will consider component functional and performance requirements, safety classification, and code and regulatory compliance. Candidate metallic and nonmetallic materials are discussed below in relationship with specific applications. This discussion will include potential applications for the candidate material, key considerations, related experience, and the current qualification status.

\subsection{Overall Material Selection Approach}

The general material selection approach for the HTGRs is summarized in Figure 1. 


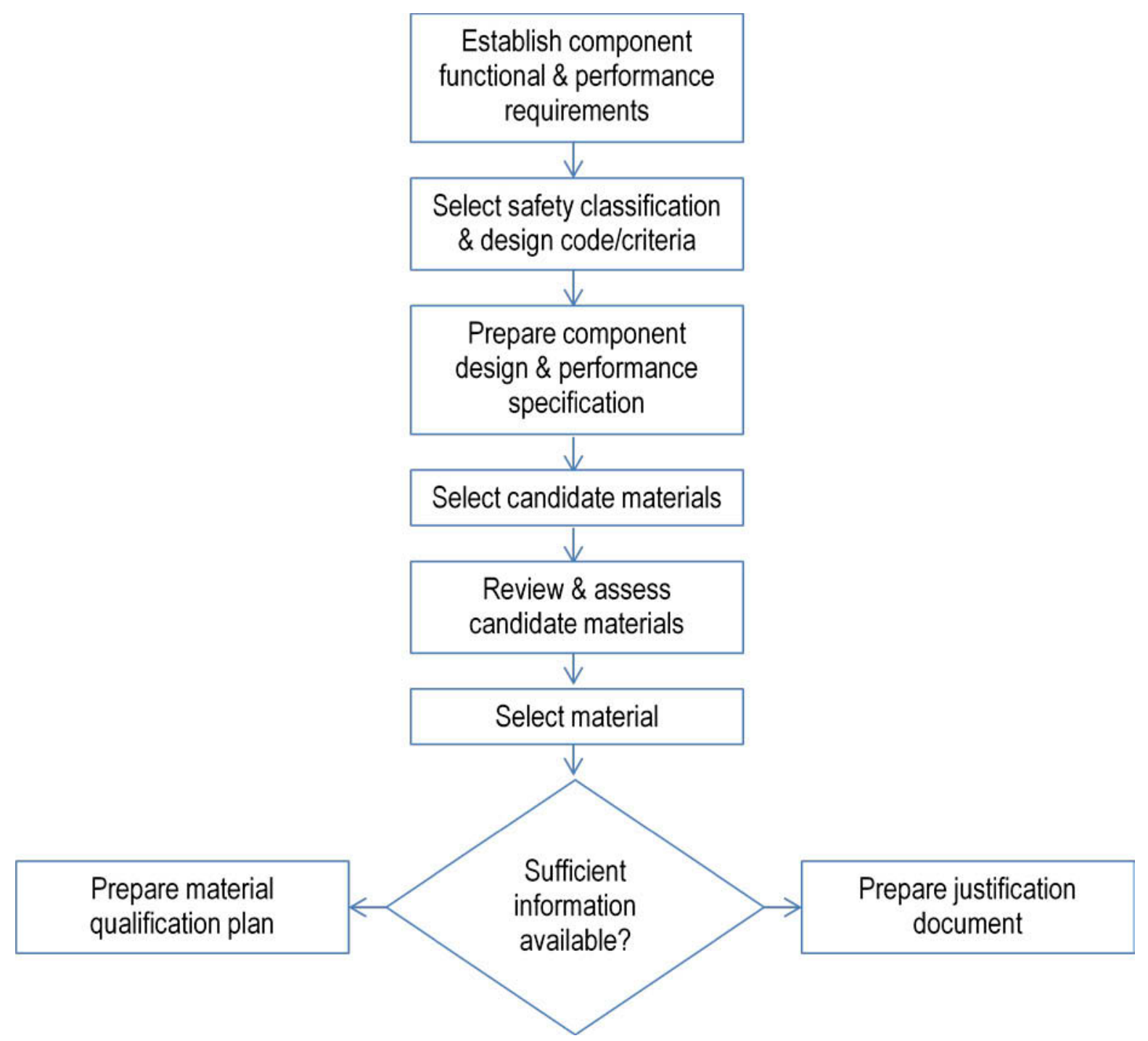

Figure 1. Material selection approach for HTGR components.

The material selection process begins by establishing component functional and performance requirements under normal and accident conditions. For example, the main functions of the core barrel under normal operating conditions are providing lateral and axial support for the graphite core structures and acting as a flow barrier between the hot helium gas in the core and the relatively cool gas in the outer annulus. Important material properties supporting these functions include high temperature strength and resistance to fracture, creep, fatigue, corrosion, neutron irradiation, and thermal aging. In addition to the above mentioned normal operation functions, the core barrel must also resist seismic loads and effectively transfer heat away from the core during a conduction cooldown event. The latter function defines the need for critical material thermal properties, such as emissivity and thermal conductivity.

Each function has a set of requirements, including performance that must be met for the range of normal and off-normal events. For those off-normal events within the design basis, SSCs relied on to meet the HTGR-specific safety functions for public safety are classified as safety-related.

The above information would then be used to develop the component design and performance specification, which will state the component material and mechanical requirements under normal and 
accident conditions. For example, the use of ASME design rules requires a Design Specification that includes key material property requirements for graphite core components. The ASME graphite design rules provide a list of required nonirradiated and irradiated mechanical property requirements for use with the ASME graphite design rules.

Material candidates will then be selected that meet, or potentially meet, all the requirements of this specification, while considering the level of existing applicable code and regulatory compliance. Priority is given to candidates that are accepted by industry consensus codes (ASME B\&PV) and the NRC at the proposed design and accident conditions. If such materials are not available, materials will be considered that meet a consensus code or are in the process of being added to a code but have not been accepted by the NRC. If there is not a codified material available that can meet design conditions, material candidates will be selected based on applicable available information.

Once material candidates are selected for a component, the materials will be assessed based on a series of key attributes, which may include:

- Code acceptability, limitations, and requirements. Each candidate material is assessed based on the acceptability, limitations, and requirements of the ASME Code for nuclear facility components. For example, Section III, Subsections NB and NH are used for Class 1 components. Both subsections contain rules for materials, design, fabrication, examination, testing, and overpressure relief of Class 1 components. The rules of Subsection NB guard only against timeindependent failure modes. Subsection NH extends specific rules of Subsection NB to elevated temperature service, provided the designer can demonstrate that the combined effects of temperature, stress level, and duration of loading do not introduce significant creep effects. Note that codification by the ASME is not required for qualification of a material for a specific application; however, the qualification process is generally more straightforward when a material is covered by the ASME Code.

- Existing design, fabrication, and operating experience. Existing design, fabrication and operating experience are considered for each candidate material. Design experience is the depth and breadth of analysis that has been performed regarding the material's performance under design conditions for the proposed application. Fabrication experience will mainly focus on lessons learned from forming, machining and welding of the candidate material. Operating experience will focus on HTGR applications, but other industrial experience will also be considered.

- Ability to procure. The ability to procure the material in the necessary form(s) and to the requisite specification and quality must be evaluated given the availability and capability of global resources. The ability to procure a material is impacted by acceptance of the material by a standards body. In the United States, this is typically an ASTM International Standard. This can be a significant issue with composite materials, for example, which are not currently covered by a procurement standard. Standardization is also a prerequisite for acceptance into the ASME Code.

- Technical maturity. The technical maturity of each material under consideration will be evaluated. For the purpose of this paper, technical maturity is defined as the amount and quality of existing data and operating experience for a given application. In general, the greater a material's maturity, the less research will be required to qualify the material. A technically mature material is ideal, but materials that require significant research may be necessary to meet the requirements of certain applications.

- Fabrication assessment. Each candidate material will undergo a fabrication assessment to determine whether the material can be economically formed, machined, welded, etc., to meet the requirements of the component. The ability to properly heat treat very large components for a very high temperature reactor (VHTR) is also an important criteria. 
- Performance assessment. A performance assessment of each potential material for a given application will be conducted to determine which candidate best meets the application requirements.

- Compatibility with environment. The compatibility of each candidate material with its operating environment will be considered. The corrosion resistance of each material will be assessed based on the temperature and reactive species present during normal and accident conditions. Components in close proximity to the core will also be evaluated for irradiation effects. The potential for degradation in properties associated with aging will also be considered.

- Regulatory acceptance review. A regulatory acceptance review will be performed for the group of candidate materials to project the likelihood of ASME code and regulatory approval and the amount of effort required to obtain such approval.

- Cost. The relative cost of each candidate material will be assessed to determine the most economic material choice.

The material that best meets these assessment criteria will be selected for the component under consideration.

At this point, a determination will be made as to whether sufficient information is available to qualify the selected material for this application. If the required information is currently available, a justification document will be prepared for qualification. If not, a document will be prepared to identify the current gaps in data and provide a detailed plan to obtain this data.

\subsection{Metallic Materials}

The following sections briefly discuss some candidate materials for the main components of the primary loop of the HTGR, such as the RPV, cross vessel, steam generator and reactor internals. The effects of welding on metallic materials are not discussed here, but will be considered during the evaluation process for qualification. Note that all stated operating and accident temperatures are estimates and may change during the design process. It is important to note that material characterization and potential qualification have been under active consideration for some candidate materials for several years. As described in Section 2.7 of this report, ASME Standards and Technology, LLC has sponsored a number of studies relating to the Code status of specific materials, including Alloy $800 \mathrm{H}$, and Grade 91 steel. The Generation IV International Forum Materials Program Management Board coordinates materials research and development relevant to VHTR systems from eight signatories. This work includes activities on Grade 91 steel and Alloys $800 \mathrm{H}$ and 617. Other candidate materials such as Alloy $\mathrm{X}$ were actively investigated for earlier programs, but are not currently under investigation for VHTR applications.

\subsubsection{SA-508/SA-533}

\subsubsection{Relevant Applications of SA-508/533}

Manganese-nickel-molybdenum low-alloy steel is being considered as the main material of construction for the vessel system, which consists of the RPV, steam generator vessel and the cross vessel. ASME SA-508 Grade 3 Class 1 is used for forgings and SA-533 Type B Class 1 is used for plate. These materials are advantageous because they represent an excellent compromise between relatively high mechanical properties, thus limiting the pressure vessel wall thickness, good aging resistance, and toughness. 


\subsubsection{Important Considerations for SA-508/533}

Important considerations for material selection and qualification for the vessel system are dependent on the function of the specific component. When selecting a material for the reactor vessel, the following characteristics must be considered: high temperature mechanical properties, toughness, thermal properties, corrosion resistance, and possible effects of irradiation and thermal aging. The main factors affecting the steam generator vessel and cross vessel are their mechanical properties and corrosion resistance, since these components will not be significantly affected by conduction cooldown events or irradiation.

The focus for high temperature mechanical properties will be on accident conditions, since there is extensive experience with this material at the projected operating temperature of $325^{\circ} \mathrm{C}\left(617^{\circ} \mathrm{F}\right)$. ASME Code Case N-499-2 sets temperature and time limits for accident conditions, which consider strength, fatigue, creep, and stress to rupture. The HTGR design will conform to the code case limits so that further analysis of these properties will not be required.

Thermal properties such as emissivity and thermal diffusivity are integral to assessing the material's ability to meet the design requirements during a conduction cooldown event. Emissivity is a measure of a material's ability to radiate heat energy, and thermal diffusivity is the ratio of thermal conductivity to volumetric heat capacity. Measurements of emissivity will be required after oxidation in air and helium to determine the most appropriate values. Nominal values of thermal diffusivity are available in ASME Section II, Part D at temperatures up to $815^{\circ} \mathrm{C}\left(1499^{\circ} \mathrm{F}\right)$.

The effects of oxidation in the helium environment will need to be evaluated, including during hot transient conditions. Furthermore, oxidation effects caused by potential air ingress or steam/water ingress events will need to be considered. However, given the present extensive database and the large material thicknesses involved, oxidation effects are not expected to be significant, making the need for new data unlikely.

Any hardening and embrittlement of the HTGR RPV material caused by neutron exposure should be much less than in LWRs because the end of life vessel fluence of the HTGR will be at least an order of magnitude less than a typical LWR vessel. However, the radiation spectrum differs between these two designs and neutron embrittlement of the vessel will still need to be considered.

\subsubsection{Related Experience with SA-508/533}

For over 40 years, manganese-nickel-molybdenum low-alloy steel has been used for LWR pressure vessel components in the United States and abroad. During this time, the material has been improved by limiting some trace elements. Weldability and toughness were improved by restricting the allowable carbon content. Toughness was further improved by reducing the allowable amount of sulfur and phosphorus. Reducing the amount of phosphorus also decreased the material's sensitivity to thermal aging. This experience applies, since the HTGR RPV normal operating temperatures will be similar to those of existing LWRs.

\subsubsection{Current Qualification Status of SA-508/533}

One of the objectives of any design option that will permit use of SA-508/SA-533 steel is to keep the vessel system wall temperatures within the acceptable range permitted by the ASME Section III Code. SA-508/SA-533 steels are ASME Code approved for Class 1 nuclear components and Subsection NB rules are applicable up to $371^{\circ} \mathrm{C}\left(700^{\circ} \mathrm{F}\right)$ for normal operation. By operating within the requirements of the ASME Code, it will be possible to take advantage of the years of operating experience with LWR reactor vessels. ASME also allows limited high temperature excursions under Code Case N-499-2, but this code case has not yet been accepted by the NRC. 
Code Case N-499-2 permits the use of SA-508/SA-533 for nuclear applications at temperatures up to $538^{\circ} \mathrm{C}$ for abnormal situations. The code case states that the component design will be based on a maximum cumulative time of 3,000 hours at metal temperatures in the range of 371 to $427^{\circ} \mathrm{C}(700$ to $\left.800^{\circ} \mathrm{F}\right)$ and 1,000 hours at metal temperatures exceeding $427^{\circ} \mathrm{C}\left(800^{\circ} \mathrm{F}\right)$ and up to $538^{\circ} \mathrm{C}\left(1000^{\circ} \mathrm{F}\right)$. The code case also requires that the number of anticipated events where metal temperatures exceed $427^{\circ} \mathrm{C}\left(800^{\circ} \mathrm{F}\right)$ be limited to a total of three. In the case of the HTGR, an abnormal situation requiring the use of Code Case N-499-2 might result from an accident involving a depressurized conduction cooldown event; however, such an event is not anticipated to occur more than once during the lifetime of the facility.

The ASME Code is also sufficient to permit the use of SA-508/SA-533 steel in the cross-vessel and the steam generator vessel because these components are not significantly affected by a conduction cooldown event or exposure to neutron radiation. However, the code does not address key requirements of the RPV design, such as emissivity and thermal aging. The qualification of this material for the RPV will thus require consideration of these factors.

\subsubsection{Alloy $800 \mathrm{H}$}

\subsubsection{Relevant Applications of Alloy $800 \mathrm{H}$}

Metallic components in contact with hot helium gas could potentially be fabricated from Alloy $800 \mathrm{H}$. For an HTGR, these components include the core support structure (including the core barrel), outer control rod cladding, control rod guide tubes, upper plenum shroud, lower plenum sidewall thermal barrier, hot duct liner, and hot end-steam generator tubing. Alloy $800 \mathrm{H}$ is an iron-nickelchromium material that is designed for high temperature service where resistance to creep and rupture is required. The operating temperature for the areas where Alloy $800 \mathrm{H}$ is being considered will depend on the outlet temperature of the reactor core. The current plan for the HTGR is to use an outlet temperature of 750 to $800^{\circ} \mathrm{C}\left(1382\right.$ to $\left.1562^{\circ} \mathrm{F}\right)$.

\subsubsection{Important Considerations for Alloy $800 \mathrm{H}$}

Important considerations for material selection and qualification for the above mentioned applications are dependent on the specific component attributes, which include operating and design temperature, environment, proximity to the core, and function.

For the core support structure, outer control rods, control rod guide tubes, upper plenum shroud, and lower plenum sidewall thermal barrier, material selection and qualification is based on high temperature strength, time dependent stresses, irradiation effects, thermal aging effects, and corrosion resistance. The core barrel material will also need to possess appropriate levels of emissivity and thermal diffusivity. Material selection and qualification for the hot end steam generator tubing is based mainly on high temperature strength, time dependent stress effects, thermal conductivity, and corrosion resistance. Material selection and qualification for the hot duct liner is based mainly on high temperature strength, corrosion resistance, and time dependent stress effects such as creep and stress rupture.

High temperature strength and time dependent stress effects such as creep and stress rupture for Alloy $800 \mathrm{H}$ are covered by ASME Section III, Division 5, which incorporated Code Case N-201-5 for core support structures and references Subsection NH. Efforts are currently underway, through the Task 13 managed by the ASME Standards Technology, LLC, as discussed in Section 2.7 above, to extend Code allowables for Alloy $800 \mathrm{H}$ regarding design life and values for yield strength, ultimate tensile strength, and minimum stress-to-ruptures. For the purposes of discussion herein, note that both Code Case N-201-5 and Section III, Subsection NH permit Alloy 800H to operate up to 
$760^{\circ} \mathrm{C}\left(1400^{\circ} \mathrm{F}\right)$. Furthermore, N-201-5 and Subsection NH state that there is no significant time dependent effect on the stress allowables for Alloy $800 \mathrm{H}$ up to about $427^{\circ} \mathrm{C}\left(800^{\circ} \mathrm{F}\right)$. This temperature limit was based on a component life of 300,000 hours. Time dependent effects related to the 60 -year design life will be evaluated during qualification. Other components will see temperatures above $425^{\circ} \mathrm{C}\left(800^{\circ} \mathrm{F}\right)$ and some nonstructural components (e.g., hot-gas-duct liner) will possibly operate as high as $800^{\circ} \mathrm{C}\left(1472^{\circ} \mathrm{F}\right)$ for the life of the plant. Consequently, allowable Alloy $800 \mathrm{H}$ stresses will need to be extended to encompass the 60-year design life for the HTGR to a minimum of at least $800^{\circ} \mathrm{C}$. Preliminary results of studies sponsored by ASME Standards and Technology, LLC have determined that there is currently sufficient information available to extend Code qualification to $850^{\circ} \mathrm{C}$ for a maximum use temperature for 500,000 hours design life for lower temperatures.

The core support structure, control rod guide tubes, and upper plenum shroud operate below $400^{\circ} \mathrm{C}$ during normal operation. Therefore, high temperature strength and time dependent stress effects such as creep and stress rupture are not considered a significant concern for these components under normal operating conditions. Further evaluation is required to determine if the core support structure will exceed the $760^{\circ} \mathrm{C}\left(1400^{\circ} \mathrm{F}\right)$ limit during a conduction cooldown event and for how long. If the core support structure is predicted to exceed $760^{\circ} \mathrm{C}\left(1400^{\circ} \mathrm{F}\right)$ during a conduction cooldown event, an extension of Section III, Subsection NH to higher temperatures may be required for the use of Alloy $800 \mathrm{H}$. In STP-NU-20, ${ }^{4}$ it is concluded that existing data are sufficient to extend the stress allowables to 600,000 hours at $900^{\circ} \mathrm{C}\left(1652^{\circ} \mathrm{F}\right)$. The control rod guide tubes and upper plenum shroud will likely exceed the current code temperature limit during a pressurized conduction cooldown event and, therefore, Alloy $800 \mathrm{H}$ will require further evaluation for fitness of use at these higher temperatures.

In the prismatic reactor, the lower plenum barrier will operate around $660^{\circ} \mathrm{C}\left(1220^{\circ} \mathrm{F}\right)$ during normal conditions, which is within the limit set by Code Case N-201-5. However, the code case does show an impact on the stress allowables at this temperature because of extended operation. An evaluation will be required to determine if the lower plenum barrier can meet the allowables over the life of the plant. If it cannot meet the code, an evaluation of existing data or the selection of alternate materials and possible further testing will be required for qualification. A conduction cooldown event would not likely cause the temperature of this component to exceed $760^{\circ} \mathrm{C}\left(1400^{\circ} \mathrm{F}\right)$, but this must be confirmed during design.

During normal operation, the outer control rods will operate around $440^{\circ} \mathrm{C}\left(824^{\circ} \mathrm{F}\right)$, which is within the limit set by Code Case N-201-5. However, N-201-5 does show a small impact on the stress allowables at this temperature caused by extended operation. An evaluation will be required to determine if this component can meet the allowables over the 60 -year life of the plant. Because of the proximity to the core, this component will also likely exceed the current code temperature limit for Alloy $800 \mathrm{H}$ during a conduction cooldown event and, therefore, will require further evaluation at these high temperatures for qualification. Note that the inner control rods in prismatic fuel reactors may see operating and accident temperatures of about $800^{\circ} \mathrm{C}\left(1472^{\circ} \mathrm{F}\right)$ and $1400^{\circ} \mathrm{C}\left(2552^{\circ} \mathrm{F}\right)$, respectively. Thus, Alloy $800 \mathrm{H}$ is not a viable option unless the inner control rods are not inserted during an accident. Note that both the outer control rods and the inner control rods can be replaced if necessary during the facility lifetime. This option will be evaluated. Irradiation effects must also be considered for the control rods, but sufficient data currently exists to undertake such an evaluation.

The hot end steam generator tubing will operate at about $600^{\circ} \mathrm{C}\left(1112^{\circ} \mathrm{F}\right)$ during normal conditions, which is within the limit set by Subsection NH. However, Subsection NH does show an impact on the stress allowables at $600^{\circ} \mathrm{C}\left(1112^{\circ} \mathrm{F}\right)$ caused by extended operation. An evaluation will be required to determine if the hot end steam generator tubing can meet these allowables over the 60yr life of the plant. If the present allowables are not sufficient, then an evaluation of existing data 
may be required for qualification. A conduction cooldown event would not likely cause the temperature of this component to exceed $760^{\circ} \mathrm{C}\left(1400^{\circ} \mathrm{F}\right)$, but this will be confirmed during design.

Some HTGR steam generator designs may involve a bimetallic weld between Alloy $800 \mathrm{H}$ tubing and ferritic steel tubing, likely $2.25 \mathrm{Cr}-1 \mathrm{Mo}$. It is not certain how this bimetal would be incorporated into the ASME Code. A conservative approach might be to consider the bimetal to possess hightemperature properties equivalent to those of the 2.25Cr-1Mo steel. However, consideration will need to be given to corrosion questions, especially where alternating wet-dry conditions might exist.

The hot duct liner will operate at the approximate reactor outlet temperature of 750 to $800^{\circ} \mathrm{C}$ $\left(1382^{\circ} \mathrm{F}\right.$ to $\left.1472^{\circ} \mathrm{F}\right)$, depending on the final design under normal conditions and the higher of these temperatures is above the limit set by ASME Section III Subsection NH. However, the hot duct liner will be under minimal stress so that the high temperature strength and time dependent stress effects that drive the $760^{\circ} \mathrm{C}\left(1400^{\circ} \mathrm{F}\right)$ limit may not directly apply. Further, as already noted earlier, data already available would support operation at even higher temperatures. During a pressurized conduction cooldown event, the hot duct liner may exceed the current code temperature and, if so, would require further evaluation at these high temperatures for qualification.

Since the outer control rods, control rod guide tubes, upper plenum shroud and core support structure are in close proximity to the core, irradiation effects also need to be evaluated for qualification. However, sufficient data already exist for this purpose. The lower plenum thermal barrier and hot duct liner will not likely accumulate enough fluence over the life of the plant to experience detrimental effects from irradiation. This will be confirmed during the design process.

Increasing temperature tends to accelerate the corrosion of all materials, including Alloy $800 \mathrm{H}$, in a helium gas environment. At temperatures below $475^{\circ} \mathrm{C}\left(887^{\circ} \mathrm{F}\right)$, extended operation studies have shown that, corrosion of Alloy $800 \mathrm{H}$ in impure helium gas is minimal. At temperatures below $900^{\circ} \mathrm{C}$ $\left(1652^{\circ} \mathrm{F}\right)$, extended operation studies in impure helium gas have shown that Alloy $800 \mathrm{H}$ develops chromia scales along with significant internal oxidation of aluminum and subsurface depletion of $\mathrm{Cr}$. However, it must be noted that the corrosion behavior is quite sensitive to levels and ratios of active impurity species and this must be considered in the evaluation process.

Ensuring the performance of Alloy $800 \mathrm{H}$ components under accident conditions requires consideration of thermal properties such as emissivity and thermal diffusivity, as these are integral to the material's ability to meet applicable design requirements during a conduction cooldown event. Emissivity values after oxidation in air and helium are the most appropriate values. These experiments have been carried out at the University of Wisconsin-Madison in a Nuclear Energy Research Initiative project and confirmed by results at the University of Missouri-Columbia. The values agree with the expectation that essentially all chromium oxide scales have similar emissivity values. Nominal values of thermal diffusivity are available in ASME Section II, Part D at temperatures up to $815^{\circ} \mathrm{C}\left(1499^{\circ} \mathrm{F}\right)$; additional data are being determined by the NGNP Technology Development Program.

The NGNP High Temperature Materials Program is described in two documents ${ }^{5,6}$. These two documents describe in detail all of the known issues that need to be addressed in the area of high temperature applications for metallic materials. They are updated whenever significant new information becomes available from the design teams.

\subsubsection{Related Experience with Alloy 800H}

Alloy $800 \mathrm{H}$ has been used in high temperature components of HTGRs for over 20 years of plant operation. FSV, the Arbeitsgemeinschaft Versuchsreaktor (AVR), and the Thorium HighTemperature Reactor (THTR) used Alloy $800 \mathrm{H}$ for steam generator tubing and heat exchanger 
components with success. These plants operated for a combined total of 34 years, with AVR operating for 20 years. The steam generator inlet temperature was around $950^{\circ} \mathrm{C}\left(1742^{\circ} \mathrm{F}\right)$ for $\mathrm{AVR}$, $775^{\circ} \mathrm{C}\left(1427^{\circ} \mathrm{F}\right)$ for $\mathrm{FSV}$, and $750^{\circ} \mathrm{C}\left(1382^{\circ} \mathrm{F}\right)$ for THTR; however, actual metal temperatures were significantly lower.

Extensive studies have been performed evaluating the effects of operating temperature on the performance of Alloy $800 \mathrm{H}$. The minimum creep rate versus stress at 593 to $760^{\circ} \mathrm{C}\left(1100\right.$ to $\left.1400^{\circ} \mathrm{F}\right)$ was determined using regression analysis. Fatigue behavior of Alloy $800 \mathrm{H}$ has been evaluated from room temperature to $760^{\circ} \mathrm{C}\left(1400^{\circ} \mathrm{F}\right)$ and low-cycle and high-cycle fatigue data were taken at $760^{\circ} \mathrm{C}$ $\left(1400^{\circ} \mathrm{F}\right)$. These studies form part of the foundation for ASME's current provisions for the use of Alloy $800 \mathrm{H}$ up to $760^{\circ} \mathrm{C}\left(1400^{\circ} \mathrm{F}\right)$. The values in the Code that resulted from these experiments define the allowable stresses in the design. In addition, there are extensive data for these properties for a range of stresses at temperatures through $1000^{\circ} \mathrm{C}\left(1832^{\circ} \mathrm{F}\right)$.

\subsubsection{Current Qualification Status of Alloy $800 \mathrm{H}$}

Code Case N-201-5 is an ASME approved addition to Section III, Subsection NG that allows the use of Alloy $800 \mathrm{H}$ for core support structures at temperatures up to $760^{\circ} \mathrm{C}\left(1400^{\circ} \mathrm{F}\right)$. Section III, Division 5 was published on November 1, 2011, and incorporates Code Case N-201-5. Alloy 800H is also addressed in Subsection NH for High temperature Class 1 components which also sets a limit for Alloy $800 \mathrm{H}$ of $760^{\circ} \mathrm{C}\left(1400^{\circ} \mathrm{F}\right)$. Since some components may exceed these temperature limits during normal operation or a conduction cooldown event, one of the following will be required: (1) modifying the Code to allow the use of Alloy $800 \mathrm{H}$ at higher temperatures; (2) qualifying Alloy $800 \mathrm{H}$ for the specific component based on existing data, and potential further testing, without code qualification; (3) modifying the design to stay below the temperature limit; or (4) fabricating these components from a different material. Since some components operate in the time-dependent stress regime, Alloy $800 \mathrm{H}$ stress allowables will need to be extended to encompass the 60-year design life of the HTGR. The draft version of German Standard KTA 3221 covers the use of Alloy $800 \mathrm{H}$ up to $1000^{\circ} \mathrm{C}\left(1832^{\circ} \mathrm{F}\right)$. An ASME and DOE joint effort is currently underway to obtain the basis of the KTA 3221 draft standard, including information on the quality assurance program under which the data were collected. The acquisition of these data may support an increase of the ASME allowable operating temperature for Alloy $800 \mathrm{H}$.

The ASME Code covers Alloy $800 \mathrm{H}$ in terms of high temperature strength and time dependent stress effects, such as creep and stress rupture. The standard atmosphere for generating data incorporated in the Code is laboratory air. Thus, the Code does not address other key requirements of these components, such as the emissivity, corrosion resistance in the helium environment thermal aging, and irradiation effects. These potential influences on the properties are being addressed in the NGNP Technology Development Program.

\subsubsection{Modified 9Cr-1Mo}

\subsubsection{Relevant Applications of Modified 9Cr-1Mo Steel}

Modified 9Cr-1Mo (9Cr-1Mo-V) (Grade 91) steel is being considered for the core support structure, including the core barrel. Modified $9 \mathrm{Cr}-1 \mathrm{Mo}$ steel experiences only a gradual reduction in strength at temperatures up to $450^{\circ} \mathrm{C}\left(842^{\circ} \mathrm{F}\right)$, but above that, allowable stresses for all low alloy steels drop off considerably. However, modified $9 \mathrm{Cr}-1 \mathrm{Mo}$ has an advantage over other steels because it retains its strength much better at these elevated temperatures. 


\subsubsection{Important Considerations for Modified 9Cr-1Mo}

Material selection and qualification for the core support structure is based on high temperature strength, time dependent stress effects, thermal aging, fatigue emissivity, thermal diffusivity, irradiation effects, and corrosion resistance.

According to Section III, Subsection NB of the ASME Code, modified 9Cr-1Mo (Grade 91) is permitted to operate at up to $371^{\circ} \mathrm{C}\left(700^{\circ} \mathrm{F}\right)$, and according to both Section III, Division 5 and Section III, Subsection NH, up to $649^{\circ} \mathrm{C}\left(1200^{\circ} \mathrm{F}\right)$. However, Section III, Division 5 does not address the use of modified $9 \mathrm{Cr}-1 \mathrm{Mo}$ for core support structure, and Section III, Subsection NH, there is no significant effect of temperature on stress allowables at temperatures below $371^{\circ} \mathrm{C}\left(700^{\circ} \mathrm{F}\right)$. This temperature limit was based on a component life of 300,000 hours. Whether this remains true for the HTGR 60-year design life will be evaluated during qualification.

During normal operation, the core support structure will operate at about $350^{\circ} \mathrm{C}\left(662^{\circ} \mathrm{F}\right)$, which is below the $371^{\circ} \mathrm{C}\left(700^{\circ} \mathrm{F}\right)$ limit set by Section III, Subsection NB. The high temperature strength and time dependent stress effects such as creep and stress rupture are therefore not considered a concern under normal operating conditions. Further evaluation is required to determine if these components will exceed the $649^{\circ} \mathrm{C}\left(1200^{\circ} \mathrm{F}\right)$ limit during a conduction cooldown event and for how long. Remaining below the $649^{\circ} \mathrm{C}\left(1200^{\circ} \mathrm{F}\right)$ limit will not guarantee acceptability, but this limit is considered helpful guidance for qualification.

The effect of thermal aging on the properties of Modified 9Cr-1Mo (Grade 91) is negligible over the temperature range of 300 to $600^{\circ} \mathrm{C}\left(572\right.$ to $\left.1112^{\circ} \mathrm{F}\right)$ for times to 75,000 hours. Yield strength, ultimate tensile strength, and ductility are not significantly affected. Therefore, thermal aging of this material is not expected to be an issue.

Thermal properties such as emissivity and thermal diffusivity are important to passive heat removal capability. Measurements of emissivity will be required after oxidation in air and helium to determine the most appropriate values. Nominal values of thermal diffusivity are available in ASME Section II, Part D at temperatures up to $815^{\circ} \mathrm{C}\left(1500^{\circ} \mathrm{F}\right)$.

Ferritic steels are susceptible to neutron embrittlement over extended periods of operation in high fluence locations. The effects of irradiation on strength and ductility are dependent on irradiation temperature and dose (dpa). Considerable hardening occurs for irradiations below $400^{\circ} \mathrm{C}\left(752^{\circ} \mathrm{F}\right)$ but hardening decreases rapidly as irradiation temperature is increased. Essentially no hardening is experienced by the time the irradiation temperature reaches $500^{\circ} \mathrm{C}\left(932^{\circ} \mathrm{F}\right)$. Data are available for irradiations from 50 to $600^{\circ} \mathrm{C}\left(122\right.$ to $\left.1112^{\circ} \mathrm{F}\right)$ for doses to $60 \mathrm{dpa}$, well above what is expected for the application of modified $9 \mathrm{Cr}-1 \mathrm{Mo}$. The projected end-of-life fluence of the modified 9Cr-1Mo core support structure will be used to evaluate the viability of this material for the intended applications.

No particular corrosion concerns are expected for modified 9Cr-1Mo at the service temperatures of the HTGR. The effects of oxidation in the helium environment during hot transient conditions will need to be evaluated; however, given the thickness of the components of interest, no significant issues are anticipated.

\subsubsection{Related Experience with Modified 9Cr-1Mo}

ASME Boiler and Pressure Vessel Code, Section III, Division 5 also provides references to the fatigue curve for modified 9Cr-1Mo alloy (for elevated temperature evaluations) via Appendix $\mathrm{T}$ in Subsection NH of Division 1. This strain range-allowable cycle curve (Fig. T-1420-1E) contains data out to $10^{8}$ cycles. 
9Cr-1Mo low alloy steel was originally developed for the fast breeder reactor starting in the 1970s. It was found to have lower thermal expansion, higher thermal conductivity, and improved oxidation resistance compared to traditional power plant steels, such as $2.25 \mathrm{Cr}-1 \mathrm{Mo}$ low alloy steel. The addition of niobium, vanadium, and nitrogen created modified $9 \mathrm{Cr} 1-\mathrm{Mo}(9 \mathrm{Cr}-1 \mathrm{Mo}-\mathrm{V})$, which exhibits a substantial increase in creep-rupture strength. Modified 9Cr-1Mo was certified by ASME in the 1980s, is now widely specified for electric utility power plants, and is moving into the oil and gas industry. For example, modified $9 \mathrm{Cr}-1 \mathrm{Mo}$ has been used for tubing in the super-heaters of power boilers for over 20 years. It has been used for piping applications up to $593^{\circ} \mathrm{C}\left(1100^{\circ} \mathrm{F}\right)$ and in tubing up to $565^{\circ} \mathrm{C}\left(1050^{\circ} \mathrm{F}\right)$. Modified $9 \mathrm{Cr}-1 \mathrm{Mo}$ has had great success in the fossil industry; however, some failures have occurred and these were traced to a lack of quality assurance. Special care must be taken during processing, fabrication, and installation to create and maintain the proper microstructure to obtain the desired material properties. The necessity for pre-weld and post-weld heat treatment makes onsite fabrication of components from this steel problematic.

Extensive studies have been conducted on modified 9Cr-1Mo to evaluate tensile strength, creep rupture, and low-cycle fatigue properties in a high temperature environment. Long-term aging effects on mechanical properties have also been determined. After aging at $482^{\circ} \mathrm{C}\left(900^{\circ} \mathrm{F}\right)$ for 75,000 hours, little effect was noticed on the ultimate tensile strength at temperatures up to $500^{\circ} \mathrm{C}\left(932^{\circ} \mathrm{F}\right)$. For the aged material, creep rates at $575^{\circ} \mathrm{C}\left(1067^{\circ} \mathrm{F}\right)$ at $14.5 \mathrm{ksi}$ showed no acceleration and only about $1 \%$ strain after 20,000 hours. For material aged at $650^{\circ} \mathrm{C}\left(1202^{\circ} \mathrm{F}\right)$ for 10,000 hours, the rupture life at $14.5 \mathrm{ksi}$ and $600^{\circ} \mathrm{C}\left(1112^{\circ} \mathrm{F}\right)$ was about 30,000 hours. Extrapolation to a test temperature of $500^{\circ} \mathrm{C}$ $\left(932^{\circ} \mathrm{F}\right)$ gives a rupture life at $14.5 \mathrm{ksi}$ that far exceeds the proposed 60-year life of the plant. Lowcycle fatigue data indicated a higher cyclic strength for the hot-rolled material compared with the hotforged material. Fatigue crack growth testing at $538^{\circ} \mathrm{C}\left(1000^{\circ} \mathrm{F}\right)$ concluded that the crack propagation rate was similar with both product forms. Fracture toughness is good and relatively constant with a $\mathrm{K}_{\mathrm{JQ}}$ value of $\sim 275 \mathrm{MPa}[\mathrm{m}]^{1 / 2}$ from room temperature through $200^{\circ} \mathrm{C}\left(392^{\circ} \mathrm{F}\right)$; irradiation to $3 \mathrm{dpa}$ reduces $\mathrm{K}_{\mathrm{JQ}}$ to $\sim 100 \mathrm{MPa}[\mathrm{m}]^{1 / 2}$, but this is still a substantial value.

\subsubsection{Current Qualification Status of Modified 9Cr-1Mo}

Based on the ASME Code, the maximum allowable temperature for modified 9Cr-1Mo per Section III Subsection NB is $371^{\circ} \mathrm{C}\left(700^{\circ} \mathrm{F}\right)$, and per Section III, Subsection NH and Division 5 is $649^{\circ} \mathrm{C}\left(1200^{\circ} \mathrm{F}\right)$. Use of modified $9 \mathrm{Cr}-1 \mathrm{Mo}$ for core support structures will need to be clarified in Section III, Division 5.

The ASME Code covers modified 9Cr-1Mo in terms of high temperature strength and timedependent stress effects such as creep and stress rupture. However, the code does not address key requirements for the design of these components such as the emissivity, corrosion, thermal aging, and irradiation effects. Therefore, the qualification of this material will require further effort.

\subsection{Cr-1Mo}

\subsubsection{Relevant Applications of 2.25Cr-1Mo}

Grade 22 of $2.25 \mathrm{Cr}-1 \mathrm{Mo}$ (as specified in Division 5 and Subsection $\mathrm{NH}$ ) is being considered for cold-end steam generator tubing that will be exposed to helium and water during normal operation. Further, 2.25r-1Mo might also apply to other components, such as the core barrel and the steam generator vessel. The allowable stress for $2.25 \mathrm{Cr}-1 \mathrm{Mo}$ is similar to modified $9 \mathrm{Cr}-1 \mathrm{Mo}$ up to about $430^{\circ} \mathrm{C}\left(806^{\circ} \mathrm{F}\right)$, but above this temperature, its strength drops off significantly relative to modified $9 \mathrm{Cr}-1 \mathrm{Mo}$. However, the cold-end steam generator tubing will experience a maximum temperature of only about $400^{\circ} \mathrm{C}\left(752^{\circ} \mathrm{F}\right)$ during normal operation, so $2.25 \mathrm{Cr}-1 \mathrm{Mo}$ may be a suitable option. 


\subsubsection{Important Considerations for 2.25Cr-1Mo}

For the cold-end steam generator tubing, material selection and qualification is based on high temperature strength, thermal aging effects, time dependent stress effects, thermal conductivity, fatigue resistance, and corrosion resistance.

According to Section III, Division 5, 2.25Cr-1Mo Grade 22 is permitted to operate at up to $600^{\circ} \mathrm{C}$ $\left(1100^{\circ} \mathrm{F}\right)$ in core support structure applications and up to $538^{\circ} \mathrm{C}\left(1000^{\circ} \mathrm{F}\right)$ for Class B components. Subsection NB permits $371^{\circ} \mathrm{C}\left(700^{\circ} \mathrm{F}\right)$. Accordance to Section III, Subsection NH, $2.25 \mathrm{Cr}-1 \mathrm{Mo}$ in the annealed form may be operated up to $649^{\circ} \mathrm{C}\left(1200^{\circ} \mathrm{F}\right)$. The latter is well above the projected operating temperature for these components (about $400^{\circ} \mathrm{C}\left[752^{\circ} \mathrm{F}\right]$ ). Based on Subsection $\mathrm{NH}$, there is no significant effect on stress allowables caused by operation to 300,000 hours at temperatures below about $371^{\circ} \mathrm{C}\left(700^{\circ} \mathrm{F}\right)$. The 60 -year design life proposed for the HTGR must be evaluated during qualification to determine if time-dependent effects, such as creep and stress rupture, must be taken into account. Further evaluation is required to determine if these components will exceed the $649^{\circ} \mathrm{C}\left(1200^{\circ} \mathrm{F}\right)$ limit during a loss-of-forced-convection event and for how long. Remaining below the $649^{\circ} \mathrm{C}\left(1200^{\circ} \mathrm{F}\right)$ limit will not guarantee NRC acceptance, but this limit is considered helpful guidance for qualification.

Thermal conductivity is integral to assessing the ability of tubing to transfer heat efficiently from the primary helium gas to the secondary side water. Measurements will be required after oxidation in air, secondary water or steam, and helium to determine whether degradation of heat transfer properties will need to be taken into account.

Previous HTGR steam generators (e.g., FSV) have used 2.25Cr-1Mo tubes in high temperature aerated water with success. The corrosion behavior of this material will still need to be evaluated for projected operating temperature and water chemistry conditions to identify whether or not additional testing is required.

Field experience has shown the $2.25 \mathrm{Cr}-1 \mathrm{Mo}$ steels are virtually immune to wet steam erosioncorrosion in LWR nuclear applications. The main difference between traditional reactor steam generator tubing and tubing in the HTGR steam generator is that the temperature is significantly higher. In the HTGR cold-end steam generator tubing, the water temperature will be about $400^{\circ} \mathrm{C}$ $\left(752^{\circ} \mathrm{F}\right)$, which experience shows will cause the formation of a protective layer of $\mathrm{Fe}_{3} \mathrm{O}_{4}$.

No significant corrosion effects related to the helium environment are expected for $2.25 \mathrm{Cr}-1 \mathrm{Mo}$ at the service temperatures projected for the cold-end steam generator tubing of the HTGR.

\subsubsection{Related Experience with 2.25Cr-1Mo}

The well-established Grade 22 of 2.25Cr-1Mo has been used in both fossil and nuclear power plants. This material has been used in boiler and pressure vessels in fossil plants at operating temperatures around $400^{\circ} \mathrm{C}\left(752^{\circ} \mathrm{F}\right)$. The Japanese HTTR has operated for over 10 years with a $2.25 \mathrm{Cr}-1 \mathrm{Mo}$ reactor vessel and heat exchanger vessel with an operating temperature of about $395^{\circ} \mathrm{C}$ $\left(742^{\circ} \mathrm{F}\right)$. This material was also used in the FSV and THTR for steam generator tubing.

A substantial database is available on the tensile, creep, fatigue, and creep-fatigue properties of 2.25Cr-1Mo ferritic steel. This database also includes the effect of long-term aging on microstructural changes and mechanical properties at temperatures consistent with the cold helium side of the HTGR. 


\subsubsection{Current Qualification Status of 2.25Cr-1Mo}

According to Section III, Division 5, 2.25Cr-1 Mo Grade 22 is permitted to operate at up to $600^{\circ} \mathrm{C}$ (approximately $\left.1100^{\circ} \mathrm{F}\right)$ in core support structure applications and up to $538^{\circ} \mathrm{C}\left(1000^{\circ} \mathrm{F}\right)$ for Class $\mathrm{B}$ components. The maximum allowable temperature for $2.25 \mathrm{Cr}-1 \mathrm{Mo}$ Grade 22 per Section III, Subsection NB is $371^{\circ} \mathrm{C}\left(700^{\circ} \mathrm{F}\right)$ per Section III, Subsection NH is $593^{\circ} \mathrm{C}\left(1100^{\circ} \mathrm{F}\right)$. Even though the use of this material is allowed under ASME Section VIII at up to $649^{\circ} \mathrm{C}\left(1200^{\circ} \mathrm{F}\right)$, significant decreases in strength occur above about $427^{\circ} \mathrm{C}\left(800^{\circ} \mathrm{F}\right)$ and will need to be considered during design. Further evaluation will be required to determine the temperature of the steam generator tubes during a conduction cooldown event.

The ASME Code covers 2.25Cr-1Mo Grade 22 in terms of high temperature strength and time dependent stress effects such as creep and stress rupture. However, the Code does not address key requirements of the design of these components, such as corrosion resistance and thermal aging effects. Therefore, the qualification of this material will require some small amount of further evaluation.

\subsubsection{Type 316 SST}

\subsubsection{Relevant Applications of Type 316H SST}

Type $316 \mathrm{H}$ austenitic SST is being considered as a material option for the HTGR core barrel assembly and other reactor metallic internal components that would experience temperatures above $593^{\circ} \mathrm{C}\left(1100^{\circ} \mathrm{F}\right)$ during service, either in normal or transient operation. Type 316 , most likely in the lower carbon $316 \mathrm{~L}$ version, is also a potential material for the steam generator tubing, which experiences maximum tube metal temperatures of about $620^{\circ} \mathrm{C}\left(1150^{\circ} \mathrm{F}\right)$. If the steam side corrosion potential can be controlled (to prevent stress corrosion cracking), a substantial cost saving can be achieved in replacing the Alloy $800 \mathrm{H}$ tubing with Type $316 \mathrm{H}$ or $316 \mathrm{~L}$ tubing.

\subsubsection{Important Considerations for Type 316HSST}

Material selection criteria for the core barrel assembly are dominated by high temperature strength, resistance to fatigue and vibration, thermal conductivity, and resistance to oxidation and neutron irradiation.

The high strength and creep resistance of $316 \mathrm{H}$, as specified in the ASME code, is ensured by controlling the carbon content and the microstructural grain size of the finished product. The carbon content is controlled between 0.04 and $0.06 \%$ and the grain size is specified to be in the range of ASTM 3-6. These controls are considered essential for operating temperatures between 427 and $593^{\circ} \mathrm{C}\left(800\right.$ and $\left.1100^{\circ} \mathrm{F}\right)$. The effects of these controls are not stated for higher temperatures, but they are still considered to be beneficial.

The emissivity of the core barrel surface is an important parameter in heat removal from the core via the core barrel sides, especially during conduction cooldown events. The emissivity of austenitic SST is highly dependent on the surface conditions, and typical total emissivity values reported are 0.11 for machined surfaces and up to 0.38 for sandblasted surfaces. The higher the emissivity, the more efficient the heat removal from the core. Increased heat removal from the core correspondingly results in lower maximum fuel temperatures, as well as lower metal temperatures for the core barrel and RPV. Furthermore, emissivity is temperature-dependent, and over the measured temperature range of 200 to $700^{\circ} \mathrm{C}\left(392^{\circ} \mathrm{F}\right.$ to $\left.1292^{\circ} \mathrm{F}\right)$, oxidized surfaces exhibit an average emissivity of about 0.85 . This is also achievable through the application of thin, ceramic-like coatings, e.g., Tyrano Coat TYR-1181. 
Because of the presence of minor concentrations of impurities in the helium coolant of HTRs, the austenitic SSTs will tend to form protective, stable oxide scales. Because of the rather low design temperatures of up to $600^{\circ} \mathrm{C}\left(1112^{\circ} \mathrm{F}\right)$, the expected scale growth rates will be slow and a typical scale thickness at the end of the 60-year design life should be $<10 \mu \mathrm{m}$.

The fast neutron $(\mathrm{E}>0.1 \mathrm{MeV})$ fluence levels for the core support structures and other metallic internals are typically below $1 \times 10^{19} \mathrm{n} / \mathrm{cm}^{2}$. This is below the level $\left(\sim 1 \times 10^{21} \mathrm{n} / \mathrm{cm}^{2}\right)$ at which austenitic SSTs begin to show significant irradiation-induced increases in tensile strength, along with associated reductions in ductility.

\subsubsection{Related Experience with Type 316H SST}

Austenitic steels of Type 304 and Type 316 are commonly used for LWR internals, such as fuel support structures, core barrels, and flow baffle plates. These are, however, all low temperature applications in aqueous conditions, and the materials used are the low-carbon versions (Type 304L or Type 316L).

\subsubsection{Current Qualification Status of Type 316H SST}

ASME Section III, Division 5 allows for the use of Type $316 \mathrm{H}$ SST up to $649^{\circ} \mathrm{C}\left(1200^{\circ} \mathrm{F}\right)$ for Class B components and up to $593^{\circ} \mathrm{C}\left(1100^{\circ} \mathrm{F}\right)$ in core support structure applications. The maximum allowable temperature for Type $316 \mathrm{H} \mathrm{SST}$ is $427^{\circ} \mathrm{C}\left(800^{\circ} \mathrm{F}\right)$ for ASME Section III, Subsection NB (Class 1 Components) and Subsection NG (subsection applicable to core support structures). It is, however, allowed for use at temperatures up to $816^{\circ} \mathrm{C}\left(1600^{\circ} \mathrm{F}\right)$ in Subsection $\mathrm{NH}$ and Code Case N201-5, which comprise extensions to Subsections NB and NG, respectively. These parts of the ASME code cover Type $316 \mathrm{H}$ in terms of high temperature strength, creep and creep-fatigue effects up to a design life of 300,000 hours. However, the Code does not address other key requirements associated with the design of these components, such as thermal aging effects and neutron embrittlement. Therefore, the qualification of this material will require some further evaluation to address these effects. Also, while Code Case N-201-5 has been incorporated into Section III, Division 5, there are currently studies being managed by the ASME Standards Technology, LLC to evaluate potential increases in the allowable time and temperature limits for Types $304 \mathrm{H}$ and $316 \mathrm{H}$ SST using available data.

\subsubsection{Alloy 617}

\subsubsection{Relevant Applications of Alloy 617}

Alloy 617 has superior strength and creep resistance compared to Alloy $800 \mathrm{H}$ above $800^{\circ} \mathrm{C}$ $\left(1472^{\circ} \mathrm{F}\right)$ and would be the preferred choice for applications at the highest temperatures where mechanical property considerations dominate. Applications might include the hot-duct liner or a high temperature IHX. Alloy 617 contains a significant amount of cobalt (10 to $15 \mathrm{wt} \%)$ that is an important contributor to high temperature strength and resistance to carburization, but it would preclude application in control rod sleeves or other applications where a significant amount of irradiation can occur.

\subsubsection{Important Considerations for Alloy 617}

Alloy 617, also designated as Inconel 617, was initially developed for high temperature applications above $800^{\circ} \mathrm{C}\left(1472^{\circ} \mathrm{F}\right)$. It is often considered for use in aircraft and land-based gas turbines, chemical manufacturing components, metallurgical processing facilities, and power generation structures. The alloy was also considered and investigated for the HTGR programs in the United States and Germany in the late 1970s and early 1980s. 
Alloy 617 has substantial creep strength at temperatures above $870^{\circ} \mathrm{C}\left(1598^{\circ} \mathrm{F}\right)$, good cyclic oxidation and carburization resistance, and good weldability. It also has lower thermal expansion than most austenitic SSTs and high thermal conductivity relative to the other candidates. It retains toughness after long-time exposure at elevated temperatures and does not form intermetallic phases that can cause embrittlement.

Alloy 617 is less resistant to oxidation however, this alloy is more prone to grain boundary oxidation because of the formation of aluminum rich grain boundary oxides. This type of oxidation would be particularly deleterious for use in thin sections associated with some compact heat exchanger designs. Preliminary testing indicates Alloy 617 has better resistance to carburization than Alloy $800 \mathrm{H}$.

Aging effects on Alloy 617 are quite complex and are not well understood. Observations and predictions of which precipitates form in Alloy 617 at given temperature ranges have not been consistent. A comprehensive review of the precipitates in Alloy 617 was performed recently and it was clear from the review that the kinetics of the precipitation and coarsening processes were important in determining the effects of aging on properties. It appears precipitates may form at initial exposure and the alloy may become stronger. But most of the precipitates will be dissolved after longterm exposure in the temperature range of interest to the NGNP IHX, and the alloy will depend on solid solution strengthening at long times. Aging at 700 to $750^{\circ} \mathrm{C}\left(1292\right.$ to $\left.1382^{\circ} \mathrm{F}\right)$ results in reduction in tensile and impact properties, however, these effects are less pronounced at higher temperatures.

The grain size also plays an important role in the strength of the alloy. For general applications, a grain size of ASTM No. $6(\sim 45 \mu \mathrm{m})$ or coarser is typically preferred, but it has been shown that creep strength increases with increasing grain size so microstructures of 100-200 $\mu \mathrm{m}$ grain size are often produced. A tradeoff exists, however, when fatigue is an issue, since finer grain sizes are preferred for fatigue resistance. In addition, for compact IHX, the thin sheet form restricts large grain size. Whether the grains will significantly coarsen after the dissolution of certain grain boundary precipitates at long-term exposure is not clear.

\subsubsection{Relevant Experience with Alloy 617}

During early development, Alloy 617 was systematically studied by Huntington Alloys, Inc., and when Alloy 617 was considered for the HTGR, it was extensively investigated by Huntington, Oak Ridge National Laboratory (ORNL), and General Electric (GE). The Huntington data were used to develop ASME B\&PV Code applications covered by Section I and Section VIII Division 1 and in a Draft Code Case for Section III.

Both the ORNL-HTGR and GE-HTGR studies generated data from Alloy 617 that had been aged and/or tested in simulated HTGR helium. The helium impurities used in those studies were the same as those considered for the NGNP system but the concentrations were different. Germany also extensively investigated Alloy 617 for its HTGR and other programs.

Over the past 5 years, interest in the behavior of Alloy 617 for VHTR applications has renewed. Activities carried out by the Korean Atomic Energy Research Institute, AREVA, French Atomic Energy Commission, and NGNP Research and Development Program are coordinated through the Gen IV International Forum Materials Program Management Board. There have been fundamental studies of Alloy 617 corrosion in VHTR atmospheres and development of predictive models for environmental effects. The creep and creep-fatigue behavior have been investigated in VHTR helium and investigators made a comparison of behavior under these conditions to newly generated data in air for the same material heats. 


\subsubsection{Code Status}

Alloy 617 is not currently qualified for use in ASME Code Section III, although it is allowed in Section I and Section VIII, Division 1 (nonnuclear service). A draft Code Case for incorporating Alloy 617 in Section III was developed and submitted in the early 1990s. Efforts to gain approval from the ASME Code committees were stopped because of termination of the associated VHTR programs. Comments obtained from ASME on the draft Code Case are being used to guide current research and development activities which are intended to update and resubmit the Code Case for approval in Section III, Subsection NB and NH. Inclusion of Alloy 617 into Subsection NH is being pursued as a priority item by the ASME Subgroup on High Temperature Reactors as a follow activity to Task 11 that was managed by the ASME Standards Technology, LLC.

Additionally, the German HTR program generated sufficient data for this material to be included in the draft version of German standard KTA 3221 , for temperatures up to $1000^{\circ} \mathrm{C}\left(1832^{\circ} \mathrm{F}\right)$ and design periods up to 100,000 hours.

\subsubsection{Other Metallics}

The metallic materials considered in this paper highlight potential options for select components in the primary loop. The need for additional or alternative metallic materials may become evident as the design progresses.

\subsection{Graphite Materials}

Material selection for the graphite components will be based on the same general principles discussed in Section 3.1. The grades of graphite that were used for previous HTGRs are no longer available. New grades of graphite have been developed based on the strengths and weaknesses of those previous grades. In order to qualify these new grades, testing is currently underway to obtain physical, thermal, mechanical (including radiation-induced creep), and oxidation properties. In some cases, past historical data and experience are being used (and discussed herein) to address the graphite selection and qualification approach.

A distinguishing feature of HTGR concepts is the extensive use of graphite in reactor internal components, including the core fuel blocks in the case of prismatic concepts. These graphite components are relied upon to establish core geometry, serve as the moderator in support of the nuclear heat generation process, and direct the flow of helium coolant. They also serve as a path for passive removal of heat in the case of certain licensing basis events, passive heat removal capability being fundamental to the HTGR safety concept.

This white paper addresses the use of graphite in core structural components. While HTGR fuel typically employs graphite, graphite fuel matrix (or fuel compact) materials are to be addressed separately in white papers specific to fuel qualification. In the case of prismatic-fuel reactors, the fuel elements (also referred to as fuel blocks), excluding the contained fuel compacts, are considered to be structural graphite. In the case of pebble-bed reactors, the fuel pebbles are considered part of the fuel, rather than core structures. The reflectors are classified as structural graphite components in both prismatic and pebble reactor concepts.

\subsubsection{Graphite Applications}

Graphite is used for the main core components in both prismatic and pebble-bed HTGR concepts, including in reflectors (typically top, bottom, and side reflectors), core support blocks, core support 
posts, and outlet plenum blocks. Graphite is also used for the fuel blocks (elements) that contain the fuel compacts in prismatic designs.

Both design concepts employ permanent and replaceable reflector components, the permanent sections usually being the peripheral reflector regions exposed to a much lower fluence and irradiation temperature. In prismatic designs, refueling outages occur at approximately 18 -month intervals, during which one-half of the fuel elements are replaced. The refueling interval and fuel element replacement schedule are presently governed by fuel cycle considerations. The inner reflector elements in prismatic designs would typically be replaced at 6 -year intervals during one of the refueling outages, leaving only the permanent reflectors to last the lifetime of the plant. In general, the lifetime and replacement schedules of replaceable reflector elements are dependent on the accumulated fast neutron fluence. As a result, elements adjacent to the active core will have shorter lifetimes. Previous assessments performed in the 1980s for the steam-cycle modular HTGR (based on stress and thermal analyses) have shown the expected lifetimes can range from 3 years (for outer reflector blocks with control rods adjacent to the active core) to 10 years (for standard reflector elements further away from the active core), with an overall average replacement schedule of approximately 6 years. For the NGNP demonstration plant, these lifetimes will be re-evaluated based on the ASME graphite design rules that are under development.

Pebble-bed concepts have historically had no design provisions for replacement of the reflector components, implying that these were expected to last the lifetime of the reactor. However, the PBMR $400 \mathrm{MW}(\mathrm{t})$ design included a replaceable reflector concept, since structural analyses of graphite reflector components used with the highest utilization (in the most extreme fluencetemperature regions) indicated that these would not last the 36 equivalent full-power year reactor design life. Reflector components in the PBMR $250 \mathrm{MW}(\mathrm{t})$ reactor, which is strongly based on the earlier German High Temperature Reactor (HTR) Module design, see a substantially lower fluencetemperature regime, resulting in a significantly longer life of just over 40 years, based on the available data and analysis methods. The life of this material could approach the 60-year target without the need for replacement through refinements in analytical methods, improvements in design data inputs, and refinement of the reflector component designs, as well as surveillance, testing, inspection, and maintenance. Hence, the expected lifetime of the graphite components in pebble bed designs and the measures to be taken to extend the safe operating lifetime of these components to 60 years, if needed, is an issue that requires further consideration.

The fluence-temperature exposure conditions of the graphite components differ between the prismatic and pebble-bed concepts, mainly because of differences in the fuel design and core configuration. For the same reactor inlet temperature, reactor outlet temperature system design pressure, and coolant flow rate, the nominal operating fuel temperature in the pebble design is expected to be $\sim 865^{\circ} \mathrm{C}\left(1589^{\circ} \mathrm{F}\right)$, with peak fuel temperatures $<1200^{\circ} \mathrm{C}\left(2192^{\circ} \mathrm{F}\right)$. Consequently, the graphite reflector components would be exposed to temperatures ranging from 250 to $800^{\circ} \mathrm{C}$ ( 482 to $\left.1472^{\circ} \mathrm{F}\right)$ under normal conditions and peak temperatures approaching $1100^{\circ} \mathrm{C}\left(2012^{\circ} \mathrm{F}\right)$ during accident conditions.

In the prismatic design, the fuel blocks will operate between about 350 and $1200^{\circ} \mathrm{C}(662$ and $\left.2192^{\circ} \mathrm{F}\right)$ and the replaceable reflectors will operate between about 350 and $800^{\circ} \mathrm{C}\left(662\right.$ and $\left.1472^{\circ} \mathrm{F}\right)$ during normal conditions, with the precise range in temperature determined by the specific core design employed. The permanent reflectors, core support, and outlet plenum will have significantly less fluence compared to the inner core graphite, even though they will operate for 60 years, because of their distance from the fuel region. During normal operation, these permanent components will operate between about 350 and $800^{\circ} \mathrm{C}\left(662\right.$ and $\left.1472^{\circ} \mathrm{F}\right)$. Some portions of graphite core components may reach $1400^{\circ} \mathrm{C}\left(2552^{\circ} \mathrm{F}\right)$ during accident conditions. 


\subsubsection{Graphite Selection and Qualification Approach}

Material selection for the graphite components will be based on the published ASME Division 5 Graphite Construction Rules. The vendor can decide whether to follow the ASME rules or provide similar graphite data and design basis for the construction rules employed independent of the ASME rules. At this time, the NRC has not endorsed ASME Section III Division 5.

Also, provided below are references to the HTTR program and the JAEA website where the public documents related to the operating experience with IG-110 and PGX can be located. The OSTI website can be used to search for other historical HTGR reactor program documents for grades of previously used graphite that are no longer available.

\subsubsection{Candidate Graphite Grades}

Nuclear graphite grades employed in past HTGR plants or developed for previous concept designs are no longer available; however, a selection of candidate grades are currently available from the major graphite suppliers. These candidate grades build on past experience, more recent developments and state-of-the-art nuclear graphite developments, and they satisfy requirements for both HTGR concepts. Table 1 provides a list of present candidate graphite grades for the HTGR and summarizes their areas of application relating to prismatic- or pebble-type designs.

Table 1. Candidate nuclear graphite grades for HTGR application.

\begin{tabular}{|c|l|l|l|l|}
\hline Grade & \multicolumn{1}{|c|}{ Supplier } & \multicolumn{1}{|c|}{ Key Characteristics } & \multicolumn{1}{c|}{$\begin{array}{c}\text { Existing } \\
\text { Precedent }\end{array}$} & \multicolumn{1}{c|}{ Area of Application } \\
\hline NBG-17 & $\begin{array}{l}\text { SGL Carbon } \\
\text { Company }\end{array}$ & $\begin{array}{l}\text { Medium grain, pitch coke filler, } \\
\text { pitch binder, vibration molded }\end{array}$ & No & $\begin{array}{l}\text { Reflector \& fuel elements, } \\
\text { prismatic type }\end{array}$ \\
\cline { 4 - 6 } NBG-18 & & $\begin{array}{l}\text { Medium grain, pitch coke filler, } \\
\text { pitch binder, vibration molded }\end{array}$ & $\begin{array}{l}\text { No, based on past } \\
\text { Grade ATR-2R }\end{array}$ & $\begin{array}{l}\text { Reflector blocks, pebble } \\
\text { type, permanent reflector } \\
\text { blocks, prismatic type }\end{array}$ \\
\hline PCEA & $\begin{array}{l}\text { Graftech } \\
\text { International }\end{array}$ & $\begin{array}{l}\text { Medium grain, petroleum coke } \\
\text { filler, pitch binder, extruded }\end{array}$ & No & $\begin{array}{l}\text { Reflector \& fuel elements, } \\
\text { prismatic type }\end{array}$ \\
\hline IG-110 & Toyo Tanso & $\begin{array}{l}\text { Fine grain, petroleum coke filler, } \\
\text { pitch binder, isostatic-molded }\end{array}$ & $\begin{array}{l}\text { Yes, used in } \\
\text { HTTR \& HTR-10 }\end{array}$ & $\begin{array}{l}\text { Reflector \& fuel elements, } \\
\text { pebble \& prismatic type }\end{array}$ \\
\cline { 4 - 6 } IG-430 & & $\begin{array}{l}\text { Fine grain, pitch coke filler, } \\
\text { pitch binder, isostatic-molded }\end{array}$ & No & $\begin{array}{l}\text { Reflector \& fuel elements, } \\
\text { prismatic type }\end{array}$ \\
\hline S2020 & $\begin{array}{l}\text { Carbone } \\
\text { Lorraine }\end{array}$ & $\begin{array}{l}\text { Fine grain, petroleum coke filler, } \\
\text { pitch binder, isostatic-molded }\end{array}$ & Yes, FSV & $\begin{array}{l}\text { Core support posts, } \\
\text { prismatic type }\end{array}$ \\
\hline
\end{tabular}

Grade selection is determined according to specific requirements of the HTGR type, including techno-economic factors. For example, raw material characteristics and availability relating to the filler coke would be a determining factor in the grade selected. NBG-17, NBG-18, and IG-430 are made from coal derived pitch coke, while grades PCEA, S2020, and IG-110 are made from crude oil derived petroleum coke. Pitch cokes are made from coal tar, which is produced as a by-product in coke ovens. Previous German developments focused on pitch coke for their graphite development program, following the oil crisis of 1978. Because of economic and environmental factors, Japan is currently the only source of pitch coke. Conversely, petroleum coke accounts for by far the largest tonnage of coke made worldwide, and is available domestically. Oil refineries are run to optimize the production of fuels, so petroleum cokes made from the heavy end of the distillation process will have variable quality and properties dependent on the crude source and refinery operation. However, on 
the west coast of the United States, certain smaller refineries have developed a niche business supplying specialty isotropic cokes made from sweet light crude.

Graphite material selection criteria further stem from the functional requirements of the graphite core components for the specific reactor type (pebble or prismatic). These key functional requirements will be described in the Design Specification. A key function not currently addressed in the ASME graphite design code is the selection of graphite grades for use in graphite components with thin ligaments, presently the responsibility of the respective designers. NGNP will petition the ASME Subgroup on Graphite Core Components to include guidance for selection of graphite grades for core components incorporating thin ligaments.

In this section, examples of graphites used in foreign reactors are presented as background information provides a historical summary of nuclear graphite manufacturing used in the foreign reactor programs. The discussion of these foreign high temperature gas reactors is not intended to provide insight to NGNP component sizes or to provide claims of manufacturability of future NGNP graphite core components.

A key requirement in prismatic fuel elements is the need for finer-grained graphite, with its correspondingly higher strength, to ensure an adequate number of grains across the thickness of the graphite webs between the fuel compacts and the coolant holes.

There is also a substantial database on irradiated properties for grades (now historical) that are similar to NBG-18 (ATR-2E, ATR-2R, and VQMB), which provide valuable insights regarding the NBG-18 irradiation behavior that is to be expected, as well as being useful for preliminary design purposes. Importantly, this historical data indicates that both ATR-2E and ATR-2R (bearing close resemblance to NBG-18) exhibited good dimensional change behavior under irradiation. That is, they underwent low maximum shrinkage with small differences in dimensional changes in the with-grain and against-grain orientations, these factors are very important in terms of reducing internal stress in core components.

As another example, Grade IG-110 has already established significant design and operating experience, being employed for both fuel elements and reflector blocks in the HTTR (Japan) and reflector components in the HTR-10 (China). The HTTR is a $30 \mathrm{MW}(\mathrm{t})$ test reactor of the prismatic design, in operation since 1998. The HTR-10 is a $10 \mathrm{MW}(\mathrm{t})$ pebble-bed design that went critical in 2000. Grade IG-110 is further earmarked as the candidate grade for the reflector blocks of the scaledup GTHTR-300 prismatic design concept (Japan) and HTR-PM pebble-bed design concept (China). There is a significant irradiated properties database for IG-110 over a range of HTGR applicable temperatures, but only to limited fluence. This is in line with the low peak fluence requirements of prismatic designs, however, the HTR-PM pebble-bed concept would necessitate that higher fluence irradiation data for IG-110 at representative operating conditions be acquired prior to construction or start-up. The little available high fluence data for IG-110 at $600^{\circ} \mathrm{C}\left(1112^{\circ} \mathrm{F}\right)$ indicates similar dimensional change behavior similar to that of historic coarser grained materials, such as ATR-2E. Irradiated properties data for IG-110 tends to be presented without directional orientation on the basis that the material is isotropic; however, this is an aspect that needs some verification, since unirradiated properties measured for IG-110 in different orthogonal directions can show some variation.

Other considerations such as supplier capability and grade manufacturability may also feature strongly amongst the selection criteria. All major manufacturers typically have the capability to produce extruded or isostatically-molded products, with vibration-molded materials being less common. The various suppliers typically have a preference based on historical developments and expertise. For example, SGL carbon has a history of producing extruded and vibration-molded 
product for the former German program and, therefore, favor extruded or vibration molded products based on isotropic filler coke. This is strongly related to the need for large graphite billets for pebble bed designs, where medium grain graphite is better suited to large block manufacture. This provides some advantage over the extrusion process in terms of the maximum size of blocks and properties achievable; hence, the development of grades NBG-17 and NBG-18, which benefit from the experience of the German program.

Toyo Tanso has focused its efforts on isostatic pressing, based on its own developments and its affiliation to the HTTR test reactor development. IG-110 represents the flagship HTGR graphite grade of the company, where the use of very fine-grain petroleum coke-based raw material provides an isotropic, high strength material well suited to a prismatic HTGR application. The isostaticpressing technique has been further extended to develop Grade IG-430, an isostatic-pressed, pitch coke derivative that fills the gap for a higher strength, high-conductivity, isotropic graphite for VHTR applications. However, the process to achieve this small grain size is said to limit the maximum size of graphite blocks that can be produced, which could pose difficulties when fabricating the larger structural components. However, it is interesting to note in this regard that the scaled up HTR-PM pebble bed design, which requires large graphite sections, currently plans to utilize IG-110 as reflector graphite. The requirement for fine-grained graphite is less significant for the outer permanent reflector elements of the prismatic design, where coarser grained graphite can be employed, as is the case with the application of PGX graphite in the HTTR.

\subsubsection{Graphite Properties}

Typical properties of the candidate grades are given in Table 2. All of the candidate graphite grades have low ash concentration, reflecting a qualitatively low level of catalytic impurities, which can potentially enhance graphite oxidation reactions with primary coolant impurities.

Table 2. Typical graphite vendor properties of candidate graphite grades.

\begin{tabular}{|c|c|c|c|c|c|c|c|c|}
\hline \multirow[b]{2}{*}{ Grade } & \multicolumn{8}{|c|}{ PROPERTY* } \\
\hline & $\begin{array}{l}\text { Density } \\
\left({\left.\mathrm{g} . \mathrm{cm}^{-3}\right)}^{-3}\right.\end{array}$ & $\begin{array}{c}\text { CTE } \\
\left(10^{-6}{ }^{\circ} \mathrm{C}^{-1}\right)\end{array}$ & $\begin{array}{l}\text { Thermal } \\
\text { Cond. } \\
\left(\mathrm{W} \cdot \mathrm{m}^{-1} \cdot \mathrm{K}^{-1}\right)\end{array}$ & $\begin{array}{c}\text { Dynamic } \\
\text { Young's } \\
\text { Modulus } \\
(\mathrm{GPa})\end{array}$ & $\begin{array}{c}\text { Tensile } \\
\text { Strength } \\
\text { (MPa) }\end{array}$ & $\begin{array}{l}\text { Comp. } \\
\text { Strength } \\
\text { (MPa) }\end{array}$ & $\begin{array}{c}\text { Ash } \\
\text { Content } \\
\text { (ppm) }\end{array}$ & $\begin{array}{c}\text { Isotropy } \\
\text { Ratio }\end{array}$ \\
\hline NBG-17 & 1.84 & $4.5,4.6$ & 130 & 11.0 & 19 & - & $<300$ & 1.02 \\
\hline NBG-18 & 1.86 & 4.6 & 136 & $11.9,11.6$ & $20.8,20.4$ & $77.4,78.5$ & $<300$ & 1.02 \\
\hline PCEA & 1.83 & $3.5,3.7$ & 162,159 & $11.3,9.9$ & $21.9,16.9$ & $60.8,67.6$ & $<300$ & 1.05 \\
\hline IG-110 & 1.77 & 4.5 & 120 & 9.8 & 25.3 & 76.8 & $<100$ & $<1.10$ \\
\hline IG-430 & 1.82 & 4.8 & 140 & 10.8 & 37.2 & 90.2 & $<100$ & $<1.10$ \\
\hline S2020 & 1.77 & 4.3 & 85 & 10.7 & 29 & 93 & 500 & 1.14 \\
\hline
\end{tabular}

These grades all qualify as isotropic or near-isotropic in accordance with ASTM D7219-08. The degree of isotropy is defined by the ratio of the larger to the smaller coefficient of thermal expansion (CTE) in the with-grain and against-grain directions. ASTM D7219-08 recommends that material exposed to high neutron flux regions of the HTGR be isotropic. It is well established on the basis of past research and operating experience that highly anisotropic grades develop large differences in their irradiation-induced dimensional changes in the with-grain and against-grain orientations, resulting in excessively large internal stresses within the graphite components. This stress can be substantially reduced in reflector components by use more isotropic grades. 
Importantly, ASTM D7219-08 specifies a range of physical and mechanical properties for isotropic grades that allows for a range of nuclear graphite grades as far as raw materials, forming method, purity level, and actual properties are concerned. In low-fluence conditions, where (a) changes to mechanical properties because of fluence exposure do not challenge the functional requirements of the graphite component and (b) the assigned Structural Reliability Class requirements defined in Section 3.3.5 can be maintained, alternate graphite grade may be considered in accordance with ASTM D7301-08.

The selection of graphite materials for HTGR core components is based on physical properties (density, CTE, thermal conductivity, specific heat capacity), mechanical properties (strength, Young's modulus, fracture toughness), neutronic properties (neutron absorption cross-section), response to irradiation, and resistance to chemical attack (e.g., oxidation).

The mechanical properties of graphite provide the basis for its use as a structural material to establish and maintain the geometric characteristics of the HTGR to assure the ability to insert reactivity control materials and to provide the required channels for the flow of helium coolant. The neutronic properties of graphite support its neutron moderator and reflector functions, while minimizing the development of activated byproducts. Physical properties such as thermal conductivity, specific heat capacity, and emissivity are critical to the HTGR safety concept, providing for thermal energy storage and transport, thus limiting fuel temperatures during certain LBEs and associated DBAs involving conduction cooldown.

The sections that follow further elaborate upon the properties of graphite and the significance of those properties in HTGR design and operation.

\subsubsection{Properties of Ideal Nuclear Graphite}

The properties most relevant for ideal nuclear reflector graphite are summarized in Table 3. These requirements are based on previous experience gained in the manufacture and application of nuclear grade graphite for reactor core internals, as well as more recent developments in nuclear graphite technology.

It can be seen from Table 3 that the properties of graphite can be classified within four general categories. ${ }^{14,15}$ The first category relates to structural functions. Important structural properties include density, strength, anisotropy, and CTE. Dimensional changes under irradiation also play a key role in the useful structural life of the graphite reflector components.

The efficiency of graphite as a neutron moderator/reflector is characterized by two properties, the density and neutron absorption cross-section, which is a function of graphite impurities. Thermal conductivity provides a measure of the heat transport capabilities of graphite, which are important to the HTGR safety concept.

\subsubsection{Manufacturing Considerations}

Graphite products are manufactured for a wide variety of conventional applications, ranging from electric motor brushes to arc-furnace electrodes. Nuclear applications of graphite date from the Chicago Pile in 1942 and, since that time, over 100 graphite moderated reactors have been constructed, including six HTGRs, of which two (the HTTR in Japan and HTR-10 in China) are presently in operation.

The ideal requirements for nuclear grade graphite are summarized in Section 3.3.4.1 above. In considering these requirements, there are a number of raw material and process variables that can be combined to produce graphite with the desired properties. 


\section{Raw Materials}

The raw materials for nuclear graphite include coke, binder, and impregnation materials. Coke is a solid carbonaceous material that is most frequently derived as a byproduct of crude oil processing or the destructive distillation of coal. Pitch, which is used as the binder, is a solid (at ambient temperature) or is a highly viscous carbonaceous liquid that is also most frequently derived from petroleum crude oil or coal. Pitch is mixed with the coke to provide a material that may be molded or extruded into the desired component shape. Impregnation materials such as pitch are used for further processing to provide for increased density and strength.

Table 3. Ideal requirements for reflector graphite.

\begin{tabular}{|c|c|c|c|}
\hline Property & Required Range & Reason & $\begin{array}{c}\text { Performance } \\
\text { Attributes }\end{array}$ \\
\hline Density & $1.7-1.9 \mathrm{~g} / \mathrm{cm}^{3}$ & $\begin{array}{l}\text { High density is indicative of lower porosity, } \\
\text { provides for more effective neutron } \\
\text { moderation/reflection per unit volume, and in } \\
\text { general, also indicates higher strength. }\end{array}$ & $\begin{array}{l}\text { Neutron efficiency } \\
\text { Structural integrity }\end{array}$ \\
\hline $\begin{array}{l}\text { Neutron absorption } \\
\text { cross-section }\end{array}$ & $<5$ mbarn & $\begin{array}{l}\text { Required for neutron efficiency of the core. The } \\
\text { limiting neutron absorbency is that of pure carbon } \\
(\sim 3.5 \text { mbarn). }\end{array}$ & Neutron efficiency \\
\hline $\begin{array}{l}\text { Thermal } \\
\text { conductivity at } \\
\text { room temperature }\end{array}$ & $>100 \mathrm{~W} / \mathrm{m} / \mathrm{K}$ & $\begin{array}{l}\text { Indicative of a high degree of graphitization and } \\
\text { typically the level required for effective heat } \\
\text { transfer in HTGR applications. }\end{array}$ & Heat transport \\
\hline $\begin{array}{l}\text { Purity (total ash } \\
\text { content) }\end{array}$ & $<300$ ppm & $\begin{array}{l}\text { Required to minimize activation and reduce } \\
\text { susceptibility to catalytic oxidation. It is possible } \\
\text { to manufacture graphite with much higher purity } \\
\text { levels using a dedicated purification step. The } \\
\text { selected and specified purity may vary depending } \\
\text { on the function of the components. This decision } \\
\text { will be based on a cost-benefit analysis. }\end{array}$ & $\begin{array}{l}\text { Component activity } \\
\text { levels during } \\
\text { replacement and/or } \\
\text { disposal. } \\
\text { Graphite Oxidation } \\
\text { under normal and } \\
\text { accident conditions. }\end{array}$ \\
\hline Tensile strength & $>15 \mathrm{MPa}$ (tensile) & $\begin{array}{l}\text { Adequate strength is required for structural } \\
\text { component integrity. } \\
\text { Higher strengths are achievable with isostatic- } \\
\text { molded, fine grain graphite, but these typically } \\
\text { possess lower fracture toughness. This is a trade- } \\
\text { off that must be taken into account in the design. }\end{array}$ & Structural integrity \\
\hline $\mathrm{CTE}\left(20\right.$ to $\left.500^{\circ} \mathrm{C}\right)$ & 3.5 to $5.5 \times 10^{-6} \mathrm{~K}^{-1}$ & $\begin{array}{l}\text { A higher value is indicative of the coke isotropy } \\
\text { and hence isotropy of the graphite. This implies } \\
\text { that the graphite will have better dimensional } \\
\text { stability when subjected to fast neutron } \\
\text { irradiation. However, lower CTE can be } \\
\text { beneficial in terms of thermal stress. }\end{array}$ & Structural integrity \\
\hline CTE isotropy ratio & $<1.10$ & Indicative of the bulk graphite isotropy. & Structural integrity \\
\hline $\begin{array}{l}\text { Dynamic elastic } \\
\text { modulus }\end{array}$ & $8-15 \mathrm{GPa}$ & $\begin{array}{l}\text { Higher modulus is typically associated with a } \\
\text { higher strength material, but increased sensitivity } \\
\text { to thermal stresses. Thus, values at the lower end } \\
\text { tend to be more beneficial. }\end{array}$ & Structural integrity \\
\hline $\begin{array}{l}\text { Dimensional } \\
\text { changes with } \\
\text { irradiation }\end{array}$ & $\begin{array}{l}\text { Minimal shrinkage } \\
\text { over the applicable } \\
\text { fluence range and } \\
\text { minimal differences } \\
\text { in the with-grain and } \\
\text { against-grain } \\
\text { directions }\end{array}$ & $\begin{array}{l}\text { This is mainly a function of temperature and } \\
\text { fluence, but is strongly dependent on the graphite } \\
\text { grade. Dimensional changes strongly influence } \\
\text { the level of internal stresses generated in core } \\
\text { components when subjected to fast neutron } \\
\text { irradiation and are critical in determining their } \\
\text { useful life. }\end{array}$ & Structural integrity \\
\hline
\end{tabular}


The properties of graphite, and particularly the irradiated properties, are highly dependent upon both the raw materials (particularly the coke) and the processing steps that are described below. For this reason, a change in the source and/or characteristics of the raw materials may require requalification of the graphite for nuclear service. Precursor materials will change over time. The current NGNP Project is performing research to understand the effects on graphite properties with changing precursor materials.

\section{Process Variables}

Process variables include the particle size distribution, production steps, and degree of purification.

The particle size distribution is generally classified by maximum grain size into coarse-, mediumand fine-grain material. Typically, medium-grain graphites have been used for nuclear applications in the United Kingdom, Germany, and the United States. Recently, fine-grain materials have been used for HTTR in Japan and HTR-10 in China.

In terms of fabrication techniques, graphite is manufactured in several stages:

1. Procurement of raw materials including coke, pitch, etc.

2. Grinding coke particles to the required size by milling.

3. Mixing of ground coke particles with pitch to form a visco-elastic mass.

4. Green fabrication of the billet by molding or extrusion.

5. Baking of the billet at 850 to $1200^{\circ} \mathrm{C}\left(1562\right.$ to $\left.2192^{\circ} \mathrm{F}\right)$ for 30 to 70 days to remove the volatile components.

6. Density increase by impregnation with pitch, generally the bake-impregnate-rebake process is done three times for a nuclear grade graphite.

7. Graphitization of the billet at 2500 to $3200^{\circ} \mathrm{C}\left(4532\right.$ to $\left.5792^{\circ} \mathrm{F}\right)$ for up to 15 days. Higher temperatures are better; however, temperatures beyond $2800^{\circ} \mathrm{C}\left(5072^{\circ} \mathrm{F}\right)$ are difficult to achieve in large size billet production because of furnace limitations.

8. Purification (may be combined with graphitization).

9. Machining to final size and shape.

The impregnation and baking stages are often repeated to improve mechanical strength and to produce a higher density product.

\subsubsection{ASME Code for Graphite Structures}

As renewed interest in HTGR applications emerged, an ASME Section III Subgroup on Graphite Core Components was established in 2004. The charter of the subgroup includes the establishment of rules for materials selection and qualification, design, fabrication, testing, installation, examination, inspection, certification, and preparation of reports for manufacture and installation of nonmetallic internal components for fission reactors, including graphite but excluding nuclear fuel. This committee's work resulted in the construction rules for graphite core components being published by ASME the new Section III, Division 5 , "High Temperature Reactors - Rules for Construction of Nuclear Facility Components" that was published on November 1, 2011. 


\subsubsection{Changing the Approach of the Prior ASME draft Code Case}

The international committee first reviewed the prior draft of the ASME graphite core component code case and decided that approach was inadequate for today's design and regulatory licensing. The prior draft was a deterministic approach that paralleled that of metallic core components. The prior code only addressed nonirradiated graphite use and did not endorse design of irradiated graphite core components. Graphite was treated as a linear Hookean material with no strength in the plastic regime. Graphite core components that suffered cracking were considered failed and would be removed at the earliest convince.

\subsubsection{Current Philosophy of Current ASME Graphite Core Component Design Rules}

The current rules apply to graphite core components utilized in a high-temperature, graphitemoderated, gas-cooled fission reactors. Graphite core components include fuel blocks, reflector blocks, shielding blocks, and any keys or dowels used to interconnect them. The rules also apply to the arrangement of graphite core components that form the graphite core assembly. The rules do not apply to fuel compacts and pebbles, bushings, bearings, seals, blanket materials, instrumentation, nor core restraints.

The committee concluded that the designer should account for the effects of irradiation on the thermal and mechanical properties of the graphite in the design of the graphite core. The design must also consider the statistical variation of strength within the billet, as well as the variations resulting from manufacture in different production runs. The committee endorsed the use of ASTM D7219-08 that provides guidance on statistical sampling and provided the minimum mechanical parameter values for near-isotropic nuclear grade graphite.

The code provides for a simplified deterministic design methodology for irradiated and nonirradiated graphite using ultimate strengths determined from Weibull statistics of the graphite billet strengths. This is a conservative method, which, if not met, does not mean the component is rejected. The code also provides a full analysis method that uses a probabilistic design approach incorporating Weibull statistics to determine the probability of failure. The margin to failure is determined by comparing the probability of failure to the three structural reliability classes (SRC) defined in the code. Each SRC is assigned a maximum probability of failure, based on the safety function and expected operational transients. The SRCs and their respective maximum probability of failure are shown in Table 4.

Table 4. Maximum probability of failure for each safety class.

\begin{tabular}{|c|c|}
\hline Structural Reliability Class & Maximum Probability of Failure \\
\hline SRC-1 & $1.0 \mathrm{E}-4$ \\
\hline SRC-2 & $\begin{array}{c}1.0 \mathrm{E}-4 \text { nonirradiated and } 1.0 \mathrm{E}-2 \\
\text { for irradiated components }\end{array}$ \\
\hline SRC-3 & $1.0 \mathrm{E}-2$ \\
\hline
\end{tabular}

A third design method is provided on the basis of the testing of full-scale graphite components. The test shall be designed to ensure that the loads determined from the tests conservatively represent the load-carrying capacity of the actual graphite core component for the specified loadings. The test objective is to demonstrate that the probability of failure is within the SRCs in Table 4. The test results shall provide values with a $95 \%$ certainty, as represented by a single-sided confidence level and envelope all appropriate design and service loadings. 
Table 4. Maximum probability of failure for each safety class.

\begin{tabular}{|c|c|}
\hline Structural Reliability Class & Maximum Probability of Failure \\
\hline SRC-1 & $1.0 \mathrm{E}-4$ \\
\hline SRC-2 & $\begin{array}{c}1.0 \mathrm{E}-4 \text { nonirradiated and } 1.0 \mathrm{E}-2 \\
\text { for irradiated components }\end{array}$ \\
\hline SRC-3 & $1.0 \mathrm{E}-2$ \\
\hline
\end{tabular}

The code's use of probabilistic design departs from standard ASME design code methodologies. The ASME code has not previously addressed irradiation induced changes to material properties. This will be the first time in ASME code history that the ASME Board of Governors has approved of this approach. The code includes instructions on how to collect the material properties changed by irradiation as a function of temperature. Irradiation induced creep is included as one of the parameters that must be measured.

Another deviation from past ASME metallic codes is allowance of cracks in the graphite components. The rules require the core designer to demonstrate through analyses or testing that cracked graphite core components can maintain their assigned safety function and that the graphite component is remotely retrievable when cracks of a specified size and orientation are present. This puts a high reliance on developing ISI techniques that provide visual and in-situ measurement of graphite properties.

The code also deviates from the ASME standard practice of defining primary and secondary stresses. Because of the brittle nature of graphite, no distinction is made between primary and secondary stresses for the purpose of assessment to ASME graphite design rules. Combined stress is thus the combination of primary and secondary stresses. Irradiation induced stresses and mechanical stress concentrations are the largest contributors to stresses in graphite core components. These irradiation-induced stresses follow thermal and neutron fast fluence gradients within the block. These stress gradients are the critical stresses in the graphite blocks. Stress concentrations arise from keyways and dowels in the graphite components producing the highest mechanical stresses. Other mechanical stresses (combined membrane, bending and peak stresses) are of lesser magnitude, but are included in the calculation of stresses at a point

ASME Section III, Division 5 provides the following clarifications:

ASME Section III, Division 5, Subsection HH, Subpart A-3100(b)

The design approach selected is semi-probabilistic, based on the variability in the strength data of the graphite grade. Due to the nature of the material, it is not possible to ensure absolute reliability, expressed as an absence of cracks, of Graphite Core Components. This is reflected in the setting of Probability of Failure (POF) targets. Also, note that due to the complex nature of the loadings of graphite components in a reactor combined with the possibility of disparate failures of material due to undetectable manufacturing defects, the Probability of Failure values used as design targets may not be precisely accurate predictions of the rate of cracking of components in service. The Designer is required to evaluate the effects of cracking of individual Graphite Core Components in the course of the design of the Graphite Core Assembly and ensure that the assembly is damage tolerant.

ASME Section III, Division 5, Subsection HH, Subpart A-3330(b)

(b) Arrange the Graphite Core Components comprising the Graphite Core Assembly so that cracking of individual Graphite Core Components does not detrimentally affect the connections between the Graphite Core Components and thus impede the functionality of the Graphite Core Assembly. 
ASME Section III, Division 5, Subsection HH, Subpart A-3214.7

The combined stress is the sum of all of the components of stress at a point. In design, it is customary to distinguish between primary and secondary stresses. These are defined as follows:

- Primary stress is any normal stress or a shear stress developed by an imposed loading that is necessary to satisfy the laws of equilibrium of external and internal forces and moments. The basic characteristic of a primary stress is that it is not self-limiting. Primary stresses that considerably exceed the material strength will result in failure. A thermal stress is not classified as a primary stress.

- Secondary stress is a normal stress or a shear stress developed by the constraint of adjacent material or by self-constraint of the structure. The basic characteristic of a secondary stress is that it is self-limiting. Local yielding and minor distortions may satisfy the conditions that cause the stress to occur.

Because of the brittle nature of graphite, no distinction is made between primary and secondary stresses for the purpose of assessment to these rules. Combined stress is thus the combination of primary and secondary stress.

Per the ASME graphite design rules, all irradiation induced loads, as well as all mechanical loads have to be included in determining the stress at a point. The stress state at a point is used in determining the probability of failure ${ }^{16}$. This paper identifies the graphite strength margins by providing anticipated stresses in graphite components and graphite strengths in prior HTGR designs.

\subsubsection{Status of the ASME Graphite Core Component Code}

\subsubsection{Graphite Materials Qualification}

This section addresses the proposed bases for graphite materials qualification. The following subsections summarize the key functions and requirements associated with the graphite reflector components and the associated material qualification requirements for HTGR application. The key elements of the graphite Material Qualification Plan are discussed through the use of examples in Section 3.3.6.4. This is followed by an overview of the main test parameters and material characterization that will be needed to provide the as-manufactured and irradiated properties of candidate graphite grades for the HTGR application.

\subsubsection{Key Functions and Requirements to be Validated}

The graphite components of HTGRs fulfill the following safety-related functions:

- Maintain core geometry

- Contain fuel compacts within the fuel elements (prismatic reactors)

- Provide undisturbed access for the insertion of reactivity control material

- Passively remove core heat, primarily by radial conduction from the fuel to the core barrel, during off-normal events when forced cooling is not available

- Control chemical attack by limiting oxidation for off-normal events involving ingress of water or air gas mixtures.

Key requirements associated with these functions are summarized below. 


\section{Design Life}

The design life of the HTGR plant is 60 years. The graphite core components are generally subdivided into two groups, replaceable components and the fixed or permanent reflectors, as required by the particular HTGR concept design. Components that cannot be designed for the full plant life (such as reflector graphite components in high flux regions) need to be designed to be replaceable and, thus, allocated a design life. Both permanent and replaceable graphite core components must adequately perform their safety-related functions for the duration of the allocated design life and this must be validated for their respective operational periods.

Prismatic HTGR designs are refueled at approximately 18-month intervals during which time typically one-half of the fuel elements are replaced. Replaceable reflector elements adjacent to the active core may also be changed out during such refueling outages, typically at 6-year intervals, leaving only the permanent reflectors to last the lifetime of the plant.

Earlier pebble-bed concepts with shorter design lifetimes (e.g., 20-30 years) did not require provisions for replacement of reflector components. Based on presently available data and analysis methods, the most highly irradiated reflector components are based on the earlier German HTR Module design and would therefore have a projected life of just over 40 years. There is a possibility that this life could be extended further, approaching the 60-year HTGR target, without the need for replacement. However, this would require refinements in analytical methods, improvements in design data inputs, and the optimization of reflector component designs as well as an effective surveillance, testing, inspection, and maintenance program. At most, one reflector replacement outage may be necessary for a $250 \mathrm{MW}(\mathrm{t})$ pebble bed design with a $750^{\circ} \mathrm{C}\left(1382^{\circ} \mathrm{F}\right)$ outlet temperature for a 60 -year life. The actual design life of the replaceable reflector components will need to be established based upon the results of materials irradiation tests, supplemented by data obtained through actual operating experience.

\section{Service Conditions}

The fluence levels and irradiation temperatures seen by the various graphite reflector components are dependent upon both the reactor type and their locations within the reactor. Service conditions seen by graphite components within pebble bed reactors are typically more limiting, because of their longer design lives and the correspondingly higher fluence levels that will be accumulated by some of these components. Normal operating temperatures for the pebble bed graphite reflector range between 250 and $800^{\circ} \mathrm{C}\left(482\right.$ and $\left.1472^{\circ} \mathrm{F}\right)$. The maximum temperatures that would be seen by the reflector graphite during certain LBEs are less than $1200^{\circ} \mathrm{C}\left(2192^{\circ} \mathrm{F}\right)$. Only components in close proximity to the pebble fuel are subjected to high fluence levels that may limit their lifetime to less than that of the design life of the plant as a whole, this maximum fluence being slightly above $1.1 \times$ $10^{22} \mathrm{n} . \mathrm{cm}^{-2}$ EDN (equivalent Dido nickel) (15 dpa). The affected parts of these components do not serve a structural function.

The maximum fast neutron fluence for the prismatic permanent reflector blocks is less than $4 \times$ $10^{20} \mathrm{n} / \mathrm{cm}^{2}(\mathrm{E}>0.18 \mathrm{MeV})$ as of the NGNP pre-conceptual design. The maximum fast neutron fluence for replaceable reflector blocks (and fuel elements) is less than $4 \times 10^{21} \mathrm{n} / \mathrm{cm}^{2}(\mathrm{E}>0.18$ $\mathrm{MeV}$ ). During normal operation and LBEs, the maximum graphite temperature in the fuel elements is approximately the same as the maximum fuel temperature. For normal operation, the maximum timeaveraged fuel temperature is $<1250^{\circ} \mathrm{C}$. The minimum graphite temperature during normal operation is approximately the same as the coolant inlet temperature.

During depressurized conduction cooldown LBEs, the maximum peak temperature is $\sim 1600^{\circ} \mathrm{C}$ and occurs in a very small region of the core (adjacent to the inner graphite reflector of the annular 
core and typically in Layers 4 and 5 of the 10 layers of fuel elements adjacent to the inner graphite reflector of the annular core) for at most a day or two.

\subsubsection{Characterization of Unirradiated Graphite}

As-manufactured graphite material must be characterized to ensure its suitability for use in the HTGR and to generate design data for graphite core components in low fluence areas that can effectively be treated as unirradiated. All design-relevant properties must be characterized (density, CTE, Young's modulus, thermal conductivity, tensile and compressive strength, specific heat capacity, fatigue strength, oxidation resistance, and neutronic properties) along with their temperature dependence.

It is important that the characterization program include enough material batches to adequately assess the material variability. Graphite properties generally display significant variability withinbillet, within-batch and from batch-to-batch. This variability has to be assessed for the candidate graphite grade. The degree of variability is influenced to some extent by the forming method and processing history, but is largely inherent to polygranular graphite materials. For a probabilistic graphite component lifetime prediction approach, the Weibull material parameters must also be established with sufficient confidence, which requires that a statistically sufficient number of samples be tested.

ASME analysis procedures use data from the Material Data Sheets collected by the designer. Reference ${ }^{17}$ provides discussions on fatigue strength from irradiated material and Reference ${ }^{16}$ for a discussion on irradiated graphite strength.

\subsubsection{Characterization of Irradiated Graphite}

During reactor operation, graphite undergoes structural changes because of fast neutron irradiation that, in turn, lead to changes in most of its physical and mechanical properties (see Appendix B). The irradiation conditions seen by various reflector graphite components are strongly dependent on their location within the reactor. The property changes with irradiation that the design must account for are:

- Dimensions

- Coefficient of thermal expansion

- Thermal conductivity

- Tensile strength

Young's modulus.

Other design properties important to the evaluation of irradiation induced and mechanical loads and stresses in accordance with the ASME graphite design rules are found in ASME Section III, Division 5, Appendix II of Subsection HHA. ASME graphite design rules define the probability of failure as crack initiation in a finite volume of the graphite component based on the assessment procedures of the ASME graphite design rules. Crack initiation does not necessary mean imminent component failure. It is the designer's responsibility to evaluate fractures predicted by the probabilistic analysis to exceed probabilistic thresholds as fluence accumulates, and to determine if the functionality of the component is lost or maintained.

The need to account for these fluence-related property changes is specified by the ASME Code for Graphite Component Design for HTGRs in Section GB-2200, "Material Properties for Design," 
and Subsection GB-2220, "Irradiated Material Properties." Important design considerations with respect to irradiation-induced changes in graphite properties are discussed below.

Dimensional changes physically influence the core structures and must be accommodated for in the reactor core design to ensure the accomplishment of safety functions (reliable insertion of control rods and passive heat removal capability during LBEs involving conduction cooldown). Therefore, the dimensional change behavior of the particular candidate grade requires proper evaluation to ensure that its influence on the component lifetime in-reactor is adequately assessed.

Thermal conductivity of the graphite is very important during normal operation in ensuring adequate heat transfer to the coolant and regulation of fuel temperature within acceptable limits. Additionally, it plays a key role in heat removal during low frequency LBEs involving conduction cooldown. In general, graphite thermal conductivity decreases dramatically with low fluence, reaches a saturation value that persists for a portion of the design fluence range, and is followed by a secondary reduction because of more advanced material degradation. Again, the design inputs that must be considered for prismatic and pebble types will differ, the latter operating the graphite into higher fluence regimes.

Other important design properties such as CTE, Young's modulus, and strength also need to be evaluated with irradiation temperature and fluence for graphites used in both reactor types. Both CTE and Young's modulus increase with fluence and reach peak values, after which they decrease below their unirradiated values. Both are important to the evaluation of thermal stress and irradiation creep in the graphite parts. Strength also increases and follows a similar progression as Young's modulus with fluence and temperature. From a design perspective, the available strength reserve must be compared against the stress within the graphite component based on the fluence-temperature history of the component.

Irradiation-induced creep in graphite is also a key design parameter whose vital role is to relieve internal stresses generated by irradiation-induced dimensional changes in graphite core components. In the absence of this stress-relieving mechanism, reactor components would fail at a much earlier stage of irradiation. While extensive fundamental research and data gathering have been conducted on this phenomenon over the past 50 years, or so, there is still need for improvement in the available creep models and their range of applicability in terms of fluence and temperature. Evolution of creep strain with fluence in irradiated graphite (differential strain between stressed and unstressed) specimens is characterized by primary, secondary, and tertiary regimes, much like those observed in metals. There is evidence to suggest that the normalized creep strain (normalized to initial elastic strain) is similar for different grades of graphite, lending support to the theory that this creep behavior is not material grade specific. Additional creep data would be useful in supporting this position and extending its application for a broader fluence-temperature range and for a wider variety of nuclear graphite grades. This may help in rationalizing and minimizing the need for costly irradiation creep experiments for current reactor graphite grades or grades that may be developed in the future.

Another important aspect related to the characterization of irradiated materials properties is the use of recognized materials test standards, typically ASTM standards, for generating the material data. This is important towards ensuring that the data capture and analysis follows recognized test procedures and that data acquired by different test facilities are directly comparable. One of the major challenges in this area is the need by Materials Test Reactor (MTR) facilities to utilize subsize test specimens (nonconformant to that specified or recommended by the applicable standard) for the graphite irradiations. This need stems from the requirement to irradiate a statistically representative population of test specimens for each property to be measured, and the limited irradiation capsule volume for accommodating test specimens. Both of these factors add to the cost of the irradiation test programs. Effort is underway within the ASTM D02 Technical Committee on Manufactured Carbon 
and Graphite (Nuclear Applications) to develop test standards for the irradiation of graphite specimens that do not conform to conventional ASTM standard test specimen sizes. As part of this effort, round robin testing would be conducted to establish the degree of reproducibility associated with using the mini-test specimens that would be recommended for irradiation and to demonstrate that properties measured on subsize specimens are valid when compared to those obtained on standard specimens.

Additionally, the NGNP Graphite Program is investigating the various effects and mechanisms influencing creep ${ }^{18,19,20,21}$. The measured creep rate as a function of dose/fluence and temperature for each major graphite grade is being investigated within the Advanced Graphite Capsule (AGC) irradiation program. Additionally, determination of the mechanisms responsible for irradiation induced creep is being pursued by the international graphite community ${ }^{21}$. Specific creep data measurements for the NGNP major grades as well as further understanding of the mechanisms will be available from the Graphite Technology Development Program in the future. ${ }^{18,19,20,21}$

\subsubsection{Graphite Development Programs}

Graphite development programs are presently underway in support of HTGR initiatives in the United States, Europe, and China. A brief overview of these programs is provided in the following sections.

\section{PBMR Graphite Development Program}

Prior to its termination in late-2010, the PBMR program in South Africa was working on the development of the Pebble Bed Modular Reactor for electricity and process energy. In support of the proposed PBMR Demonstration Power Plant (DPP), a detailed Materials Qualification Plan (MQP) was developed for NBG-18 graphite and partially implemented. The objectives of the MQP were two-fold:

- To characterize the as-manufactured and irradiated properties of NBG-18 graphite as a basis for confirming its suitability for use in the PBMR and its compliance with the requirements established for the PBMR reflector components.

- To validate the PBMR analytical models for predicting the behavior of irradiated graphite.

The approach taken in the MQP was to utilize the extensive historical database characterizing the irradiated properties of the earlier German ATR-2E and VQMB graphites, since those grades were believed to be similar to NBG-18. The MQP's irradiation test program would then have been used to validate the use of this existing database in developing analytical models for the initial design and structural analysis of the graphite core structures, and to supplement this database in areas where data were sparse or unavailable.

The overall strategy was for the irradiated properties database to be sufficiently complete by initial startup of the DPP to confirm or improve the accuracy of analytical models for graphite design, and to justify operation of the plant over a substantial portion of its life. Thereafter, the remainder of the irradiation test program would substantially lead the actual operation of the initial plants.

By the time of program termination, several batches of pre-production NBG-18 graphite had been acquired and characterized. The characterization of as-manufactured properties was effectively complete. The graphite irradiation tests were in the planning stage, but not started. All data have been turned over to the South African Government for archiving. The data are not presently available to the NGNP Project. 


\section{NGNP Graphite Development Program}

With the advent of the NGNP project, an advanced graphite development effort was initiated in the United States and structured within a program led by Idaho National Laboratory (INL). The activities associated with this program fall into the following areas:

- Unirradiated and irradiated material properties characterization

- Modeling

- $\quad$ ASTM test development

- ASME Code development.

The graphites used in earlier HTGRs built in the United States (e.g., H-451) are no longer available. The NGNP graphite development effort addresses a range of potential materials, as well as historical grades, utilized in contemporary HTGR applications (HTTR and HTR-10), which are included for comparison. The grades presently being considered within the NGNP Advanced Graphite Development Program are summarized in Table 4.

Six graphite grades (from four manufacturers) were initially selected as the principal candidates for the HTGR application: NBG-17, NBG-18, PCEA, PGX, 2020, and IG-430.22 An additional graphite grade, 2114, has since been added to the recommended list. The latter is a pitch coke, isostatically molded graphite that is a potential replacement for grade 2020.

Respectively, NBG-18 (coarse grain size, pitch coke, vibration molded) and PCEA (medium grain size, petroleum coke, extruded) graphites are considered to be grades most likely to meet the initial pebble-bed and prismatic design requirements. The other recommended grades are included for the following reasons and are all fine-to-medium grain graphites that could potentially be used to support a prismatic core design:

- NBG-17: Pitch coke, vibration molded candidate for high dose regions of the core (not currently available commercially)

- PGX: Petroleum coke, extruded, large blocks for permanent structures (used in HTTR)

- 2020: Petroleum coke, isostatically molded for permanent structures in the core

- IG-430-Pitch coke, isostatically molded, candidate for high dose regions of the core. 
Table 4. Graphite grades in the NGNP development program.

\begin{tabular}{|c|c|c|c|c|}
\hline Grade & Supplier & Forming Method & Coke Type & Application \\
\hline \multicolumn{5}{|c|}{ Recommended Grades } \\
\hline NBG-17 & \multirow[t]{2}{*}{ SGL Carbon } & Vibration molded & Pitch coke & Prismatic fuel \& reflector \\
\hline NBG-18* & & Vibration molded & Pitch coke & Pebble bed reflector \\
\hline PCEA* & \multirow[t]{2}{*}{ Graftech } & Extruded & Petroleum coke & Prismatic fuel \& reflector \\
\hline PGX & & Extruded & Petroleum coke & Prismatic permanent reflector \\
\hline 2020 & \multirow{2}{*}{$\begin{array}{l}\text { Carbone } \\
\text { Lorraine }\end{array}$} & Isostatically-molded & Petroleum coke & Prismatic fuel \& core supports \\
\hline 2114 & & Isostatically-molded & Pitch coke & Core support; 2020 replacement \\
\hline IG-430 & Toyo Tanso & Isostatically-molded & Pitch coke & Prismatic fuel \& core supports \\
\hline \multicolumn{5}{|c|}{ Other Grades Considered } \\
\hline $\begin{array}{l}\text { H-451 } \\
\text { (Historical grade) }\end{array}$ & Great Lakes & Extruded & Petroleum coke & Provides a basis for comparison \\
\hline IG-110 & Toyo Tanso & Isostatically-molded & Petroleum coke & HTTR, HTR-10 \\
\hline NBG-10 & \multirow[t]{3}{*}{ SGL Carbon } & Extruded & Pitch coke & Replaced by NBG-18 \\
\hline NBG-25 & & Isostatically-molded & Petroleum coke & Core support \\
\hline HLM & & Extruded & Petroleum coke & FSV permanent reflector \\
\hline PPEA & \multirow[t]{2}{*}{ Graftech } & Extruded & Pitch coke & Pebble bed reflector \\
\hline PCIB & & Isostatically-molded & Pitch coke & Core support \\
\hline
\end{tabular}

Additional graphite types are also being considered for various reasons. H-451, which was used in the FSV reactor, is being used as a primary historical reference for irradiations. IG-110 is used in the HTTR and HTR-10 reactors. Other grades are being considered based on reactor designer interest.

Complete properties data need to be developed for the graphite(s) eventually selected for the NGNP. Once the baseline material properties for the selected graphite grade(s) have been established, irradiation induced property changes must then be determined, including the characterization of irradiation induced creep. Determining these properties are important data needed for the design to satisfy the safety-related functions indentified in Section 3.3.6.1. These data will be developed through a series of irradiation experiments in the Advanced Test Reactor (ATR) at INL and HTV at the High Flux Isotope Reactor at ORNL.

As noted above and in Appendix B, irradiation creep plays an important role with respect to the operating life of structural graphite components. This property is also difficult to measure and requires the development of an Advanced Graphite Capsule (AGC) designed to characterize the irradiation induced creep rate as a function of temperature and fluence. A cross-section through the AGC irradiation capsule is given in Figure 2. The approach used in the ATR experiments is to irradiate matched pairs of stressed and unstressed graphite samples. This is achieved by taking advantage of the axial flux symmetry in the ATR to irradiate compressively stressed specimens above the core centerline and unstressed specimens below the core centerline in each of six vertical channels in the capsule around the capsule periphery. This arrangement maximizes the number of specimens that can be tested at the target temperature range along the 4-foot usable vertical section of the ATR core. Target temperature ranges are maintained by gamma heating, selective neutron shielding, selected inert sweep gas ratios of helium and argon in the gas jacket of the capsule, and varying gas channel widths in the vertical orientation. The center channel is used for 
nonstressed drop-in samples. The creep strain is determined from the difference in irradiation-induced dimensional changes between the stressed and unstressed samples.

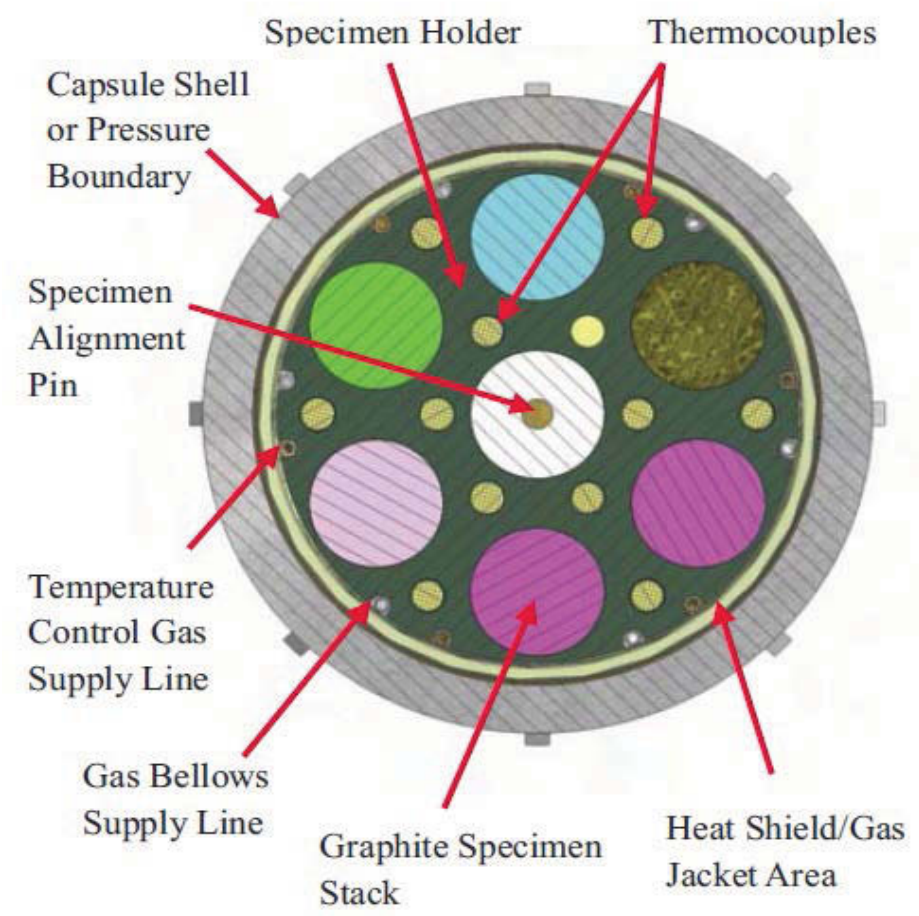

Figure 2. Cross section through typical AGC.

The reactor coolant outlet temperature of previous and current High Temperature Gas-cooled Reactors (HTGR) reactors range up to $700^{\circ} \mathrm{C}\left(1292^{\circ} \mathrm{F}\right)$. Advanced Gas-cooled Reactors $\left(650^{\circ} \mathrm{C}\right)$, THTR $\left(750^{\circ} \mathrm{C}\right)$, Fort St. Vrain $\left(785^{\circ} \mathrm{C}\right)$, AVR $\left(950^{\circ} \mathrm{C}\right)$, and HTTR $\left(950^{\circ} \mathrm{C}\right)^{23,24}$ all had extensive material development programs before being constructed including irradiated graphite material studies. A historical database of both reactor core experience and material testing programs with large amounts of graphite material data is available for the graphite types used in these current and past reactors.

To achieve the outlet temperatures needed for HTGR or VHTR operation the NGNP program elected to irradiate currently available types of graphite outside of the previous operating temperature envelope of $400^{\circ} \mathrm{C}$ to $650^{\circ} \mathrm{C}$. High temperatures of $900^{\circ} \mathrm{C}$ to $1200^{\circ} \mathrm{C}$ were chosen to envelope the anticipated operating temperatures for both HTGR and VHTR designs. The lower $600^{\circ} \mathrm{C}$ irradiation temperature was selected to provide comparison data to determine how current graphite types compare to the historical nuclear grade graphite types in the historical database.

Additionally, based upon the NGNP reactor design, the operating temperatures experienced by most of the highly irradiated graphite components will be enveloped by the $600^{\circ} \mathrm{C}$ to $1200^{\circ} \mathrm{C}$ test matrix temperature. These components include the fuel blocks (prismatic design), inner reflector blocks, lower plenum area, and core support columns. Only a few graphite components in the upper part of the core could be exposed to temperatures less than the $600^{\circ} \mathrm{C}$ to $1200^{\circ} \mathrm{C}$ envelope and they are not expected to receive high levels of neutron dose nor significant material property changes as a result. These lower temperature components include the outer permanent graphite blocks, and upper reflector blocks above the active core region. So, while these components are expected to be exposed to lower temperatures (lowest estimated temperature as low as $265^{\circ} \mathrm{C}$ ) the total dose received is expected to be an order of 
magnitude lower than the regions adjacent to the active core resulting in significantly less irradiation damage over time.

Considerable historical data exists at these moderate temperatures and relatively low dose levels for a variety of different nuclear graphite types, which possess similar properties to the NGNP major grades of graphite. There is sufficient data at these lower temperature conditions to assess the trending behavior of current types of graphite. In addition, the behavior differences between graphite types are small at low irradiation doses so the extent of material property changes can be extrapolated from the historical data for these outer graphite components. Thus, to support the NGNP design, the graphite irradiation program required the existing lower temperature irradiated graphite database to be extended into the operating temperature regime of $600^{\circ} \mathrm{C}$ to $1200^{\circ} \mathrm{C}$. A series of graphite capsules irradiated within this higher temperature range were designed to gather this irradiation data at these higher temperature levels for the NGNP graphite development program, Figure 3. The distribution of AGC experiment irradiations showing planned neutron dose and temperatures is given in Figure 3. . The AGC experiments will be conducted at three different temperatures; $600^{\circ} \mathrm{C}\left(1112^{\circ} \mathrm{F}\right), 900^{\circ} \mathrm{C}\left(1652^{\circ} \mathrm{F}\right)$, and $1200^{\circ} \mathrm{C}\left(2192^{\circ} \mathrm{F}\right)$. At each temperature, two different capsules will be irradiated to different fluence levels; the first from 0.5 to $4 \mathrm{dpa}$ and the second from 5 to $7 \mathrm{dpa}$. AGC-1,2 capsules cover the $600^{\circ} \mathrm{C}\left(1112^{\circ} \mathrm{F}\right)$ irradiations while AGC-3,4 and AGC-5, 6 cover $900^{\circ} \mathrm{C}\left(1652^{\circ} \mathrm{F}\right)$ and $1200^{\circ} \mathrm{C}\left(2192^{\circ} \mathrm{F}\right)$ respectively (Ref: PLN-2497, Rev. 1, Graphite Technology Development Plan, October 2010).

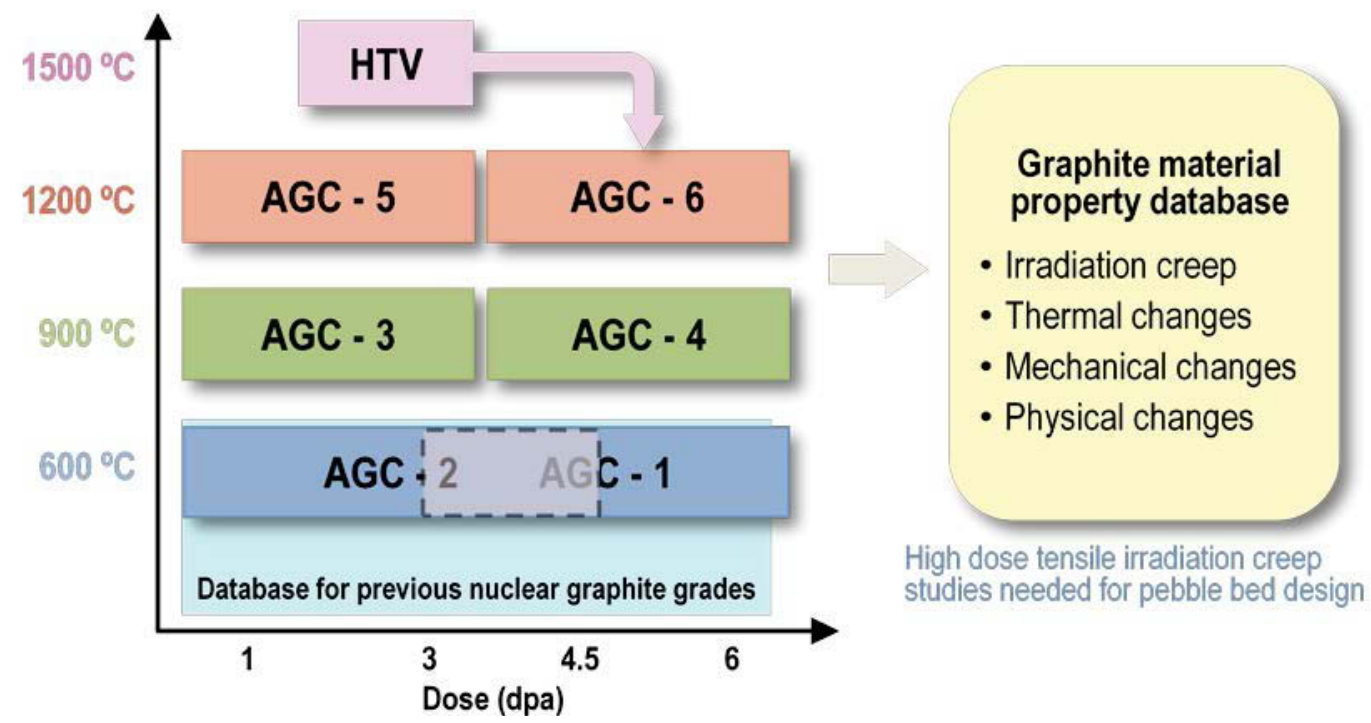

Figure 3. Planned dose and temperature distributions for the AGC experiments.

The HTV irradiations shown in Figure 3 are drop-in experiments only, and may be required prior to irradiation of the AGC-6 capsule, since the AGC-6 capsule is the only one in the series that may approach expected turnaround limits for the selected graphite types. The HTV experiments will be operated at much higher temperatures (inducing faster turnaround) but at lower doses so that turnaround for these materials can be established prior to the irradiation of AGC-6. The prismatic HTGR design assumes that fuel and reflector blocks will be replaced well before turnaround. The pebble bed HTGR design assumes that the front facing reflector blocks adjacent to the pebble fuel will stay in the reactor beyond turnaround to maximize service life. The peak 7 dpa dose in the AGC experiments supports both prismatic and pebble-bed graphite designs; however, relevant volume contraction data will be provided at the AGC 
peak doses. Higher dose volume expansion experiments can be considered to support the pebble bed concept at a later time.

Post-irradiation examination and testing of the irradiated samples will be conducted at INL and ORNL facilities.

AGC-1 is the first of the six experiments designed for the ATR and will focus on the prismatic fluence range. The AGC-1 experiment was inserted in the ATR during Cycle 145A in September 2009 and is scheduled to be discharged in Cycle 148b in October 2010. As of January 2010, AGC-1 had attained approximately one-third of its target fluence. Preirradiation characterization of graphite samples for AGC-2 is presently underway.

\section{Other Graphite Development Programs}

Additional graphite development and irradiation test programs are underway in the European Union (EU) and China. The EU FP5 and FP6 Materials Test Reactor Programs include irradiation of all the candidate grades mentioned above, as well as additional piggyback grades and historical (archive) grades. The major graphite grades being tested in the EU program are shown in Table 5.

Table 5. Major graphite grades in the EU FP graphite irradiation program.

\begin{tabular}{|c|c|c|c|}
\hline Grade & Supplier & Forming Method & Coke Type \\
\hline NBG-10 & \multirow{5}{*}{ SGL Carbon } & Extruded & Pitch coke \\
\hline NBG-17 & & Vibration molded & Pitch coke \\
\hline NBG-18 & & Vibration molded & Pitch coke \\
\hline NBG-20 & & Extruded & Petroleum coke \\
\hline NBG-25 & & Isostatically-molded & Petroleum coke \\
\hline PPEA & \multirow{2}{*}{ Graftech } & Extruded & Pitch coke \\
\hline PCEA & & Extruded & Petroleum coke \\
\hline IG-110 & \multirow{2}{*}{ Toyo Tanso } & Isostatically-molded & Petroleum coke \\
\hline IG-430 & & Isostatically-molded & Pitch coke \\
\hline
\end{tabular}

Test specimens from these grades were irradiated at $750^{\circ} \mathrm{C}\left(1382^{\circ} \mathrm{F}\right)$ up to fluences of approximately $10 \mathrm{dpa}$. A second phase of irradiation at $950^{\circ} \mathrm{C}\left(1742^{\circ} \mathrm{F}\right)$ up to fluences of between 12 and 14 dpa has been completed. These irradiations at HFR Petten (Netherlands) aim to provide irradiated properties data that can be used to compare irradiation behavior and post-irradiation properties of the different reactor grades available today. When the HFR Petten irradiation data are publically released, NGNP will compare the Petten data with NGNP irradiation data.

Non-NGNP graphite irradiation tests programs are planned by China in support of the HTR-PM, a steam cycle pebble bed concept designed as a commercial follow-on to the HTR-10. The Chinese program is graphite-specific and covers the operating fluence- temperature envelope expected for the HTR-PM. The HTR-PM design is very similar to the German HTR Modul. However, unlike its German predecessor, which employed coarse grain, pitch coke nuclear graphite as reflector material (e.g., ATR2E, ASR-1RS, PXA2N), the HTR-PM will employ fine-grained, isostatically-molded, petroleum-coke based IG-110 as the reflector graphite. This follows from the use of IG-11 for the HTR-10 graphite reflector. Data from the Chinese program are proprietary and not available to the NGNP Project and, thus, will not be used by the NGNP Project 


\subsubsection{Graphite Operational Considerations}

\subsubsection{Approach for Identifying and Validating the Operational Period}

During reactor operation, graphite undergoes structural changes that lead to changes in most of its physical and mechanical properties. The changes in properties and their consequent influence on the graphite structures must be accommodated in reactor core design. The most significant design related property changes include changes in dimensions, CTE, strength, modulus, and thermal conductivity, plus the effects of irradiation creep. Oxidation of graphite components must also be considered, however, its influence on component strength and, hence, structural integrity is not expected to be significant for events within the design basis.

Given the expected changes in materials properties during operation, the requirement is to ensure the safe performance of the graphite components under all applicable operating conditions over their allocated design life. For the pebble-bed designs, reflector replacement may be required once during the reactor lifetime. The following approach will be utilized for pebble-bed designs and is also applicable for extending the life of replaceable reflectors in prismatic designs:

1. The design life of graphite core structures will be initially established on a conservative basis, using probabilistic analysis methods.

It is reiterated here that the initial design life is based upon the criterion that the probability of a failure in the most highly stressed reflector components will not exceed the levels specified in Table 4 below. The most highly stressed components are those adjacent to the pebble fuel, which receive the highest fluence. These components will be designed to be replaced, where appropriate.

Nonreplaceable graphite reflector components are exposed to only modest fluence levels and are expected to have lifetimes that substantially exceed the design life of the plant.

Table 4. Maximum probability of failure for each safety class.

\begin{tabular}{|c|c|}
\hline Structural Reliability Class & Maximum Probability of Failure \\
\hline SRC-1 & $1.0 \mathrm{E}-4$ \\
\hline SRC-2 & $\begin{array}{c}1.0 \mathrm{E}-4 \text { nonirradiated and } 1.0 \mathrm{E}-2 \\
\text { for irradiated components }\end{array}$ \\
\hline SRC-3 & $1.0 \mathrm{E}-2$ \\
\hline
\end{tabular}

In the absence of irradiated properties data for the specific graphite in question, conservative estimates must account for uncertainties in the materials models used for design. This additional conservatism results in lifetime estimates for the most highly irradiated components that are less than those expected when materials-specific data are available. The design life estimates will be updated as materials test reactor data become available.

2. The operational life of the most highly irradiated graphite components will be further evaluated in in future qualification and testing programs.

Given the conservative basis upon which the initial design life is established and the inherent fault tolerance of the reflector design, the actual operational lifetime is expected to be substantially greater than that predicted. This will be evaluated during service through a combination of improved modeling and future qualification and testing programs.

\subsection{Ceramic Insulation Materials}

Graphite, the principal material used in HTGR core structures, has a relatively high thermal conductivity. The high conductivity of graphite is advantageous in terms of transport of heat from the 
fuel to the helium coolant during normal operation and via the Reactor Cavity Cooling System during certain LBEs. In some applications, however, it is desirable or necessary to control the flow of heat from the graphite core structures to adjacent metallic components (e.g., core support structure) to avoid excessive temperatures. Ceramic insulation may be used in conjunction with the graphite core structures to achieve this objective. Two classes of ceramic insulation have been used in HTGRs to date, baked carbon and fused or sintered quartz. While quartz-based materials provide a greater degree of insulation, baked carbon is often utilized, where practical, based on economic considerations and the similarity of its properties (e.g., neutronic properties, coefficient of thermal expansion) to those of the adjacent graphite core structures

At present, specific ceramic insulation materials have not yet been selected for development within the NGNP Project.

In addition, there are no established general design codes or standards addressing ceramic insulation materials for HTGR applications that are analogous to the ASME Code for metallic or graphite components. However, there is an active effort in the ASME Subgroup on Graphite Core Components (SGCC) to develop construction rules for composite core components This subgroup has been officially sanctioned by the Board on Nuclear Codes and Standards as part of the BPV Code Section III infrastructure. The SGCC has concentrated its efforts to date on nuclear graphite (see Section 3.3.4); however, high temperature composites and manufactured carbon (ceramic insulation) materials are also a part of the subgroup charter. Currently only graphite construction rules are published in Section III, Division 5.

Given the current status, the proposed bases for qualification of ceramic insulation components have not yet been developed. However, general information from past and present research and development programs is presented herein to provide a background understanding of the general issues that are involved in qualifying ceramic insulation components for use in HTGRs. The specific bases for qualification and regulatory review are to be developed later.

In this context, a discussion of baked carbon for use as core insulation is given in this section. In the subsections that follow, additional details are given regarding the manufacturing processes, properties, and prior uses of baked carbon. This is followed by a summary of the approach for the design and structural evaluation, as well as the representative bases for qualification of these insulation components.

\subsubsection{Relevant Applications}

A typical use of ceramic insulation in HTGR's is found in the reference PBMR design, in which baked carbon is being considered for use in the lowermost layers of the bottom reflector, below the core outlet plenum. The purpose of this insulation is to ensure that the service temperatures of the metallic Core Barrel Support Structure are maintained within allowable limits. The bottom reflector insulation layers extend across the full cross-section of the core structure. As noted above, baked carbon is preferred for use as an insulator in this area because it offers an economic alternative with attractive physical and mechanical properties that are similar to those of the reflector graphite structures. Baked carbon also presents advantages in terms of manufacturing. Much larger billets can be produced compared with other types of ceramic insulation, such as fused silica. Baked carbon is also more easily machined to the desired final configuration. It is also worth noting that baked carbon may be obtained from the same supplier as the reflector graphite, which offers specific advantages in terms of both procurement and fabricating experience.

For example, the current PBMR design utilizes SGL Carbon NBC-07 as the reference baked carbon material in conjunction with the NBG-18 graphite reflector components. Other baked carbon/core 
structure graphite combinations could be used, depending on specific reactor design considerations. However, since the insulation requirements of other HTGR reactor designs have not yet been identified, NBC-07 baked carbon will be used in this section as a basis for discussing the primary considerations in the use of ceramic insulation material.

\subsubsection{Important Considerations}

\subsubsection{Manufacturing}

NBC-07 baked carbon is essentially identical to NBG-18 graphite in terms of raw materials and initial processing steps. It is manufactured from the same raw materials as NBG-18, utilizing an isotropic pitch coke filler and coal tar pitch binder and it is formed by vibration molding. The grain size of NBC-07 is identical to that used for NBG-18, thus qualifying NBC-07 as a medium-grain carbon. It is pitch impregnated and re-baked once, following a similar processing route as NBG-18 except for a higher baking temperature of $1100^{\circ} \mathrm{C}$. The principal difference in processing is that the NBC-07 baked carbon is not graphitized.

\subsubsection{Properties}

Key properties of NBC-07 baked carbon insulation are summarized in Table 7 and compared with NBG-18 graphite and the target values for nuclear graphite. Also included in the table are the properties of the ASR-0RB baked carbon insulation used in the Japanese HTTR reactor (see Section 3.4.3 that follows). As can be seen from the table, the most significant difference between NBC-07 and NBG-18 is the higher thermal conductivity of the latter. NBC-07 also exhibits a somewhat higher compressive strength and elastic modulus, plus a CTE that is highly compatible with NBG-18.

Table 7. Properties of NBC-07 and ASR-0RB carbon insulation compared to the target value for nuclear graphite.

\begin{tabular}{|l|l|l|l|l|l|}
\hline \multicolumn{1}{|c|}{ Property } & \multicolumn{1}{|c|}{ Unit } & $\begin{array}{c}\text { ASR-0RB } \\
\text { Carbon }\end{array}$ & $\begin{array}{c}\text { NBC-07 } \\
\text { Carbon }\end{array}$ & $\begin{array}{c}\text { NBG-18 } \\
\text { Graphite }\end{array}$ & $\begin{array}{c}\text { Target Value } \\
\text { for Nuclear } \\
\text { Graphite }\end{array}$ \\
\hline Bulk Density & $\mathrm{g} / \mathrm{cm}^{3}$ & 1.6 & 1.7 & 1.87 & $1.7-1.9$ \\
\hline Coefficient of Thermal Expansion & $\times 10^{-6} / \mathrm{K}^{-}$ & 4.4 & $4.6-4.8$ & $4.5-4.6$ & $3.5-5.5$ \\
\hline Thermal Conductivity & ${\mathrm{W} \cdot \mathrm{m}^{-1} \cdot \mathrm{K}^{-1}}^{\text {Nong }}$ & 10 & $4.9-5.0$ & $140-145$ & $>100$ \\
\hline Tensile Strength & $\mathrm{MPa}$ & 17.8 & 15 & 20 & $>15$ \\
\hline Compressive Strength & $\mathrm{MPa}$ & 50.4 & 138.5 & $77-78$ & $>50$ \\
\hline Elastic Modulus & $\mathrm{GPa}$ & 8.7 & 15.7 & 12 & $8-15$ \\
\hline Ash Content & $\mathrm{ppm}$ & 5000 max. & 4100 max. & $<300$ avg. & $<300$ avg. \\
\hline
\end{tabular}

\subsubsection{Related Experience}

Baked carbon insulation has been previously used in HTGRs, including the HTTR and HTR-10. ${ }^{25,26}$

In the HTTR, blocks of nuclear grade ASR-0RB carbon are used to insulate the metallic core support structures from excessive heat that would otherwise flow from the bottom of the graphite core structures. These insulating blocks were required to keep these metallic structures below $500^{\circ} \mathrm{C}$.

The HTR-10 reactor, which bases its design strongly on the German HTR-Module concept, also uses carbon thermal insulation in the core to protect metallic components. Carbon block insulation is used at the top, bottom and around the core reflector graphite blocks. The bottom carbon insulation blocks are 
composed of three layers, which support the bottom and side reflector graphite blocks. Shaped carbon blocks are used at various locations in the core structures to insulate selected components from hot gas flow. The carbon blocks around the reflector, at the top of the reflector and the upper insulation layer below the reflector have $5 \mathrm{wt} \%$ boron carbide added to the carbon to reduce neutron irradiation to the adjacent metallic components in these areas. The carbon insulation blocks were produced by the Lanzhou Carbon Works to ensure low thermal conductivity and good dimensional stability at high temperature.

It is also worth noting that baked carbon was employed in past German pebble-bed designs such as the AVR and THTR-300, and was intended as bottom reflector ceramic insulation for the HTR-Module and HTR-500 concept designs. For the HTR-Module concept design, Grade AK4 baked carbon manufactured by the SIGRI Company (predecessor to SGL Carbon) was the identified candidate material. This baked carbon had a nominal, indicated bulk density of just over $1.5 \mathrm{~g} . \mathrm{cm}-3$, CTE of $3.5 \times 10-6^{\circ} \mathrm{C}-1$ and thermal conductivity of about $3.8 \mathrm{~W} . \mathrm{m}-1 . \mathrm{K}-1$. In addition, HTR-Module design documents indicate that a $5 \mathrm{wt} \%$ boron carbide surrogate of the AK4 baked carbon was under consideration for shielding purposes in lower temperature areas. Boron carbide pin inserts in graphite core components were identified as the most likely design option in higher temperature core locations that were identified as needing neutronic shielding.

\subsubsection{Approach to Design and Qualification}

As is the case with the graphite and carbon fiber reinforced carbon (CFRC) components discussed in other sections, there are at present no established industrial standards for the design and analysis of ceramic insulation components in nuclear applications. For example, PBMR selected the requirements for the design and manufacture of the ceramic internals (see Appendix A) as the most suitable basis for ceramic insulation design and for assessments of structural reliability. The applicable methods are similar to those used to characterize graphite. In this regard, the following are noted:

- A Structural Reliability Class (in this case SRC-3) is assigned to the ceramic insulation components. As with graphite, the SRC is related to the component functions.

- Based upon the assigned SRC, the allowable failure probabilities are $1 \times 10^{-2}$ for Load Category A and $5 \times 10^{-2}$ for Load Category B.

- The Weibull distribution functions of the component-specific strength values are experimentally determined.

Structural loads imposed on the ceramic insulation are determined by analysis. During normal operation and for anticipated operational occurrences, such loads primarily relate to compressive stresses associated with the weight of core structure ceramic (CSC) components above. For DBEs, Operating Basis Earthquake loads must also be addressed. Thermally-induced stresses associated with temperature gradients and transient thermal loadings will be modest in the ceramic insulation, based on both the material properties and the specific application.

The temperatures seen by baked carbon insulation during normal operation are limited to $600^{\circ} \mathrm{C}$. The peak temperature that could be seen during transients is approximately $800^{\circ} \mathrm{C}$. At these temperatures, physical properties changes (notably thermal conductivity) are expected to be negligible.

The use of ceramic insulation in the CSC is restricted to areas where it is not exposed to significant fast neutron irradiation (e.g., $<10^{18} \mathrm{n} . \mathrm{cm}^{2} \mathrm{EDN}$ ) and, consequently, irradiation-induced changes in properties will be negligible. The baked carbon insulation will be designed for the full HTGR plant life of 60 years. 


\subsubsection{Material Qualification Plan}

An MQP has been developed for NBC-07 baked carbon. The objectives of the MQP are to characterize the properties of the insulation, to confirm its suitability for use in the HTGR and to demonstrate compliance with requirements established for the insulation components. The properties to be developed in accordance with the MQP for NBG-07 baked carbon insulation are summarized in Table 8 .

Table 8. Characterization of baked carbon insulation.

\begin{tabular}{|c|c|c|c|}
\hline Property & Units & Test Method & Conditions \\
\hline Bulk Density & kg.m $\mathrm{m}^{-3}$ & ASTM C559 & RT \\
\hline Mean Coefficient of Thermal Expansion & $\times 10^{-6} \mathrm{~K}^{-1}$ & DIN 51909 & $20-800^{\circ} \mathrm{C}$ \\
\hline Isotropy Ratio & - & DIN 51937 & - \\
\hline Electrical Resistivity & $\mu \mathrm{Ohm} . \mathrm{m}$ & DIN 51911 & RT \\
\hline \multirow{2}{*}{ Thermal Conductivity } & \multirow{2}{*}{$\mathrm{W} \cdot \mathrm{m}^{-1} \cdot \mathrm{K}^{-1}$} & DIN 51908 & RT \\
\hline & & DIN 51936 & $20-1000^{\circ} \mathrm{C}$ \\
\hline Specific Heat Capacity & $\mathrm{J} . \mathrm{kg}^{-1} \cdot \mathrm{K}^{-1}$ & - & $20-1000^{\circ} \mathrm{C}$ \\
\hline Emissivity (Total, Normal) & - & ASTM E307 & $20-800^{\circ} \mathrm{C}$ \\
\hline Water Absorption & - & ASTM C20 & RT \\
\hline \multirow{2}{*}{ Tensile Strength } & \multirow{2}{*}{$\mathrm{MPa}$} & DIN 51914 & RT \\
\hline & & - & Elevated Temperature \\
\hline Tensile Weibull Modulus & - & As per RDMCI & RT \\
\hline Tensile Weibull Characteristic Strength & $\mathrm{MPa}$ & As per RDMCI & RT \\
\hline \multirow{2}{*}{ Compressive Strength } & \multirow{2}{*}{$\mathrm{MPa}$} & ASTM C695 & RT \\
\hline & & - & Elevated Temperature \\
\hline \multirow{2}{*}{ Flexural Strength (4-point) } & \multirow{2}{*}{ MPa } & DIN 51944 & RT \\
\hline & & - & Elevated Temperature \\
\hline \multirow{2}{*}{ Dynamic Elastic Modulus } & \multirow{2}{*}{ GPa } & ASTM C747 & RT \\
\hline & & - & Elevated Temperature \\
\hline Static Elastic Modulus & GPa & ASTM C749 & RT \\
\hline \multirow{2}{*}{ Poisson's Ratio $(v)$} & \multirow{2}{*}{ - } & - & All Temperatures \\
\hline & & - & Elevated Temperature \\
\hline $\begin{array}{l}\text { Friction Coefficient } \\
\text { (Carbon-Graphite) }\end{array}$ & - & $\begin{array}{l}\text { ASTM C808, } \\
\text { ASTM G115 }\end{array}$ & RT- $900^{\circ} \mathrm{C}$ (Helium) \\
\hline Chemical Analysis & ppm & DIN 51096 & As per test method \\
\hline Ash Content & ppm & DIN 51903 & As per test method \\
\hline Equivalent Boron Content (EBC) & ppm & PBMR Procedure & $\mathrm{N} / \mathrm{A}$ \\
\hline Open Porosity & $\%$ & DIN 51918 & RT \\
\hline Pore Size Distribution & - & DIN 66133 & - \\
\hline Air Permeability & Darcy & DIN 51935 & - \\
\hline Air Reactivity & ug. $g^{-1} \cdot h^{-1}$ & SGL Procedure & $400^{\circ} \mathrm{C}, 24 \mathrm{~h}$ \\
\hline BET Surface Area & $\mathrm{m}^{2} \cdot \mathrm{g}^{-1}$ & DIN ISO 9277 & Elevated Temperature \\
\hline
\end{tabular}




\subsection{Composite Materials}

Currently there has been no application of Carbon Fiber Reinforced Carbon (CFRC) composites in nuclear reactors, including HTGRs. Germany conducted some development work on CFRC components in the past, and the US NGNP program has addressed some current aspects of structural CFRC components for the NGNP design. However, the use of composite components is very design specific, with some reactor designs requiring components made from composite materials but other designs not requiring any composite components. Because specific composite components have not yet been selected for development within the NGNP Project, the project cannot provide specific information on areas for composite research and development.

In addition, there are no established general design codes or standards addressing ceramic insulation materials for HTGR applications that are analogous to the ASME Code for metallic or graphite components. However, there is an active effort in the ASME Subgroup on Graphite Core Components (SGCC) to develop construction rules for composite core components This subgroup has been officially sanctioned by the Board on Nuclear Codes and Standards as part of the BPV Code Section III infrastructure. The SGCC has concentrated its efforts to date on nuclear graphite (see Section 3.3.4); however, high temperature composites and manufactured carbon (ceramic insulation) materials are also a part of the subgroup charter. Currently only graphite construction rules are published in Section III, Division 5.

Given the current status, the proposed bases for qualification of composite components have not yet been developed. However, general information from past and present research and development programs for composite components is presented herein to provide a background understanding of the general issues that are involved in qualifying composites for use within HTGRs. The specific bases for qualification and regulatory review are to be developed later.

\subsubsection{Relevant Applications}

In principle, CFRC components can fulfill a broad range of requirements in HTGR environments with the proviso that their application is limited to specific conditions. Typically, these would be applications where the maximum fluence is limited to a few dpa and the components are not likely to suffer significant oxidation damage during normal operation or LBEs, particularly if the components of interest are safety related. Further discrimination can be made with respect to the maximum fluence as it determines whether the material can be regarded as effectively unirradiated. Therefore, for a maximum limiting fluence, there would be a need for further irradiated properties data.

The following provides a typical examples of HTGR applications for which CFRC materials are being considered:

- Top reflector supports (pebble bed)

- Upper plenum insulation supports (prismatic)

- Upper core restraint devices (prismatic)

- Core lateral restraints

- RSS channel interface tubes

- Core outlet connection nozzle (between core outlet plenum and internal hot gas duct)

- Control rod components (advanced application involving high fluence). 
To date, there has been limited development of CFRC components for the above applications. Early development work addressed the upper core restraints and control rod components for prismatic designs, including the manufacture of prototype control rod components at ORNL. More recently, PBMR has undertaken development of top reflector supports (Tie Rods) and core lateral restraint components (Racetrack Straps) for the DPP.

\subsubsection{Important Considerations}

This section identifies the characteristic properties of CFRC materials that could lead to their selection in HTGR components. This is followed by a discussion of materials processing and operational considerations.

\subsubsection{Characteristic Properties of CFRCs}

Characteristic properties of CFRCs that should be considered when evaluating their use in HTGR components include the following:

- Heat resistance in an inert atmosphere to temperatures in excess of $2000^{\circ} \mathrm{C}$

- High specific strength and rigidity

- Low density and low thermal expansion

- Extremely high resistance to thermal shock

- Good to excellent electrical conductivity and thermal conductivity

- Anisotropy: in materials with aligned carbon fibers, the flexural and tensile strength and electrical and thermal conductivity have different values for orientations parallel and perpendicular to the fiber orientation

- Excellent fatigue resistance, even at high temperatures

- Excellent resistance to thermal creep at temperatures up to $1600^{\circ} \mathrm{C}$

- Pseudoplastic fracture behavior

- Relative chemical inertness

- Moderate resistance to fast neutron irradiation damage

- Production of high purity grades is possible

\subsubsection{Manufacturing and Processing Considerations}

CFRCs are comprised of two components- highly ordered carbon fibers and a carbon matrix. They are most commonly made by gradually building up a carbon matrix on a fiber preform through a series of impregnation and pyrolysis steps. Although more expensive than graphites, CFRCs are considerably stronger and tougher than graphites and retain many of the desirable attributes of graphite, including excellent machinability, high thermal conductivity and low thermal expansion. CFRC materials are typically described as being unidirectional (1-D), two-directional (2-D), or three-directional (3-D). This indicates the number of fiber bundle directions that the composite possesses. In 2-D CFRCs, the fibers, in the form of multi-filament tows, are woven into a cloth or, alternatively, carbon filaments may be sprayed from a spinneret to form a felt or mat. The woven cloth is then layered to form the desired thickness. Tubular forms are also considered to be 2-D components in most cases. In a 3-D CFRC, the fiber bundles are usually orthogonal. 
The manufacture of carbon based composites begins with the production of the carbon fibers, which at the crystal structure level is comprised of an array of graphite crystallites with their layered crystal structure preferentially aligned with the fiber axis. The fibers are, therefore, highly anisotropic and, for example, may have an elastic modulus in the fiber direction (a-axis) that is greater than 100 times the modulus perpendicular to the fiber (c-axis). For commercial high performance CFRC, the fiber precursor material is generally either polyacrylonitrile (PAN) or mesophase pitch. PAN-based carbon fibers are far more resistant to compressive failure than their pitch-based counterparts. They are used predominantly in high strength, high temperature applications and represent $\sim 90 \%$ of the total carbon fiber production. However, the PAN-based carbon fibers do not achieve tensile modulus and thermal conductivity values comparable to those of fibers produced from mesophase pitch, and the latter are used where those properties are important. $^{27}$

The processing of carbon fibers, whether from PAN- or pitch-based precursors, is quite similar. Production of both of the fiber types involves spinning, oxidative stabilization in air at 200 to $400^{\circ} \mathrm{C}$, and high temperature carbonization and graphitization. Important steps in fiber processing are thermal stabilization at $200-400^{\circ} \mathrm{C}$ under tension to preserve the fiber molecular structure generated during drawing and carbonization at $1000-1500^{\circ} \mathrm{C}$ in an inert atmosphere to convert the polymer chain structure of the fibers into bundles of linked graphite crystallites. Additional heat treatment reduces strength but dramatically raises tensile modulus, which is important for applications demanding high rigidity. Interestingly, PAN based carbon fibers develop a fibrillar microstructure (Figure 4), which contains regions of undulating ribbons. This structure is much more resistant to premature tensile failure resulting from microscopic flaws than microstructures with extended graphitic regions transverse to the fiber axis, such as those seen in mesophase pitch-based carbon fibers. For this reason, PAN-based fibers tend to develop exceptional tensile strengths. The leading PAN-based fiber, T300, is widely used in the aerospace industry; primary suppliers are Toray and Cytec. A potential issue with these fibers is lot-to-lot variation in properties (as much as $15 \%$ ).

Pitch-based carbon fibers are unique in that they can develop extended graphitic crystallinity during carbonization/graphitization. The mesophase pitches used for the production of high-modulus fibers are most commonly formed by the thermal polymerization of petroleum or coal tar-based pitches. Petroleumbased pitches now dominate because of environmental concerns relative to the coal-tar pitches. The petroleum pitch is commonly formed as a by-product during cracking of the heavy oil fraction of crude oil. A mesophase pitch is produced by heating the pitch in an inert atmosphere for an extended period of time at 400 to $550^{\circ} \mathrm{C}$. The procedures used in the manufacture of carbon fibers from mesophase pitch are quite similar to those discussed in the paragraph above for PAN-based fibers. The four basic steps are melt-spinning, oxidative stabilization, carbonization and graphitization. After carbonization, the fibers are heated to the graphitization temperature range $\left(>1700^{\circ} \mathrm{C}\right)$ that is required to develop their high strength, high modulus properties. During graphitization, dislocations are removed from the carbon structure of the fibers and this eventually results in the formation of a three-dimensional graphite lattice.

The second phase in CFRC production is the creation of a carbon matrix around the fibers. The two most common methods of accomplishing this are chemical vapor deposition and vacuum or pressure impregnation with resin or pitch. The usual commercial method for the production

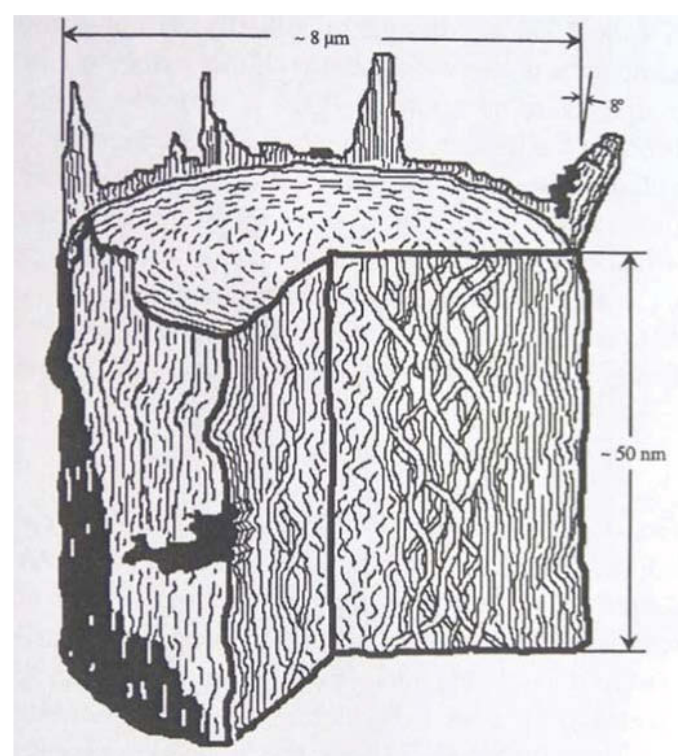

Figure 4. Illustration of the fibrillar texture of a carbonized PAN fiber. 
of CFRC items is resin or pitch-impregnation of preforms that are built up from carbon fiber textiles (woven or non-woven) or yarns. Resin can be injected at temperatures as low as $65^{\circ} \mathrm{C}$; pitch is typically injected at $300^{\circ} \mathrm{C}$. A commonly used petroleum pitch is A-240; phenolic resins such as 91LD and SC1008 are aerospace qualified and readily available, but offer no advantage over pitches except in a few special applications involving processing of complicated shapes.

In the chemical vapor deposition method, the preform (usually formed from several layers of woven carbon fabric in the desired final shape) is heated in a furnace pressurized with an organic gas such as methane or acetylene. The gas decomposes under the high temperature and pressure conditions existing in the furnace and deposits layers of carbon onto the preform. The gas must diffuse through the entire preform to make a uniform matrix; therefore, the process is very slow. It usually requires several weeks and numerous processing steps to make a single part and is, thus, expensive.

A typical production sequence involving impregnation begins with an initial impregnation under vacuum and is followed by carbonization of the impregnated part at 650 to $1000^{\circ} \mathrm{C}$ to convert the organic matrix to an amorphous carbon material. Carbon yield is $\sim 50 \%$ of the volume of pitch or PAN resin injected. Subsequent impregnations and carbonizations may be done at high pressure to improve the carbon yield in each cycle to $\sim 85 \%$. Each impregnation and carbonization cycle is followed by a graphitization treatment at 2000 to $2800^{\circ} \mathrm{C}$. The number of cycles required to produce high density material is typically three to five. As a general rule, the thermal and mechanical properties of the material are found to improve with density; however, there is a trade-off between the properties obtained and the increased cost of multiple impregnation cycles. The final graphitization may be done at temperatures in the lower end of the graphitization temperature range to minimize cracking in the matrix and at the fibermatrix interface. A typical CFRC will contain a volume fraction of fibers of from 40 to $50 \%$.

Additionally, the material will contain between 35 and $40 \%$ impregnant derived matrix graphite. The remainder of the composite volume is porosity distributed in the matrix and at the fiber/matrix interface.

The CFRC can be purified by means of additional halogen treatment at high temperature, typically above $2000^{\circ} \mathrm{C}$. This ensures that the oxidation catalyzing impurities are minimized and that the oxidation resistance of the CFRCs is suitable for the HTGR application.

\subsubsection{Properties}

The material properties of CFRC are strongly influenced by the fiber fraction, fiber type employed, fiber dimensions, fiber lay-up orientation and/or textile weave type (architecture), matrix material type, the individual properties of the fiber and matrix, details of the manufacturing process and the graphitization heat treatment temperature.

Fiber properties depend on the precursor material (PAN or Pitch), production processes, including the tensioning step, and the degree of graphitization. The matrix precursor material and its manufacturing method also influence the properties of the finished composite. Although this may at first seem to present an overwhelming and confusing number of possibilities, it also allows the opportunity to select and tailor materials and processes to achieve a CFRC with physical and/or mechanical properties optimized for the intended application.

Some typical physical and mechanical values for CFRC materials are shown in Table 9 in relation to properties of "isotropic" graphite.

Table 9. Typical properties of graphite and CFRC materials at room temperature.

\begin{tabular}{|l|l|l|l|}
\hline \multicolumn{1}{|c|}{ Property } & $\begin{array}{c}\text { 1-D CFRC } \\
\text { (parallel to fibers) }\end{array}$ & 3-D CFRC & $\begin{array}{c}\text { Fine Grained } \\
\text { Isotropic Graphite }\end{array}$ \\
\hline Density $\left[\mathrm{g} / \mathrm{cm}^{3}\right]$ & $1.7-1.8$ & $1.7-1.8$ & $1.75-1.85$ \\
\hline
\end{tabular}




\begin{tabular}{|l|l|l|l|}
\hline Thermal Conductivity $[\mathrm{W} / \mathrm{m} \cdot \mathrm{K}]$ & $400-600$ & $100-200$ & $90-200$ \\
\hline $\begin{array}{l}\text { Coefficient of Thermal } \\
\text { Expansion }\left[10^{-6} / \mathrm{K}\right]\end{array}$ & $0.1-2.0$ & $0.1-0.2$ & $2-5$ \\
\hline Young's Modulus $[\mathrm{GPa}]$ & $150-250$ & $75-125$ & $10-15$ \\
\hline Bending Strength $[\mathrm{MPa}]$ & $50-150$ & Values not available & $40-70$ \\
\hline Tensile Strength $[\mathrm{MPa}]$ & $300-900$ & $150-400$ & $40-60$ \\
\hline Compressive Strength $[\mathrm{MPa}]$ & $200-500$ & $100-200$ & $100-200$ \\
\hline Fracture Toughness $\left[\mathrm{MPa} \cdot \mathrm{m}^{1 / 2}\right]$ & $2-3$ & $4-6$ & $<1$ \\
\hline
\end{tabular}

The densities here are typical of CFRC materials with multiple (3 to 5) densification cycles; some commercial products with single densification cycles have densities as low as $1.35 \mathrm{~g} / \mathrm{cm}^{3}$. Note that the thermal conductivity values given for the isotropic graphite and the 3-D CFRC are essentially independent of orientation (the measurement direction). Values shown for the 1-D CFRC are for the direction parallel to the fibers; thermal conductivity in directions perpendicular to the fiber axis can be up to 25 times smaller.

Similar considerations/trends apply to the other properties listed for 1-D materials, except for the coefficient of thermal expansion, as noted below. However, the reduction factors for the perpendicular versus the parallel direction are typically much smaller than for thermal conductivity. With regard to the exception, the coefficient of thermal expansion in directions perpendicular to the fiber axis is 4 to 10 times larger than that parallel to the fiber axis.

In the context of the above, the following observations are important to the application of advanced, high-temperature CFRC materials in HTGR applications:

- Tensile and compressive strength and modulus values of CFRC are superior to those of graphite and increase over the entire range of temperatures of relevance for gas-cooled reactors.

- Both fracture toughness and impact resistance of CFRC are better than for graphite.

- Thermal conductivity is high but very sensitive to CFRC architecture, heat treatment and fiber properties.

- Thermal expansion is essentially zero over a wide range of temperature.

- Thermal shock poses little, if any, problem because of the good thermal conductivity and low thermal expansion.

Thermal creep does not occur at even the highest temperatures of interest for gas-cooled reactors; however, irradiation creep may occur in high fluence environments (not applicable for present HTGR CFRC components).

\subsubsection{Operational Considerations}

For the near-term application at 700 to $750^{\circ} \mathrm{C} \mathrm{ROT}$, the use of CFRC would be limited to areas where it is not exposed to significant fast neutron irradiation and, consequently, irradiation-induced changes in properties will be negligible. Irradiation-induced mechanical property changes at fluences below $2 \times 10^{20} \mathrm{n} / \mathrm{cm}^{2} \mathrm{EDN}$ for an irradiation temperature of between 400 and $600^{\circ} \mathrm{C}$ are expected to be enveloped by the values given in Table 10 . 
Table 10. Irradiation induced property changes for CFRC.

\begin{tabular}{|l|l|l|}
\hline \multicolumn{1}{|c|}{ Property } & \multicolumn{1}{c|}{ Unit } & \multicolumn{1}{c|}{ Value } \\
\hline Dimensional Change & & $<0.1 \%$ \\
\hline Tensile Strength & $\mathrm{MPa}$ & +3 to $>10 \%$ \\
\hline Young's Modulus & $\mathrm{GPa}$ & +5 to $>10 \%$ \\
\hline $\mathrm{CTE}$ & $\times 10^{-6} \mathrm{C}^{-1}$ & +3 to $>10 \%$ \\
\hline $\mathrm{K}_{\mathrm{IC}}$ & $\mathrm{MPa} \mathrm{m}^{1 / 2}$ & No detrimental change \\
\hline Thermal Conductivity & $\mathrm{W} \mathrm{m}^{-1} \mathrm{~K}^{-1}$ & $-25 \%$ \\
\hline
\end{tabular}

For higher fluence exposure, irradiation testing would be required to ascertain the magnitude of irradiation-induced changes in these parameters from both a design and operational perspective.

The potential for oxidation of CFRC components must be considered for the operating conditions and LBEs within the design basis. Relevant parameters are the oxidation resistance of the material, the impurity levels in the helium coolant and the temperatures seen by the components in service. Regarding the first, the CFRC grades used in HTGRs would typically be subjected to a halogen purification step at high temperature. This would ensure that the level of impurities available to catalyze an oxidation reaction is limited and imparts better oxidation resistance to the CFRCs for application within the reactor. Given the typical specifications for the helium coolant in HTGRs and the nature and locations of the components identified in Section 3.5.1, oxidation effects within the design basis are not expected to be significant.

\subsubsection{Related Experience}

CFRC materials are widely used in consumer and industrial products. Of particular note is their use in aerospace applications, including critical structural components, such as aircraft braking systems, pressurized cabin structures, wings and other airfoils. Despite their wide commercial application, there has been no experience with CFRC materials in an operational nuclear power plant, including HTGRs.

Although operating experience with CFRC materials in HTGR environment is non-existent, it is worth noting that CFRC materials were under investigation in the German HTR development program for specific applications. The extent of research and testing achieved at the time was limited but points to the potential of CFRC materials under consideration.

\subsubsection{Approach to Design and Qualification}

\subsubsection{Design}

As is the case with graphite, there are at present no established industrial standards for the design and analysis of CFRC components in nuclear applications. For example, the RDMCI document was developed as the basis for CFRC design and for assessments of structural reliability. In this regard, the following are noted:

- An SRC is assigned to each of the respective components. As with graphite, the SRC is related to the component functions

- Based upon the assigned SRC, the allowable failure probability is determined

- The Weibull distribution functions of the component-specific strength values are experimentally determined and the corresponding allowable stress values are calculated 
- Based on the above, load limits corresponding to the allowable probability of failure are developed for the component in question

The RDMCI was developed for graphite and carbon parts and is based on the draft German design code for HTR ceramic core internals (KTA-3232). It does not specifically address the design requirements for core internals made from ceramic matrix composite materials such as CFRC. The design basis for CFRC materials is in the form of a set of extended rules to the RDMCI. This extended set of rules recognizes the unique properties and, hence, design requirements pertaining to composite materials for HTGRs. The extended rules relative to the RDMCI include consideration of oxidation and fluence effects; however, oxidation and fluence effects would be minimal for the conditions seen by CFRCs within the design basis of the NGNP.

\subsubsection{Qualification}

As an example, two different CFRC grades were selected for the Tie Rods (top reflector support) and Racetrack Straps (core restraints). The main difference in these CFRC materials is the fiber architecture, which is tailored to the specific application. These CFRC materials were selected in lieu of metallic alternatives on the basis of their high temperature strength and creep resistance, as well as their low thermal expansion properties.

For both the tie rods and racetrack straps, extensive component level tests were performed. Due to the specific geometry and loading configuration of these parts, it was necessary to determine the component failure loads under representative loading conditions. This could not be satisfied through material specimen tests. Both subscale and full-scale Tie Rod and Racetrack Strap components were tested on a preliminary basis to establish component failure data. However, further work is needed to obtain statistically significant data.

In addition to component failure load tests, both Tie Rod and Racetrack Strap cyclic loading (fatigue) tests were conducted on a preliminary basis to establish safe-cycling load limits for these components in service. Sub-scale components were cycled at varying load ranges exceeding $80 \%$ of the mean failure load for these components and the number of cycles to failure recorded. Given their low-cycle fatigue application in the DPP, the design working load was set at the load at which no failure occurred after 2000 cycles. Additional work is required to improve on the statistics of the available fatigue data and full-scale cyclic loading tests were also planned.

Also, where material testing cannot satisfy component design requirements or provide the requisite design data, component tests must be conducted.

\subsubsection{Status of Codes for Composite Materials}

\section{ASME}

There are no established general design codes or standards addressing ceramic insulation materials for HTGR applications that are analogous to the ASME Code for metallic or graphite components. However, there is an active effort in the ASME Subgroup on Graphite Core Components (SGCC) to develop construction rules for composite core components. This subgroup has been officially sanctioned by the Board on Nuclear Codes and Standards as part of the BPV Code Section III infrastructure. The SGCC has concentrated its efforts to date on nuclear graphite (see Section 3.3.4); however, high temperature composites and manufactured carbon (ceramic insulation) materials are also a part of the subgroup charter. Currently only graphite construction rules are published in Section III, Division 5.

- Establishing an ASME Code framework for the use of CFRC and/or SiC/SiC composites in a HTGR will require at a minimum the development of: 
- Design codes, which list "rules" and guidelines for employing composite materials and incorporating them into component designs

- Design codes which regulate the certification procedures for processing materials, fabricating components, and assembling final designs

- Rules for testing material and components, as appropriate, in a manner that will produce valid and statistically significant data to support the design.

\section{ASTM}

- ASTM test standards for ceramic matrix composites are developed through ASTM Subcommittee C28.07 on Ceramic Matrix Composites. Presently available standards are:

- C1275-00 (2005) el Standard Test Method for Monotonic Tensile Behavior of Continuous FiberReinforced Advanced Ceramics with Solid Rectangular Cross-Section Test Specimens at Ambient Temperature

- C1292-00(2005) Standard Test Method for Shear Strength of Continuous Fiber-Reinforced Advanced Ceramics at Ambient Temperatures

- C1337-96(2005) Standard Test Method for Creep and Creep Rupture of Continuous Fiber-Reinforced Ceramic Composites under Tensile Loading at Elevated Temperatures

- C1341-00(2005) Standard Test Method for Flexural Properties of Continuous Fiber-Reinforced Advanced Ceramic Composites

- C1358-05 Standard Test Method for Monotonic Compressive Strength Testing of Continuous FiberReinforced Advanced Ceramics with Solid Rectangular Cross-Section Test Specimens at Ambient Temperatures

- C1359-05 Standard Test Method for Monotonic Tensile Strength Testing of Continuous FiberReinforced Advanced Ceramics with Solid Rectangular Cross-Section Test Specimens at Elevated Temperatures

- C1360-01 Standard Practice for Constant-Amplitude, Axial, Tension-Tension Cyclic Fatigue of Continuous Fiber-Reinforced Advanced Ceramics at Ambient Temperatures

- C1425-05 Standard Test Method for Inter-laminar Shear Strength of 1-D and 2-D Continuous FiberReinforced Advanced Ceramics at Elevated Temperatures

- C1468-00 Standard Test Method for Trans-thickness Tensile Strength of Continuous FiberReinforced Advanced Ceramics at Ambient Temperature

- C1469-00(2005) Standard Test Method for Shear Strength of Joints of Advanced Ceramics at Ambient Temperature

- C1557-03 e1 Standard Test Method for Tensile Strength and Young's Modulus of Fibers.

\section{Other Standards}

Limited standardization of composite materials has been addressed in the following full-consensus standards organizations:

- Comité Européen de Normalisation (CEN) Subcommittee TC184/SC1 on Ceramic Composites

- International Organization for Standardization Technical Committee TC206 on Fine (Advanced, Technical) Ceramics. 
In addition, other noteworthy standards for CFRCs have been developed by the Department of Defense and NASA High Speed Research/Enabling Propulsion Program in the United States and the Petroleum Energy Center (PEC) in Japan.

The Department of Defense Handbook on Composite Materials consists of five volumes. Volumes 1 through 3 cover polymer matrix composites, Volume 4 covers metal matrix composites and Volume 5 (which includes composite materials discussed in this report) covers ceramic matrix composites. It appears that the information in Volume 5 will directly support ASME codification activities. Volume 5 is organized into four parts:

- Part A Introduction and Guidelines

- Part B Design and Supportability

- Part C Testing

- Part D Data Requirements and Data Sets. 


\section{MATERIALS ISSUES FOR CONSIDERATION}

Given the existing regulatory foundation summarized in Section 2, and the technical status of prospective materials for the NGNP described in Section 3, this section summarizes materials-related issues that need to be addressed in the course of licensing an NGNP. Issues pertaining to metallic materials are summarized in Section 4.1, while issues pertaining to nonmetallic materials are summarized in Section 4.2. In some cases, the issues discussed in this section are presently being addressed within the NGNP design or development programs or in related activities, such as the ASME/DOE cooperative agreement for code development in support of HTGRs, and this section summarizes the present status. In other cases, a specific response is requested from the NRC. For the latter, the specific questions presented for NRC response are found in Section 5 of this report.

\subsection{Metallic Materials}

\subsubsection{Negligible Creep Limits for Extended Lifetime}

The design life proposed for the HTGR plant is 60 years, which is significantly longer than the initial design life of commercial LWR plants now in operation. The current negligible creep temperature limit for SA508/SA533 low alloy steel is specified to be $370^{\circ} \mathrm{C}\left(700^{\circ} \mathrm{F}\right)$ in the ASME Code for Section III, Division 5 Class A components. The $370^{\circ} \mathrm{C}\left(700^{\circ} \mathrm{F}\right)$ limit was originally established over 30 years ago, using existing data for 300,000 hours that were employed for the design of LWRs, which operate closer to $315^{\circ} \mathrm{C}\left(600^{\circ} \mathrm{F}\right)$. Since HTGR, vessels are expected to operate at higher temperatures, and for longer times, the creep database were revaluated to determine if the codified limit was sufficiently conservative. These preliminary assessments using extrapolation of data to 600,000 hours indicate that the negligible creep limit for SA-508/SA-533 is closer to $350^{\circ} \mathrm{C}\left(662^{\circ} \mathrm{F}\right)$ for a 500,000 to 600,000 hour life.

If the negligible creep limit was reduced to $350^{\circ} \mathrm{C}\left(662^{\circ} \mathrm{F}\right)$ repercussions might include modifying the maximum temperature limit for this material in Section III, Division 5 and Subsection NB of the ASME Code. Both of these actions could affect the HTGR design, so evaluation of this temperature limit will be taken into consideration during the HTGR design.

It should be noted that currently, the equivalent number of operational hours associated with a 60year design lifetime is considered to be 500,000 hours. This value is obtained by determining the total number of hours over a 60 -year time interval and assuming a $95 \%$ availability factor.

$(60$ years $) *(365.25$ days/year $) *(24 \text { hours/day })^{*}(.95)=499662$ hours $=500,000$ hours.

\subsubsection{Application of ASME Section III, Division 5 in RPV Design}

Code Case N-499-2 was incorporated into the new ASME B\&PV Code Section III, Division 5. In present NGNP concepts, which are expected to have reactor outlet temperatures in the range of 750 to $800^{\circ} \mathrm{C}\left(1382\right.$ to $\left.1472^{\circ} \mathrm{F}\right)$, the primary helium pressure boundary vessels, including the Reactor Vessel, will employ conventional metallic materials currently approved for nuclear service within Section III of the ASME B\&PV Code. In the case of the reactor vessel, the material of choice is expected to be SA-508/SA-533 low-alloy steel. With the exception of the reactor vessel, the components would operate within the negligible creep range at all times and for all events within the plant lifetime. The reactor vessel would also be designed to operate in the region of negligible creep during normal operation and for anticipated operational occurrences that are expected to occur within the lifetime of a given plant. However, there is a potential that the temperature limits for neglible creep would be exceeded for short periods of time during low frequency design basis events involving conduction cooldown. For such 
events, the provisions of Section III, Division 5, Article HBB-I-3000 will apply, which provides for shortterm operation at temperatures up to $538^{\circ} \mathrm{C}\left(1000^{\circ} \mathrm{F}\right)$.

\subsubsection{Application of Metallic Materials at Elevated Temperatures}

Metallic materials seen as potential candidates for elevated temperature components (vessels, support structures, hot duct liners, etc.) were identified and discussed in Section 3.2. At present, the material candidates include SA508/SA533 low-alloy steel, Alloy 800H, Alloy 617, modified 9Cr-1 Mo steel, 2.25Cr-1Mo steel, and Type 316 SST. Most of these materials are candidates for more than one hightemperature component and no final material/component matches have been made. All of the alloys above are mature in terms of database and industrial experience.

Table 6 shows the status of the development of ASME B\&PV codes for the materials of interest. It can be seen that all of the potential metallic materials, with the exception of Alloy 617, have some degree of ASME Section III approval for nuclear service (Subsections NB, NC and/or ND). Additionally, all of the materials except Alloy $\mathrm{X}$ have provisions for nuclear service at temperatures where allowable stresses can be time-dependent (Subsection NB with Code Case N-499-2 for SA508/SA533, Subsection NG with Code Case N-201-5, and Subsection NH for the others). However, only the use of SA508/SA533 in accordance with Subsection NB, NC, and ND applications is currently fully accepted by the NRC.

Table 6. Current ASME code limits for potential HTGR materials.

\begin{tabular}{|c|c|c|}
\hline Alloy & Applicable ASME Code Section & Prescribed Limits \\
\hline SA-508/SA-533 & $\begin{array}{l}\text { Section III, Division } 5 \text { and Division } 1 \text {, } \\
\text { Subsection NB, NC, ND }\end{array}$ & $370^{\circ} \mathrm{C}\left(700^{\circ} \mathrm{F}\right)$ \\
\hline SA-508/SA-533 & $\begin{array}{l}\text { Section III, Division } 5 \text { (from } \\
\text { Code Case N-499-2) }\end{array}$ & $\begin{array}{l}370^{\circ} \mathrm{C}\left(700^{\circ} \mathrm{F}\right) \text { to } 425^{\circ} \mathrm{C}\left(800^{\circ} \mathrm{F}\right) \text { for } \\
3,000 \text { hours (Level } \mathrm{B}) \\
425^{\circ} \mathrm{C}\left(800^{\circ} \mathrm{F}\right) \text { to } 540^{\circ} \mathrm{C}\left(1000^{\circ} \mathrm{F}\right) \text { for } \\
1,000 \text { hours (Level } \mathrm{C} \text { or } \mathrm{D}) \\
\text { Maximum of } 3 \text { events over } 425^{\circ} \mathrm{C}\end{array}$ \\
\hline SA-508/SA-533 & Section VIII, Division 1 & $427^{\circ} \mathrm{C}\left(800^{\circ} \mathrm{F}\right)$ \\
\hline $316 \mathrm{SS}$ & $\begin{array}{l}\text { Section III, Division } 5 \text { (from revised } \\
\text { incorporation of Code Case N-201-5) }\end{array}$ & $\begin{array}{l}649^{\circ} \mathrm{C}\left(1200^{\circ} \mathrm{F}\right) \text { Core Support } \\
\text { Structures } \\
593^{\circ} \mathrm{C}\left(1100^{\circ} \mathrm{F}\right) \text { Class B Components }\end{array}$ \\
\hline $316 \mathrm{SS}$ & Section III, Subsection NH & $816^{\circ} \mathrm{C}\left(1500^{\circ} \mathrm{F}\right)$ \\
\hline $316 \mathrm{SS}$ & Section III, Subsection NB, NC, ND & $427^{\circ} \mathrm{C}\left(800^{\circ} \mathrm{F}\right)$ \\
\hline Alloy $800 \mathrm{H}$ & $\begin{array}{l}\text { Section III, Division } 5 \text { (from Code } \\
\text { Case N-201-5) }\end{array}$ & $760^{\circ} \mathrm{C}\left(1400^{\circ} \mathrm{F}\right)$ \\
\hline Alloy $800 \mathrm{H}$ & Section III, Subsection NB, NC, ND & $427^{\circ} \mathrm{C}\left(800^{\circ} \mathrm{F}\right)$ \\
\hline Alloy $800 \mathrm{H}$ & Section III, Subsection NH & $760^{\circ} \mathrm{C}\left(1400^{\circ} \mathrm{F}\right)$ \\
\hline Alloy $800 \mathrm{H}$ & Section VIII, Division 1 & $899^{\circ} \mathrm{C}\left(1650^{\circ} \mathrm{F}\right)$ \\
\hline Alloy 617 & Section VIII, Division 1 & $899^{\circ} \mathrm{C}\left(1650^{\circ} \mathrm{F}\right)$ \\
\hline Modified 9Cr-1Mo & Section III, Subsection NB, NC, ND & $371^{\circ} \mathrm{C}\left(700^{\circ} \mathrm{F}\right)$ \\
\hline Modified 9Cr-1Mo & $\begin{array}{l}\text { Section III, Division } 5 \text { and Division } 1 \text {, } \\
\text { Subsection NH }\end{array}$ & $649^{\circ} \mathrm{C}\left(1200^{\circ} \mathrm{F}\right)$ \\
\hline Modified 9Cr-1Mo & Section VIII, Division 1 & $649^{\circ} \mathrm{C}\left(1200^{\circ} \mathrm{F}\right)$ \\
\hline
\end{tabular}




\begin{tabular}{|c|c|c|}
\hline Alloy & Applicable ASME Code Section & Prescribed Limits \\
\hline $2 \frac{1}{4} \mathrm{Cr}-1 \mathrm{Mo}$, Grade 22 & Section III, Subsection NB, NC, ND & $371^{\circ} \mathrm{C}\left(700^{\circ} \mathrm{F}\right)$ \\
\hline $2 \frac{1}{4} \mathrm{Cr}-1 \mathrm{Mo}$, Grade 22 & $\begin{array}{l}\text { Section III, Division } 5 \text { (from } \\
\text { Code Case N-201-5) }\end{array}$ & $\begin{array}{l}600^{\circ} \mathrm{C}\left(1100^{\circ} \mathrm{F}\right) \text { Core Support } \\
\text { Structures } \\
538^{\circ} \mathrm{C}\left(1000^{\circ} \mathrm{F}\right) \text { Class B Components }\end{array}$ \\
\hline
\end{tabular}

The prescribed limits shown in the table do not in all cases and for all alloys sufficiently cover the temperatures and times associated with the elevated temperature components for which they are proposed. In an attempt to remedy this deficiency, the following ASME-based activities are in progress or being proposed:

- Reevaluation of the ASME Section III negligible creep temperature limits (currently $370^{\circ} \mathrm{C}\left(1000^{\circ} \mathrm{F}\right.$ ) based on 300,000-hour service) for SA508/SA533 low-alloy steel. This re-evaluation is needed because of the possibility that service for 500,000 hours may result in the need to impose a lower negligible creep temperature limit (see Section 4.1.1 above).

- Similarly, the $427^{\circ} \mathrm{C}\left(800^{\circ} \mathrm{F}\right)$ negligible creep temperature limits for Alloy $800 \mathrm{H}$, Type 304 and 316 SST, will be revisited in light of the projected 60-year service life of the HTGR. The negligible creep temperature limit of $371^{\circ} \mathrm{C}\left(1000^{\circ} \mathrm{F}\right)$ for modified $9 \mathrm{Cr}-1 \mathrm{Mo}$ and $2.25 \mathrm{Cr}-1 \mathrm{Mo}$ will also be reevaluated based on the longer expected service life.

- Alloy $800 \mathrm{H}$ is qualified under Section III Division 1, Subsections NH and NG and Division 5 (from incorporation of Code Case N-201-5) for operation at temperatures to $760^{\circ} \mathrm{C}\left(1400^{\circ} \mathrm{F}\right)$. All of these need to be extended to temperatures $>800^{\circ} \mathrm{C}\left(1472^{\circ} \mathrm{F}\right)$, preferably up to $950^{\circ} \mathrm{C}\left(1742^{\circ} \mathrm{F}\right)$, to cover operating, off normal, and accident conditions for various high-temperature components. German Standard KTA 3221 allows use of Alloy $800 \mathrm{H}$ up to $1000^{\circ} \mathrm{C}\left(1832^{\circ} \mathrm{F}\right)$.

- Efforts are needed to include Alloy 617 in ASME Section III Division 5 and Division 1, Subsections $\mathrm{NH}$ and $\mathrm{NG}$ to at least $900^{\circ} \mathrm{C}\left(1652^{\circ} \mathrm{F}\right)$.

- Finally, consideration is now being given on how to incorporate the effects of chemical environment, thermal aging and irradiation on properties into the various ASME codes, particularly those that permit operation at high temperatures.

In the present designs, the use of metallic materials at elevated temperatures beyond the timeindependent limits of ASME Section III is limited to components within, but excluding, the primary helium pressure boundary. For those components, which exceed the time-independent limits, NRC acceptance of the following will be required:

1. Section III, Division 5 - This is an ASME-approved Division that incorporates several Code Cases written against Section III Division 1, Subsection NG that provides for the design and construction of High Temperature Reactor components.

2. Section III, Subsection $\mathrm{NH}$ - This is an ASME-approved code for elevated temperature service of metals (Alloy 800H, Types 304 and 316 SST, modified 9Cr-1Mo, and 2.25Cr-1Mo) for Class 1 components.

\subsubsection{Extended Role of Metallic Materials in LBEs}

Assessment of plant response during normal, off-normal, and postulated accident conditions provides the basis on which plant safety analyses are developed. The HTGR includes passive safety features in which material properties are relied upon to accomplish safety functions. Therefore, complete plant response to accident prevention and/or mitigation functions depends on qualified material properties. 
This reliance on material performance during normal and accident environment conditions is fundamental to the materials selection and qualification process.

Strength, corrosion properties, thermal aging behavior, and the influence of radiation are among the additional factors to code status that must be considered in the selection and qualification process. For components that must perform a passive safety function during licensing basis events, additional material properties such as heat capacity, emissivity, thermal conductivity, thermal coefficient of expansion, or other physical properties may be relied on. Also important are the environmental conditions and time during normal operating or accident conditions that could influence material properties. Therefore, the material certification processes must consider the passive safety functions of the components to identify and include additionally unique material properties for qualification.

The plant design and investment protection characteristics also play an important role in determining required material properties. For example, a design goal of HTGR technology that influences material selection and qualification is the capability to return to commercial operation following any LBE, including the DBEs from which deterministic DBAs are derived. This goal potentially results in additional material performance and qualification requirements beyond the normal range of operating parameters. Material performance requirements during LBE conditions must therefore be addressed as part of the material qualification and codification process, from both licensing and investment protection viewpoints.

In order for a metallic material and, more generally, any structural material to be considered for use in the HTGR, it must be qualified for the appropriate service conditions and environment. In this usage, qualification implies that the material has been evaluated, based on a set of experimental data sufficient to reliably describe its behavior, and found to be able to meet the requirements placed upon it by the design for conditions of operation.

\subsubsection{Alternate Methods for Materials Qualification}

Metallic materials that are candidates for application in the HTGR have been discussed in Section 3.2. In terms of the basis for qualification, these materials fall into several categories:

- Materials contained and operated within the limits of a code or standard that the NRC has accepted

- Materials contained and operated within the limits of a code or standard that has been accepted by a standards body but which the NRC has not yet accepted

- Materials that are not contained and/or operated within the limits of a code or standard available at the present time and for which design will be based upon first principles, with appropriate supporting qualification programs.

In the case of the latter, the behavior and performance characteristics of the materials will need to be qualified for use based on analysis and/or testing specific to the HTGR application. It is anticipated that the qualification program would be based upon attributes similar to those supporting code case development, but with more focus on the specific needs of the HTGR. These attributes may include:

- Development of a bounding set of performance criteria based on the design requirements for all anticipated modes of operation, including licensing basis events

- Compilation and analysis of appropriate existing industry data

- Performance of tests and experiments necessary to supplement existing data

- Development of analytical and/or empirical models sufficient to describe the material behavior under the anticipated HTGR conditions 
- Development of a qualification package sufficient to support use of the material in the HTGR.

The plans and required schedules for these qualification efforts will be developed on a case specific basis as the design of the HTGR progresses and specific material needs are developed.

\subsubsection{PIRT-Identified Phenomena}

In 2007, the NRC (with support from DOE) conducted a series of Phenomena Identification and Ranking Table (PIRT) workshops for a range of HTGR technology-specific topics. The PIRT workshops were based on very high temperature HTGRs, with reactor outlet temperatures to $1000^{\circ} \mathrm{C}\left(1832^{\circ} \mathrm{F}\right)$. While the reactor outlet temperatures of present HTGR designs are significantly lower, the hightemperature materials and graphite PIRT topics are of interest to this white paper.

Metallic materials phenomena considered in the workshops included conventional material properties such as strength, creep, fatigue, and the associated aging in a potential 60 -year lifetime for some of the plant components. The service conditions considered covered a range that included both chemical attack and thermal cycling; they also encompassed irradiated material properties for metallic and nonmetallic components in or near the core and the primary system. The maintenance of adequate safety margins over time was a major concern for these PIRT reviews. The PIRT results indicated that the most significant phenomena associated with the materials in HTGRs include those related to:

- High temperature stability and components' ability to withstand service conditions

- Long-term thermal aging and environmental degradation

- Issues associated with fabrication and heavy-section properties of the RPV.

A number of other lower ranked issues were also identified by the PIRT panel for other components. These included material performance issues associated with candidate materials in the reactivity control elements, power conversion unit, helium circulator, RPV internals (core barrel, supports, restraints, and insulation), and primary system valves.

A range of candidate designs envisioned for the HTGR were reviewed against the PIRT results. This review concluded that no additional phenomena, other than the negligible creep issue discussed in Section 4.1.1 above, have been introduced or revealed by the proposed configurations.

\subsection{Nonmetallic Materials}

\subsubsection{Graphite}

\subsubsection{Materials Selection and Qualification}

Nuclear graphite has been employed in the construction and operation of gas-cooled reactors, including HTGRs, for over 50 years. Up until this time, no industrial design code or regulatory basis was in existence to assist in the regulatory approval process concerning graphite core structures. In the U.S., past HTGR designs were licensed as DOE demonstration reactors with a Class 104 NRC license. Construction rules for graphite core components is contained in ASME Section III, Division 5, Subsection HHA.

The grades of nuclear graphite previously employed in HTGRs have varied considerably, and graphite source materials used in the manufacture of many earlier grades can no longer be obtained. However, a selection of candidate grades is currently available from the major graphite suppliers. These candidate grades build on past experience and more recent developments in the state-of-the-art of nuclear graphite. They are evaluated here to satisfy the requirements of both the pebble and prismatic HTGR 
concepts. Different reference grades have been selected for these respective reactor concepts, based on specific differences in requirements; for example, the large block sizes utilized in the pebble-bed reflectors and the small grain size requirements associated with the thickness of webs between fuel compacts and helium coolant passages in prismatic fuel blocks. The accumulation of high fluence at the end of service life is a defining characteristic of certain pebble bed graphite components adjacent to the pebble core.

The properties and behavior of nuclear graphite under irradiation vary significantly as a function of source materials, fabrication processes, and heat treatment. However, experience indicates that materials produced using similar source materials and processing will possess similar as-manufactured properties and will exhibit similar trends in behavior under irradiation. The present graphite MTR programs are based on the premise of using a limited number of test specimens for calibrating and validating analytical models of graphite behavior that were developed from large legacy databases.

As an example, Figure 5 illustrates the relationship between the legacy German database and the PBMR specific Materials Test Reactor Program irradiation conditions that were selected earlier for the proposed PBMR Demonstration Power Plant in South Africa. The solid blue line in the figure represents the projected temperature-fluence envelope at the end of service life for components that serve a structural function (SRC-1, as defined in Table 4), whereas the dotted red line denotes a similar envelope for the most highly-irradiated nonstructural components adjacent to the pebble fuel (SRC-2). As shown in Figure 5, the primary and secondary MTR data are designed to both confirm the applicability of the historical data and to supplement that data where required.

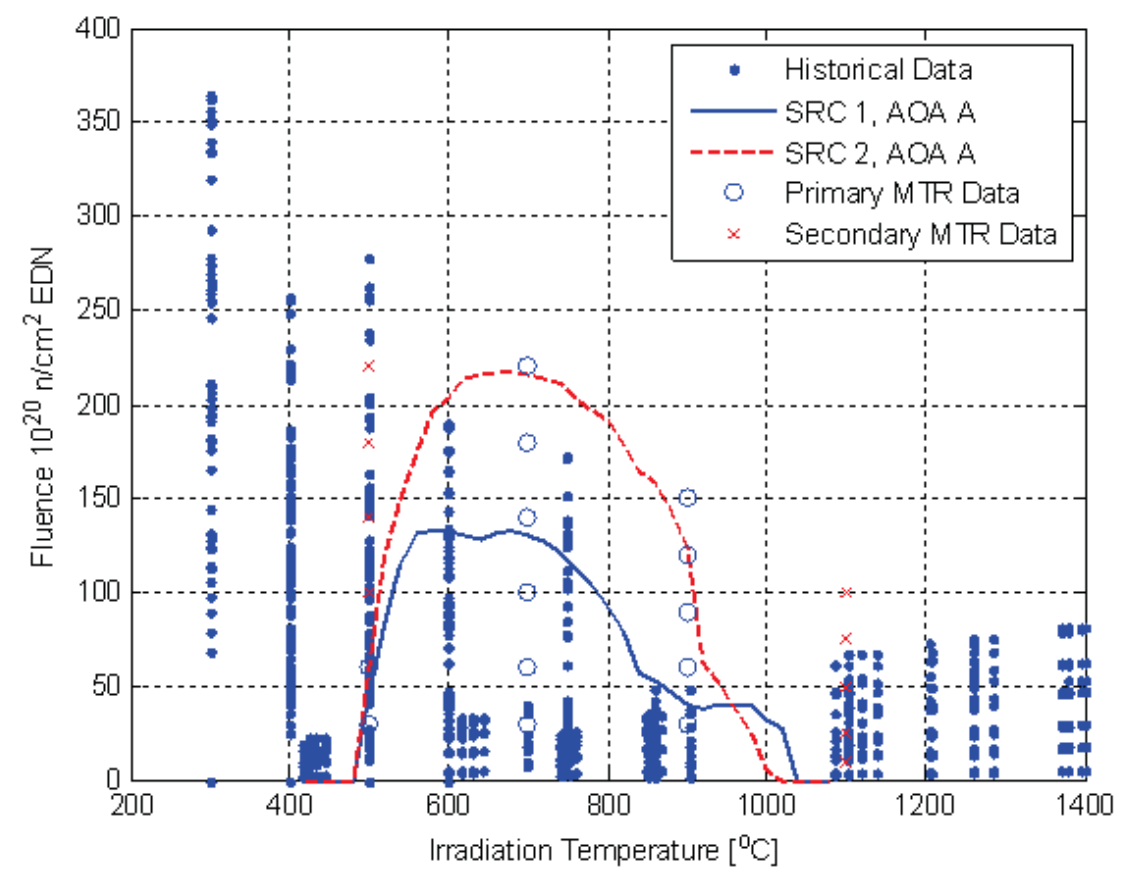

Figure 5. Comparison of the MTR data and PBMR Demonstration Power Plant service conditions.

Finally, the proposed service life of the graphite components in the PBMR implies the need for a relatively lengthy MTR program. On this basis, the PBMR approach is to acquire MTR data for a significant portion of the service life prior to the start of the lead reactor. The balance of the MTR data would be acquired in such a manner that it substantially leads the actual operation of the reactor. 
The most highly irradiated components of the prismatic reactor design are the fuel blocks and replaceable reflectors. These components are replaced before they acquire fluences that would be associated with significant degradation. Accordingly, the requirements of the corresponding MTR program are limited.

\subsubsection{Basis for Establishing Component Lifetimes}

Graphite, located in the high-fluence regions of the core, undergoes structural changes during reactor operation that lead to changes in dimensions and in most of its physical and mechanical properties. The changes in properties and their consequent influence on the graphite structures must be accommodated in reactor core design. Oxidation must also be considered, but its influence on component strength and, hence, structural integrity is not expected to be significant for events within the design basis.

Given the expected changes in materials properties during operation, the requirement is to ensure the safe performance of the graphite components under all applicable operating conditions over their allocated design life. Meeting this requirement is considered more challenging for pebble bed designs, in which reflector replacement is projected to occur only once during the reactor's lifetime, if at all. By contrast, the replacement of fuel elements and reflector blocks in prismatic designs occurs routinely and at lower fluence.

The design life of graphite core structures is based upon the criterion that the probability of a failure in the most highly stressed reflector components will not exceed a specified level. It will be established on a conservative basis using the probabilistic analysis methods noted in Section 3.3.5.2. Nonreplaceable graphite reflector components are exposed to modest fluence levels and are expected to have lifetimes that substantially exceed the design life of the plant. In the absence of irradiated properties data for the specific graphite in question, conservative estimates must account for uncertainties in the materials models used for design. The design life estimates will be updated as materials test reactor data become available.

The operational life of the most highly irradiated graphite components in pebble bed reactors will be further evaluated in service through programs involving visual examination, detection, and evaluation of cracks by eddy current techniques, trepanning of small material samples from the reflector adjacent to the core, or evaluation of replaced components post-service.

\subsubsection{PIRT-Identified Phenomena}

The scope of the PIRT-identified phenomena related to nuclear graphite component include graphite properties such as strength, creep, stress, fatigue, and any associated aging in a potential 60 -year lifetime for some of the core components. The scope also includes oxidation and the aspects of helium gas impurities as well as the effects of gamma and neutron irradiation. The PIRT results indicated that the most significant phenomena in the graphite area include:

- Irradiation effects on material properties (expansion/contraction, thermal conductivity)

- Consistency of graphite quality and performance over the service life.

\subsubsection{Baked Carbon Insulation}

Baked carbon insulation has also seen prior service in HTGR reactors. As with graphite, there is no existing industrial code or regulatory basis to support licensing approval; however, unlike graphite, none is presently being developed. Based on its similarity to graphites, the approach to materials selection and qualification would be similar. Unlike graphite, baked carbon insulation is not expected to see significant fluence during service. The basis for design and assessing the structural adequacy of baked carbon insulation components is proposed to be identical to that of effectively unirradiated graphite. 


\section{OUTCOME OBJECTIVES}

Development of this white paper considers applicable information from sources such as (1) past papers on materials, (2) NRC regulatory guidance, (3) insights gained from NRC public meetings, (4) available industry standards, (5) Modular High Temperature Gas-cooled Reactor (MHTGR) licensing documents, ${ }^{29}$ (6) Pebble Bed Modular Reactor (PBMR) licensing documents, ${ }^{30}$ (7) American Society of Mechanical Engineers (ASME) Codes and Code Cases, and (8) other gas-cooled reactor documents.

The primary objectives of this white paper are to:

- Establish regulatory policies and guidance that may apply to materials expected to be used in HTGRs.

- Establish an acceptable approach for selecting materials, identifying properties, qualification, and accepting materials for key gas-cooled reactor components.

- Obtain feedback from the NRC on ASME B\&PV Code Section III Division 5, "High Temperature Reactors - Rules for Construction of Nuclear Facility Components." This new Division 5 incorporated many of the outstanding Code Cases that apply to HTGRs.

- Identify technical issues that should be discussed and resolved with the NRC, prior to COL or design certification application phase of the project.

The desired outcome of this white paper is to obtain NRC agreement with the recommended approach for qualification and regulatory acceptance of materials for the high temperature service conditions of the HTGR. However, further dialog is required with the NRC to address those outstanding issues raised in the NRC assessment report, dated May 9, 2012. The NRC stated that the staff will not provide a final conclusion regarding the design and qualification of any NGNP components, materials, or their use in the plant design, until an NGNP combined license or design certification application is received and reviewed.

Therefore, based on above, this Revision 1 of the white paper incorporates those changes that were committed in the NGNP RAI responses and updates the sections in the white paper that requires further clarifications, as appropriate. The resolution of those outstanding issues raised in the NRC assessment report will be addressed during the combined license or design certification application phase of the project. 


\section{REFERENCES}

1. NUREG-1338, Preapplication Safety Evaluation Report for Modular High-Temperature GasCooled Reactor (MHTGR), U.S. Nuclear Regulatory Commission, 1995.

2. U.S. Design Certification-High-Temperature Materials-Metallics, Report No\#\%089723, Revision 1, PBMR (Pty) Ltd., 2008.

3. Next Generation Nuclear Plant Phenomena Identification and Ranking Tables (PIRTs), NUREG/CR6944, U.S. Nuclear Regulatory Commission, 2008.

4. Verification of Allowable Stresses in ASME Section III, Subsection NH for Alloy 800H, STP-NU-20, (Page 19), ASME Standards Technology LLC, 2008.

5. PLN-2803, "Next Generation Nuclear Plant Pressure Vessel Materials Research and Development," Rev. 1, July 2010.

6. PLN-2804, "Next Generation Nuclear Plant Steam Generator and Intermediate Heat Exchanger Materials Research and Development Plan,” Rev. 1, September 2010.

7. Japan Atomic Energy Agency website: http://jolissrch-inter.tokaisc.jaea.go.jp/search/servlet/interSearch?LANG=en.

8. Osti: http://www.osti.gov/bridge.

9. Konomo Sanokawa, "IAEA Specialists Meeting on Graphite Component Structural Design," JAERIM 86-192, September 8-11, 1986.

10. Taiju, Motokuni Eto, Eiji Kunimoto, Shusaku Shiozawa, Kazuhiro Sawa, Tatsuo Oku, Tadashi Maruyama, , "Draft of standard for graphite core components in High Temperature Gas-cooled Reactor," JAEA-Research-2009-042, January 2010.

11. Masahiro Ishihara, Tatsuo Iyoku, and Shusaku Shiozawa, "An Explication of design data of the graphite structural design code for core support components of High Temperature Engineering Test Reactor," JAERI-M 91-154, September 1991.

12. Shinzo Saito, et. al., "Design of High Temperature Engineering Test Reactor (HTTR)," JAERI 1332, September 1994.

13. JAERI-M 7647, Temperature Irradiation Effect on the Mechanical Properties of HTGR Graphites, Tatsuo Oko, Motokuni Eto, Katsuo Fujisaki, dated March, 1978.

14. KLI16 - Reflector Graphite Licensing Issues, Document 012664, Rev. 5, 11 Feb 2005.

15. B. J., Marsden, Graphite Selection for the PBMR Reflector, AEAT-6070, August 1999.

16. B. T. Kelly, "Radiation Damage in Graphite and Its Relevance to Reactor Design," Progress in Nuclear Energy, Vol. 2, 1978.

17 Price, R. J. "Cyclic Fatigue of Near-Isotropic Graphite: Influences of Stress Cycle and Neutron Irradation", Carbon, Vol 16, 1978.

18. Analysis of irradiation creep experiments on nuclear reactor graphite Kelly, B.T. ${ }^{1}$; and Burchell, T.D. ${ }^{1}$ Source: Carbon, v 32, n 1, p 119-125, 1994; DOI: 10.1016/00086223(94)90017-5; Publisher: Publ by Pergamon Press Inc.

19. Irradiation induced creep behavior of H-451 graphite Burchell, Timothy D. (Materials Science and Technology Division, Oak Ridge National Laboratory, P.O. Box 2008, Oak Ridge, TN 37831-6088, United States) Source: Journal of Nuclear Materials, v 381, n 1-2, p 46-54, October 31, 2008. 
20. Irradiation induced creep of graphite Burchell, T.D. (Materials Science and Engineering Division, Oak Ridge National Laboratory, Oak Ridge, United States); Murty, K.L.; Eapen, J. Source: JOM, v 62, n 9, p 93-99, September 2010.

21. IAEA, 2011, www.iaea.org/NuclearPower/Technology/CRP, accessed September 21, 2011.

22. Burchell, T., Bratton, R. and Windes, W, NGNP Graphite Selection and Acquisition Strategy, ORNL/TM-2007/153, September 2007.

23. Energy Outlook 2008, AEN Nuclear Energy Agency, November 2008

24. Survey of Materials Research and Development Needs to Support Early Deployment, INEEL/EXT03-00141, January 2003

25. Ishihara, M., et. al., "Principle Design and Data of Graphite Components", Nuclear Engineering and Design 233, pp251-260, 2004.

26. Zhang, Z., et. al., "Structural Design of Ceramic Internals of HTR-10", Nuclear Engineering and Design 218, pp123-36, 2002.

27. Carbon Materials for Advanced Technologies, edited by T. D. Burchell, Pergamon Press, 1999.

28. Creep Effects on Design Below the Temperature Limits of ASME Section III subsection NB, HTR2008-58281, 2008.

29. NUREG-1338, Preapplication Safety Evaluation Report for Modular High-Temperature Gas-Cooled Reactor (MHTGR), U.S. Nuclear Regulatory Commission, 1995.

30. U.S. Design Certification-High-Temperature Materials-Metallics, Report No\#\%089723, Revision 1, PBMR (Pty) Ltd., 2008.

Other General Reference Materials

1. PLN-2497, “Graphite Technology Development Plan,” Rev. 1, October 2010.

2. ASME, "Boiler and Pressure Vessel Code," Section III, Division 5. 


\section{Appendix A}

\section{Historical Experience with Nuclear Graphite}




\section{Appendix A Historical Experience with Nuclear Graphite}

\section{Experience with Nuclear Graphite}

Graphite has been used for core structural components in nuclear reactors for over 60 years. There is a substantial base of experience with the use of graphite in commercial high temperature gas-cooled reactors (HTGRs), both $\mathrm{CO}_{2}$ and helium-cooled. The summary of experience discussed here is from the United Kingdom, Germany, United States, Japan, and China; however, there has also been extensive experience with graphite moderated reactors in both France and Russia.

\section{United Kingdom}

The first commercial reactors in the United Kingdom were of the natural uranium-fueled Magnox type. Four Magnox reactors were initially built at Calder Hall and achieved full power operation between 1956 and 1960. Each reactor had around 1,700 fuel channels moderated by graphite with a design heat output of $180 \mathrm{MW}(\mathrm{t})$. A further nine Magnox stations were built between 1962 and 1971, the largest and last being a twin reactor station at Wylfa, each reactor having over 6,100 channels and a design heat output of more than $1800 \mathrm{MW}(\mathrm{t})$. The first plant closure came in 1989 and the final closure is scheduled soon after 2010. Magnox plants of UK-design were also built in Japan (Tokai) and Italy (Latina). French-designed Magnox plants were built in France (reactors) and Spain (Vandellos). All these plant are shut down and in the process of decommissioning.

The graphite used in the UK-based Magnox reactors was Pile Grade A (PGA) graphite made from 'needle' coke which had a needle-like appearance after crushing. The anisotropic graphite crystal structure tends to be preferentially aligned along the length of these needle-like grains. Since the PGA reactor components were formed by extrusion, which preferentially aligns the needle-coke grains in the product, preferential alignment of the graphite crystallites occurs along the extrusion direction resulting in a highly anisotropic bulk material. Production graphite had a density of about $1.7 \mathrm{~g} / \mathrm{cm}^{3}$, was quite porous and had moderate strength with highly anisotropic properties (isotropy ratio of 2.2). Therefore, the dimensional change behavior of PGA graphite under irradiation was very anisotropic. In the direction parallel to the direction of extrusion, the graphite shrank progressively with increasing dose at all irradiation temperatures of interest. In the perpendicular direction, however, the graphite shrank at irradiation temperatures greater than around $300^{\circ} \mathrm{C}\left(572^{\circ} \mathrm{F}\right)$, but below this temperature it exhibited growth, the lower the temperature, the greater the rate of growth. Nominal graphite operating temperatures ranged between 200 and $400^{\circ} \mathrm{C}\left(392\right.$ and $\left.752^{\circ} \mathrm{F}\right)$ with peak fluence at end of life expected to be about $6 \times 10^{21} \mathrm{n} . \mathrm{cm}^{-2} \mathrm{EDN}$ (equivalent dido nickel).

The Magnox reactors were followed by Advanced Gas Cooled Reactors (AGRs), the first two of which were commissioned in the United Kingdom at Hinkley Point and Hunterston in 1976. Overall, seven stations were built using four different designs over the years. Experience confirmed that the dimensional change rates exhibited by PGA graphite were unacceptable for the much higher irradiation fluence and temperature combination that would be attained in commercial AGRs. Nominal graphite operating temperatures in the AGR ranged between 250 to $650^{\circ} \mathrm{C}\left(482\right.$ to $\left.1202^{\circ} \mathrm{F}\right)$, with a peak design fluence in excess of $5 \times 10^{21} \mathrm{n} . \mathrm{cm}^{-1} \mathrm{EDN}$. Therefore, development and testing of graphites with greater dimensional stability and higher strength were undertaken. Another problem in both the Magnox and AGR reactors was radiolytic oxidation caused by radiolysis of the $\mathrm{CO}_{2}$ coolant and subsequent graphite oxidation. Several materials were produced, but the graphite eventually chosen for the first AGR at Dungeness, and all subsequent AGRs, was made using Gilsonite pitch coke. The Gilsonite pitch coke grains have an approximately spherical shape and, by using a molding process to make the graphite 
blocks, near isotropic graphite was produced. The resulting graphite was referred to as Gilsocarbon graphite. However, available sources of Gilsonite pitch were eventually exhausted and are no longer available.

\section{United States}

Fort St. Vrain was a U.S. designed and built, helium-cooled, graphite moderated HTGR that utilized a ${ }^{235} \mathrm{U}$ - thorium fuel cycle, a prismatic fuel element design and a prestressed concrete reactor vessel. Gross reactor power output was $842 \mathrm{MW}(\mathrm{t})$ and $330 \mathrm{MW}(\mathrm{e})$. The reactor core consisted of vertical columns of hexagonal graphite fuel-moderator elements and graphite reflector blocks grouped into a cylindrical array and supported by a graphite core support structure. The active core had the approximate shape of a right circular cylinder with an equivalent diameter of approximately $5.9 \mathrm{~m}$ (meter) and a vertical height of approximately $4.8 \mathrm{~m}$. The side reflector had a mean thickness of about $1.2 \mathrm{~m}$, giving an overall mean core and reflector diameter of approximately $8.3 \mathrm{~m}$. The top reflector had an effective thickness of about $1 \mathrm{~m}$ and the bottom reflector had an effective thickness of about $1.2 \mathrm{~m}$, giving an overall assembly height of about $6.9 \mathrm{~m}$. The core was contained within a steel core barrel that provided lateral constraint and support for the fuel and reflector columns. The active core was composed of 1,482 hexagonal graphite fuel elements stacked in 247 vertical columns. The individual graphite fuel elements were approximately $35.6 \mathrm{~cm}$ across the flats and $78.7 \mathrm{~cm}$ high. The replaceable reflector elements assemblies were composed of 2,188 hexagonal graphite blocks. Some of these blocks incorporated boronated graphite material for shielding purposes. The permanent reflector block and spacer assemblies were composed of 312 graphite blocks and included boronated graphite material in the top or the peripheral spacers.

The graphite used for the Fort St. Vrain (FSV) core support blocks was PGX graphite, a mediumgrain graphite with A low coefficient of thermal expansion (CTE) and elastic modulus, marginal strength (mean tensile $\sim 8 \mathrm{MPa}$ ) and high ash content $(7,000 \mathrm{ppm}$ max). The core support posts were made from ATJ graphite, a fine-grain, isostatically-molded grade of high strength (27 MPa WG, $23 \mathrm{MPa} A G)$ and very low CTE $\left(2.2-2.6 \times 10^{-60} \mathrm{C}^{-1}\right)$, relatively low modulus $(9.7-9.5 \mathrm{GPa})$ and high thermal conductivity $\left(125-110 \mathrm{~W} \cdot \mathrm{m}^{-1} \cdot \mathrm{K}^{-1}\right)$, giving this grade good thermal shock resistance and an isotropy ratio of 1.18 . The permanent side reflectors were made from HLM graphite, a medium-grain, extruded-grade of marginal strength (tensile $\sim 12 \mathrm{MPa}$ ), high anisotropy ratio of 1.5 , high thermal conductivity $(>150 \mathrm{~W} \cdot \mathrm{m}-1 . \mathrm{K}-1)$ and high ash content $(1,000-3,000 \mathrm{ppm})$. The primary fuel element and reflector structural material in the initial FSV core and the first and second reloads was H-327 graphite, an anisotropic grade made using needle coke with an isotropy ratio in excess of 2.0. After some time, the high anisotropy of H-327 was recognized as being problematic. Beginning with the third reload, $\mathrm{H}-451$ graphite, an extruded near isotropic grade made from petroleum coke, was substituted for the fuel and reflector elements. This remained the primary graphite material used beginning with Reload 3. Analysis confirmed that $\mathrm{H}-451$ graphite improved the mechanical, thermal, and fluid flow characteristics of the reactor.

The design life of the core fuel elements and the replaceable reflector elements adjacent to the core in the FSV reactor was 1,800 effective full-power days. The remaining permanent reflector elements, blocks, and spacers had a design lifetime of 30 years. The cumulative clearances between fuel and control rod columns across any core diameter was specified to limit the maximum possible bowing deflection of any individual column to ensure that insertion of the control rods and reserve shut-down neutron absorber material were not restricted under any conditions for normal or abnormal operation.

\section{Germany}

The first German pebble bed reactor was the $15 \mathrm{MW}(\mathrm{e})$ Arbeitsgemeinschaft Versuchsreaktor (AVR), or research reactor, which began operation in 1967. The performance of this pebble bed reactor was generally good throughout its 21 years of operation. The reflector graphite employed in the AVR was Grade ASR/AMT, a highly anisotropic, petroleum coke grade. Despite the large difference in 
dimensional change of the ARS grade with-grain and against-grain, no operational problems were attributed to graphite material performance, primarily because of the limited irradiation exposure of the top and side reflector components. Whereas the top reflector only accumulated a fast neutron fluence of $<2 \mathrm{dpa}\left(<1.5 \times 10^{21} \mathrm{EDN}\right)$ at $1000^{\circ} \mathrm{C}$, the side reflector received four times this fluence in the peak flux regions, but at lower temperatures, so that the anisotropic dimensional changes which did occur were not of operational consequence.

The AVR was followed by the $300 \mathrm{MW}$ (e) thorium high temperature reactor (THTR-300), which began operation in 1985. The graphite used in the THTR-300 was Grade PXA2N, an isotropic, medium grain nuclear graphite made from Gilsonite pitch coke. By this time, the German graphite development program had reached an advanced stage, and it was well recognized and understood that control of graphite isotropy and processing parameters could dramatically improve material properties and behavior under irradiation.

THTR-500, a higher capacity follow-on to THTR-300, was designed, but never built. However, the graphite materials and reflector design associated with THTR-500 have been used, in part, as the basis for the current pebble bed modular reactor design. The High Temperature Reactor (HTR)-Module was another pebble-bed reactor concept that was designed and reviewed by the German licensing authorities for a site-independent licensing permit. Though never built, it was a key milestone in the evolution of the inherent and passive safety concepts that are prevalent in current modular HTGR concepts. As with present modular HTGR designs, fuel temperatures were to be limited during design-basis accidents by inherent and passive features. Design documentation and safety analysis report information pertaining to the HTR-Module indicate that the concept graphite core structures design was based on ASR-1RS graphite, a grade that was in development at the time. Grade ASR-1RS represented the apex of the German graphite development effort in following respects:

1. It was a medium-grain $(1.0 \mathrm{~mm})$, isotropic pitch coke, vibration molded grade

2. The coke was subjected to a specialized secondary coking technique to reduce the dependence of the final graphite properties on the coke source and to achieve the highest level of isotropy attainable at that time

3. It was tested under irradiation to compare against other development grades at the time and excellent isotropy in irradiation behavior, including very low dimensional shrinkage was confirmed

4. Several batches were produced over a period of a decade or so to evaluate the influence of raw materials, refine processing parameters, and optimize material properties.

Perhaps the biggest disadvantage with ASR-1RS was the high cost of the secondary coking process, which stemmed from the significant additional processing steps required.

\section{Japan}

Renewed development of HTGRs began with construction of the High Temperature Engineering Test Reactor (HTTR) in Japan. The HTTR is a $30 \mathrm{MW}(\mathrm{t}$ ) helium-cooled high-temperature prismatic fuel reactor that reached initial criticality in 1998 and has operated at reactor outlet temperatures of up to $950^{\circ} \mathrm{C}$. A wide variety of commercially available graphites were examined as candidates for the graphite core components. Most core components (reflector and fuel elements) are fabricated from IG-110 nuclear graphite and the larger core support blocks are fabricated from PGX nuclear graphite. Since inception, there has been ongoing development and testing of both graphite material and core components with extensive publications regarding the performance of IG-110 under a variety of test conditions This has included data on physical and mechanical properties at ambient and high temperature, fatigue, irradiation creep, and oxidation. Importantly, there has been a sustained effort in the development of surveillance 
and in-service inspection techniques for the HTTR to assess the condition of the core components, both in situ and out of core.

The HTTR graphite structural design was based on conventional stress analysis approaches, similar to that used for metallic components, and an expanded version of the original draft Code for graphite core components issued to the ASME for review and comment in 1990. Significant extensions made by the Japan Atomic Energy Research Institute, now the Japan Atomic Energy Agency to this previous draft code related to the allowable stress limits for irradiated components, treatment of fatigue and buckling limits (for core supports), oxidation, and irradiation creep.

\section{China}

The most recent addition to the HTGR family is the Chinese HTR-10, a 10 MW(t) pebble bed test reactor that reached initial criticality in 2002. This is a scaled-down design that also draws significantly from the HTR-Module concept. However, the graphite selected for the HTR-10 was IG-11, an isostaticmolded, fine-grain material, in contrast to the medium-grain reflector grades that were the focus of the German program. Given the short-term experience of the HTR-10, there is little published information regarding the graphite core component performance to date. However, the Institute of Nuclear and New Energy Technology, the Chinese developer, has revealed that the purified version of IG-11, i.e., IG-110, will be employed for the graphite core in the scaled up, twin $250 \mathrm{MW}(\mathrm{t})$ HTR-PM plant, with construction beginning by 2013 .

\section{Summary}

It can be said that the quality of reactor graphite grades has improved over the years with significant improvements in the density, strength, isotropy, and purity of current grades. It is also clear that these modern grades have been developed based on the strengths and weaknesses of past grades as assessed from their performance in test reactors and in HTGR components. The physical, thermal and mechanical properties of these modern graphite grades are currently being evaluated by INL and ORNL for use in HTGR applications, and by other parties involved in HTGR research and development in Europe, China, Japan, and Korea. These test programs cover both unirradiated and irradiated conditions.

\section{Status of Graphite Qualification for the HTGR}

Recent HTGR graphite experience in the United States has been mainly with Grades H-327 and H-451 at FSV. However, these graphites are no longer available because the coke source used to manufacture the graphite is not available. New graphite grades, such as those discussed in Section 3.3.3, have been designed based on the strengths and weaknesses of H-451 and other previous grades' performance in lab tests and in HTGR components. A complete properties database for these newly available candidate grades of graphite must be developed to support the design and licensing of HTGR core components. Data are required for thermal, mechanical (including radiation-induced creep), and oxidation properties of these graphite grades. Moreover, the data must be statistically sound and take account of in-billet, between billet, and lot-to-lot variations in properties.

Testing is currently underway at Idaho National Laboratory (INL) to gather data on these new graphite grades. The INL graphite development program provides for a number of capsules that will be used to characterize the effects of irradiation, temperature, and compression simultaneously over a range of temperatures and fluences (see Section 3.3.6). Existing data and related international programs undertaking the characterization of irradiation effects on these grades of graphite may also be used in the qualification process. 
Appendix B

Graphite Structure and the Effects of Irradiation 


\section{Appendix B Graphite Structure and the Effects of Irradiation}

In its perfect form, the crystal structure of graphite consists of tightly-bonded (covalent) sheets of carbon atoms in a hexagonal lattice network as shown in Figure B-1. The sheets are weakly bound with van der Waals type bonds in an $\mathrm{ABAB}$ stacking sequence

A

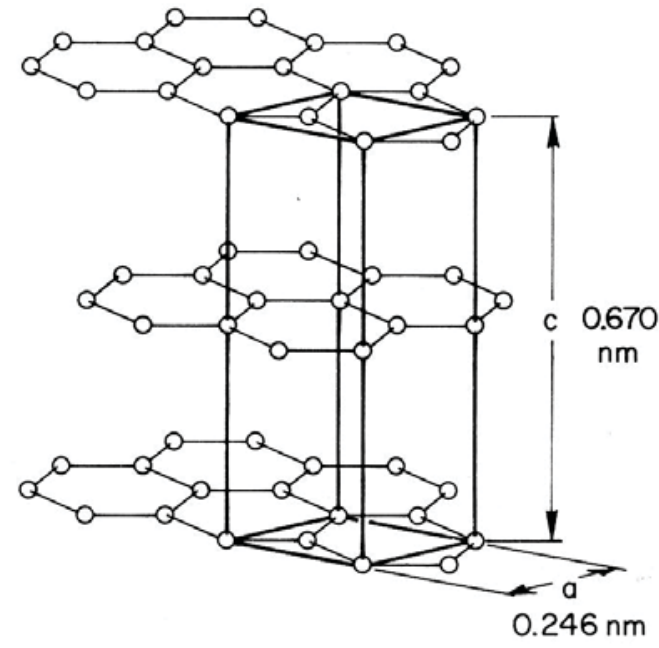

Figure B-1. Crystal structure of graphite.

Changes in graphite properties resulting from nuclear irradiation are the result of displacements of atoms in the crystal structure. The primary atomic displacement (primary knock-on carbon atoms) produced by energetic particle collisions produce further carbon atom displacements in a cascade effect. The cascade carbon atoms are referred to as secondary knock-on atoms. The displaced secondary knockon atoms tend to be clustered in small groups of 5 to 10 atoms, and for most purposes, it is satisfactory to treat the displacements as if they occur randomly. The total number of displaced carbon atoms will depend upon the energy of the primary knock-on carbon atoms, which is itself a function of the neutron energy spectrum, and the neutron flux. Once displaced, the carbon atoms recoil through the graphite lattice, displacing other carbon atoms and leaving vacant lattice sites. However, not all of the carbon atoms remain displaced. The displaced carbon atoms diffuse between the graphite layer planes in two dimensions and a high proportion will recombine with lattice vacancies. Others will coalesce to form $\mathrm{C} 2$, $\mathrm{C} 3$, or C4 linear molecules. These in turn may form the nucleus of a dislocation loop-essentially a new graphite plane. Interstitial clusters may, on further irradiation, be destroyed by a fast neutron or carbon knock-on atom (irradiation annealing). Adjacent lattice vacancies in the same graphitic layer are believed to collapse parallel to the layers, thereby forming sinks for other vacancies, which are increasingly mobile above $600^{\circ} \mathrm{C}$ and, hence, can no longer recombine and annihilate interstitials.

These changes in the graphite structure under irradiation produce corresponding changes in the properties of graphite, which are summarized in the sections that follow.

\section{Dimensional Changes with Neutron Irradiation}

A principal result of carbon atom displacements is crystallite dimensional change. Interstitial defects will cause crystallite growth perpendicular to the layer planes (c-axis direction), and relaxation in the layer plane because of coalescence of vacancies will cause a shrinkage parallel to the layer plane (a-axis direction). The damage mechanism and associated dimensional changes are illustrated in Figure B-2. 


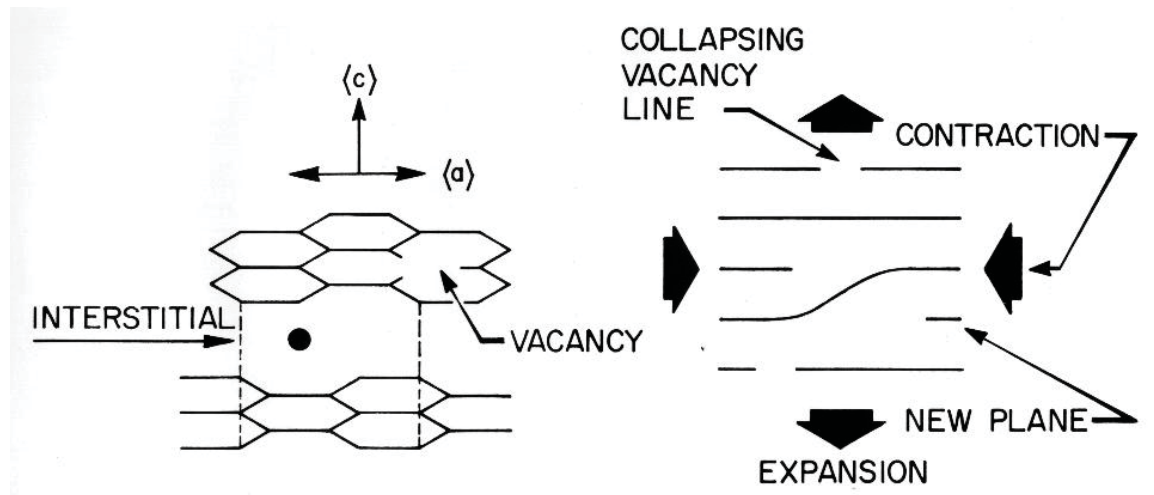

Figure B-2. Neutron irradiation damage mechanism illustrating induced crystal dimensional changes.

Irradiation-induced dimensional changes can be very large, in well-ordered graphite materials, such as pyrolytic graphite, which has frequently been used to study neutron-irradiation induced dimensional changes. Polygranular graphites, which are more typical of materials used in high temperature gas-cooled reactors (HTGRs), possess a polycrystalline structure, usually with significant texture resulting from the manufacturing method. Consequently, structural and dimensional changes in polygranular graphites are a function of both the crystallite dimensional changes and the graphite's texture. In polygranular graphite, thermal shrinkage cracks that occur during manufacture and that are preferentially aligned in the crystallographic a-direction will initially accommodate the c-direction expansion, so mainly a-direction contraction will be observed. The graphite thus undergoes net volume shrinkage. With increasing neutron dose (displacements), the incompatibility of crystallite dimensional changes leads to the generation of new porosity oriented parallel to the basal planes, and the volume shrinkage rate falls, eventually reaching zero. The graphite now begins to swell at an increasing rate with increasing neutron dose. The fluence at which the volume change with irradiation switches from the initial contraction phase to the volume expansion mode is termed the turnaround point. At extremely high fluence levels, the accumulation of pores and microcracks effectively leads to a loss of the material integrity or cohesion. This is referred to as the cohesive life limit. These trends are illustrated in Figure B-3 and Figure B-4 for a relatively isotropic graphite.

The rate of shrinkage, the maximum shrinkage observed, the turnaround fluence, and expansion rate are strongly influenced by the actual irradiation temperature. Historically, the fluence at which the graphite dimensions returned to their original values, defined as the return-to-original-volume was considered as a measure of the useful life of the graphite. Reactor grades that returned to original volume at higher fluence at a given temperature were regarded as having a longer life. For the German program, volumetric swelling amounting to $10 \%$ beyond the initial value was used as the end-of-life criterion.

Analyses, however, indicate that the stresses resulting from dimensional changes in irradiated graphite components are typically more limiting in terms of component life than volumetric swelling criteria. Stresses arising from dimensional changes must be assessed in combination with other stresses, in evaluating the likelihood of component failure. End-of-life is said to be reached when the likelihood of failure exceeds established limits. It must also be pointed out that the external stresses imposed on core components while under irradiation will alter their dimensional change behavior. A stressed graphite component under irradiation will undergo irradiation creep. The irradiation creep strain is defined as the difference in dimensional change between stressed and unstressed material irradiated under the same conditions of fluence and temperature. Therefore, the creep strain has also to be considered in the total stress analysis of the irradiated component. 


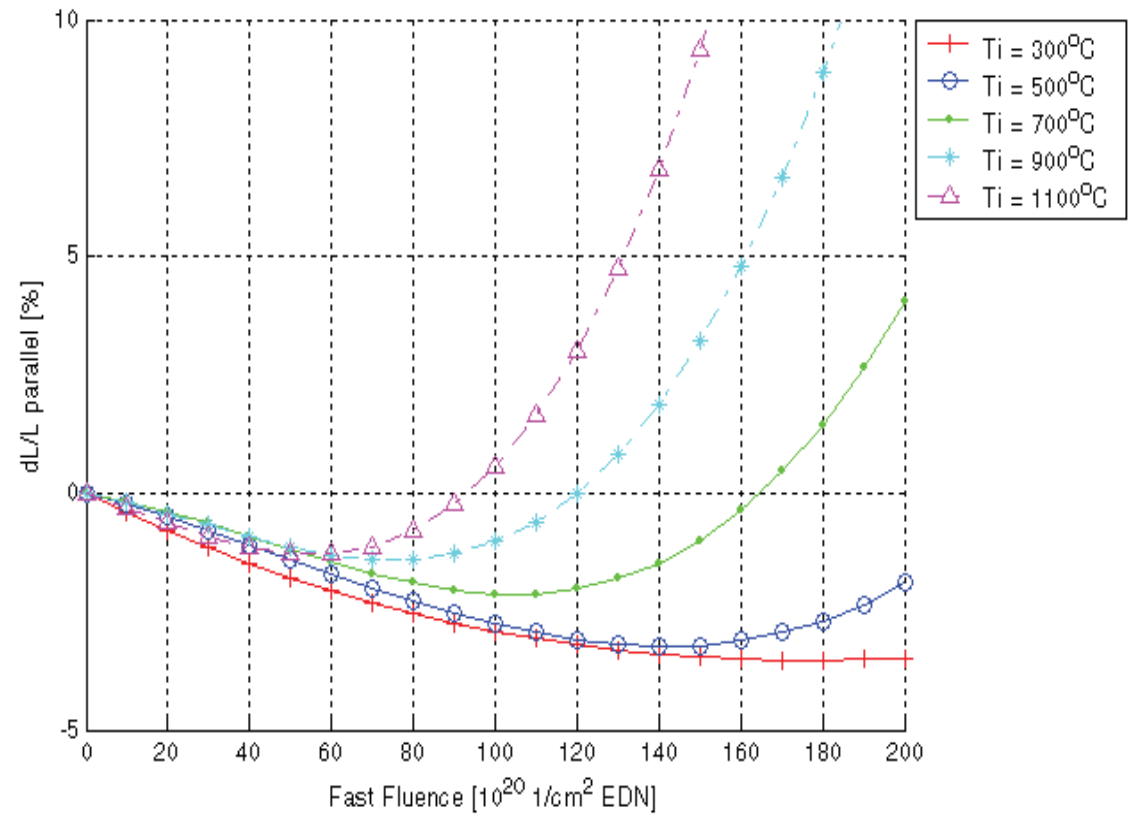

Figure B-3. Typical irradiation-induced dimensional changes in reactor graphite, parallel direction.

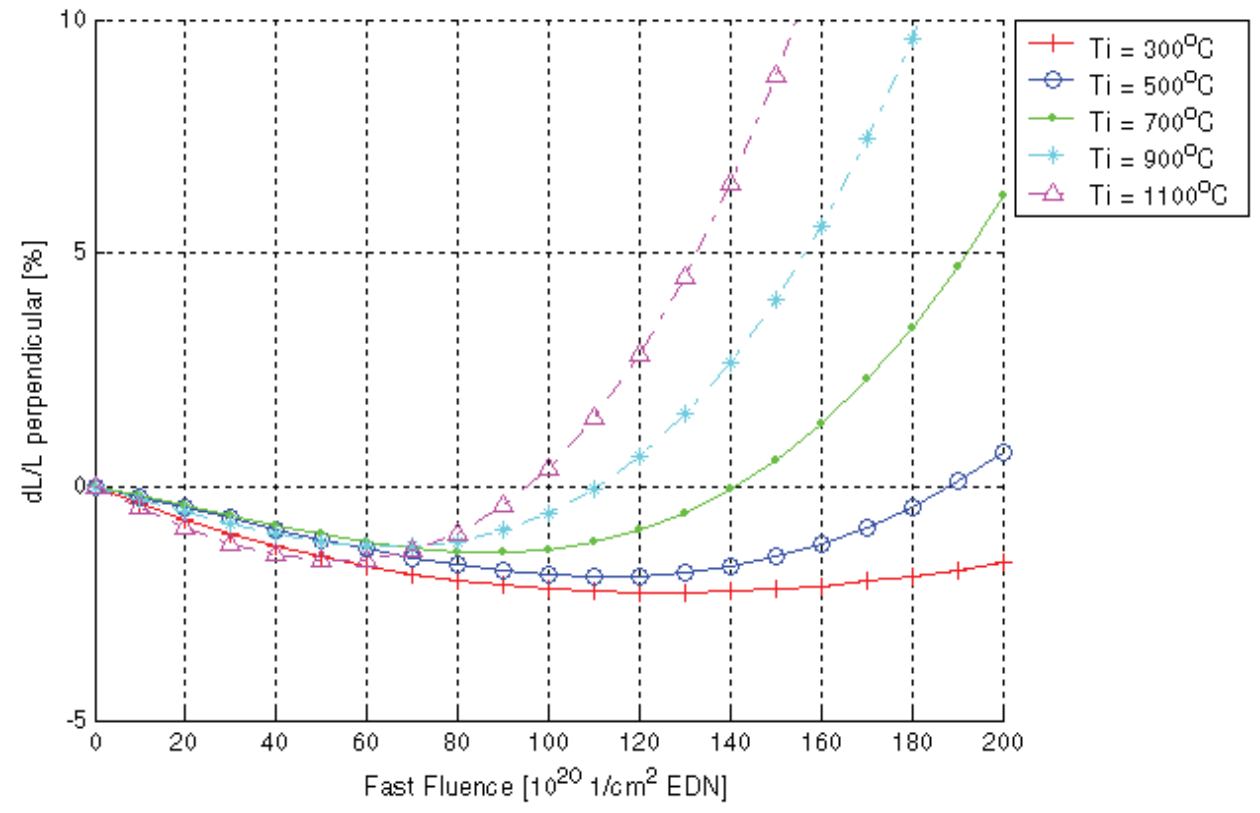

Figure B-4. Typical irradiation-induced dimensional changes in reactor graphite, perpendicular direction.

\section{Thermal Conductivity Changes with Neutron Irradiation}

Thermal conductivity is critical to HTGR design, as it plays a key role in determining the ability to transfer decay heat from the core during conduction cooldown events, thus limiting maximum fuel temperatures. This property is controlled by raw materials, processing (e.g., forming method) and heat treatment temperature and the graphite irradiation fluence-temperature history. High graphitization temperature $\left(>2700^{\circ} \mathrm{C}\right)$ is required during the final stage of billet manufacture to ensure sufficient thermal conductivity for HTGR applications. 
Fast neutron fluence typically produces a rapid decrease in the thermal conductivity of graphite from the value at low fluences to an intermediate saturation level. This saturation value persists over a significant portion of the remaining fluence range until further irradiation-induced structural changes in the graphite (notably pore generation at and beyond the dimensional change turnaround fluence) cause a secondary reduction in thermal conductivity (decline). As the irradiation temperature increases, thermal annealing of irradiation damage causes the reduction in thermal conductivity to be reduced. For example, at $300^{\circ} \mathrm{C}\left(572^{\circ} \mathrm{F}\right)$, graphite exposed to a fast fluence of about $5 \times 10^{21} \mathrm{n} / \mathrm{cm}^{2}(\mathrm{EDN})$ will have a thermal conductivity of about $10 \%$ that of unirradiated graphite. Graphite exposed to a fast fluence of $5 \times 10^{21} \mathrm{n} / \mathrm{cm}^{2}(\mathrm{EDN})$ at $600^{\circ} \mathrm{C}\left(1112^{\circ} \mathrm{F}\right)$ will only drop to about $40 \%$ of its unirradiated value. Typical irradiation-induced thermal conductivity changes in reactor graphite are illustrated in Figure B-5. The stages in these changes are summarized in Table B-1.

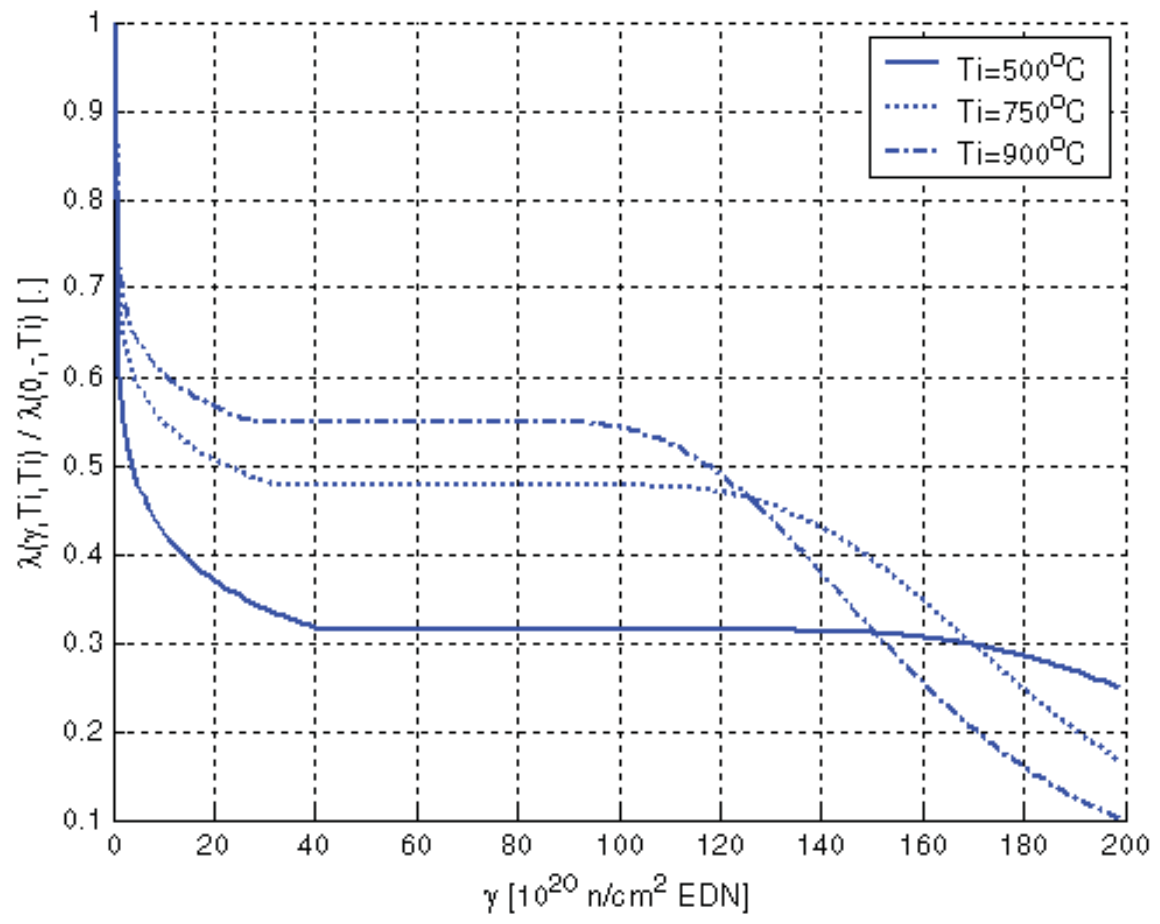

Figure B-5. Typical irradiation-induced thermal conductivity changes in reactor graphite.

Table B-1. Stages of change in thermal conductivity because of irradiation.

\begin{tabular}{|l|l|}
\hline \multicolumn{1}{|c|}{ Phase } & \multicolumn{1}{c|}{ Description } \\
\hline Nonirradiated (virgin material) & The material is in its virgin state. \\
\hline $\begin{array}{l}\text { Initial breakdown in thermal } \\
\text { conductivity (low dose) }\end{array}$ & $\begin{array}{l}\text { Degradation by neutron-induced point defects in the crystal lattice. } \\
\text { The conductivity drops steeply with dose in this stage. }\end{array}$ \\
\hline Saturation (intermediate dose) & $\begin{array}{l}\text { Thermal annealing counteracts the neutron-induced defect } \\
\text { formation; the thermal conductivity degradation reaches a steady } \\
\text { state value where the generation and annealing of single (point) } \\
\text { defects occur at an equal rate. The level at which the thermal } \\
\text { conductivity saturates is a function of the temperature at which the } \\
\text { irradiation takes place. }\end{array}$ \\
\hline $\begin{array}{l}\text { Secondary breakdown in thermal } \\
\text { conductivity (high dose) }\end{array}$ & $\begin{array}{l}\text { Large volumetric expansion caused by pore generation within the } \\
\text { material causes a secondary breakdown in the thermal conductivity. }\end{array}$ \\
\hline
\end{tabular}


It has been established that the saturation thermal conductivity level is practically independent of graphite grade when the relative thermal conductivity change (\% based) is considered. This is important from a design perspective. Additionally, the thermal conductivity at the irradiation temperature is always higher for the operational temperatures of interest than the value measured at room temperature, a factor which must be accounted for in design. It may be further considered that there is some recovery in thermal conductivity when irradiated graphite is heated past its irradiation temperature (normal operation temperature in this instance). This may present some margin for heat transfer under accident conditions. However, this latter aspect would require verification based on the specific operating conditions of the HTGR concept.

\section{Specific Heat Capacity}

Specific heat capacity, which is the energy required to increase the temperature of a unit mass of a material by unit temperature, is an important property of graphite in HTGR applications. The relatively high specific heat capacity of graphite tends to moderate transients and enhances its capability to store thermal energy during the initial stages of LBEs involving conduction cooldown. This, in turn, is a factor in limiting temperatures of the fuel and metallic components to acceptable levels. Extensive studies of nuclear graphite grades have shown that heat capacity increases with temperature and it does not vary significantly among graphite grades. Measurements on past grades and present candidates confirm the nonvariability of this property between the different grades and its correlation with theoretically calculated specific heat capacity for graphite (see ASTM C781 for example). More importantly, indications are that the specific heat of irradiated graphite varies little from the virgin value (over the applicable temperature range), a factor which is very useful from a practical design perspective, particularly when assessing conduction cooldown heat transfer conditions.

\section{Emissivity}

Another important physical property during postulated accident conditions is emissivity, a measure of a material's ability to transport heat via radiation. Thermal radiation is an important thermal energy transport mechanism for LBEs involving conduction cooldown, particularly under depressurized conditions. During such events, heat must be transferred from the region of the core outward, through and between the graphite blocks and, then to the core barrel. Emissivity is defined as the ratio of energy radiated by the material to that radiated by a black body $($ emissivity $=1)$ at the same temperature. The emissivity of a given graphite will depend on its surface condition and the environmental temperature. Generally, the duller or blacker the material, the closer its emissivity is to that of a black body. Typical emissivity values for carbon or graphite range between 0.8 and 0.9 . Extensive tests of previous and current grades show that machined nuclear grade graphite has an emissivity of about 0.85 at elevated temperatures. The emissivity of nuclear graphite is not expected to change significantly with irradiation.

\section{Thermal Expansion Changes with Neutron Irradiation}

The coefficient of thermal expansion (CTE) of graphite is an important consideration in the setting of graphite component dimensional tolerances during both normal operation and accident conditions. This property must be assessed in conjunction with irradiation-induced dimensional changes. Graphite CTE is determined by a combination of the in-crystal CTE, bearing in mind its highly anisotropic nature, and ex-crystal microstructural features such as Mrozowski cracks, which are ultra-fine, interlamellar cracks that lie between crystalline regions of filler grains. Other characteristics, such as the type of coke and, to a lesser degree, grain size, forming method, etc. also play a role in determining the bulk CTE. The Mrozowski cracks play a dominant role in controlling the thermal expansion characteristics of the bulk graphite by accommodating intercrystalline expansion within the bulk, thus contributing to the very low CTE of polycrystalline graphite. This expansion mechanism gives graphite good thermal shock resistance, allowing large crystal expansion in the direction of cracking without leading to intercrystalline 
cracking. Nonetheless, the bulk CTE is also strongly influenced by the filler coke CTE and, in this respect, the selection of raw material for the candidate grade requires consideration. There is a competing requirement for relatively low bulk CTE to reduce secondary operational stresses in graphite components (thermal stress) while ensuring sufficient isotropy in the bulk material. ASTM D7219-08 makes specific recommendations regarding the allowable coke CTE range for graphite components exposed to a high fluence regime. The temperature-dependent CTE of reactor grades (past and present) at high temperature has been extensively characterized, and the available data are deemed sufficient for the design of unirradiated graphite components.

More significantly, the graphite CTE will first increase slightly under irradiation, reach a peak, and then drop well below the unirradiated value as the fast neutron fluence increases as shown in Figure B-6. The extent of the peak and irradiation-induced drop in CTE varies with irradiation temperature, tending towards a lower peak value and more rapid drop to values well below the initial value as irradiation temperature increases. While the change in graphite CTE with irradiation has been extensively characterized for a range of graphites (past and present), additional data will be required for the HTGR design conditions and grade of choice. The above mentioned factors will need to be taken into account when determining the projected coefficient of thermal expansion of the selected graphite.

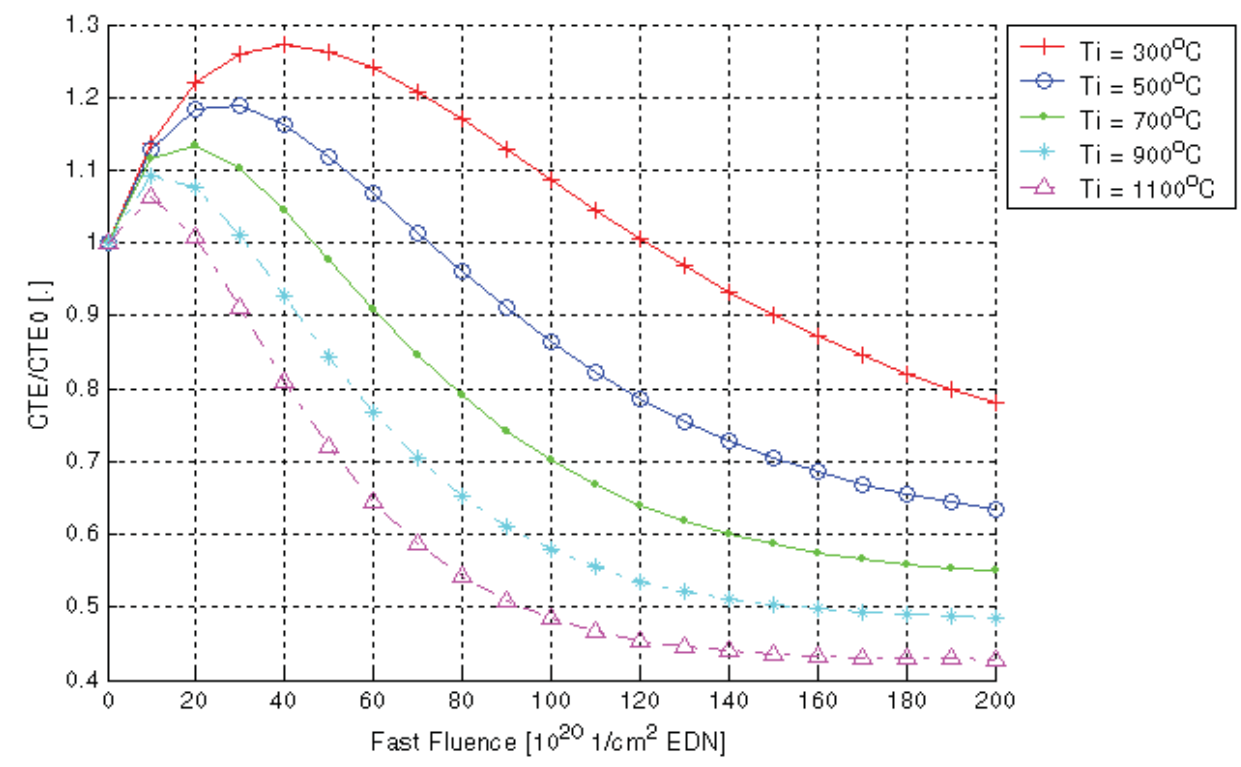

Figure B-6. Typical changes in linear coefficient of thermal expansion because of irradiation.

\section{Strength and Elastic Modulus}

Graphite strength is the most significant property for ensuring the structural integrity of the core components. Graphite is a good choice for core components because its strength increases with temperature up to about $2000^{\circ} \mathrm{C}\left(3632^{\circ} \mathrm{F}\right)$, well beyond the projected peak core temperatures that would be seen under accident conditions. This increase in strength with temperature is largely because of the closure of fine lamellar (Mrozowski) cracks and additional microcracks that form during cooldown from the extreme production (graphitization) temperatures. 
The strength of graphite, when subjected to neutron irradiation, increases over an extensive portion of the total fluence range as shown in Figure B-7. The strength increase takes place in two stages. At very low fluences, there is an initial rise in strength that is attributed to dislocation pinning at irradiation-induced lattice defect sites. This effect has largely saturated at doses $>1 \mathrm{dpa}$ $\left(\sim 7.6 \times 10^{20} \mathrm{n} \bullet \mathrm{cm}^{-2} \mathrm{EDN}\right)$. Above $\sim 1 \mathrm{dpa}$, a more gradual increase in strength occurs. These further increases in strength are more the result of interlamellar and microcrack closure as a result of dimensional changes within the graphite crystallites themselves. (The curves in Figure B-6, as well as Figure B-7, are based on immediate pinning of the crystal structure and, thus, do not show the initial increase.) A strength reduction follows the period of strength increase, with this effect being quite closely matched with the turnaround point in the volumetric change behavior. At this point, the mechanical properties of the graphite begin to decrease with the generation of internal porosity. The compressive strength of graphite also first increases and then decreases with irradiation in a manner similar to the tensile strength. These changes are caused by the same mechanisms described above.

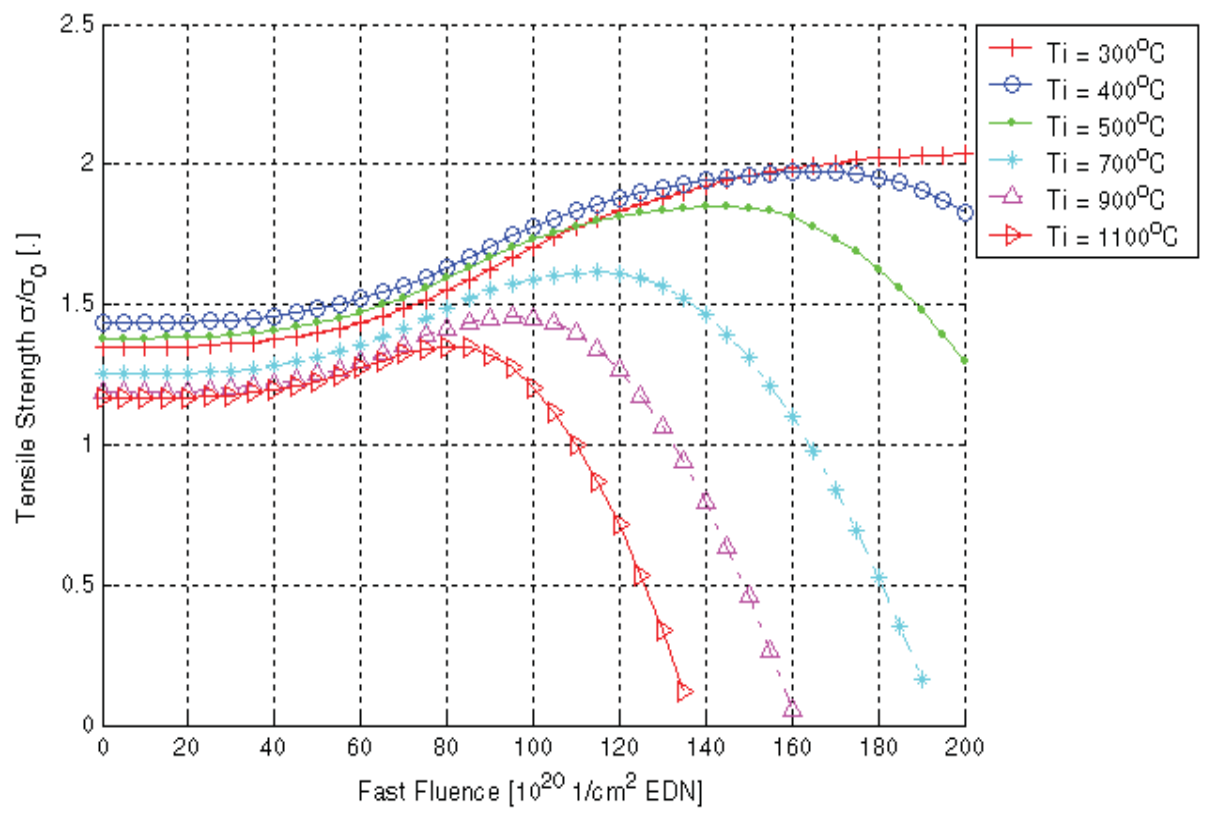

Figure B-7. Typical irradiation-induced strength changes in reactor graphite.

The Young's modulus change with irradiation (Figure B-8) closely resembles the progression of strength change with irradiation. Both increase to a peak value and decline thereafter, and tend to saturate at a value close to the original value. As with other properties described earlier, the progression in both strength and elastic modulus change with irradiation is strongly dependent of irradiation temperature.

\section{Irradiation Creep}

Graphite experiences creep deformation under neutron irradiation and stress at temperatures below $1600^{\circ} \mathrm{C}$, where thermal creep is normally negligible. The phenomenon of irradiation creep in graphite has been widely studied because of its significance to the operation of graphite moderated fission reactors. The beneficial effect of irradiation creep is to reduce irradiation induced stresses in graphite moderators, thus allowing acceptable service lifetimes to be achieved. 


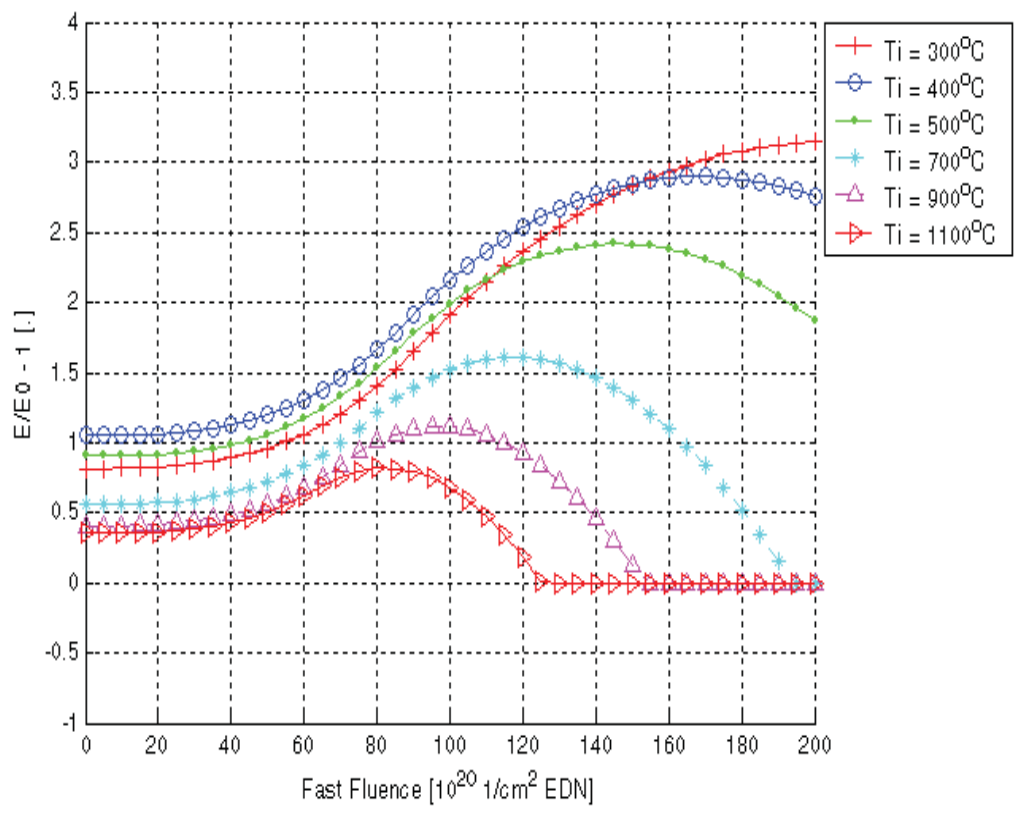

Figure B-8. Typical irradiation-induced modulus changes in reactor graphite. 


\section{Appendix C}

\section{NRC RAI Letter Number 004 (Request for Additional Information No.'s 5901, 5898, 5800.5899, and 5900) dated July 25, 2011}




\title{
Appendix C NRC RAI Letter Number 004 (Request for Additional Information No.'s 5901, 5898, 5800.5899, and 5900) dated July 25, 2011
}

\author{
July 25, 2011
}

Mr. Jim Kinsey

Director, Regulatory Affairs

Next Generation Nuclear Plant Project

Idaho National Laboratory

P.O. Box 1625

2525 North Fremont Ave

Idaho Falls, ID 83415

SUBJECT: NEXT GENERATION NUCLEAR PLANT - REQUEST FOR ADDITIONAL INFORMATION LETTER NO. 004 REGARDING HIGH TEMPERATURE MATERIALS

Dear Mr. Kinsey:

On June 25, 2010, the Idaho National Laboratory (INL), Next Generation Nuclear Plant (NGNP) Project, submitted INL/EXT-09-17187, "NGNP [Next Generation Nuclear Plant] High

Temperature Materials White Paper." INL requested Nuclear Regulatory Commission (NRC) staff review of these documents to facilitate resolution of key design, safety, and licensing issues for the NGNP project.

The NRC staff has identified that additional information is needed to complete its assessment of the white paper. The enclosures to this letter provide requests for additional information addressing each of the major topic areas described in the white paper.

Should you have questions, please contact me at (301) 415-1470 or Joseph.Williams@nrc.gov.

Sincerely,

IRA/

Joseph F. Williams, Sr. Project Manager Advanced Reactors Branch 1

Advanced Reactor Program Office of New Reactors

Project No: 0748

Enclosures:

1. RAl 5901: General questions

2. RAl 5898: High temperature metals questions

3. RAI 5800: Graphite questions

4. RAI 5899: Carbon composite questions

5. RAI 5900: Ceramic insulation questions 
Mr. Jim Kinsey

Director, Regulatory Affairs

Next Generation Nuclear Plant Project

Idaho National Laboratory

P.O. Box 1625

2525 North Fremont Ave

Idaho Falls, ID 83415

\section{SUBJECT: NEXT GENERATION NUCLEAR PLANT - REQUEST FOR ADDITIONAL INFORMATION LETTER NO. 004 REGARDING HIGH TEMPERATURE MATERIALS}

Dear Mr. Kinsey:

On June 25, 2010, the Idaho National Laboratory (INL), Next Generation Nuclear Plant (NGNP) Project, submitted INL/EXT-09-17187, "NGNP [Next Generation Nuclear Plant] High Temperature Materials White Paper." INL requested Nuclear Regulatory Commission (NRC) staff review of these documents to facilitate resolution of key design, safety, and licensing issues for the NGNP project.

The NRC staff has identified that additional information is needed to complete its assessment of the white paper. The enclosures to this letter provide requests for additional information addressing each of the major topic areas described in the white paper.

Should you have questions, please contact me at (301) 415-1470 or Joseph.Williams@nrc.gov.

Sincerely

/RA/

Joseph F. Williams, Sr. Project Manager Advanced Reactors Branch 1

Advanced Reactor Program

Office of New Reactors

Project No.: 0748

Enclosures:

1. RAI 5901: General questions

2. RAI 5898: High temperature metals questions

3. RAI 5800: Graphite questions

4. RAI 5899: Carbon composite questions

5. RAI 5900: Ceramic insulation questions

DISTRIBUTION:

RidsNroArp NRO_ARP_ARB1

ADAMS Accession Number: ML112030174- pkg.

\begin{tabular}{|l|l|l|}
\multicolumn{2}{l|}{ NRO-002 } \\
\hline OFFICE & NRO/ARP/ARB1 & NRO/ARPIARB1 \\
\hline NAME & JWilliams & TKevern \\
\hline DATE & 7/25/2011 & 7/25/2011 \\
\hline
\end{tabular}

*Approval captured electronically in the electronic RAI system.

OFFICIAL RECORD COPY 
Request for Additional Information No. 5901 Revision 0

$7 / 20 / 2011$

Next Generation Nuclear Plant Pre-Application Activities

Department of Energy - Idaho National Laboratory

Docket No. PROJ 0748

SRP Section: NGNP GEN - HTM General

Application Section: General

QUESTIONS for Advanced Reactor Branch 1 (ARB1)

NGNP GEN -1

GEN-1. What are the effects of degradation and failure of sealants, gaskets, attachments to high temperature metal piping, etc. degradation, debris on high temperature metallic materials, graphite, and $\mathrm{C}-\mathrm{C}$ and other composite materials?

\section{NGNP GEN -2}

GEN-2. What are the effects of insulation lift-off and consequent debris generation on high temperature metallic materials, graphite, and $\mathrm{C}-\mathrm{C}$ and other composite materials?

\section{NGNP GEN -3}

GEN-3. What type of specific information exists or needed to address aging management issues tailored to specific postulated or known degradation mechanism? This information is especially important to select the appropriate inspection methods, periods, and examination area.

\section{NGNP GEN -4}

GEN-4. The white paper does not address decommissioning issues related to NGNP HTGR graphite core components and other ceramic and carbon-carbon composites. Provide information regarding decommissioning of these materials.

\section{NGNP GEN -5}

GEN-5. In LWRs, the integrity of the reactor coolant pressure boundary is assured through a defense-in-depth approach, such limits on allowable identified reactor coolant leakage. Leakage through the pressure boundary is not allowed during power production. How will such defense-in-depth approach be applied to metallic pressure boundary components for the NGNP? In other words, how will GDC 30 be met?

\section{NGNP GEN -6}


GEN-6. The staff is aware of design data need (DDN) documents, which were generated by Westinghouse, AREVA, and GA for graphite. These vendors had analyzed the graphite PIRT results and their conceptual designs and identified several topical areas where more information is needed. This white paper does not provide any information on these documents, DOE's evaluation of these documents, and provide a nexus between the potential vendors indentified DDNs and DOE-INL's research which would supposedly provide such data to the designer. Provide a discussion of specific data needs identified by these DDNs. The staff is particularly interested in graphite spalling, especially during the later stages of reactor operation.

\section{NGNP GEN -7}

GEN-7. In Section 2.8, it is stated that "Further development of the regulatory infrastructure will be desirable in support of follow-on commercial plants." However, there does not appear to be any further discussion within the white paper describing what infrastructure development is considered desirable to support a review of a HTGR commercial plant license application. Given that this regulatory infrastructure development could be beneficial for NGNP licensing, provide additional discussion of specific needs

\section{NGNP GEN -8}

GEN-8. In general, references have not been provided in the white paper. The staff needs corresponding technical citations for conducting an informed review. Provide a comprehensive list of references, and incorporate this information into any future revision of the white paper. 
Request for Additional Information No. 5898 Revision 0

$7 / 20 / 2011$

Next Generation Nuclear Plant Pre-Application Activities

Department of Energy - Idaho National Laboratory

Docket No. PROJ 0748

SRP Section: NGNP HTM - High Temperature Metals

Application Section: High Temperature Metals

\section{QUESTIONS for Advanced Reactor Branch 1 (ARB1)}

\section{NGNP HTM-1}

HTM-1. In Section 3.2.1.2, it is stated that "However, given the present extensive database and the large material thicknesses involved, oxidation effects are not expected to be significant, making the need for new data unlikely." What information is currently available on the "internal oxidation", and oxidation of grain boundaries, in addition to surface oxidation for these materials? How are the important performance-related properties affected by potential long-term internal oxidation?

\section{NGNP HTM-2}

HTM-2. Regarding the Section 3.2.1.3 discussion of experience with SA-508/533, what information is available on the potential carburization due to the presence of potential carbon/graphite dust in the HTGR?

\section{NGNP HTM-3}

HTM-3. In Section 3.2.2.2, it is stated that "Material selection and qualification for the hot duct liner is based mainly on high temperature strength, corrosion resistance, and time dependent stress effects such as creep and stress rupture." What technical considerations would be required with regard to erosion and erosion/corrosion effects due to potential carbonaceous dust and insulation debris flowing along with the helium coolant? What flow-induced vibration effects should be considered for the hot duct liner? Why is not the cross "vessel" not a duct? Will this cross "vessel" also contain hot duct liner?

\section{NGNP HTM-4}

HTM-4. Section 3.2.2: For the use of Alloy $800 \mathrm{H}$ as core support component, what technical issues need to be addressed or known to have been resolved with respect to the effects of oxidation and erosion, and erosion/corrosion reducing the potential load bearing capacity in shear?

\section{NGNP HTM-5}


HTM-5. In Section 3.2.2.2 it is stated that "Studies sponsored by ASME Standards and Technology, LLC have determined that there is currently sufficient information available to extend Code qualification to $850^{\circ} \mathrm{C}$ for a maximum use temperature for 500,000 hours design life for lower temperatures." What information is available for Alloy $800 \mathrm{H}$

containing potential cracks, especially when used as hot-gas-duct liner? Are there crack growth rate data available under the conditions of expected design loads and service environments to provide assurance that potential crack growth would be within the tolerance limits, if any?

\section{NGNP HTM-6}

HTM-6. In Section 3.2.2.2, a discussion has been provided on the bimetallic weld between the Alloy $800 \mathrm{H}$ tubing and ferritic steel tubing. It is mentioned that "However, special consideration will need to be given to corrosion questions, especially where alternating wet-dry conditions might exist." It is not clear what this special consideration is. From the LWR operating experience, the staff might potentially expect data on potential stress corrosion cracking (SCC) as well as material loss due to corrosion, and the effects of wet-dry cycling on SCC.

\section{NGNP HTM-7}

HTM-7. In the Section 3.2.2.2 discussion of the hot duct liner, it is stated that "the hot duct liner will be under minimal stress so that the high temperature strength and time dependent stress effects that drive the $760^{\circ} \mathrm{C}\left(1400^{\circ} \mathrm{F}\right)$ limit may not directly apply. Further, as already noted earlier, data already available would support operation at even higher temperatures. During a pressurized conduction cool down event, the hot duct liner may exceed the current code temperature and, if so, would require further evaluation at these high temperatures for qualification." The staff notes that because of thermal transients, the potential for thermal cracking of the hot duct liner cannot be ruled out, especially in regions where changes in cross section geometry occur. What is the effect of the presence of pre-existing or operation-induced cracks on these available data?

\section{NGNP HTM-8}

HTM-8. In Section 3.2.2.2, it is stated that "At temperatures below $900^{\circ} \mathrm{C}\left(1652^{\circ} \mathrm{F}\right)$, extended operation studies in impure helium gas have shown that Alloy $800 \mathrm{H}$ develops chromia scales along with significant internal oxidation of aluminum and subsurface depletion of $\mathrm{Cr}$. However, it must be noted that the corrosion behavior is quite sensitive to levels and ratios of active impurity species and this must be considered in the evaluation process."

The formation of corrosion-induced scale (oxidation product of the corrosion reaction) could be a potential regulatory concern. The adhesion characteristics of the heavy metal oxide scale could potentially dictate the potential for peeling of such scales over time due to a variety of reasons including the effect of the flowing coolant. Such peeling could result in the coolant gas acting as the carrier of the activated heavy metal 
radionuclide in the stream. What information is currently known or planned to be investigated in this regard?

\section{NGNP HTM-9}

HTM-9. In Section 3.2.2.2, a statement is made that "Measurements of emissivity will be required after oxidation in air and helium to determine the most appropriate values." Similar statements could be found throughout the white paper for other properties and situations. As currently written, the white paper does not provide a roadmap to access these needed information.

Provide to the staff the status of addressing these information needs, including description of the programs and organizations that are addressing these needs. Also, discuss how the results are expected to inform the design, or confirm the existing design concepts.

\section{NGNP HTM-10}

HTM-10. The discussion in Section 3.2.2.3 describes operating experience with Alloy $800 \mathrm{H}$ during operation of various HTGRs around the world. However, it is not clear to the staff that the history described is at full designed power output of the facilities. Provide additional information regarding the operational histories and how that experience is expected to be applicable to NGNP. What limitations are involved in extrapolating this operating experience to NGNP?

\section{NGNP HTM-11}

HTM-11. Section 3.2.2.3 states that "Extensive studies evaluating the effects of operating temperature on the performance of Alloy $800 \mathrm{H}$ have been performed." However, it is not clear if these studies were performed at the NGNP expected loads and atmosphere. Describe how these data will be extrapolated for the HTGR conditions, especially over long periods of reactor operation.

\section{NGNP HTM-12}

HTM-12. Section 3.2.2.4 states that, for Alloy $800 \mathrm{H}$ "..., the [ASME] code does not address other key requirements of the design of these components, such as the emissivity, corrosion resistance, thermal aging, and irradiation effects." What efforts are currently underway in the ASME Code development for this apparent deficiency? How does the NGNP project plan to address this deficiency?

\section{NGNP HTM-13}

HTM-13. In Section 3.2.3.2, it is stated that "An alternative under consideration is using a high temperature composite for the control rods." However, no information was provided in the white paper on this topic. Provide additional discussion of the materials being considered so that the staff can compare and evaluate the options. 


\section{NGNP HTM-14}

HTM-14. In Section 3.2.3.1, it is stated that "However, all of the components being considered are composed of relatively thick sections, so that the overall effects of corrosion are likely to be minimal." Given the absence of data on internal oxidation and its effect on significant properties, the selection of "relatively thick sections" may or may not be effective in mitigating progressive degradation due to potential (stress corrosion/fatigue) cracking. Provide additional justification for the claimed expected effect of corrosion.

\section{NGNP HTM-15}

HTM-15. In Section 3.2.3.3 states that "Testing of rupture time variation with applied stress showed that Alloy $\mathrm{X}$ would not rupture at $7 \mathrm{MPa}(1000 \mathrm{psi})$ and $871^{\circ} \mathrm{C}\left(1600^{\circ} \mathrm{F}\right)$ during the 60 -year life of the plant. Test data also indicated that the creep rate at $871^{\circ} \mathrm{C}$ $\left(1600^{\circ} \mathrm{F}\right)$ would be insignificant. These studies may later form part of the foundation for ASME allowing use of Alloy X at up to $871^{\circ} \mathrm{C}\left(1600^{\circ} \mathrm{F}\right)$ during normal operation."

Considering the possibility of micro and macro cracks after some duration of reactor operation, what creep and rupture data exist to confirm the applicability of such data in the presence of cracks?

\section{NGNP HTM-16}

HTM-16. Section 3.2.3.4 states that "The ASME Code does not currently address key requirements of the design of Alloy X/XR components such as corrosion resistance, thermal aging effects, irradiation effects, high temperature strength, and time dependent stress effects such as creep and stress rupture, so the qualification of these materials will require further evaluation." Does NGNP research address these evaluations? If so, what is the status of these evaluations?

\section{NGNP HTM-17}

HTM-17. Section 3.2.4.2 does not list fatigue as one of the important considerations for modified $9 \mathrm{Cr}-1 \mathrm{Mo}$ alloy as a material for core support structure. However, limited information is provided in Section 3.2.4.3 on this issue. Provide additional information regarding the potential limitations involved in extrapolation of these limited data to 60 year behavior

\section{NGNP HTM-18}

HTM-18. In section 3.2.5, and other places throughout the white paper, a 60 -year design has been proposed for several components. Reference is also made for data availability for definite time periods, such as, for example, $300,000 \mathrm{hr}$. How many hours do you anticipate that the 60 year life represents? 


\section{NGNP HTM-19}

HTM-19. There are apparently contradictory statements in Section 3.2.4.2. While comparing 300,000 hour data availability, a statement is made that "Whether this [behavior] remains true for the HTGR 60-year design life will be evaluated during qualification." However, while considering thermal aging, data are available for only 75,000 hours, while a statement is made "Yield strength, ultimate tensile strength, and ductility are not significantly affected. Therefore, thermal aging of this material is not expected to be an issue." The staff needs some clarification on this apparent discrepancy in concepts.

\section{NGNP HTM-20}

HTM-20. Section 3.2.4.2 states that "No particular corrosion concerns are expected for Modified $9 \mathrm{Cr}-1 \mathrm{Mo}$ at the service temperatures of the HTGR." Provide justification for this statement, including possible effects of internal oxidation, and describing any research to evaluate this aspect for $9 \mathrm{Cr}-1$ Mo alloy.

\section{NGNP HTM-21}

HTM-21. As mentioned in Section 3.2.4.3, the use of $9 \mathrm{Cr}-1 \mathrm{Mo}$ alloy in the fossil fuel industry has had qualified success due to the lack and/or implementation of quality assurance in the production of the components made from this material. It is stated that "Special care must be taken during processing, fabrication, and installation to create and maintain the proper microstructure to obtain the desired material properties. It is not currently possible to insure that the steel is properly heat treated through-thickness by means of nondestructive examination. The necessity for pre-weld and post-weld heat treatment makes onsite fabrication of components from this steel problematic." Provide a discussion of how these issues will be addressed in the intended nuclear application.

\section{NGNP HTM-22}

HTM-22. At the end of Section 3.2.4.3 it is stated that "Fracture toughness is good and relatively constant with a KJQ value of $\sim 275 \mathrm{MPa}[\mathrm{m}]^{1 / 2}$ from room temperature through $200^{\circ} \mathrm{C}\left(392^{\circ} \mathrm{F}\right)$; irradiation to $3 \mathrm{dpa}$ reduces $\mathrm{KJQ}$ to $\sim 100 \mathrm{MPa}[\mathrm{m}]^{1 / 2}$, but this is still a substantial value." This statement is potentially arguable since the expected operating temperatures are potentially much higher. In addition, "substantial" is a relative and subjective term, so the staff is unable to ascertain what the minimum value should be required for a given level of confidence in component performance. Therefore, provide additional discussion addressing these issues.

\section{NGNP HTM-23}

HTM-23. In section 3.2.5.2, fatigue is not listed as one of the important considerations for $2.25 \mathrm{Cr}-1 \mathrm{Mo}$ alloy as a material for cold-end steam generator tubing. Provide justification for not including fatigue in these considerations. 


\section{NGNP HTM-24}

HTM-24. In the Section 3.2.5.2 discussion of the use of 2.25Cr-1Mo alloy for cold-end steam generator tubing, it is stated that "Thermal conductivity is integral to assessing the ability of tubing to transfer heat efficiently from the primary helium gas to the secondary side water. Measurements will be required after oxidation in air and helium to determine whether degradation of heat transfer properties will need to be taken into account." However, it was also stated in Section 3.2.5.1 that such tubing "will be exposed to helium and water during normal operation". Provide a rationale as to why such tests are not required after oxidation in water environment.

\section{NGNP HTM-25}

HTM-25. In Section 3.2.5.2, regarding the formation of protective layer for continued corrosion possibility, it is stated that "In the HTGR cold-end steam generator tubing, the water temperature will be about $400^{\circ} \mathrm{C}\left(752^{\circ} \mathrm{F}\right)$, which should cause the formation of a protective layer of $\mathrm{Fe} 3 \mathrm{O} 4$." Provide information on the adhesion capacity and lift-off characteristics of this protective (apparently in-situ formed) coating for the NGNP operating environment.

\section{NGNP HTM-26}

HTM-26. In Section 3.2.5.3, and in other places in the white paper, it is stated that "The Japanese HTTR has operated for over 10 years." However, this statement is vague, and does not adequately characterize the HTTR operating experience for evaluation of material performance. Provide additional information regarding the HTTR operating history, including actual years of full design power reactor operation, the cumulative fluence (dose), and the process parameters (i.e., temperatures, pressures, chemical environment) experienced by the various materials and components referenced in the white paper to provide some meaningful comparison.

\section{NGNP HTM-27}

HTM-27. In Section 3.2.6.2, fatigue is not listed as one of the important considerations for $316 \mathrm{H}$ stainless steel as a material for core barrel assembly. Provide justification for not including fatigue in these considerations.

\section{NGNP HTM-28}

HTM-28. A potential issue for materials used for hot duct liner is the possible chemical reaction with the material it is adjacent to it. For example, if the hot duct design involves tube-in-tube configuration with the inner tube consisting of the so-called "hot duct liner" and the outer tube of material not experiencing very high temperature with ceramic insulation in-between, then potentially two issues could be envisioned. First, in areas where the ceramic insulation is not in contact with the inner liner, those areas would not dissipate heat via conduction as readily as those areas where contact with the ceramic insulation exists, which could lead to the formation of hot spots in the inner liner. Over time, creep could occur due to material softening. Second, in areas where contact with 
ceramic insulation occurs, the constituents of the ceramic insulation could thermodynamically react with the liner material resulting in corrosion, pitting, cracking, and eventually stress corrosion cracking. If a crack breaks through the liner, the ceramic insulation could be loosened due to high coolant flow and ceramic insulation could be carried as debris with the coolant, which could also lead to erosion, erosion corrosion of the liner and other contacting components. Provide information on how these potential issues are addressed in NGNP research and design.

\section{NGNP HTM-29}

HTM-29. In Section 3.2.2.4 and other locations, reference is made to German Standard KTA 3221. For example, Section 3.2.24 states that "German Standard KTA 3221 allows use of Alloy $800 \mathrm{H}$ up to $1000^{\circ} \mathrm{C}\left(1832^{\circ} \mathrm{F}\right)$." However, the rationale for this allowance does not appear to have been provided in the text in the white paper. Section 3.2.2.4 states that "An ASME and DOE joint effort is currently underway to obtain the basis of the KTA 3221 draft standard, including information on the quality assurance program under which the data were collected." Provide additional information which to describe the basis for the KTA 3221 standard and justify its applicability to NGNP.

\section{NGNP HTM-30}

HTM-30. Section 4.1.4 states that "In order for a metallic material and, more generally, any structural material to be considered for use in the HTGR, it must be qualified for the appropriate service conditions and environment. In this usage, qualification implies that the material has been evaluated, based on a set of experimental data sufficient to reliably describe its behavior, and found to be able to meet the requirements placed upon it by the design for conditions of operation." Please state how the Code Cases mentioned in Section 4.1.3, (Code Case N-201-5 and Section III, Subsection NH) will assist in qualifying these metallic structural materials (as indicated in Section 5.1). 
Request for Additional Information No. 5800 Revision 0

$7 / 20 / 2011$

Next Generation Nuclear Plant Pre-Application Activities

Department of Energy - Idaho National Laboratory

Docket No. PROJ 0748

SRP Section: NGNP G - Graphite

Application Section: Graphite

QUESTIONS for Advanced Reactor Branch 1 (ARB1)

NGNP G-1

G-1. Section 3.1. Are there data or will data be generated for the compressive strength of graphite as functions of cumulative dose and temperature? How will such data be used in design?

NGNP G-2

[DELETED]

NGNP G-3

[DELETED]

\section{NGNP G-4}

G-4. The first paragraph of Section 3.3 briefly outlines graphite qualification testing. The completeness of the oxidation data may be questionable since in-pore diffusion data may not be available for reactor operating conditions. The significance of the diffusion characteristics as a function of oxidation depth needs to be established to understand the uncertainties in the bulk oxidation data, obtained in the kinetics region alone. How will planned graphite qualification testing ensure adequate understanding of oxidation?

\section{NGNP G-5}

G-5. Section 3.3.1 states that the fuel cycle for a prismatic reactor is expected to be about 18 months long, with about half of the fuel elements replaced at the end of that cycle. Since the fuel compacts are packed inside the fuel element block, does this mean that the fuel element blocks are replaced at 18-month intervals? Are the fuel "elements" the same as fuel "blocks?" What experience exists currently in replacing fuel blocks in a safe manner, without affecting the structural integrity of adjacent blocks or other core components, which could potentially be more brittle due to irradiation hardening and damage? During the lifetime contemplated for the reactor, how will the irradiated blocks be stored to ensure their long term integrity? What industry demonstrated methods of safe disposition currently exist for these irradiated blocks? 


\section{NGNP G-6}

G-6. Section 3.3.1 states that inner reflector elements will be replaced about every 6 years: What is the technical basis for replacement at 6-year intervals? What inservice inspections and evaluations are planned to ensure any potential degradation during this 6-year interval is detected and understood so that the elements meet design requirements? Is it anticipated that reflector blocks may be returned to the reactor? If so, what criteria, including internal cracking, will be used to justify their continued service?

\section{NGNP G-7}

G-7. Section 3.3.1. Describe the operating experience lessons learned from reflect block replacement in gas reactors. For example, how does the potential irradiationinducedbrittleness affect safe removal of the block without damage to the core, such as impact of falling chunks from replacement blocks, sidewall friction to adjacent blocks, etc.?

\section{NGNP G-8}

G-8. Section 3.3.1 describes projected graphite component peak temperature during accident conditions as approximately $1100^{\circ} \mathrm{C}$ for pebble bed design and around $1400^{\circ} \mathrm{C}$ for prismatic design. What dataexist for thermal conductivity and irradiation-induced expansion and contraction at these temperatures for short duration (pulse) exposure? Discuss the effect of these factors on the NGNP safety case, especially for the degradation of metallic components due to sudden creep into the tertiary regime potentially resulting in rupture of pressure boundary and release of nuclide inventory?

\section{NGNP G-9}

\section{G-9. [DELETED]}

NGNP G-10

G-10. Section 3.3.2 states that, "Until the graphite code is published and accepted by the NRC, graphite material selection will focus on existing design and operating experience with both past and currently available grades of reactor graphite." Provide a description of any operating experience for currently available grades of reactor graphite. Describe any regulatory body-certified design experience for currently available grades of reactor graphite.

\section{NGNP G-11}

G-11. Based on information provided in 3.3.2, it appears that the technical basis for graphite selection is being developed for currently available grades of reactor graphite. If this understanding is correct, what basis is used for the NGNP graphite core component design? 
NGNP G-12

G-12. Section 3.3.2 states that, "Fabrication experience and technical maturity are additional selection criteria that must be considered." Explain how these aspects will be considered, and what criteria will be used, including their technical basis.

\section{NGNP G-13}

G-13. Section 3.3.3 states, "A key requirement in prismatic designs is the need for fine grained graphite, with its correspondingly higher strength, for the fuel elements to ensure an adequate number of grains across the thickness of the graphite webs between the fuel compacts and the coolant holes. Relatively high thermal stresses are generated in the thin graphite ligaments between the coolant and fuel channels in these elements. Ideally, a ligament should be no thinner than 10-times the maximum grain size." Describe how this statement is guided by design code?

NGNP G-14

G-14. In Section 3.3.3, it is stated that, 'The little available high fluence data for IG-110 at $600^{\circ} \mathrm{C}\left(1112^{\circ} \mathrm{F}\right)$ indicates similar dimensional change behavior similar to that of historic coarser grained materials, such as ATR-2E. Irradiated properties data for IG-110 tends to be presented without directional orientation on the basis that the material is isotropic; however, this is an aspect that needs some verification, since unirradiated properties measured for IG-110 in different orthogonal directions can show some variation." Provide information on the behavior of these materials (for comparison verification) for the NGNP operating conditions of temperature, fluence, atmosphere (coolant chemistry) and residence time. What information is available for these materials under accident conditions?

\section{NGNP G-15}

G-15. In Section 3.3.3, on page 31, the last paragraph contains a discussion on the manufacturability of graphite core components, dictated by the component size. For comparison purposes, provide relative size information for the various designs cited in this white paper, compared to the contemplated NGNP HTGR.

NGNP G-16

G-16. Section 3.3.4, Table 2 lists the properties of various graphite grades. Are these average properties? Are these properties originating from the manufacturer's data? Do they originate from the same type of fabrication and sources of raw materials as those being currently investigated at INL? Provide a discussion of how variation in material properties affect the NGNP design.

NGNP G-17 
G-17. In Section 3.3.4, it is stated that, "More anisotropic grades not precisely meeting the D7219-08 degree of isotropy requirement may still be applied in HTGR applications, provided due diligence is paid to material behavior under irradiation, operating conditions (fluence-temperature), and design considerations. These grades can be applied to lower fluence regions as recommended by ASTM D7301-08, which would typically apply to the outer reflector regions." What is the basis for this apparent deviation from ASTM D721908 and ASTM D7301-08 requirements for near-isotropic graphite specifications for nuclear core components?

NGNP G-18

G-18. In Section 3.3.4, it is stated that, "It is important to recognize that the degree of isotropy only serves as an initial indicator of the graphite behavior under irradiation. Endproduct isotropy is influenced by raw material, grain size, forming method, and heat treatment." The reviewer understood that materials data after irradiation have been or will be generated using "end-product" specimens. Is this understanding correct? Furthermore, what specifically is noteworthy in this paragraph compared to what has been stated earlier regarding graphite manufacture in Section 3.3.3?

NGNP G-19

G-19. In Table 3 it is stated that, "The strength reserves offered by the material must exceed the allowable operating component stresses." Explain what is meant by "strength reserves?" The response should address how these reserves compare with safety factor for design margin, and how they correlate with the probability of failure requirements for various structural reliability classes in the proposed ASME code for design of graphite core components, and discuss what assurance is provided that these "strength reserves" will remain during reactor operating life.

\section{NGNP G-20}

G-20. In Table 3, it is stated that "higher strengths are achievable with isostatic-molded, fine grain graphite, but these typically possess lower fracture toughness." In Section 3.3.3, it is stated that "A key requirement in prismatic designs is the need for fine grained graphite, with its correspondingly higher strength, for the fuel elements to ensure an adequate number of grains across the thickness of the graphite webs between the fuel compacts and the coolant holes. Relatively high thermal stresses are generated in the thin graphite ligaments between the coolant and fuel channels in these elements. Ideally, a ligament should be no thinner than 10-times the maximum grain size." Provide an explanation of the relationship between these two statements with respect to the expected or desired functionality requirement.

\section{NGNP G-21}

G-21. In Section 3.3.4.2, under the heading "Process Variables", it is stated that "the particle size distribution is generally classified by maximum grain size into coarse-, medium-, and fine-grain material." Since size distribution denotes a range of particle 
sizes existing in a material, clarify the classification by "maximum grain size." Also, describe what is meant by "volatile carbon artifacts."

NGNP G-22

G-22. [COMBINED WITH G-21]

NGNP G-23

G-23. In Section 3.3.4.2, under the heading "Process Variables, clarify what is meant by "furnace limitations."Since graphitization is said to occur through the passage of current through the billet at very high current, is it the difficulty in having the needed electrical resistance of the billet for graphitization?

NGNP G-24

G-24. Regarding item 6 under the heading "Process Variables" in Section 3.3.4.2, do the baking and impregnation occur at different or same location. If at different locations, what considerations need to be addressed to maintain the integrity and geometry of the blocks during the process cycle?

NGNP G-25

G-25. In Table 4 of Section 3.3.5.2, clarify the definition of probability of failure. For example, is it the probability of failure of a single brick per a reactor year of operation or the probability of failure based on the distribution of expected strength of a graphite core component, when subject to operational stress at any given time of operation? Is this probability of failure based on irradiated data? If based on non-irradiated data, discuss why this usage is considered conservative.

\section{NGNP G-26}

G-26. In Section 3.3.5.2, it is stated that "Another deviation from past ASME metallic codes is allowance of cracks in the graphite components. The rules require the core designer to demonstrate through analyses or testing that cracked graphite core components can maintain their assigned safety function and that the graphite component is remotely retrievable when cracks of a specified size and orientation are present." However, the staff is not able to find this provision in the draft code. The current draft code allows for defined probability of failure values for several structural reliability classes for graphite core components. The graphite core assembly itself should maintain its required geometry and be able to perform its intended functions.

Section 3.3.5.2 also states that "The code also deviates from the ASME standard practice of defining primary, secondary, and membrane stresses." However, NRC staff is unable to confirm this statement from reading the draft Code. Provide clarification, reconciling provisions of the draft ASME Code with the white paper description. 
NGNP G-27

G-27. [COMBINED WITH G-26]

NGNP G-28

G-28. It is stated in Section 3.3.5.2 that "the mechanical stresses (primary, secondary, and membrane) do not challenge the graphite core components strength margins." However, it would appear that the geometry and placement of the core components, and the presence of notches, keyways, and dowels could potentially create stress concentration effects different than primary, secondary, and membrane stress. Arguably, these stresses need to be combined with those from the irradiation induced strain and the resulting stresses to arrive at the combined stress on the component. Provide a discussion addressing these considerations.

NGNP G-29

G-29. In Section 3.3.6.1, projected service conditions for the pebble bed reactor has been provided. Provide similar information for a prismatic reactor design.

NGNP G-30

G-30. Section 3.3.6.2 describes properties for baseline characterization, including compressive strength and fatigue strength. However, these properties are not discussed in Section 3.3.6.3 regarding characterization of irradiated graphite. What bases exist to suggest that compressive strength and fatigue strength are not subjected to potential degradation due to irradiation?

NGNP G-31

G-31. In Section 3.3.6.3, it is mentioned that the thermal conductivity of irradiated graphite depends on the fluence and that a secondary reduction in thermal conductivity occurs at high fluence range due to more advanced material degradation. Describe what is meant by "advanced material degradation?" For example, is it "pore generation", as mentioned in Appendix B, page 82? The mechanism for vacancy generation by displacement of atoms is understood. What is the mechanism for generation of pores? Is it physically possible to remove material by irradiation to form pores, or are these postulated mechanisms waiting for experimental evidence? If evidence exists in the form of transmission electron microscopy observation, have they been verified to be consistent across different graphite types? What is the impact of such degradation on the need for removal of graphite blocks either for replacement, or for decommissioning and disposal?

NGNP G-32 
G-32. In Section 3.3.6.3, it is stated that "From a design perspective, the available strength reserve must be compared against the stress within the graphite component based on the fluence-temperature history of the component." Explain how this concept is handled in the design code. What criteria should be used for comparison and why? Describe the basis for accepting or rejecting a component for further service after such comparison.

NGNP G-33

G-33. In Section 3.3.6.3, it is stated that "Evolution of creep strain with fluence in irradiated graphite (differential strain between stressed and unstressed) specimens is characterized by primary, secondary, and tertiary regimes, much like those observed in metals." However, this statement may not be accurate. While the traditional metallic creep is analyzed by the behavior of creep strain as a function of time at constant temperature and varying applied (tensile) stress or at constant applied (tensile) stress and varying temperature, the irradiation creep is analyzed as the strain as a function of cumulative irradiation dose at mostly constant applied (compressive) stress and temperature. The staff understands that the irradiation dose could be proportional to cumulative time. However, because of the 3-dimensional variation in the temperature and dose, a brick could potentially experience, the concept may not be applicable. Provide additional justification for the white paper's description of creep strain evolution in graphite.

\section{NGNP G-34}

G-34. In Section 3.3.6.3 it is stated that "There is evidence to suggest that the normalized creep strain (normalized to initial elastic strain) is similar for different grades of graphite, lending support to the theory that this creep behavior is not material grade specific. Additional creep data would be useful in supporting this position and extending its application for a broader fluence-temperature range and for a wider variety of nuclear graphite grades. This may help in rationalizing and minimizing the need for costly irradiation creep experiments for current reactor graphite grades or grades that may be developed in the future." Other sections of the white paper suggest that all graphite properties, normalized or not, depend strongly on the type of graphite and the way it is manufactured. While some dependencies can be mathematically cancelled out by "normalization", this does not mean, per se, that the irradiation creep behavior of the different types of graphite will be the same or similar and that irradiation experiments may not be needed for various types of graphite. Why should creep be different purely from the perspective of its microstructure influencing its mechanical behavior? Provide additional discussion and justification for the white paper description of normalized creep strain.

\section{NGNP G-35}

G-35. In Section 3.3.6.3, it is stated that a program is underway to demonstrate that properties measured on subsize specimens are valid when compared to those obtained on standard specimens. However, the validity of measurements on small samples could still be questionable in representing the "sampling" volume of graphite core component 
of the reactor. Provide additional justification for the planned use of subsize test specimens.

NGNP G-36

G-36. Section 3.3.6.4 describes the PBMR Graphite Development Program. However, this program no longer exists. Revise the white paper to reflect the status of this program.

NGNP G-37

G-37. In Section 3.3.6.4, under the heading "NGNP Graphite Development Program", it is stated that, "respectively, NBG-18 (coarse grain size, pitch coke, vibration molded) and PCEA (medium grain size, petroleum coke, extruded) graphites are considered to be grades most likely to meet the initial pebble-bed and prismatic design requirements." However, in Section 3.3.3, it is stated that "A key requirement in prismatic designs is the need for fine grained graphite, with its correspondingly higher strength, for the fuel elements to ensure an adequate number of grains across the thickness of the graphite webs between the fuel compacts and the coolant holes." Thus, Section 3.3.3 advocates the use of fine-grained iso-molding processing and material derived thereby. Clarify the implications of potentially different materials used for the same purpose. Are these materials interchangeable? Can one be substituted by the other for replacement?

NGNP G-38

G-38. In Section 3.3.6.4, it is stated that "Complete properties data need to be developed for the graphite(s) eventually selected for the NGNP. Once the baseline material properties for the selected graphite grade(s) have been established, irradiation induced property changes must then be determined, including the characterization of irradiation induced creep. Determining these properties are important data needed for the design to satisfy the safety-related functions indentified in Section 3.3.6.1." Describe plans to provide sufficient data and information on the selected graphites for verification and confirmation by the NRC staff in review of the expected NGNP combined license application. If data are not expected to be available when that application is submitted, describe how the application will address this issue so that the NRC staff can conduct an informed evaluation.

NGNP G-39

G-39. Appendix B states that "structural and dimensional changes in polygranular graphites are a function of both the crystallite dimensional changes and the graphite's texture." Describe what is meant by graphite's texture.? If texture is related to the surface structure of graphite, for example roughness, then what role does irradiation play to roughen the surface? Discuss the effect of roughness on coolant flow.

NGNP G-40 
G-40. Appendix B describes the cohesive life limit. Provide additional definition of this limit. For example, is it a function of cumulative dose? How is the cohesive life limit affected by the temperature, atmosphere (coolant chemistry), and imposed stress? Can the cohesive limit creep-in before the expansion?

\section{NGNP G-41}

G-41. Appendix B: What difference, if any, exists between the irradiation creep when tensile stress is imposed versus the application of a compressive stress? What type of calculations and/or predictive relationships exist between the volumetric changes, considering the two types of stresses? If mixed type of stress (e.g., biaxial tension or compression) exists, what would be their effect on irradiation creep and the resulting volumetric change in graphite? Discuss the importance of these factors for the NGNP design.

\section{NGNP G-42}

G-42. [PENDING CLARIFICATION]

\section{NGNP G-43}

G-43. Appendix B states that specific heat is rather invariant with graphite type and also is not influenced by irradiation. However, there seem to be observations which indicate that irradiation affects specific heat, at least at low temperature. For example, see : (1) T. Iwata and M. Watanabe, "Increase in specific heat and possible hindered rotation of interstitial C2 molecules in neutron-irradiated graphite" Phys. Rev. B 81, 014105 (2010); (2) W. DeSorbo and W.W. Tyler, "Effect of Irradiation on the Low-Temperature Specific Heat of Graphite", J. Chem. Phys. 26, 244 (1957). Furthermore, different equations have been provided for different types of graphite in General Atomics "Graphite Handbook." In addition, that W. Windes, T. Burchell, and R. Bratton in "Graphite Technology Development Plan", INL/EXT-07-13165, p 23 (2007) state that "changes to the specific heat due to oxidation and/or irradiation will be compared to as-received values." Provide additional discussion of graphite specific heat characteristics, addressing information given in the references cited.

\section{NGNP G-44}

G-44. Appendix B states that "emissivity of given graphite will depend on its surface condition and the environmental temperature." It is further stated that "The emissivity of nuclear graphite is not expected to change significantly with irradiation." Provide additional justification for the expected irradiation performance, including discussion of irradiation effects on graphite surface structure.

\section{NGNP G-45}

\section{G-45. [PENDING CLARIFICATION]}


NGNP G-46

G-46. Section 3.3.6.4 states 4that "the prismatic HTGR design assumes that fuel and reflector blocks will be replaced well before turnaround." Clarify what is meant by "well before turnaround". What specific monitoring and inservice inspection will be used to know the dose limit "well before turnaround?"

NGNP G-47

G-47. In Section 3.3.6.4, it is stated that "test specimens from these grades were irradiated at $750^{\circ} \mathrm{C}\left(1382^{\circ} \mathrm{F}\right)$ up to high fluence (in excess of $\left.20 \mathrm{dpa}\right)$, beyond turnaround" in Petten irradiation program. However, results have not been provided in the white paper. Based on the results, describe how these grades compare in their volumetric change due to irradiation. Particularly for the prismatic design, apparently contradictory statements have been made about the merits of using fine-grained as well as medium-grained graphite for fuel elements. Provide additional information on the dimensional change behavior of these two grades.

NGNP G-48

G-48. In Section 3.3.6.4, it is stated that "Graphite irradiation tests programs are also planned by China in support of the HTR-PM..." Describe what properties will be determined after irradiation using IG-110 graphite and when these data may become publicly available. Are there attempts to determine the extent of similarity of the Chinese irradiated specimens to those which are being irradiated in AGC program?

NGNP G-49

G-49. In Section 3.3.7.1 it is stated that "Oxidation of graphite components must also be considered, however, its influence on component strength and, hence, structural integrity is not expected to be significant for events within the design basis." What is the basis for this statement? For example, what evidence is currently available for the effect of simultaneous irradiation-induced graphite degradation and chemical reactivity degradation with the coolant constituents? Are they cumulative (separately additive) in nature? How are tensile, compressive, and shear strength of graphite affected by the combined degradation mechanisms?

NGNP G-50

G-50. In Section 3.3.7.2, "inherent fault tolerance" of the reflector is mentioned in several places. Provide a definition of this term, including discussion of defined engineering margins which are used to support statements in the white paper. Why does this fault tolerance provide safety confidence?

NGNP G-51 
G-51. In Section 3.3.7.2, visual inspection has been mentioned as a potential candidate for the RIM program. What are the effects of potential coating of cracks or other flaws by graphite dust and thus compromising possible detection? If flaws or cracks or cracklike defects are observed, what mechanisms are there for evaluating the safety significance of these observed "defects"? How will observance of these defects relate to the concept of "inherent fault tolerance" mentioned in this section?

NGNP G-52

G-52. In Section 3.3.7.2, it is mentioned that "the designs of prismatic reactor concepts typically provide for the replacement of permanent graphite structures should unanticipated degradation occur." What is the operational experience in replacing such rather tightly packed columns without potential damage to adjacent components and structures? Discuss how lessons learned from this experience will inform NGNP design and operation.

NGNP G-53

G-53. In Section 4.2.1.1, it is stated that "Nuclear graphite has been successfully employed in the construction and operation of gas-cooled reactors, including HTGRs, for over 50 years." However, arguably, no such experience exists to extrapolate information for the expected operational conditions of the NGNP. For example, even though the British AGRs have been operating for a long time, their operational conditions are vastly different than the NGNP HTGR. Additionally, cracking in fuel element channels and control rod channels have been observed in the British AGRs since 2002, while such cracking was not initially expected. It appears that EDF Energy is providing revised safety case documents based on inspection data and the British regulators are continuously reviewing these documents to authorize continued reactor operation. The other HTGRs have not had field experience for such long term operation, including the Japanese HTTR and the Chinese HTR-10. Thus, the statement about "successful operation" is arguable. As has been stated in the white paper, properties information are lacking and are being generated currently for the newer grades of nuclear graphite. Provide additional discussion of the relevance and limitations of applying operating experience for graphite in other gas-cooled reactors to NGNP.

NGNP G-54

G-54. Section 4.2.1.1 includes a discussion of a test program planned for deployment of the PBMR in South Africa. However, this project no longer exists, so the relevance of those plans to NGNP is questionable. Provide revisions to the white paper to reflect the current status of the PBMR project, including test programs which may not have been completed before the project was terminated.

NGNP G-55

G-55. In Section 4.2.1.3, it is stated that "The PIRT panel also concluded that theories that can explain graphite behavior have been postulated and, in many cases, shown to represent experimental data well." It is the NRC staff's understanding that 
phenomenological (curve-fitting) relationships developed using MTR data has worked reasonably well to predict graphite behavior, specifically for the British AGRs, but do not reflect operating conditions projected for the NGNP HTGR. Also, the NRC staff is not aware of any tested and proven theories which have explained the graphite behavior for all the graphite properties. British AGRs have experienced cracking in unexpected places, and in cracking modes that were not predicted. There is also some Japanese work which has developed theory for volume change due to irradiation; however, the staff is not aware of any operational experience which has supported such theory. Provide additional discussion of the relevance and limitations of applying current graphite behavior theories to NGNP. 
Request for Additional Information No. 5899 Revision 0

$7 / 20 / 2011$

Next Generation Nuclear Plant Pre-Application Activities

Department of Energy - Idaho National Laboratory

Docket No. PROJ 0748

SRP Section: NGNP COMP - Carbon Composites

Application Section: Carbon Composites

\section{QUESTIONS for Advanced Reactor Branch 1 (ARB1)}

\section{NGNP COMP -1}

COMP-1. Information presented in Section 3.5.2.1 is unclear, because the meaning and usage of qualitative adjectives used (i.e., high, low, extremely high, excellent, relative, moderate, etc.) is unclear. The text states such attributes should be "considered." Since these are relative terms, what bases are being used for comparison? Are the properties determination methods the same for these varying attributes, namely for the entire range or the methods could differ for different ranges for these properties?

\section{NGNP COMP -2}

COMP-2. Section 3.5.4.2: With respect to fatigue resistance, especially for tie-rods, straps, and other functional components, how will the acceptable fatigue limits be determined and applied? What type of modification to currently acceptable fatigue rule will be made?

\section{NGNP COMP -3}

COMP-3. Section 3.5.4.2: What is the effect of oxidation on the fatigue strength of these composites? What information exists or needed to establish the effects of oxidation corrosion and potential cyclic fatigue of $\mathrm{C}-\mathrm{C}$ and/other ceramic tie rods and functionallyrelated core internals, such as straps. Describe plans to demonstrate seismic reliability of such components via analytical and/or experimental programs?

\section{NGNP COMP -4}

COMP-4. In Section 3.5.4.2, it is mentioned that fatigue tests were performed with component level tests for tie rods racetrack strap components. At what temperature and environment were these tests conducted, and how do those conditions compare to expected NGNP service conditions? Were such tests conducted with "reference" material to qualify the test?

\section{NGNP COMP -5}

COMP-5. Deleted. 
NGNP COMP -6

COMP-6. Section 3.5.4.2: How will composite components, such as tie rods and straps, be attached or bonded to other components? What are the structural requirement considerations for these linking or bonding " devices?

\section{NGNP COMP -7}

COMP-7. Deleted.

\section{NGNP COMP -8}

COMP-8. Section 3.5.4.2: Discuss the need for and types of redundancy and/or diversity which will be considered for tie rods and straps. 
Request for Additional Information No. 5900 Revision 0

$7 / 20 / 2011$

Next Generation Nuclear Plant Pre-Application Activities

Department of Energy - Idaho National Laboratory

Docket No. PROJ 0748

SRP Section: NGNP INS - Ceramic Insulation

Application Section: Ceramic Insulation

\section{QUESTIONS for Advanced Reactor Branch 1 (ARB1)}

\section{NGNP INS - 1}

INS-1. Table 7 in Section 3.4.2 provides properties data for carbon insulation and nuclear graphite. What ASTM material specification standard exists for carbon insulation materials for nuclear application to state nuclear grade carbon? Considering that the thermal conductivity of carbon insulation is lower than graphite, and thus potentially reducing resistance to thermal shock, what structural integrity requirements are contemplated for carbon insulation? Later, in Section 3.4.4, it is mentioned that Structural Reliability Class (SRC)-3 will be assigned to ceramic insulation components. What information is available on the strength of this insulation after multiple thermal shock loadings, and after irradiation?

\section{NGNP INS -2}

INS-2. In Section 3.4.3, "nuclear grade ASR-ORB carbon" is discussed. What is the specification for this "nuclear grade" material? Is NBC-07 also a "nuclear grade" carbon? If so, what specification makes it a "nuclear grade"?

\section{NGNP INS -3}

INS-3. In Section 3.4.3, it is stated that "Shaped carbon blocks are used at various locations in the core structures to insulate selected components from hot gas flow." What type of thermal (heat transfer) analysis procedures are used to ensure adequate carbon thickness for the "shaped" carbon component to provide the required insulation? Does the thermal conductivity of carbon depend on temperature and neutron dose? If so, how this dependence accounted for in thermal calculations? Are such calculations based on consensus standard procedure?

\section{NGNP INS -4}

INS-4. In Section 3.4.3, it is stated that "the carbon blocks around the reflector, at the top of the reflector and the upper insulation layer below the reflector have $5 \mathrm{wt} \%$ boron carbide added to the carbon to reduce neutron irradiation to the adjacent metallic components in these areas." How does the addition of boron carbide affect the thermal conductivity as a function of temperature? What is the time-dependency of thermal conductivity at temperature for the life time of the carbon component? 


\section{NGNP INS -5}

INS-5. In Section 3.4.3, it is stated that "the carbon insulation blocks were produced by the Lanzhou Carbon Works to ensure low thermal conductivity and good dimensional stability at high temperature." Clarify this statement to clearly identify what component or components are being described (e.g. the insulating block, or metallic structures) Why is dimensional stability important and to what extent? How do you assure that the good dimensional stability is maintained? What inspections would be conducted to assure this expected behavior?

\section{NGNP INS -6}

INS-6. In Section 3.4.4, it is stated that "the use of ceramic insulation in the CSC is restricted to areas where it is not exposed to significant fast neutron irradiation (e.g., $<1018$ n.cm-2 EDN) and, consequently, irradiation-induced changes in properties will be negligible." The value given for fast neutron irradiation appears to be misformatted. Is it correct to assume that it should appear as $<10^{18} \mathrm{n} \mathrm{cm}^{-2}$ ? Throughout Section 3.4 , clarify the various operating conditions, the specific materials to be used, and properties required to assure expected design performance.

\section{NGNP INS -7}

INS-7. Table 8 in Section 3.4.5, characterizes baked carbon insulation properties. Temperature-dependent friction coefficient in helium between graphite and carbon is one of the properties. This friction property between graphite and baked carbon insulation has not been identified for characterization in Sections 3.3.6.2 or 3.3.6.3 for graphite. Explain this discrepancy.

\section{NGNP INS -8}

INS-8. In Section 3.4.5, is the PBMR procedure for determining equivalent boron content, mentioned in Table 8, publicly available? Provide a description of the procedure, and discuss any review and approval by a consensus standards organization, such as ASTM?

\section{NGNP INS -9}

INS-9. Section 3.4: Cracking and continuously inter-connected porosity is a possibility for ceramic materials. Thus, while insulating characteristics may be functionally adequate, what is the possibility of the coolant flowing through this inter-connected porosity ("thermal streaking") which could potentially lead to hot spots continuously impinged by hot gas on the metallic strictures? If such thermal streaking is possible, then how can the design assure the structural integrity of pressure boundary material?

NGNP INS -10 
INS-10. Section 3.4 states that ceramic insulation will be adjacent to metallic components. How will reactor operating conditions contribute to thermodynamic and chemical reactions which may occur between these materials? What are the consequences resulting from potential degradation due to such reactions? If there is spalling of insulation refractory materials, as is typical in the case of refractory (thermal protection) use, what are the consequences? How will such degradation be detected and its effects mitigated? 


\section{Appendix D}

\section{INL Letter Number CCN 225396, NGNP Submittal - Response to NRC RAls Letter No. 004, dated September 27, 2011}




\section{Appendix D}

\section{INL Letter Number CCN 225396, NGNP Submittal - Response to NRC RAls Letter No. 004, dated September 27, 2011}

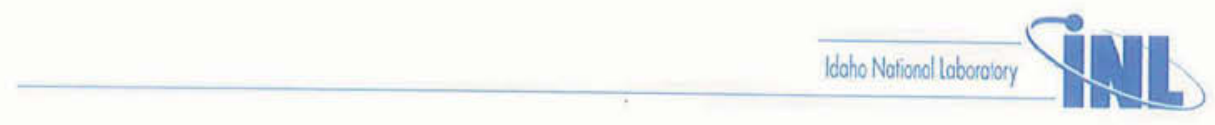

September 27, 2011

CCN 225396

NRC Project $\# 0748$

U.S. Nuclear Regulatory Commission

Document Control Desk

Washington, D.C. 20555-0001

SUBJECT: Contract No. DE-AC07-05ID14517 - Next Generation Nuclear Plant Project Submittal Response to Nuclear Regulatory Commission Request for Additional Information Letter No. 004 Regarding Next Generation Nuclear Plant Project High Temperature Materials White Paper - NRC Project \# 0748

Consistent with the actions identified in "NGNP Licensing Strategy - Report to Congress," dated August 2008, the purpose of this letter is to submit responses to the subject U.S. Nuclear Regulatory Commission (NRC) Request for Additional Information regarding the subject Next Generation Nuclear Plant (NGNP) Project white paper. The enclosure contains the NGNP Project's responses for those Requests for Additional Information (RAIs) received in NRC RAI Letter Number 004 (Request for Additional Information No's. 5901, 5898, 5800, 5899, and 5900), dated July 25, 2011.

The NRC licensing process encourages early interactions to identify and resolve policy, regulatory, and key technical issues related to the proposed facility. Conducting effective interactions with the NRC is a critical part of the NGNP licensing strategy because the early resolution of issues can significantly impact the preparation of an acceptable license application, the subsequent application review schedule, and the ultimate deployment of the NGNP. This NGNP Porject response to the NRC's RAIs represents one in a series of submittals that address priority licensing topics related to establishing High Temperature GasCooled Reactor (HTGR) regulatory requirements using the process outlined in the Licensing Strategy.

Following NRC Staff review of these RAI responses, and pending resolution of associated follow-on questions, the NGNP Project requests that the NRC provide feedback and documentation of its review in a format that will facilitate resolution of key design, safety, and licensing issues on the topic of high temperature materials that can be used as a firm basis for the preparation of future HTGR license application(s).

If you have any questions, please contact me at (208) 526-6063 or James Kinsey, Director, NGNP Regulatory Affairs at (208) 569-6751.

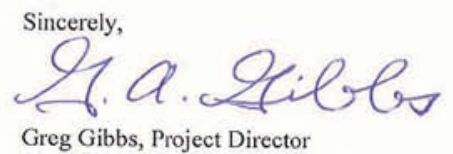

Greg Gibbs, Project Director

Next Generation Nuclear Plant Project

$\mathrm{JK}: \mathrm{CN}$ 
Document Control Desk

September 27, 2011

CCN 225396

Page 2

Enclosure:

1. NGNP Response to NRC RAI No's. 5901, 5898, 5800, 5899, and 5900, Revision 0.

References:

(a) "Next Generation Nuclear Plant - High Temperature Materials White Paper," June 25, 2010, CCN 221269

(b) NRC RAI Letter Number 004 (Request for Additional Information No's. 5901, $5898,5800,5899$, and 5900), dated July 25, 2011

$\begin{array}{ll}\text { cc: } & \text { DOE-HQ } \\ \text { T. J. O'Connor } \\ \text { C. J. Sink } \\ \text { J. Zamore } \\ \text { DOE-ID } \\ \text { M. L. Adams, (w/o Enc.) } \\ \text { B. Blythe } \\ \text { P. K. Bowvers, (w/o Enc.) } \\ \text { C. P. Fineman } \\ \text { R. V. Furstenau } \\ \text { G. R. McClellan } \\ \text { S. M. Olson, (w/o Enc.) }\end{array}$

$\underline{\text { INL }}$

J. Alvarez, (w/o Enc.)

J. J. Grossenbacher, (w/o Enc.)

D. J. Hill, (w/o Enc.)

D. M. Storms, (w/o Enc.)

J. M. Welch, (w/o Enc.)

NRC

S. Basu

M. E. Mayfield

T. A. Kevern

J. F. Williams 
Document Control Desk

September 27, 2011

CCN 225396

Page 3

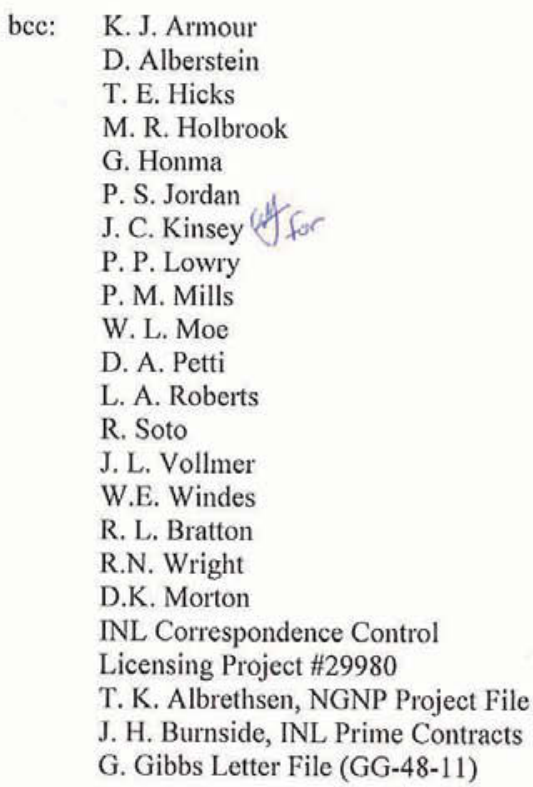

Uniform File Code: $\underline{8406}$

Disposition Authority: RD1-A-3

Retention Schedule: Cutoff after project/program completion, cancellation, or termination. Destroy 10 years after termination of project/program.

NOTE: Original disposition authority, retention schedule, and Uniform Filing Code applied by the sender may not be appropriate for all recipients. Make adjustments as needed. 
Enclosure 1

September 27, 2011

CCN 225396

Page 1 of 67

\section{Consolidated Draft RAI Responses}

for High Temperature Materials

\section{Acronym List}

$\begin{array}{ll}\text { AGC } & \text { Advanced Graphite Creep } \\ \text { AGR } & \text { Advanced Gas-cooled Reactor } \\ \text { ANS } & \text { American Nuclear Society } \\ \text { ASME } & \text { American Society of Mechanical Engineers } \\ \text { ATR } & \text { Advanced Test Reactor } \\ \text { AVR } & \text { Arbeitsgemeinschaft Versuchsreaktor } \\ \text { BPV } & \text { boiler and pressure vessel } \\ \text { CFRC } & \text { carbon fiber reinforced carbon } \\ \text { CSC } & \text { core structure ceramic } \\ \text { CTE } & \text { coefficient of thermal expansion } \\ \text { DDN } & \text { design data need } \\ \text { Dido } & \text { Materials Test Reactor (UK) } \\ \text { DOE } & \text { Department of Energy } \\ \text { dpa } & \text { displacements-per- atom } \\ \text { DPP } & \text { demonstration power plant } \\ \text { EDF } & \text { Electricité De France } \\ \text { EDN } & \text { equivalent Dido nickel } \\ \text { FSV } & \text { Fort St. Vrain } \\ \text { GA } & \text { General Atomics } \\ \text { GDC } & \text { general design criteria } \\ \text { HFR } & \text { high flux reactor } \\ \text { HTGR } & \text { high temperature gas-cooled reactor } \\ \text { HTM } & \text { high temperature material } \\ \text { HTR } & \text { high temperature reactor } \\ \text { HTR-PM } & \text { High Temperature Reactor-Pebble-bed Module (Chinese HTGR) } \\ \text { HTS } & \text { heat transport system } \\ \text { HTTR } & \text { High Temperature Test Reactor } \\ & \end{array}$


Enclosure 1

September 27, 2011

CCN 225396

Page 2 of 67

$\begin{array}{ll}\text { IAEA } & \text { International Atomic Energy Agency } \\ \text { INL } & \text { Idaho National Laboratory } \\ \text { ISFS } & \text { independent spent fuel storage } \\ \text { JAEA } & \text { Japan Atomic Energy Agency } \\ \text { JAERI } & \text { Japanese Atomic Energy Research Institute, Tokai-Mura Japan } \\ \text { JNM } & \text { Journal of Nuclear Materials } \\ \text { KTA } & \text { Kerntechnische Ausschuss (German Standards Agency) } \\ \text { LBE } & \text { licensing basis event } \\ \text { LLC } & \text { limited liability company } \\ \text { LWR } & \text { light water reactor } \\ \text { MTR } & \text { materials test reactor } \\ \text { MQP } & \text { Material Qualification Plan } \\ \text { NDE } & \text { nondestructive examination } \\ \text { NEUP } & \text { Nuclear Energy University Program } \\ \text { NGNP } & \text { Next Generation Nuclear Plant } \\ \text { NIMS } & \text { National Institute for Materials Science } \\ \text { NRC } & \text { Nuclear Regulatory Commission } \\ \text { ORNL } & \text { Oak Ridge National Laboratory } \\ \text { OSTI } & \text { Office of Science and Technical Information } \\ \text { PBMR } & \text { Pebble Bed Modular Reactor } \\ \text { PIE } & \text { post irradiation examination } \\ \text { PIRT } & \text { phenomena identification and ranking table } \\ \text { POF } & \text { probability of failure } \\ \text { Q/A } & \text { questions and answers } \\ \text { QA } & \text { quality assurance } \\ \text { R\&D } & \text { research and development } \\ \text { RAI } & \text { request for additional information } \\ \text { RI-PB } & \text { risk informed and performance based } \\ & \end{array}$




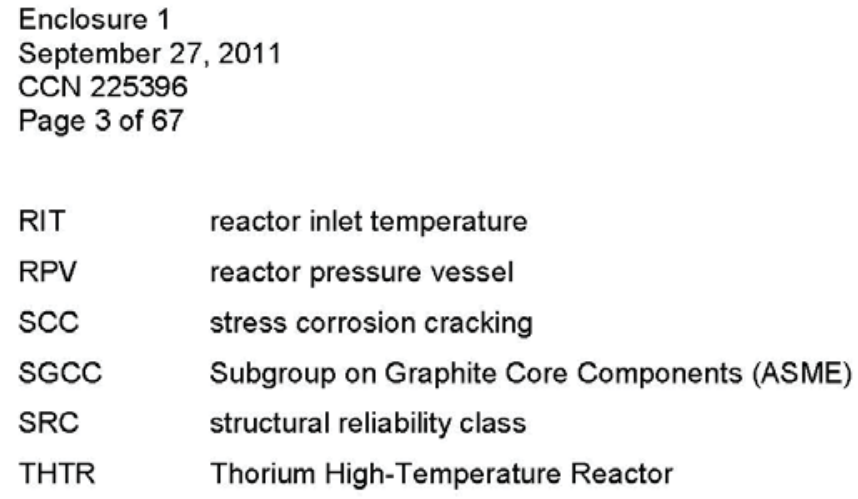


Enclosure 1

September 27, 2011

CCN 225396

Page 4 of 67

\section{Consolidated Draft RAls Responses for High Temperature Materials}

\section{General RAls No. 5901 Revision 0}

RAI GEN-1: What are the effects of degradation and failure of sealants, gaskets, attachments to high temperature metal piping, etc. degradation, debris on high temperature metallic materials, graphite, and $\mathrm{C}-\mathrm{C}$ and other composite materials?

\section{Response GEN-1:}

This question is pertinent to the issue of material compatibility and must be addressed during review of the design for the NGNP reactor. The NGNP design has not yet advanced to the level of detail at which these features have been defined. Therefore, this topic was not included within the outcome objectives summarized in Section 5 of the white paper. These potential degradation effects will be addressed as a part of the future license application process.

RAI GEN-2: What are the effects of insulation lift-off and consequent debris generation on high temperature metallic materials, graphite, and C-C and other composite materials?

\section{Response GEN-2:}

Specific effects of insulation lift-off and/or debris generation must be assessed once the reference design, technical specifications, components, and material selections have been established. Therefore, this topic was not included within the outcome objectives summarized in Section 5 of the white paper.

In presently proposed NGNP designs, this issue is limited to the hot duct assembly and upper plenum shroud, which are the only identified internal components employing internal insulation. As can be seen by referring to the response to RAI HTM-3, the generation of insulation-derived debris from the hot duct assembly would require a major failure of the internal liner of the hot duct assembly. For the upper plenum shroud, the generation of insulation-derived debris would require major failure of metallic cover plates.

RAI GEN-3: What type of specific information exists or needed to address aging management issues tailored to specific postulated or known degradation mechanism? This information is especially important to select the appropriate inspection methods, periods, and examination area.

Response GEN-3:

Specific aging issues for the graphite and metallic components are being actively pursued within the Graphite and High Temperature Materials Research \& Development (R\&D) Programs

(References 1-3). Specific aging issues include irradiation induced dimensional changes and creep within graphite components, creep-fatigue and creep within metallic components, longterm environmental degradation of metallic and graphite components, and loss of mechanical strength and fracture resistance in graphite due to long term irradiation dose. Information from these NGNP programmatic studies will determine the appropriate mitigation and inspection measures required to assure the safety case of the high temperature gas-cooled reactor (HTGR). The NGNP program is not directly assessing the aging issues of composite systems 
Enclosure 1

September 27, 2011

CCN 225396

Page 5 of 67

but is directing work being performed at university programs under the Nuclear Energy University Program (NEUP).

However, specific aging monitoring programs, monitoring methods, periods, and examination areas of components can only be determined once the reference design, technical

requirements, components, and material selections have been established. Aging management will be addressed as a part of the future license application process.

References:

1. PLN-2497, 2010, "Graphite Technology Development Plan," Rev 1, October 2010.

2. PLN-2803, 2010, "Next Generation Nuclear Plant Pressure Vessel Materials Research and Development Plan," Rev. 1, July 2010.

3. PLN-2804, 2010, "Next Generation Nuclear Plant Steam Generator and Intermediate Heat Exchanger Materials Research and Development Plan," Rev. 1, September 2010.

RAI GEN-4: The white paper does not address decommissioning issues related to NGNP HTGR graphite core components and other ceramic and carbon-carbon composites. Provide information regarding decommissioning of these materials.

\section{Response GEN-4:}

Decomissioning was not considered in the Materials High Temperature White Paper and was not an objective of this white paper. This topic will be addressed in the future licensing application process.

RAI GEN-5: In LWRs, the integrity of the reactor coolant pressure boundary is assured through a defense-in-depth approach, such limits on allowable identified reactor coolant leakage. Leakage through the pressure boundary is not allowed during power production. How will such defense-in-depth approach be applied to metallic pressure boundary components for the NGNP? In other words, how will GDC 30 be met?

\section{Response GEN-5:}

The programmatic defense-in-depth approach is addressed in INL/EXT-09-17139, "Next Generation Nuclear Plant Defense-in-Depth Approach." In general, NGNP defense-in-depth relies partially on a functional containment approach utilizing multiple physical barriers to radionuclide release, including the Helium Pressure Boundary. The Helium Pressure Boundary will be designed and fabricated to ASME Boiler and Pressure Vessel Code Section III requirements for metallic pressure boundary components. Details will be addressed during development of the detailed design and during the future license application process.

RAI GEN-6: The staff is aware of design data need (DDN) documents, which were generated by Westinghouse, AREVA, and GA for graphite. These vendors had analyzed the graphite PIRT results and their conceptual designs and identified several topical areas where more information is needed. This white paper does not provide any information on these documents, DOE's evaluation of these documents, and provide a nexus between the potential vendor's identified DDNs and DOE-INL's research which would supposedly provide such data to the designer. Provide a discussion of specific data needs identified by these DDNs. The staff is particularly interested in graphite spalling, especially during the later stages of reactor operation. 
Enclosure 1

September 27, 2011

CCN 225396

Page 6 of 67

\section{Response GEN-6:}

The High Temperature Materials White Paper, as well as all of the other NGNP white papers, was written in a manner to be generic with regard to HTGR technology (i.e., independent of variations among potential reactor suppliers in design details and technology development needs). This approach is appropriate at this stage of the NGNP Project, with no decision having yet been made regarding which reactor supplier will conduct the final design of the NGNP. Accordingly, specific DDNs are not discussed in any of the NGNP white papers.

In general, the data needs and additional research and development needs identified in the PIRT reviews are consistent with the plans (Reference 1). Graphite oxidation from a steam incursion is being addressed through oxidation activities in the plan. Dust generation and tribology studies are being performed in university research programs under the NEUP program. The effects or probability of fracture failure leading to spallation of graphite components is being addressed under the multi-axial strength and failure mechanism development sections of the graphite technology development program.

Reference

1. PLN-2497, 2010, "Graphite Technology Development Plan," Rev 1, October 2010.

RAI GEN-7: In Section 2.8, it is stated that "Further development of the regulatory infrastructure will be desirable in support of follow-on commercial plants." However, there does not appear to be any further discussion within the white paper describing what infrastructure development is considered desirable to support a review of a HTGR commercial plant license application. Given that this regulatory infrastructure development could be beneficial for NGNP licensing, provide additional discussion of specific needs

\section{Response GEN-7:}

By stating that further regulatory infrastructure development to support modular HTGR licensing is desirable, the NGNP Project is referring to a future risk informed and performance based regulatory infrastructure. The project also believes that the ongoing regulatory gap analysis will support the proposed materials selection and qualification process proposed in this white paper.

Furthermore, as stated in Section 2.8 of the white paper - "The candidate materials being considered for primary HTGR components are generally commercially available and are in use in high temperature applications in other industries and, in some cases, have been used in HTGR applications in the U.S. and other countries."

However, specific requirements will be addressed once the reference design, technical requirements, components, and material selections have been established. Therefore, details will be addressed during development of the detailed design and during the future license application process.

RAI GEN-8: In general, references have not been provided in the white paper. The staff needs corresponding technical citations for conducting an informed review. Provide a comprehensive list of references, and incorporate this information into any future revision of the white paper. 


\section{Enclosure 1}

September 27, 2011

CCN 225396

Page 7 of 67

Response GEN-8:

Although some references are provided in Section 6 of the white paper, additional references that support technical citations have been provided in responses to RAls. These references will be collected and will be provided in the next revision of the white paper, as appropriate. The additional reference materials will be those that are already publically available. 
Enclosure 1

September 27, 2011

CCN 225396

Page 8 of 67

High Temperature Metals RAls No. 5898 Revision 0

\section{NGNP's General Response for High Temperature Metals RAls}

ASME has recently completed development of the Section III, Division 5 Rules for Construction of Nuclear Facility Components that apply to High Temperature Reactors, including HTGRs (Reference 1). According to the ASME Web site, release of the Division 5 Code is scheduled for October 31, 2011. In part, the new Division 5 Code incorporates updated versions of ASME Code Cases N-201-5 and N-499-2, which are referenced at several locations within the High Temperature Materials White Paper, notably including Section 2.7, which summarizes the status of ASME Code development, and Section 5.1, which identifies the outcome objectives for metallic materials. As the new Division 5 rules are published, it is anticipated that the referenced Code Cases will be annulled.

For this reason, Section 2.7, Section 5.1 and additional sections in the High Temperature Materials White Paper that identify these specific Code Cases will be modified to acknowledge the anticipated evolution from the present Code Cases to the new Division 5 rules. In the RAI responses below, references to Code Cases N-201-5 and N-499-2 should be understood in the above context. The modification to the white paper will be completed upon resolution of the issues raised in the RAls.

Reference:

1. http://www.asme.org/products/codes---standards/bpvc-iii-5---2011-bpvc-section-iii-rulesfor-const

RAI HTM-1: In Section 3.2.1.2, it is stated that "However, given the present extensive database and the large material thicknesses involved, oxidation effects are not expected to be significant, making the need for new data unlikely." What information is currently available on the "internal oxidation", and oxidation of grain boundaries, in addition to surface oxidation for these materials? How are the important performance-related properties affected by potential long-term internal oxidation?

\section{Response HTM-1:}

The properties of SA-508/533 are measured in air for the Code; therefore, the majority of properties that have been determined and tabulated include the effects of an oxidizing environment, including any potential internal oxidation. The reactor pressure vessel (RPV), which sees the highest vessel temperatures, normally operates at temperatures comparable to those seen by LWR vessels (in the range of $300^{\circ} \mathrm{C}$ in the NGNP steam cycle designs-see response to RAI HTM-2). The exterior of the vessel is exposed to air; the internal environment is the primary helium coolant, which normally contains low levels of oxidants (typically $\leq 10 \mathrm{ppm}$ total). Bounding transients seen by the RPV are limited by design to $\angle 540^{\circ} \mathrm{C}$, the Code Case $\mathrm{N}$ 499-2 limit, and are of low frequency and limited duration.

RAI HTM-2: Regarding the Section 3.2.1.3 discussion of experience with SA-508/533, what information is available on the potential carburization due to the presence of potential carbon/graphite dust in the HTGR? 
Enclosure 1

September 27, 2011

CCN 225396

Page 9 of 67

\section{Response HTM-2:}

Based on exposures of low alloy steel materials such as SA-508/533 to simulated HTGR environments, neither significant carburization nor decarburization was observed at temperatures below about $450^{\circ} \mathrm{C}$ (Reference 1). In the designs of interest to this the High Temperature Materials White Paper, the normal operating temperature of the vessel system is driven by the reactor inlet temperature (RIT), which is much lower, typically in the range of $300^{\circ} \mathrm{C}$. For example, in recent prismatic steam cycle designs, the RIT ranges from $290-325^{\circ} \mathrm{C}$; for the pebble bed HTR-Modul 200 , the RIT is $250^{\circ} \mathrm{C}$. The actual temperature of the vessel would be still lower by some $25-50^{\circ} \mathrm{C}$, depending upon the details of the design.

No data specific to SA-508/533-carbon reaction/diffusion couples are known to exist. However, given the modest temperature and robust structure, no significant degree or effect of carburization would be expected.

Reference:

1. P. L. Rittenhouse, "Creep and Corrosion Behaviour of Ferritic Steels in a Simulated Steam-Cycle HTR Environment, High Temperature Materials Programme," HTMP Report No. 4, March 1977.

RAI HTM-3: In Section 3.2.2.2, it is stated that "Material selection and qualification for the hot duct liner is based mainly on high temperature strength, corrosion resistance, and time dependent stress effects such as creep and stress rupture." What technical considerations would be required with regard to erosion and erosion/corrosion effects due to potential carbonaceous dust and insulation debris flowing along with the helium coolant? What flowinduced vibration effects should be considered for the hot duct liner? Why is not the cross "vessel" not a duct? Will this cross "vessel" also contain hot duct liner?

\section{Response HTM-3:}

To provide a context for the responses to this and subsequent questions (i.e., RAls HTM-5, HTM-7, and HTM-28), Figure 1 shows the overall arrangement of a nuclear heat supply system that is typical of the concepts of interest to this white paper. The reactor is contained in one vessel and the primary heat exchanger is contained in a second vessel, with the cross vessel providing a connection between the two. The primary heat exchanger is located to the side and below the level of the reactor to minimize natural circulation of hot gas to the primary heat exchanger during pressurized conduction cooldown events, when active heat removal with forced circulation is not available. 
Enclosure 1

September 27, 2011

CCN 225396

Page 10 of 67

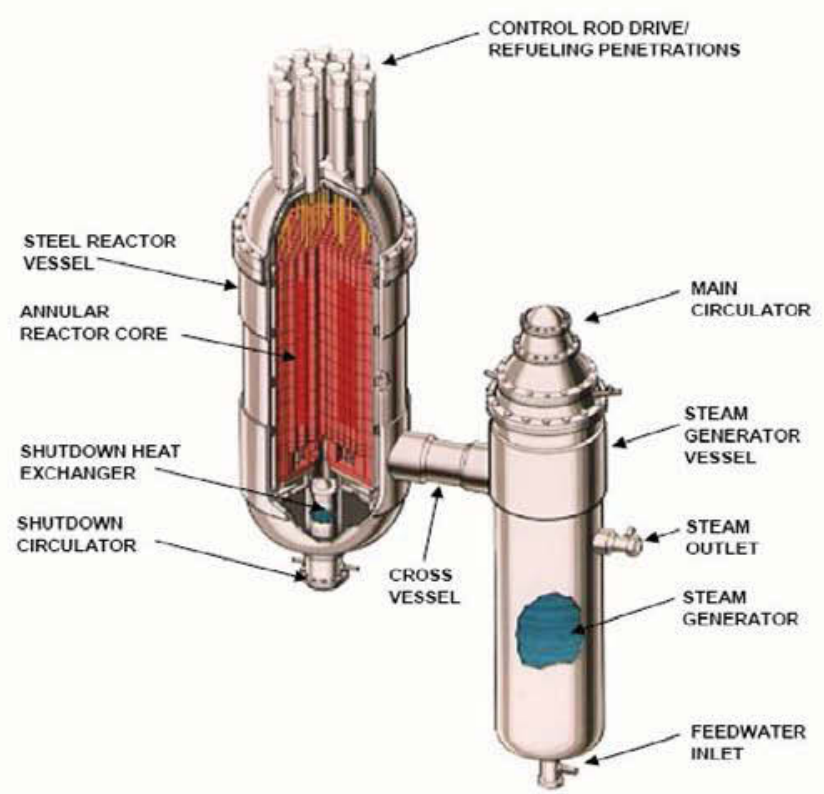

Figure 1. Typical Nuclear Heat Supply System Arrangement.

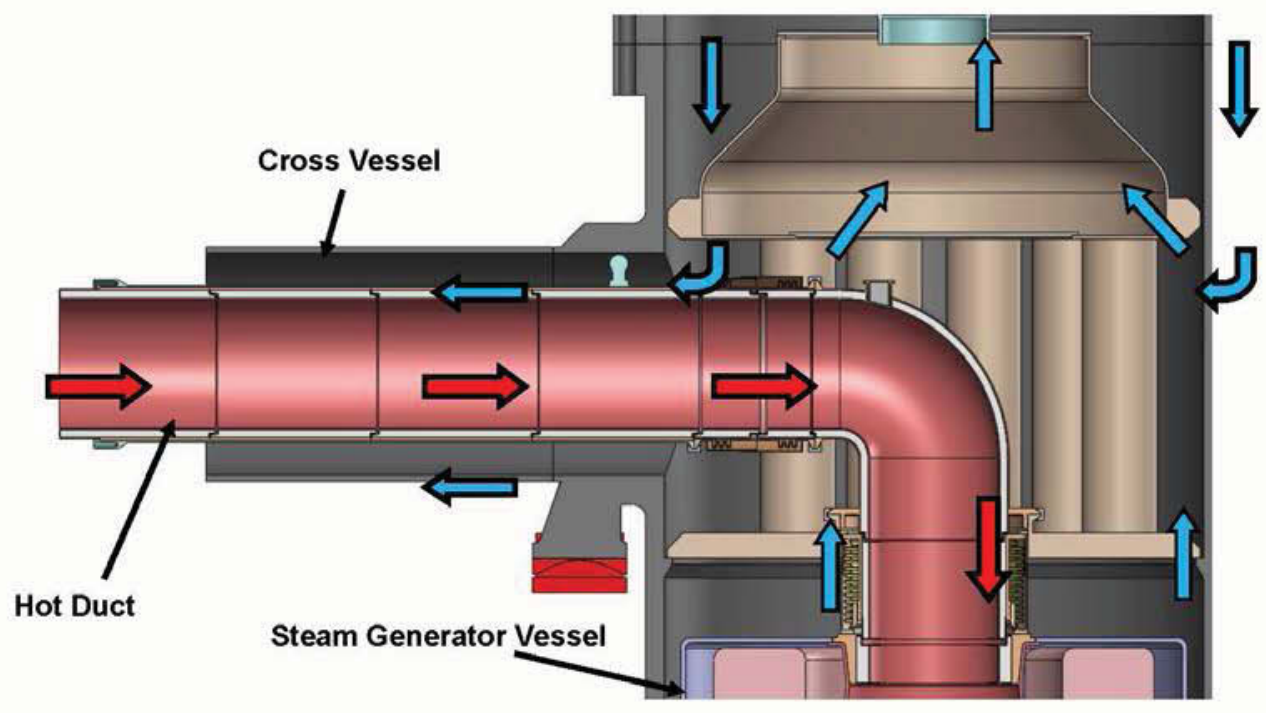

Figure 2. Typical Hot Gas Duct Arrangement within Cross Vessel. 
Enclosure 1

September 27, 2011

CCN 225396

Page 11 of 67

A typical arrangement illustrating the concepts associated with the hot gas duct is shown in Figure 2. Note that the hot gas duct is located within and is concentric to the cross vessel. During normal operation, the high-temperature, lower pressure helium leaving the reactor (shown with the red arrows) flows within the hot gas duct, and the cool, higher pressure helium (blue arrows) returning from the steam generator and circulator flows in the annulus between the hot gas duct and the cross vessel. While details vary in specific designs, the hot gas duct functionally comprises three layers:

1) an outer layer that serves as an internal pressure boundary, with the maximum pressure difference being the pressure rise across the circulator;

2) an insulating layer that prevents regenerative heat exchange between reactor outlet and reactor inlet streams; and

3) an inner liner (not pressure tight) that retains the insulation and defines the flow path for the high-temperature helium leaving the reactor. 4)

Since the higher pressure is on the outside of the hot gas duct, any leakage would be from outside (cold) to inside (hot).

In response to the specific questions of this RAI, the cross vessel is a part of the vessel system that comprises the major part of the primary helium pressure boundary. It is designed as a vessel in accordance with the rules of ASME Section III, Class 1, just as are the reactor vessel and the steam generator (SG) vessel. The cross vessel has internals just as the reactor vessel and SG vessel; it encloses the hot gas duct, of which the liner is the innermost layer.

The thickness selected for the inner liner of the hot gas duct will include an allowance for corrosion and erosion that has not yet been established. The corrosion allowance will be based on the reactor outlet temperature and the primary coolant chemistry specification, in conjunction with materials corrosion data. The allowance for erosion will take into account the temperature, velocity, and geometry of the flow path; the number of dust and debris particles per unit of flow volume; and particle size, density, and hardness.

In general, the allowances for corrosion and erosion are not expected to be large relative to the thickness of the liner. Provisions will be included to visually inspect the interior of the hot gas duct as a means of detecting unanticipated deterioration. While the hot gas duct is designed for the plant life, it can be replaced, if necessary.

The potential for flow induced vibration and its effects on the hot gas duct liner will be addressed by analysis. The effects of vibration on the insulating properties of the hot gas duct will be characterized by testing.

RAI HTM-4: Section 3.2.2: For the use of Alloy $800 \mathrm{H}$ as core support component, what technical issues need to be addressed or known to have been resolved with respect to the effects of oxidation and erosion, and erosion/corrosion reducing the potential load bearing capacity in shear?

\section{Response HTM-4:}

Erosion and corrosion can reduce the wall thickness of components, and oxidation can affect the surface of materials by various means including degradation of the grain boundaries, thereby reducing the strength of the affected volume of surface material. Hence, the effects of 
Enclosure 1

September 27, 2011

CCN 225396

Page 12 of 67

erosion and corrosion on the axial, shear, bending, and torsion load carrying capacity of core support components need to be taken into account during the design process. The ASME Boiler and Pressure Vessel Code, Section III, Subsection NG (construction rules for core support structures) provides clear guidance. The first sentence of NG-3121 indicates:

Material subject to thinning by corrosion, erosion, mechanical abrasion, or other environmental effects shall have provision made for these effects during the design or specified life of the structure by a suitable increase in or addition to the thickness of the base metal over that determined by the design formulas.

The NGNP Project is currently investigating the potential loss of load bearing area for $800 \mathrm{H}$ materials under quasi-static environmental conditions to support the quantification of this effect. Quantification of erosion/corrosion effects will be determined later after further design details become known.

Note that the core support component for which Alloy $800 \mathrm{H}$ is a candidate material is the core support structure, which comprises the core support floor and the core barrel. The core support structure encloses and supports the core graphite structures, including the fuel. During normal operation, the flow path is such that the temperatures seen by the core support structure are governed by the reactor inlet temperature, which is in the range of $300^{\circ} \mathrm{C}$ (see response to RAI HTM-2). At these temperatures, corrosion would be minimal, even if corrosive elements were available in the helium coolant. As noted above, the potential effects of erosion will be evaluated and will be addressed by a thickness allowance, if necessary; however, such effects are expected to be minimal in the inlet region.

RAI HTM-5: In Section 3.2.2.2 it is stated that "Studies sponsored by ASME Standards and Technology, LLC have determined that there is currently sufficient information available to extend Code qualification to $850^{\circ} \mathrm{C}$ for a maximum use temperature for 500,000 hours design life for lower temperatures." What information is available for Alloy $800 \mathrm{H}$ containing potential cracks, especially when used as hot-gas-duct liner? Are there crack growth rate data available under the conditions of expected design loads and service environments to provide assurance that potential crack growth would be within the tolerance limits, if any?

\section{Response HTM-5:}

Although the NGNP technology and development program is expecting to generate Alloy $800 \mathrm{H}$ crack growth data at a later date, those testing plans are not included in current NGNP Project documentation. Once these test plans have been formalized and documented, that information then can be shared with the NRC.

Note that since the hot gas duct liner does not serve a pressure retaining function, extensive cracking would be required to result in major failure of that component.

RAI HTM-6: In Section 3.2.2.2, a discussion has been provided on the bimetallic weld between the Alloy $800 \mathrm{H}$ tubing and ferritic steel tubing. It is mentioned that "However, special consideration will need to be given to corrosion questions, especially where alternating wet-dry conditions might exist." It is not clear what this special consideration is. From the LWR operating experience, the staff might potentially expect data on potential stress corrosion 
Enclosure 1

September 27, 2011

CCN 225396

Page 13 of 67

cracking (SCC) as well as material loss due to corrosion, and the effects of wet-dry cycling on SCC.

\section{Response HTM-6:}

The word "special" will be deleted in the next update of the white paper. Corrosion is a normal consideration in the water-side environment of a steam generator, and alternate wetting and drying implies the potential for local concentration effects that have posed difficulties in LWR steam generators. It is noted that Alloy 800 is now a preferred tube material in German LWRs and has had excellent service experience in the more difficult two-phase wetted environment of the LWR steam generator shell side. In the HTGR steam generators, water is on the tube side, which avoids crevice concentration effects.

RAI HTM-7: In the Section 3.2.2.2 discussion of the hot duct liner, it is stated that "the hot duct liner will be under minimal stress so that the high temperature strength and time dependent stress effects that drive the $760^{\circ} \mathrm{C}\left(1400^{\circ} \mathrm{F}\right)$ limit may not directly apply. Further, as already noted earlier, data already available would support operation at even higher temperatures. During a pressurized conduction cool down event, the hot duct liner may exceed the current code temperature and, if so, would require further evaluation at these high temperatures for qualification." The staff notes that because of thermal transients, the potential for thermal cracking of the hot duct liner cannot be ruled out, especially in regions where changes in cross section geometry occur. What is the effect of the presence of pre-existing or operation-induced cracks on these available data?

\section{Response HTM-7:}

Refer to the response to RAI HTM-3 for a summary description of the hot gas duct.

The loads imposed on the hot gas duct liner (both thermal and structural) will be assessed using established thermal/structural analysis methods and available data for Alloy $800 \mathrm{H}$, which have been established to minimize the incidence of failures, such as cracks. The liner is not a pressure boundary and, by design, will see minimal loads during normal operation and during other events within the duty cycle. While the possibility of locally high temperatures during pressurized conduction cooldown events (loss of forced cooling by both the main Heat Transport System (HTS) and the independent Shutdown Cooling System) has not been ruled out, the following are noted:

- Temperatures significantly exceeding those seen during normal operation are unlikely, since the main circulator includes a flow-assisted check valve that passively closes when the HTS circulator stops. The check valve is required for proper operation of the shutdown cooling system used for maintenance; however, it is not required for passive heat removal via the path through the reactor vessel. Also, the HTS design is configured to prevent natural circulation through the hot gas duct to the steam generator during conduction cooldown events.

- Pressurized conduction cooldown events are rare events with a correspondingly low number of cycles. A typical design duty cycle might include five such events for evaluation purposes. 
Enclosure 1

September 27, 2011

CCN 225396

Page 14 of 67

- Since there is no active circulation, the hot gas duct liner has no assigned function during pressurized conduction cooldown events, and the presence or absence of cracks would have no bearing on the outcome of these events.

RAI HTM-8: In Section 3.2.2.2, it is stated that "At temperatures below $900^{\circ} \mathrm{C}\left(1652^{\circ} \mathrm{F}\right)$, extended operation studies in impure helium gas have shown that Alloy $800 \mathrm{H}$ develops chromia scales along with significant internal oxidation of aluminum and subsurface depletion of $\mathrm{Cr}$. However, it must be noted that the corrosion behavior is quite sensitive to levels and ratios of active impurity species and this must be considered in the evaluation process."

The formation of corrosion-induced scale (oxidation product of the corrosion reaction) could be a potential regulatory concern. The adhesion characteristics of the heavy metal oxide scale could potentially dictate the potential for peeling of such scales over time due to a variety of reasons including the effect of the flowing coolant. Such peeling could result in the coolant gas acting as the carrier of the activated heavy metal radionuclide in the stream. What information is currently known or planned to be investigated in this regard?

\section{Response HTM-8:}

The corrosion behavior of Alloy $800 \mathrm{H}$ is dependent upon time, temperature and coolant chemistry. These considerations have been extensively studied in prior HTGR research and development (R\&D) efforts for the range of conditions expected for the HTGR reactor design (Reference 1).

In the case of components normally exposed to the reactor inlet conditions (core support structures, inlet plenum thermal shield components, control rod drive components), the normal operating temperature of the inlet helium is in the range of $300^{\circ} \mathrm{C}$ (see response to RAI HTM-2), and no significant corrosion would be expected in these inlet areas. While higher temperatures might be seen as a result of certain licensing basis events (LBEs) involving conduction cooldown, they are both rare and of limited duration. Given these considerations, no significant degradation of inlet area metallic components is expected in most cases, and none is expected for structural components (e.g., core support structure). The one potential exception is control rod components if they are made of metallic materials. While the degradation would not be sufficient to affect the functions of control rod insertion and reactor shutdown, it may be necessary to replace the control rods following such rare events.

By contrast, the hot gas duct liner and certain hot end steam generator components (including the tubes) will be exposed to the reactor outlet temperature of $750^{\circ} \mathrm{C}$ during normal operation. Temperatures during LBEs would not significantly exceed the normal operation temperature and would be of limited duration. Data from prior R\&D efforts indicate that, with proper chemistry control during normal operation, corrosion rates are acceptable at these temperatures and would be addressed through the normal application of a corrosion allowance.

Cobalt is the alloying element that would be of greatest potential concern for activation if it were carried through the core in the coolant stream. This element is in low concentration in Alloy $800 \mathrm{H}$ and has not been found to be present in significant quantity in the oxide scale. The microchemistry of the oxide scale resulting from environmental interaction with helium containing varying levels of impurities is being characterized in the NGNP Technology Development Program (References 2 - 4). 
Enclosure 1

September 27, 2011

CCN 225396

Page 15 of 67

Reference:

1. Advanced Gas Cooled Nuclear Reactor Materials Evaluation and Development Program Quarterly Progress Reports, July 1, 1980 through September 30, 1983, DOE-ET-3402 $51,-54,-57,-64,-67,-71,-73,-83,-85,-87$, and -90 .

2. PLN-2497, 2010, "Graphite Technology Development Plan," Rev 1, October 2010.

3. PLN-2803, 2010, "Next Generation Nuclear Plant Pressure Vessel Materials Research and Development Plan," Rev. 1, July 2010.

4. PLN-2804, 2010, "Next Generation Nuclear Plant Steam Generator and Intermediate Heat Exchanger Materials Research and Development Plan," Rev. 1, September 2010.

RAI HTM-9; In Section 3.2.2.2, a statement is made that "Measurements of emissivity will be required after oxidation in air and helium to determine the most appropriate values." Similar statements could be found throughout the white paper for other properties and situations. As currently written, the white paper does not provide a roadmap to access these needed information.

Provide to the staff the status of addressing these information needs, including description of the programs and organizations that are addressing these needs. Also, discuss how the results are expected to inform the design, or confirm the existing design concepts.

\section{Response HTM-9:}

The NGNP High Temperature Materials Program has two documents that describe the NGNP high temperature material technology development needs [References 1, 2]. These two documents describe in detail all of the known issues that need to be addressed in the area of high temperature applications for metallic materials. They are updated whenever significant new information becomes available from the design teams.

During the next revision of the white paper, Section 3.2.2.2 (page 18) will be revised to provide clarification as follows:

Ensuring the performance of Alloy $800 \mathrm{H}$ components under accident conditions requires consideration of thermal properties such as emissivity and thermal diffusivity, as these are integral to the material's ability to meet applicable design requirements during a conduction cooldown event. Emissivity values after oxidation in air and helium are the most appropriate values. These experiments have been carried out at University of Wisconsin-Madison in a Nuclear Energy Research Initiative project and confirmed by results at University of Missouri-Columbia. The values agree with the expectation that essentially all chromium oxide scales have similar emissivity values. Nominal values of thermal diffusivity are available in ASME Section II, Part D at temperatures up to $815^{\circ} \mathrm{C}$ $\left(1499^{\circ} \mathrm{F}\right)$; additional data are being determined by the NGNP Technology Development Program.

References:

1. Plan PLN-2803, "Next Generation Nuclear Plant Pressure Vessel Materials Research and Development," Rev. 1, July 2010.

2. PLN-2804, "Next Generation Nuclear Plant Steam Generator and Intermediate Heat Exchanger Materials Research and Development Plan," Rev. 1, September 2010. 
Enclosure 1

September 27, 2011

CCN 225396

Page 16 of 67

RAI HTM-10: The discussion in Section 3.2.2.3 describes operating experience with Alloy $800 \mathrm{H}$ during operation of various HTGRs around the world. However, it is not clear to the staff that the history described is at full designed power output of the facilities. Provide additional information regarding the operational histories and how that experience is expected to be applicable to NGNP. What limitations are involved in extrapolating this operating experience to NGNP?

\section{Response HTM-10:}

The introductory paragraph to Section 3.2.2.3 was provided as background only to highlight the many hours of operation experienced in HTGR plants without notable issues with heat exchanger or steam generator materials. Detailed histories of the heat exchanger operating conditions that would allow direct extrapolation are not presently available to the NGNP Project.

RAI HTM-11: Section 3.2.2.3 states that "Extensive studies evaluating the effects of operating temperature on the performance of Alloy $800 \mathrm{H}$ have been performed." However, it is not clear if these studies were performed at the NGNP expected loads and atmosphere. Describe how these data will be extrapolated for the HTGR conditions, especially over long periods of reactor operation.

Response HTM-11:

Previous studies form part of the foundation for ASME's current provisions for the use of Alloy $800 \mathrm{H}$ up to $760^{\circ} \mathrm{C}\left(1400^{\circ} \mathrm{F}\right)$. The values in the Code that resulted from these experiments define the allowable stresses in the design. In addition, there are extensive data for these properties for a range of stresses at temperatures through $1000^{\circ} \mathrm{C}\left(1832^{\circ} \mathrm{F}\right)$. The influence of atmosphere has been examined for some properties, e.g., creep for up to 125,000 hours in the most likely HTGR helium chemistry. The Code allowable for design using $800 \mathrm{H}$ will be extended by ASME to a range of $850-900^{\circ} \mathrm{C}$ and up to 500,000 hours in air. This time and temperature will define the design limits for this alloy.

Note that in the present NGNP designs, Alloy $800 \mathrm{H}$ components in the reactor inlet area (see response to RAI HTM-8) will normally see temperatures close to the reactor inlet temperature and are expected to operate in the time-independent materials properties range except during limited duration LBEs (see response to RAI HTM-2). The Hot Gas Duct liner and certain steam generator components, including the tubing, will normally be exposed to reactor outlet conditions (see response to RAI HTM-3).

During the next revision of the white paper, Section 3.2.2.3 (page 18) will be revised to provide clarification as the following:

Extensive studies evaluating the effects of operating temperature on the performance of Alloy $800 \mathrm{H}$ have been performed. The minimum creep rate versus stress at $593-760^{\circ} \mathrm{C}$ $\left(1100-1400^{\circ} \mathrm{F}\right)$ was determined using regression analysis. Fatigue behavior of Alloy $800 \mathrm{H}$ has been evaluated from room temperature to $760^{\circ} \mathrm{C}\left(1400^{\circ} \mathrm{F}\right)$ and low-cycle and high-cycle fatigue data were taken at $760^{\circ} \mathrm{C}\left(1400^{\circ} \mathrm{F}\right)$. These studies form part of the foundation for ASME's current provisions for the use of Alloy $800 \mathrm{H}$ up to $760^{\circ} \mathrm{C}$ $\left(1400^{\circ} \mathrm{F}\right)$. The values in the Code that resulted from these experiments define the allowable stresses in the design. In addition, there are extensive data for these properties for a range of stresses at temperatures through $1000^{\circ} \mathrm{C}\left(1832^{\circ} \mathrm{F}\right)$. 
Enclosure 1

September 27, 2011

CCN 225396

Page 17 of 67

RAI HTM-12: Section 3.2.2.4 states that, for Alloy $800 \mathrm{H}$ "..,the [ASME] code does not address other key requirements of the design of these components, such as the emissivity, corrosion resistance, thermal aging, and irradiation effects." What efforts are currently underway in the ASME Code development for this apparent deficiency? How does the NGNP project plan to address this deficiency?

Response HTM-12:

The ASME Code covers Alloy $800 \mathrm{H}$ in terms of high temperature strength and time dependent stress effects, such as creep and stress rupture. The standard atmosphere for generating data incorporated in the Code is laboratory air. Thus, the Code does not address other key requirements of the design of these components, such as the emissivity, corrosion resistance, thermal aging, and irradiation effects. All of these potential influences on the properties are being addressed in the NGNP Technology Development Program.

During the next revision of the white paper, Section 3.2.2.4 (page 19) will be revised to provide clarification as the following:

The ASME Code covers Alloy $800 \mathrm{H}$ in terms of high temperature strength and time dependent stress effects, such as creep and stress rupture. The standard atmosphere for generating data incorporated in the Code is laboratory air. Thus, the Code does not address other key requirements of the design of these components, such as the emissivity, corrosion resistance in the helium environment thermal aging, and irradiation effects. These potential influences on the properties are being addressed in the NGNP Technology Development Program.

RAI HTM-13: In Section 3.2.3.2, it is stated that "An alternative under consideration is using a high temperature composite for the control rods." However, no information was provided in the white paper on this topic. Provide additional discussion of the materials being considered so that the staff can compare and evaluate the options.

Response HTM-13:

With regard to the specific question, if metallic alloy properties are not sufficient based on detailed design analysis, composite control rods may be considered. Both carbon fiber/carbon matrix and $\mathrm{SiC}$ fiber/SiC matrix composites have been suggested, however, there is no present activity under the NGNP Project to qualify these materials. Possible use of these materials is addressed in Section 3.5 of the High Temperature Materials White Paper.

At this time, the NGNP Project is not considering the use of Alloy X/XR at the current core outlet temperatures. Section 3.2.3 will be deleted from the whitepaper, as will other areas of the whitepaper that address Alloy X/XR.

RAI HTM-14: In Section 3.2.3.1, it is stated that "However, all of the components being considered are composed of relatively thick sections, so that the overall effects of corrosion are likely to be minimal." Given the absence of data on internal oxidation and its effect on significant properties, the selection of "relatively thick sections" may or may not be effective in mitigating progressive degradation due to potential (stress corrosion/fatigue) cracking. Provide additional justification for the claimed expected effect of corrosion. 
Enclosure 1

September 27, 2011

CCN 225396

Page 18 of 67

\section{Response HTM-14:}

At this time, the NGNP Project is not considering the use of Alloy X/XR at the current core outlet temperatures. In the next revision, Section 3.2.3 will be deleted from the white paper, as will other areas of the white paper that address Alloy $\mathrm{X} / \mathrm{XR}$.

RAI HTM-15: In Section 3.2.3.3 states that "Testing of rupture time variation with applied stress showed that Alloy $X$ would not rupture at $7 \mathrm{MPa}(1000 \mathrm{psi})$ and $871^{\circ} \mathrm{C}\left(1600^{\circ} \mathrm{F}\right)$ during the 60 year life of the plant. Test data also indicated that the creep rate at $871^{\circ} \mathrm{C}\left(1600^{\circ} \mathrm{F}\right)$ would be insignificant. These studies may later form part of the foundation for ASME allowing use of Alloy $\mathrm{X}$ at up to $871^{\circ} \mathrm{C}\left(1600^{\circ} \mathrm{F}\right)$ during normal operation." Considering the possibility of micro and macro cracks after some duration of reactor operation, what creep and rupture data exist to confirm the applicability of such data in the presence of cracks?

Response HTM-15:

At this time, the NGNP Project is not considering the use of Alloy X/XR at the current core outlet temperatures. In the next revision, Section 3.2 .3 will be deleted from the white paper, as will other areas of the white paper that address Alloy X/XR.

RAI HTM-16: Section 3.2.3.4 states that "The ASME Code does not currently address key requirements of the design of Alloy X/XR components such as corrosion resistance, thermal aging effects, irradiation effects, high temperature strength, and time dependent stress effects such as creep and stress rupture, so the qualification of these materials will require further evaluation." Does NGNP research address these evaluations? If so, what is the status of these evaluations?

\section{Response HTM-16:}

At this time, the NGNP Project is not considering the use of Alloy X/XR at the current core outlet temperatures. In the next revision, Section 3.2 .3 will be deleted from the white paper, as will other areas of the white paper that address Alloy X/XR.

RAI HTM-17: Section 3.2.4.2 does not list fatigue as one of the important considerations for modified $9 \mathrm{Cr}-1 \mathrm{Mo}$ alloy as a material for core support structure. However, limited information is provided in Section 3.2.4.3 on this issue. Provide additional information regarding the potential limitations involved in extrapolation of these limited data to 60 -year behavior.

\section{Response HTM-17:}

Section 3.2.4.2 should have listed fatigue as an important consideration for designing components made from modified $9 \mathrm{Cr}$-1Mo alloy. During the next revision, the white paper will be corrected to include fatigue in Section 3.2.4.2. The newly approved ASME Boiler and Pressure Vessel Code, Section III, Division 5 provides references to the fatigue curve for modified $9 \mathrm{Cr}-1 \mathrm{Mo}$ alloy (for elevated temperature evaluations) via Appendix $\mathrm{T}$ in Subsection $\mathrm{NH}$ of Division 1. This strain range-allowable cycles curve (Fig. T-1420-1E) contains data out to $10^{8}$ cycles.

RAI HTM-18: In section 3.2.5, and other places throughout the white paper, a 60-year design has been proposed for several components. Reference is also made for data availability for definite time periods, such as, for example, $300,000 \mathrm{hr}$. How many hours do you anticipate that the 60 year life represents? 
Enclosure 1

September 27, 2011

CCN 225396

Page 19 of 67

\section{Response HTM-18:}

The equivalent number of operational hours associated with a 60 -year design lifetime is considered to be 500,000 hours. This value is obtained by determining the total number of hours over a 60 -year time interval and assuming a $95 \%$ availability factor.

$$
(60 \text { years }) \times(365.25 \text { days/year }) \times(24 \text { hours/day })(.95)=499662 \text { hours } \approx 500,000 \text { hours }
$$

The $95 \%$ availability factor equates to about three months of shutdown every five years, which is conservative for time of use evaluations.

RAI HTM-19: There are apparently contradictory statements in Section 3.2.4.2. While comparing 300,000 hour data availability, a statement is made that "Whether this [behavior] remains true for the HTGR 60 -year design life will be evaluated during qualification." However, while considering thermal aging, data are available for only 75,000 hours, while a statement is made "Yield strength, ultimate tensile strength, and ductility are not significantly affected. Therefore, thermal aging of this material is not expected to be an issue." The staff needs some clarification on this apparent discrepancy in concepts.

\section{Response HTM-19:}

For the HTGR design, the core support structure/core barrel is the only component for which Modified $9 \mathrm{Cr}-1 \mathrm{Mo}$ is being considered. In this application, the normal operating temperature is expected to governed by the reactor inlet temperature (in the range of $300^{\circ} \mathrm{C}$ ), and will be in the time-independent materials properties range. Operation at elevated temperatures during rare LBEs involving conduction cooldown would be of limited duration and is expected to be within the range of the ASME Section III coverage. Also, see response to RAI HTM-2.

RAI HTM-20: Section 3.2.4.2 states that "No particular corrosion concerns are expected for Modified $9 \mathrm{Cr}-1 \mathrm{Mo}$ at the service temperatures of the HTGR." Provide justification for this statement, including possible effects of internal oxidation, and describing any research to evaluate this aspect for $9 \mathrm{Cr}-1 \mathrm{Mo}$ alloy.

\section{Response HTM-20:}

Modified $9 \mathrm{Cr}-1 \mathrm{Mo}$ is not currently specified for a pressure retaining application in the present steam cycle NGNP designs. Regarding its potential use in the core support structure (including the core support floor and core barrel), service temperatures during normal operation would be governed by the reactor inlet temperature (in the range of $300^{\circ} \mathrm{C}$ ), except during rare LBEs involving conduction cooldown. During such events, temperatures could be elevated for limited durations (see response to RAI HTM-2). It is further noted that this alloy is a chromia former, as are Alloys $800 \mathrm{H}$ and 617 . For these reasons, corrosion is not a particular concern. Also, see response to RAI HTM-2. Additional discussion of this topic is further provided in References 1 and 2 .

\section{References:}

1. Shah V. N., et al., Argonne National Laboratory, Review and Assessment of Codes and Proceduresfor HTGR Components; NUREG/CR-6816; June 2003.

2. Natesan K., et al., Argonne National Laboratory, Materials Behavior in HTGR Environments; ANL-02/37 NUREG/CR-6824; February 2003. 
Enclosure 1

September 27, 2011

CCN 225396

Page 20 of 67

RAI HTM-21: As mentioned in Section 3.2.4.3, the use of 9Cr-1Mo alloy in the fossil fuel industry has had qualified success due to the lack and/or implementation of quality assurance in the production of the components made from this material. It is stated that "Special care must be taken during processing, fabrication, and installation to create and maintain the proper microstructure to obtain the desired material properties. It is not currently possible to insure that the steel is properly heat treated through-thickness by means of nondestructive examination. The necessity for pre-weld and post-weld heat treatment makes onsite fabrication of components from this steel problematic." Provide a discussion of how these issues will be addressed in the intended nuclear application.

\section{Response HTM-21:}

There are currently no plans to consider the use of Modified $9 \mathrm{Cr}$-1Mo for the current HTGR steam cycle concept in a pressure-retaining application. For most of the core internals and support structures where Modified $9 \mathrm{Cr}-1 \mathrm{Mo}$ is being considered, the fabrication would not be performed on-site. Where onsite fabrication is necessary, it would be performed to the same quality standards as shop fabrication, including heat treatments. If Modified $9 \mathrm{Cr}-1 \mathrm{Mo}$ is selected for consideration for the core barrel, the wall thickness would be thin enough that current fabrication techniques would be used. The weld and inspection techniques would need to be developed and qualified.

For potential future applications requiring thick section fabrication of components using Modified $9 \mathrm{Cr}-1 \mathrm{Mo}$, a thorough qualification program would be required. Such components are not planned for the current HTGR steam cycle concept.

In the next update of the High Temperature Materials White Paper, the sentence in the second paragraph of Section 3.2.4.3 will be deleted to provide clarification;

It is not currently possible to insure that the steel is properly heat treated throughthickness by means of nondestructive examination.

While technically true, NDE is not the basis for such determinations. Rather it is accomplished by design and analysis of the heat treatment arrangement and confirmed by the monitoring of temperatures during heat treatment.

RAI HTM-22: At the end of Section 3.2.4.3 it is stated that "Fracture toughness is good and relatively constant with a KJQ value of $\sim 275 \mathrm{MPa}[\mathrm{m}] 1 / 2$ from room temperature through $200{ }^{\circ} \mathrm{C}$ $\left(392^{\circ} \mathrm{F}\right.$ ); irradiation to 3 dpa reduces $\mathrm{KJQ}$ to $\sim 100 \mathrm{MPa}[\mathrm{m}] 1 / 2$, but this is still a substantial value." This statement is potentially arguable since the expected operating temperatures are potentially much higher. In addition, "substantial" is a relative and subjective term, so the staff is unable to ascertain what the minimum value should be required for a given level of confidence in component performance. Therefore, provide additional discussion addressing these issues.

Response HTM-22:

Fracture toughness requirements for LWR components are addressed in the ASME Code, Section III, and, for pressure retaining components, in 10 CFR 50, Appendix G (Fracture Toughness Requirements), which further references Section XI of the ASME Code. The same requirements (including the requirement to account for the effects of neutron irradiation) are judged to be applicable to the modular HTGR. Since Modified $9 \mathrm{Cr}-1 \mathrm{Mo}$ is not being considered 
Enclosure 1

September 27, 2011

CCN 225396

Page 21 of 67

for pressure retaining components in HTGR, concerns with this material related to startup and pressurization are not applicable in the present HTGR steam cycle designs. In the case of core support components, loads are relatively low and temperatures modest during normal operation (in the range of $300^{\circ} \mathrm{C}$; see the response to RAI HTM-2). Note also that fracture toughness improves with temperature over the operating range of interest.

RAI HTM-23: In section 3.2.5.2, fatigue is not listed as one of the important considerations for $2.25 \mathrm{Cr}-1 \mathrm{Mo}$ alloy as a material for cold-end steam generator tubing. Provide justification for not including fatigue in these considerations.

Response HTM-23:

A discussion of fatigue should have been provided in Section 3.2.5.2. Therefore, during the next revision of the white paper, Section 3.2.5.2 (page 24) will be revised as follows:

For the cold-end steam generator tubing, material selection and qualification is based on high temperature strength, thermal aging effects, time dependent stress effects, thermal conductivity, fatigue resistance, and corrosion resistance.

RAI HTM-24: In the Section 3.2.5.2 discussion of the use of 2.25Cr-1Mo alloy for cold-end steam generator tubing, it is stated that "Thermal conductivity is integral to assessing the ability of tubing to transfer heat efficiently from the primary helium gas to the secondary side water. Measurements will be required after oxidation in air and helium to determine whether degradation of heat transfer properties will need to be taken into account." However, it was also stated in Section 3.2.5.1 that such tubing "will be exposed to helium and water during normal operation". Provide a rationale as to why such tests are not required after oxidation in water environment.

\section{Response HTM-24:}

A discussion of oxidation in water should have been provided in Section 3.2.5.2. Therefore, during the next revision of the white paper, Section 3.2.5.2 (page 24) will be revised as follows: Thermal conductivity is integral to assessing the ability of tubing to transfer heat efficiently from the primary helium gas to the secondary side water. Measurements will be required after oxidation in air, secondary water or steam, and helium to determine whether degradation of heat transfer properties will need to be taken into account.

RAI HTM-25: In Section 3.2.5.2, regarding the formation of protective layer for continued corrosion possibility, it is stated that "In the HTGR cold-end steam generator tubing, the water temperature will be about $400^{\circ} \mathrm{C}\left(752^{\circ} \mathrm{F}\right)$, which should cause the formation of a protective layer of $\mathrm{Fe}_{3} \mathrm{O} 4$." Provide information on the adhesion capacity and lift-off characteristics of this protective (apparently in-situ formed) coating for the NGNP operating environment.

\section{Response HTM-25:}

There is extensive experience with the use of this steel in fossil boiler applications and more limited experience in HTGRs and sodium cooled reactors. The native oxide has shown good adherence under the conditions encountered in these prior applications. The tenacity of this oxide may require experimental verification in either thermal cycling or flow testing if further design information suggests conditions that are significantly outside the base of experience (not expected). 
Enclosure 1

September 27, 2011

CCN 225396

Page 22 of 67

In addition, during the next revision of the white paper, Section 3.2.5.2 (page 24) will be revised to provide clarification as follows:

In the HTGR cold-end steam generator tubing, the water temperature will be about $400^{\circ} \mathrm{C}\left(752^{\circ} \mathrm{F}\right)$, which experience shows will cause the formation of a protective layer of $\mathrm{Fe}_{3} \mathrm{O}_{4}$.

RAI HTM-26: In Section 3.2.5.3, and in other places in the white paper, it is stated that "The Japanese HTTR has operated for over 10 years." However, this statement is vague, and does not adequately characterize the HTTR operating experience for evaluation of material performance. Provide additional information regarding the HTTR operating history, including actual years of full design power reactor operation, the cumulative fluence (dose), and the process parameters (i.e., temperatures, pressures, chemical environment) experienced by the various materials and components referenced in the white paper to provide some meaningful comparison.

\section{Response HTM-26:}

The statement regarding HTTR was provided as background information. There is currently no intention to utilize HTTR materials operating data to proceed with design work for the NGNP Project. With regard to the $2.25 \mathrm{Cr}-1$ Mo material, existing data as available in the ASME BPV Code and other databases will be utilized for HTGR design. Also, as discussed in Section 3.2.5.4, the Code does not address key requirements of the design components, such as corrosion resistance and thermal aging effects. Therefore, additional research \& development effort will be required.

RAI HTM-27: In Section 3.2.6.2, fatigue is not listed as one of the important considerations for $316 \mathrm{H}$ stainless steel as a material for core barrel assembly. Provide justification for not including fatigue in these considerations.

Response HTM-27:

A discussion of the potential effect of fatigue should have been provided in Section 3.2.6.2. Therefore, during the next revision of the white paper, Section 3.2.6.2 (page 25) will be revised to provide the following:

Material selection criteria for the core barrel assembly are dominated by high temperature strength, resistance to fatigue and vibration, thermal conductivity, and resistance to oxidation and neutron irradiation.

RAI HTM-28: A potential issue for materials used for hot duct liner is the possible chemical reaction with the material it is adjacent to it. For example, if the hot duct design involves tube-intube configuration with the inner tube consisting of the so-called "hot duct liner" and the outer tube of material not experiencing very high temperature with ceramic insulation in-between, then potentially two issues could be envisioned. First, in areas where the ceramic insulation is not in contact with the inner liner, those areas would not dissipate heat via conduction as readily as those areas where contact with the ceramic insulation exists, which could lead to the formation of hot spots in the inner liner. Over time, creep could occur due to material softening. Second, in areas where contact with ceramic insulation occurs, the constituents of the ceramic insulation could thermodynamically react with the liner material resulting in corrosion, pitting, cracking, and 
Enclosure 1

September 27, 2011

CCN 225396

Page 23 of 67

eventually stress corrosion cracking. If a crack breaks through the liner, the ceramic insulation could be loosened due to high coolant flow and ceramic insulation could be carried as debris with the coolant, which could also lead to erosion, erosion corrosion of the liner and other contacting components. Provide information on how these potential issues are addressed in NGNP research and design.

Response HTM-28:

Refer to the response to RAI HTM-3 for a description of the hot gas duct.

The interior of the hot gas duct liner will, by design, operate at the reactor outlet temperature during normal operation when active flow is present; thus, the formation of insulation-related "hot spots" is not a relevant issue. As noted in the response to RAI HTM-7 the stresses seen by the liner are minimal by design, and the thermal structural characteristics of the liner will be addressed by analysis.

The compatibility of the liner and insulation material will be addressed by testing where data are not presently available. Testing of the insulating characteristics of the liner, including vibration testing and cyclic thermal testing are needed to confirm the expected performance of the insulation system and to identify any potential for insulation degradation resulting from the plant design duty cycle. Details regarding the above will be addressed during detailed design efforts and the future license application process.

RAI HTM-29: In Section 3.2.2.4 and other locations, reference is made to German Standard KTA 3221. For example, Section 3.2.24 states that "German Standard KTA 3221 allows use of Alloy $800 \mathrm{H}$ up to $1000^{\circ} \mathrm{C}\left(1832^{\circ} \mathrm{F}\right)$." However, the rationale for this allowance does not appear to have been provided in the text in the white paper. Section 3.2.2.4 states that "An ASME and DOE joint effort is currently underway to obtain the basis of the KTA 3221 draft standard, including information on the quality assurance program under which the data were collected." Provide additional information which to describe the basis for the KTA 3221 standard and justify its applicability to NGNP.

\section{Response HTM-29:}

The NGNP Project does not plan to use the German Standard KTA 3221 for design purposes. It was only a draft standard that was never finalized. However, the underlying data, which includes work at Petten that was undertaken in support of the HTGR programs in Europe, are being used in an ongoing ASME/DOE Generation IV Reactor Material Project task (identified as Task 13) being managed by ASME Standards Technology, LLC. In the work on Task 13, the ASME material experts have made an effort to identify the sources of the data and to show how one source stands relative to another. Generally, the ASME material experts found that the Petten data produced more conservative stress values than the original US-produced values or the Japanese National Institute for Materials Science (NIMS) values. Any incorporation of this data will be subject to the strenuous review and approval process of the ASME BPV II Standards Committee on Materials. These issues are expected to be discussed in a final report on Task 13, anticipated to be available by the end of 2011.

RAI HTM-30: Section 4.1.4 states that "In order for a metallic material and, more generally, any structural material to be considered for use in the HTGR, it must be qualified for the appropriate service conditions and environment. In this usage, qualification implies that the material has 
Enclosure 1

September 27, 2011

CCN 225396

Page 24 of 67

been evaluated, based on a set of experimental data sufficient to reliably describe its behavior, and found to be able to meet the requirements placed upon it by the design for conditions of operation." Please state how the Code Cases mentioned in Section 4.1.3, (Code Case N-201-5 and Section III, Subsection $\mathrm{NH}$ ) will assist in qualifying these metallic structural materials (as indicated in Section 5.1).

Response HTM-30:

The definition proposed for the use of the word "qualification" from Section 4.1.4 and repeated in the RAI is consistent with the intent of its use in the white paper. In the next revision of the White Paper, Section 5.1 will be further updated to make it clear that the ASME Code is not proposed as the exclusive basis for qualification. This will be done in conjunction with the changes noted in NGNP's General Response for Metals RAls at the beginning of the Metals RAl section.

A further requirement for successful licensing is that the qualification findings must also be acknowledged by the NRC in cases where safety is an issue. Acceptance of the mentioned Code Cases by the NRC would provide a basis for regulatory compliance for evaluating the modular HTGR materials and associated application functions and requirements. While NRC acceptance of these Code Cases would significantly reduce the burden on the designer, it is acknowledged that evaluation against the Code and/or Code Cases alone is not sufficient. 
Enclosure 1

September 27, 2011

CCN 225396

Page 25 of 67

\section{Graphite RAls No. 5800 Revision 0}

RAI G-1: Section 3.1. Are there data or will data be generated for the compressive strength of graphite as functions of cumulative dose and temperature? How will such data be used in design?

Response G-1:

The NGNP Technology Development Program includes compression testing of nonirradiated samples as part of the billet characterization program. The use of nonirradiated graphite compression properties is consistent with the ASME graphite design rules (see paragraph below) and is conservative within the range of the NGNP application. As further validation, the irradiation program will include compression testing of a limited number of samples. The response to RAI G-25 provides additional discussion regarding the use of nonirradidated graphite data in the ASME code.

Currently, the NGNP Project is developing a document to further elucidate the ASME graphite design rules. The document will provide the background theories used in the ASME design rules and their application in code assessments (e.g., compressive strength requirements, use of tensile strength for determination of probability of failure requirements for various structural reliability classes, how the graphite component lifetime is determined using the design code). The plan is for this document to be an addendum to the updated white paper in the future. If the document becomes available prior to the update to the High Temperature Materials White Paper, it will be provided as a reference.

The ASME graphite design rules require the Design Specification to include key graphite material property requirements for graphite core components. For a list of required nonirradiated and irradiated mechanical property requirements for use with the ASME assessment methods, see ASME, Section III, Division 5, Subsection HH, Subpart A and Subpart A Appendixes.

During the next revision of the white paper, Section 3.1 (page 13) will be revised to provide clarification regarding the ASME design process as follows:

The above information would then be used to develop the component design and performance specification, which will state the component material and mechanical requirements under normal and accident conditions. For example, the use of ASME design rules requires a Design Specification that includes key material property requirements for graphite core components. The ASME graphite design rules provide a list of required nonirradiated and irradiated mechanical property requirements for use with the ASME graphite design rules.

\section{RAI G-2:}

Deleted by the NRC.

\section{RAI G-3:}

Deleted by the NRC. 
Enclosure 1

September 27, 2011

CCN 225396

Page 26 of 67

RAI G-4: The first paragraph of Section 3.3 briefly outlines graphite qualification testing. The completeness of the oxidation data may be questionable since in-pore diffusion data may not be available for reactor operating conditions. The significance of the diffusion characteristics as a function of oxidation depth needs to be established to understand the uncertainties in the bulk oxidation data, obtained in the kinetics region alone. How will planned graphite qualification testing ensure adequate understanding of oxidation?

Response G-4:

Oxidation occurs in three primary regimes: (1) kinetically controlled regime, (2) in-pore diffusion controlled regime; and (3) boundary-layer diffusion controlled regime. Understanding the phenomena that control all three regimes is important for predicting overall oxidation behavior. The kinetically controlled regime is characterized by lower temperatures, essentially unlimited supply of oxidants, limited diffusion of oxidants into the graphite microstructure, and nearly uniform oxidation with depth into the graphite. The in-pore diffusion controlled regime is characterized by intermediate temperatures with both kinetics and diffusion through the graphite pores controlling the overall oxidation rate. As a result, the level of oxidation (sometimes referred to as "burnoff") decreases with depth into the graphite. The boundary-layer diffusion controlled regime occurs at higher temperatures and oxidants are reacted before they can diffuse to any significant depth into the graphite. As a result, the overall oxidation rate is essentially independent of kinetics and diffusion within the graphite, and the graphite ablates at the surface. The transition temperatures for these regimes will depend on the specific grade of graphite, the oxidant (e.g., oxygen vs. water vapor), and the flow regime. The phenomena that control all three regimes are well understood and models have been developed that seamlessly account for all three regimes. These models have been verified and validated to a limited extent using data from previous experiments.

For oxidation of graphite with air in the kinetically-controlled regime, ASTM has recently developed a standard for measuring the kinetic parameters (ASTM D-7542). General Atomics has used similar procedures to measure the kinetic parameters for oxidation of grades $\mathrm{H}-327$ and $\mathrm{H}-451$ graphite by oxygen and water vapor. Previous data for $\mathrm{H}-451$ graphite have shown that the oxidation rate peaks at an intermediate level of burnoff $(\sim 20-40 \%)$ in the kinetically controlled regime, and models have been developed to account for this burnoff dependence. The kinetic rate expressions are different for oxidation by oxygen and water vapor. For oxygen, the kinetic rate generally has a power-law dependence with oxygen concentration, with the exponent ranging from $0.5-1.0$. For water vapor, the kinetic rate generally follows a LangmuirHenschelwood mechanism. In this mechanism, the rate is proportional to water vapor concentration at low concentrations, is independent of water vapor concentration at high concentrations, and is inhibited by the reaction product (hydrogen).

In the in-pore diffusion controlled regime, the effective diffusivity is an additional parameter that must be measured in order to predict the overall oxidation rate. The effective diffusivity also depends on burnoff, and correlations have been developed to account for this effect. Typically, graphite specimens that have been oxidized in the kinetically-controlled regime to different levels of burnoff (uniform burnoff throughout the specimen) are used for effective diffusivity measurements. 
Enclosure 1

September 27, 2011

CCN 225396

Page 27 of 67

In the boundary-layer diffusion controlled regime, the parameter of primary interest is the effective mass transfer coefficient of the oxidant across the boundary layer, accounting for counter diffusion of reaction products.

An ongoing activity in NGNP Graphite Technology Development Plan (Reference 1) will provide the data to determine the parameters described above and their effects on the rate of oxidation. Further, various university research grants have been awarded in this area with the intent to determine the effects of oxidation on graphite performance, specifically at normal operating conditions. These data will be combined with the programmatic data generated from the NGNP graphite research and development program to ensure an adequate understanding of oxidation mechanisms in all three oxidation regimes.

As discussed above, there are oxidation data and models for previous grades of graphite, including grades $\mathrm{H}-327$ and $\mathrm{H}-451$ used in the Ft. St. Vrain reactor. The NGNP program has completed a literature review of available oxidation reports and literature from past reactor development programs.

Note that the potential for significant oxidation would be limited to rare and limited duration LBEs. As stated in Section 3.3.7.1 of the white paper, "Oxidation of graphite components must also be considered, however, its influence on component strength and, hence, structural integrity is not expected to be significant for events within the design basis." This is due to the limited time for oxidation during one of these events (seconds to minutes for water ingress; hours to a few days for air ingress), and further mitigated by the limitations on oxidant ingress that are integral to the respective designs.

Reference:

1. PLN-2497, 2010, “Graphite Technology Development Plan," Rev 1, October 2010.

RAI G-5: Section 3.3.1 states that the fuel cycle for a prismatic reactor is expected to be about 18 months long, with about half of the fuel elements replaced at the end of that cycle. Since the fuel compacts are packed inside the fuel element block, does this mean that the fuel element blocks are replaced at 18-month intervals? Are the fuel "elements" the same as fuel "blocks?" What experience exists currently in replacing fuel blocks in a safe manner, without affecting the structural integrity of adjacent blocks or other core components, which could potentially be more brittle due to irradiation hardening and damage? During the lifetime contemplated for the reactor, how will the irradiated blocks be stored to ensure their long term integrity? What industry demonstrated methods of safe disposition currently exist for these irradiated blocks?

Response G-5:

Based on multiple questions in RAI G-5, questions and answers (Q/A) have been separated, as given below:

Q. Since the fuel compacts are packed inside the fuel element block, does this mean that the fuel element blocks are replaced at 18-month intervals? Are the fuel "elements" the same as fuel "blocks"?

A. Yes, the fuel "elements" are the same as fuel "blocks" and consist of graphite blocks loaded with fuel compacts and burnable poison compacts, which are sealed inside the graphite 
Enclosure 1

September 27, 2011

CCN 225396

Page 28 of 67

block. In typical prismatic reactor fuel cycles, half of the fuel elements are replaced at intervals ranging from approximately $18-24$ months. Thus, individual fuel blocks may reside in the core for up to four years.

Q. What experience exists currently in replacing fuel blocks in a safe manner, without affecting the structural integrity of adjacent blocks or other core components, which could potentially be more brittle due to irradiation hardening and damage?

A. The Fort St. Vrain reactor was successfully refueled on three occasions and was defueled for decommissioning with no damage to fuel or reflector elements. No prismatic reactor graphite core components experience irradiation doses exceeding turnaround, thus avoiding doses approaching the ASME cohesive limit.

Q. During the lifetime contemplated for the reactor, how will the irradiated blocks be stored to ensure their long term integrity?

A. For fuel being directly removed from the reactor temporary storage and cooling of used fuel elements can utilizes dry wells within pools of circulating water. Design options are also available for utilizing natural-convection air-cooling for this system. After one to two years of temporary storage and cooling, the fuel elements are transferred to long-term dry storage within the Nuclear Island of the plant site.

The non-fueled graphite core components in Fort St. Vrain were disposed as low level waste. Used graphite fuel blocks (graphite blocks containing fuel compacts) are stored on the Fort St. Vrain site at the Independent Spent Fuel Storage (ISFS) installation operated by the Department of Energy under NRC Docket Number 72-09. This is a dry well storage system utilizing natural-convection air-cooling. The fuel blocks are being stored in the interim until Department of Energy has identified final deposition for the fuel.

Q. What industry-demonstrated methods of safe disposition currently exist for these irradiated blocks?

A. Safe disposition of Modular Helium Reactor spent fuel elements has been evaluated [1] and it was concluded that these fuel elements are a robust waste form for permanent disposal in a geologic repository. If a strategy were adopted to separately dispose of fuel compacts and the graphite blocks (to reduce high-level waste volume), the blocks themselves would meet the current requirements for Class $\mathrm{C}$ low-level waste, based on a conservative activation analysis. Additionally, spent nuclear fuel from Fort St. Vrain and Peach Bottom Cores 1 and 2 are included in the DOE application for geological storage of spent nuclear fuel at the Yucca Mountain repository under NRC Docket 63-001.

During the next revision of the white paper, Section 3.3.1 (page 29) will be revised to provide clarification regarding the ASME design process as the following:

Both design concepts employ permanent and replaceable reflector components, the permanent sections usually being the peripheral reflector regions exposed to a much lower fluence and irradiation temperature. In prismatic designs, refueling outages occur at approximately 18-month intervals, during which one-half of the fuel elements are 
Enclosure 1

September 27, 2011

CCN 225396

Page 29 of 67

replaced. The refueling interval and fuel element replacement schedule are presently governed by fuel cycle considerations. The inner reflector elements in prismatic designs would typically be replaced at 6-year intervals during one of the refueling outages, leaving only the permanent reflectors to last the lifetime of the plant. In general, the lifetime and replacement schedules of replaceable reflector elements are dependent on the accumulated fast neutron fluence. As a result, elements adjacent to the active core will have shorter lifetimes. Previous assessments performed in the 1980s for the steamcycle modular HTGR (based on stress and thermal analyses) have shown the expected lifetimes can range from 3 years (for outer reflector blocks with control rods adjacent to the active core) to 10 years (for standard reflector elements further away from the active core), with an overall average replacement schedule of approximately 6 years. For the NGNP demonstration plant, these lifetimes will be re-evaluated based on the ASME graphite design rules that are under development.

Reference:

1. General Atomics, 2002, "Assessment of GT-MHR Spent Fuel Characteristics and Repository Performance," PC-000502, Rev. 0, April 2002.

RAI G-6: Section 3.3.1 states that inner reflector elements will be replaced about every 6 years: What is the technical basis for replacement at 6-year intervals? What in-service inspections and evaluations are planned to ensure any potential degradation during this 6-year interval is detected and understood so that the elements meet design requirements? Is it anticipated that reflector blocks may be returned to the reactor? If so, what criteria, including internal cracking, will be used to justify their continued service?

\section{Response G-6:}

The replacement schedule is an initial estimate based upon the expected dose levels at this location in the core. The criterion behind this estimate is to keep the dose below levels that approach turnaround to ensure that the graphite components remain in a compressive stress state, thus minimizing the probability of fracture. However, this initial estimate may change based upon the results from NGNP graphite irradiation experiments, wherein the onset of turnaround will be determined as a function of dose for each graphite grade that has been identified as a potential candidate for NGNP.

Inspection of replaceable reflector elements removed from the reactor during refueling operations will provide additional information that will augment the replacement schedule decisions based upon irradiation experiments performed by the NGNP Technology Development Program.

During the next revision of the white paper, Section 3.3.1 (page 29) will be revised as shown in the response to RAI G-5 to provide clarification regarding the ASME design process.

RAI G-7: Section 3.3.1. Describe the operating experience lessons learned from reflect block replacement in gas reactors. For example, how does the potential irradiation-induced brittleness affect safe removal of the block without damage to the core, such as impact of falling chunks from replacement blocks, sidewall friction to adjacent blocks, etc.? 
Enclosure 1

September 27, 2011

CCN 225396

Page 30 of 67

\section{Response G-7:}

The Fort St. Vrain reactor was successfully refueled on three occasions and was defueled for decommissioning with no damage to fuel or reflector elements. The replaceable reflector blocks were removed and replaced in the same manner and using the same equipment as the fuel elements. The fuel elements and reflector blocks were designed with appropriate dimensions and tolerances to provide the small gaps needed for installation and removal of these components. At shutdown, irradiation-induced shrinkage serves to slightly widen these gaps. During the cold shutdown conditions for refueling, the gaps were generally somewhat wider than they were at the beginning of the fuel cycle. Prismatic graphite core components receive doses well short of the cohesive life limit, therefore spalling is not expected.

Reference 1 provides a summary of Fort St. Vrain operating and maintenance experience. The Fort St. Vrain fuel handling system demonstrated that refueling could be accomplished quickly and efficiently with no damage to fuel or reflector elements and with minimal worker dose.

In the case of pebble bed reactors, the core would be unloaded prior to replacement of reflector components.

Reference:

1. W.A. Simon, A.J. Kennedy, and D.W. Warembourg, 1992, "The Fort St. Vrain Power Station Operating and Maintenance Experience," GA-A21080, General Atomics, San Diego, CA.

RAI G-8: Section 3.3.1 describes projected graphite component peak temperature during accident conditions as approximately $1100^{\circ} \mathrm{C}$ for pebble bed design and around $1400^{\circ} \mathrm{C}$ for prismatic design. What data exist for thermal conductivity and irradiation-induced expansion and contraction at these temperatures for short duration (pulse) exposure? Discuss the effect of these factors on the NGNP safety case, especially for the degradation of metallic components due to sudden creep into the tertiary regime potentially resulting in rupture of pressure boundary and release of nuclide inventory?

\section{Response G-8:}

By way of clarification, the transients associated with the noted elevated temperatures are rare design basis events that would evolve over periods of hours to a few days. There are no short duration or "pulse" exposures associated with these events.

In part, the question asks whether there are material property changes that could preclude the insulating graphite blocks from thermally protecting the surrounding metallic components during a thermal transient under postulated accident conditions. In response, the principal effect of such elevated temperatures would be a tendency to anneal the effects of accumulated irradiation damage. There are no anticipated thermal annealing effects from such thermal transients that would change the thermal conductivity or the physical dimensions of the graphite components to the extent that the metallic components could become thermally degraded from direct exposure to the hot outlet gas. Further, during such events, there would be no neutron flux, so no irradiation-induced changes (i.e., dimensional changes) would result.

Any thermally induced changes to the graphite core components will be evaluated from experience from previous nuclear graphite components as well as data from current irradiation 
Enclosure 1

September 27, 2011

CCN 225396

Page 31 of 67

testing under the NGNP Project. Data from the NGNP Graphite R\&D program and the core design will be utilized to model the likely thermal conductivity and dimensional changes

The actual thermal property changes will be obtained from the NGNP Graphite Technology Development Program. The graphite irradiation program will be measuring the specific thermal property changes in a number of graphite types proposed for use in the HTGR design.

However, in general, thermal conductivity values during thermal transient events will actually be conservative since the core temperature will increase above normal operating conditions and the irradiation damage inside the graphite core components will tend to be annealed out of the material, allowing the conductivity to increase from values that were established during normal operating conditions. The change of the thermal expansion property (i.e., coefficient of thermal expansion) is a little more complex since it is dependent upon the dose received for each individual component. In general, the thermal expansion has been observed to increase slightly for graphite that has received low dose levels but to decrease significantly for those graphite components that have received larger doses. The specific thermal expansion changes to the graphite type(s) selected for the NGNP design will be determined from the NGNP graphite irradiation program. Based upon the data from the graphite irradiation program and the core design, no metallic components would be exposed to these maximum core temperatures. See the response to RAI HTM- 8 for further discussion related to metallic components.

\section{RAI G-9:}

Deleted by the NRC.

RAI G-10: Section 3.3.2 states that, "Until the graphite code is published and accepted by the NRC, graphite material selection will focus on existing design and operating experience with both past and currently available grades of reactor graphite." Provide a description of any operating experience for currently available grades of reactor graphite. Describe any regulatory body-certified design experience for currently available grades of reactor graphite.

\section{Response G-10:}

Until the graphite code is published and accepted by the NRC, graphite material selection will focus on existing design and operating experience to guide the selection of new grades of nuclear grade graphite and/or the inclusion of currently utilized nuclear grade graphites. Graphite grade selection will consider graphite manufacturers' recommendations on proposed analog grades of graphite to replace discontinued grades or newly developed grades to replace past nuclear grade graphites.

Below are references to the HTTR program and the JAEA website where the public documents related to the operating experience with IG-110 and PGX can be downloaded. The OSTI website can be used to search for other historical HTGR reactor program documents for grades of previously used graphite that are no longer available. The British Magnox and AGR reactors are not representative of U.S. HTGR designs. The Fort St. Vrain and Peach Bottom 1 reactors were DOE demonstration reactors operating under a Class 104 NRC license. Other foreign HTGRs were research or demonstration reactors.

During the next revision of the white paper, Section 3.3.2 (page 29) will be revised to provide clarification regarding the graphite grade selection process as follows: 
Enclosure 1

September 27, 2011

CCN 225396

Page 32 of 67

Material selection for the graphite components will be based on the same general principles discussed in Section 3.1. One significant difference is that, up until now, only minimal guidance has been available from established regulatory requirements or the ASME Code regarding the use of these materials. This situation is expected to evolve, since a consensus ASME code on graphite component design for HTGRs has been prepared by the ASME Subgroup on Graphite Core Components and is expected to be published in 2011 (see Section 3.3.5 below). As explained in Section 3.3.5, the addition of nuclear grade graphite to the ASME Code would be ideal, but it is not required for nuclear grade graphite selection. Until the graphite code is published and accepted by the NRC, graphite material selection will focus on existing design and operating experience to guide the selection of new grades of nuclear grade graphite and the inclusion of past nuclear grade graphites. Graphite grade selection will consider graphite manufacturers' recommendations on proposed analog grades of graphite to replace discontinued grades or newly developed grades to replace past nuclear grade graphites.

\section{References:}

1. JAEA website: http://jolissrch-inter.tokaisc.jaea.go.jp/search/servlet/interSearch?LANG=en

2. Osti: http://www.osti.gov/bridge/

3. JAERI-M 86-192, IAEA Specialists Meeting on Graphite Component Structural Design, Sanokawa, Konomo, dated September 8-11, 1986

4. JAEA-Research-2009-042, Draft of standard for graphite core components in High Temperature Gas-cooled Reactor, Taiju; Eto, Motokuni; Kunimoto, Eiji; Shiozawa, Shusaku; Sawa, Kazuhiro; Oku, Tatsuo; Maruyama, Tadashi, dated January, 2010

5. JAERI-M 91-154, An Explication of design data of the graphite structural design code for core support components of High Temperature Engineering Test Reactor, Ishihara, Masahiro; lyoku, Tatsuo; Shiozawa, Shusaku, dated September, 1991

6. JAERI-M 7647, Temperature Irradiation Effect on the Mechanical Properties of HTGR Graphites, Tatsuo Oko, Motokuni Eto, Katsuo Fujisaki, dated March, 1978

7. JAERI 1332, Design of High Temperature Engineering Test Reactor (HTTR), Shinzo Saito, et. al., dated September 1994

RAI G-11: Based on information provided in 3.3.2, it appears that the technical basis for graphite selection is being developed for currently available grades of reactor graphite. If this understanding is correct, what basis is used for the NGNP graphite core component design?

\section{Response G-11:}

Until the graphite code is published and accepted by NRC, graphite material selection will focus on existing design and operating experience to guide the selection of new grades of nuclear grade graphite and the inclusion of current utilized nuclear grade graphites. Graphite grade selection will consider graphite manufacturers' recommendations on proposed analog grades of graphite to replace discontinued grades or on newly developed grades to replace past nuclear grade graphites.

RAI G-12: Section 3.3.2 states that, "Fabrication experience and technical maturity are additional selection criteria that must be considered." Explain how these aspects will be considered, and what criteria will be used, including their technical basis. 
Enclosure 1

September 27, 2011

CCN 225396

Page 33 of 67

\section{Response G-12:}

The quote from Section 3.3.2 states that graphite grades that have more the fabrication experience and technical maturity will be produced with improved consistency and fewer defects (disparate flaws, density variations, mixing issues, etc.). Additionally the graphite grades selected must satisfy ASTM D-7219-08, "Standard Specification for Isotropic and Near-isotropic Nuclear Graphites." The fabrication maturity was used by the NGNP Graphite Technology Development Program in part to define which graphite types were "major" grades and which were "minor" grades. The criterion used to distinguish major from minor grades was whether the grade had experience with at least one full sized batch fabrication run. Those grades that had a full-sized fabrication run were considered mature and ready for use within a reactor core and were designated as a major grade. Graphite types that only had limited fabrication batches or even laboratory process runs were not considered mature enough for consideration as a major grade.

RAI G-13: Section 3.3.3 states, "A key requirement in prismatic designs is the need for fine grained graphite, with its correspondingly higher strength, for the fuel elements to ensure an adequate number of grains across the thickness of the graphite webs between the fuel compacts and the coolant holes. Relatively high thermal stresses are generated in the thin graphite ligaments between the coolant and fuel channels in these elements. Ideally, a ligament should be no thinner than 10-times the maximum grain size." Describe how this statement is guided by design code?

Response G-13:

The new ASME graphite design code does not currently provide guidance in selecting graphite grades for use in components with thin ligaments. Such features are, therefore, the responsibility of the respective designers. The NGNP Project will petition the ASME Subgroup on Graphite Core Components to include guidance for selection of graphite grades for core components incorporating thin ligaments.

During the next revision of the white paper, Section 3.3.3 (pages 30-31) will be revised to provide clarification regarding the ASME design process as the following:

"Graphite material selection criteria further stem from the functional requirements of the graphite core components for the specific reactor type (pebble or prismatic). These key functional requirements will be described in the Design Specification. A key function not currently addressed in the ASME graphite design code is the selection of graphite grades for use in graphite components with thin ligaments, presently the responsibility of the respective designers. NGNP will petition the ASME Subgroup on Graphite Core Components to include guidance for selection of graphite grades for core components incorporating thin ligaments.

In the remaining paragraphs of this section, examples of graphites used in foreign reactors are presented as background information providing a historical summary of nuclear graphite manufacturing used in the foreign reactor programs. The introduction of these foreign high temperature gas reactors is not intended to provide insight to NGNP component sizes or to provide claims of manufacturability of future NGNP graphite core components." 
Enclosure 1

September 27, 2011

CCN 225396

Page 34 of 67

RAI G-14: In Section 3.3.3, it is stated that, 'The little available high fluence data for IG-110 at $600^{\circ} \mathrm{C}\left(1112^{\circ} \mathrm{F}\right)$ indicates similar dimensional change behavior similar to that of historic coarser grained materials, such as ATR-2E. Irradiated properties data for IG-110 tends to be presented without directional orientation on the basis that the material is isotropic; however, this is an aspect that needs some verification, since unirradiated properties measured for IG-110 in different orthogonal directions can show some variation." Provide information on the behavior of these materials (for comparison verification) for the NGNP operating conditions of temperature, fluence, atmosphere (coolant chemistry) and residence time. What information is available for these materials under accident conditions?

\section{Response G-14:}

The NGNP Graphite Technology Development Program will provide data on the behavior of directional orientation material property values for isotropic graphite types (i.e., IG-110, etc.) for the NGNP operating conditions of temperature, fluence, atmosphere (coolant chemistry) and residence time. These data will be generated from the AGC irradiation experiment, and some data will also be obtained from the as-fabricated baseline testing program once it is complete. Additional historical data on isotropic graphite types will be provided, if necessary, once a design has been established and an application is submitted. Finally, specifications and definitions for isotropic and near isotropic graphites are addressed in ASTM D7219 "Standard Specification for Isotropic and Near-isotropic Nuclear Graphites". This specification covers the classification, processing, and properties of nuclear grade graphite billets with dimensions sufficient to meet the designer's requirements for fuel elements and reflector blocks in a high temperature gas-cooled reactor.

RAI G-15: In Section 3.3.3, on page 31, the last paragraph contains a discussion on the manufacturability of graphite core components, dictated by the component size. For comparison purposes, provide relative size information for the various designs cited in this white paper, compared to the contemplated NGNP HTGR.

Response G-15:

The conceptual design of the HTGR is still underway, and a final decision regarding the HTGR design has not yet been made. Accordingly, the requested comparison cannot be made at this time. The reactor designer will use the key requirements in a design specification to select a graphite grade, considering manufacturability, grain size, and graphite costs, to achieve compliance with the ASME graphite design rules. See the response to RAI G-13.

RAI G-16: Section 3.3.4, Table 2 lists the properties of various graphite grades. Are these average properties? Are these properties originating from the manufacturer's data? Do they originate from the same type of fabrication and sources of raw materials as those being currently investigated at INL? Provide a discussion of how variation in material properties affect the NGNP design.

\section{Response G-16}

Properties from Table 2 are average values and are from public manufacturer-published source material. The fabrication process for each graphite type currently under investigation in the NGNP Graphite Technology Development Program will be the same or very similar [1]. 
Enclosure 1

September 27, 2011

CCN 225396

Page 35 of 67

The raw materials used to fabricate the graphite will be different, resulting in possible very small changes to the material properties between different batches. This variation between batches is one of the main research activities for the NGNP graphite program. Billets from different batches (and different raw material sources) will be compared to determine the variation in material properties as a function of batch. In addition, the irradiation testing program will use samples from different batches to ascertain the effects of raw material variation on irradiation induced material property changes. These changes will be determined from the NGNP Graphite Technology Development Program once irradiation testing is completed.

Reference:

1. PLN-2497, 2010, "Graphite Technology Development Plan," Revision 1, Idaho National Laboratory, October 2010.

RAI G-17: In Section 3.3.4, it is stated that, "More anisotropic grades not precisely meeting the D7219-08 degree of isotropy requirement may still be applied in HTGR applications, provided due diligence is paid to material behavior under irradiation, operating conditions (fluencetemperature), and design considerations. These grades can be applied to lower fluence regions as recommended by ASTM D7301-08, which would typically apply to the outer reflector regions." What is the basis for this apparent deviation from ASTM D7219-08 and ASTM D730108 requirements for near-isotropic graphite specifications for nuclear core components?

\section{Response G-17:}

More anisotropic grades not precisely meeting the ASTM D7219-08 degree of isotropy requirement may still be applied in HTGR applications, in low fluence conditions where changes to mechanical properties due to fluence exposure do not challenge the functional requirements of the graphite component. ASTM D7301-08 permits the use of graphite not meeting the isotropy requirement of ASTM D7219-08 for use in components where irradiation induced dimensional changes at low fluences do not challenge the functionality of the component and maintain the assigned Structural Reliability Class (SRC) requirements (see the ASME addendum to the updated white paper on the definition of Structural Reliability Class).

In the next revision of the white paper, Section 3.3 .4 (page 32) will be revised to provide clarification regarding the ASTM standards as follows:

Importantly, ASTM D7219-08 specifies a range of physical and mechanical properties for isotropic grades that allows for a broad range of nuclear graphite grades as far as raw materials, forming method, purity level, and actual properties are concerned. In lowfluence conditions, where changes to mechanical properties due to fluence exposure do not challenge the functional requirements of the graphite component and the assigned Structural Reliability Class requirements defined in Section 3.3.5 can be maintained, alternate materials may be considered in accordance with ASTM D7301-08.

RAI G-18: In Section 3.3.4, it is stated that, "It is important to recognize that the degree of isotropy only serves as an initial indicator of the graphite behavior under irradiation. End-product isotropy is influenced by raw material, grain size, forming method, and heat treatment." The reviewer understood that materials data after irradiation have been or will be generated using "end-product" specimens. Is this understanding correct? Furthermore, what specifically is 
Enclosure 1

September 27, 2011

CCN 225396

Page 36 of 67

noteworthy in this paragraph compared to what has been stated earlier regarding graphite manufacture in Section 3.3.3?

\section{Response G-18}

"End-product" specimens will be used in the irradiation program. This paragraph repeats the behavior of isotropic materials previously discussed. It will therefore be deleted in the next revision to the white paper.

The following paragraph in Section 3.3 .4 will be deleted to provide clarity to this section:

It is important to recognize that the degree of isotropy only serves as an initial indicator of the graphite behavior under irradiation. End-product isotropy is influenced by raw material, grain size, forming method, and heat treatment. Graphite billets can be fabricated by extrusion, isostatic molding, or vibration molding. Extrusion tends to yield graphites that are less isotropic and less dimensionally stable under irradiation than molded graphites, although isotropy can be improved remarkably through careful control of raw material and processing. Isostatic-molded graphite is commonly available in smaller sizes than extruded grades, while vibration molding is available for larger block sizes.

RAI G-19: In Table 3 it is stated that, "The strength reserves offered by the material must exceed the allowable operating component stresses." Explain what is meant by "strength reserves?" The response should address how these reserves compare with safety factor for design margin, and how they correlate with the probability of failure requirements for various structural reliability classes in the proposed ASME code for design of graphite core components, and discuss what assurance is provided that these "strength reserves" will remain during reactor operating life.

Response G-19:

The term "strength reserves" is not a concept used in the ASME code. Therefore, during next revision of the white paper, the use of this term will be deleted. Currently, the NGNP Project is developing a document to further elucidate the ASME graphite design rules. The document will provide the background theories used in the ASME design rules and their application in code assessments (e.g., compressive strength requirements, use of tensile strength for determination of probability of failure requirements for various structural reliability classes, how the graphite component lifetime is determined using the design code). The plan is for this document to be an addendum to the updated white paper in the future. If the document becomes available prior to the update to the white paper, it will be provided as a reference material.

RAI G-20: In Table 3, it is stated that "higher strengths are achievable with isostatic-molded, fine grain graphite, but these typically possess lower fracture toughness." In Section 3.3.3, it is stated that "A key requirement in prismatic designs is the need for fine grained graphite, with its correspondingly higher strength, for the fuel elements to ensure an adequate number of grains across the thickness of the graphite webs between the fuel compacts and the coolant holes. Relatively high thermal stresses are generated in the thin graphite ligaments between the coolant and fuel channels in these elements. Ideally, a ligament should be no thinner than 10 times the maximum grain size." Provide an explanation of the relationship between these two statements with respect to the expected or desired functionality requirement. 
Enclosure 1

September 27, 2011

CCN 225396

Page 37 of 67

\section{Response G-20:}

The new ASME graphite design code does not presently address requirements for designs with thin ligaments. The evaluation of such features is, therefore, the responsibility of the respective designers. NGNP will petition the ASME Subgroup on Graphite Core Components to address requirements for thin ligaments (also see response to RAI G-13).

RAI G-21: In Section 3.3.4.2, under the heading "Process Variables", it is stated that "the particle size distribution is generally classified by maximum grain size into coarse-, medium-, and fine-grain material." Since size distribution denotes a range of particle sizes existing in a material, clarify the classification by "maximum grain size." Also, describe what is meant by "volatile carbon artifacts."

\section{Response G-21:}

Graphite grades are categorized by the market they serve (i.e., electrode or nuclear grade graphite) and then classified by grain size. Nuclear grade graphite is made from a mixture of solid filler particles (graphite flour) and liquid binder (tar pitch) which is then heated (baked) to form a solid green body form by solidifying the liquid binder material. The liquid binder solidifies at these baking temperatures forming a solid, carbon-rich phase and short chained hydrocarbon gases comprising the "volatiles". The solid phase stays in the porous body binding the graphitic flour together while the gaseous volatiles (e.g., short-chained hydrocarbons) are driven out of the green body during this baking stage. "Volatile carbon artifacts" refers to these gaseous volatiles.

Specific graphite grain size definitions are listed in ASTM D7219 "Standard Specification for Isotropic and Near-isotropic Nuclear Graphites." For nuclear graphite, the maximum grain size is $1.68 \mathrm{~mm}$ as specified in D7219.

In addition, "volatile carbon artifacts" will be replaced with "volatile components" in Section 3.3.4.2.

\section{RAI G-22:}

Deleted by the NRC.

RAI G-23: In Section 3.3.4.2, under the heading "Process Variables, clarify what is meant by "furnace limitations. "Since graphitization is said to occur through the passage of current through the billet at very high current, is it the difficulty in having the needed electrical resistance of the billet for graphitization?

\section{Response G-23:}

"Furnace limitations" refers to the physical size limitations of the furnaces. These are large graphite components, which take a great deal of energy to fabricate, and as such the furnaces need to be rather large. As long as the furnace size meets the component requirements this is not an important issue. It is expected the reactor designer would select a graphite manufacturer and graphite grade for which the furnace size does not limit the component's size.

RAI G-24: Regarding item 6 under the heading "Process Variables" in Section 3.3.4.2, do the baking and impregnation occur at different or same location. If at different locations, what 
Enclosure 1

September 27, 2011

CCN 225396

Page 38 of 67

considerations need to be addressed to maintain the integrity and geometry of the blocks during the process cycle?

Response G-24:

Graphite manufacturing processes are controlled by and proprietary to the manufacturers. The NGNP Project does not have access to this information and therefore cannot comment on manufacturing processes and facilities. Questions regarding the graphite manufacturers'

processes and facilities should be directed to the specific graphite manufacturer and issues should be addressed during the design and licensing application phase.

The graphite manufacturers must have the knowledge and confidence in their proprietary production process to demonstrate that their graphite meets the requirements of the ASME code. The ASME code requires the final graphite billets be supplied by a manufacturer with a quality assurance program accepted by the ASME.

RAI G-25: In Table 4 of Section 3.3.5.2, clarify the definition of probability of failure. For example, is it the probability of failure of a single brick per a reactor year of operation or the probability of failure based on the distribution of expected strength of a graphite core component, when subject to operational stress at any given time of operation? Is this probability of failure based on irradiated data? If based on non-irradiated data, discuss why this usage is considered conservative.

\section{Response G-25}

The ASME graphite design rules define the probability of failure as crack initiation in a finite volume of the graphite component based on the assessment procedures of the ASME graphite design rules. The evaluation is applied throughout lifetime operation.

The prediction of crack initiation does not necessary mean imminent component failure. It is the designer's responsibility to evaluate fractures predicted by the ASME analysis procedures as fluence accumulates, and to determine if the component has lost or still maintain its functionality. The ASME graphite design rules define peak equivalent stress as the stress state at a point in the component determined using irradiated thermal properties and local irradiation strains and creep. This stress is used in calculating the probability of failure. The tensile and compressive strength used in the ASME code is collected on nonirradiated specimens. This is conservative for, as the graphite acquires fluence, both strengths increase until a limiting value of fluence defined by the cohesive life limit, is reached. The graphite core designer takes into account this behavior in designing the reactor's components. Currently, the NGNP Project is developing a document to further elucidate the ASME graphite design rules. The document will provide the background theories used in the ASME design rules and their application in code assessments (e.g., compressive strength requirements, use of tensile strength for determination of probability of failure requirements for various structural reliability classes, how the graphite component lifetime is determined using the design code). The plan is for this document to be an addendum to the updated white paper in the future. If the document becomes available prior to the update to the white paper, it will be provided as a reference material. 
Enclosure 1

September 27, 2011

CCN 225396

Page 39 of 67

In addition, Table 4, Maximum probability of failure for each safety class, will be revised to clarify the maximum probability of failure for the respective structural reliability classes as follows:

Table 4. Maximum probability of failure for each safety class.

\begin{tabular}{|c|c|}
\hline Structural Reliability Class & Maximum Probability of Failure \\
\hline SRC-1 & $1.0 \mathrm{E}-4$ \\
\hline SRC-2 & $\begin{array}{c}1.0 \mathrm{E}-4 \text { nonirradiated and } 1.0 \mathrm{E}- \\
2 \text { for irradiated components }\end{array}$ \\
\hline SRC-3 & $1.0 \mathrm{E}-2$ \\
\hline
\end{tabular}

RAI G-26: In Section 3.3.5.2, it is stated that "Another deviation from past ASME metallic codes is allowance of cracks in the graphite components. The rules require the core designer to demonstrate through analyses or testing that cracked graphite core components can maintain their assigned safety function and that the graphite component is remotely retrievable when cracks of a specified size and orientation are present." However, the staff is not able to find this provision in the draft code. The current draft code allows for defined probability of failure values for several structural reliability classes for graphite core components. The graphite core assembly itself should maintain its required geometry and be able to perform its intended functions.

Section 3.3.5.2 also states that "The code also deviates from the ASME standard practice of defining primary, secondary, and membrane stresses." However, NRC staff is unable to confirm this statement from reading the draft Code. Provide clarification, reconciling provisions of the draft ASME Code with the white paper description.

Response G-26:

ASME Section III, Division 5 provides the following clarifications related to Section 3.3.5.2:

ASME Section III, Division 5, Subsection $\mathrm{HH}$, Subpart A-3100(b)

The design approach selected is semi-probabilistic, based on the variability in the strength data of the graphite grade. Due to the nature of the material, it is not possible to ensure absolute reliability, expressed as an absence of cracks, of Graphite Core Components. This is reflected in the setting of Probability of Failure (POF) targets. Also note that due to the complex nature of the loadings of graphite components in a reactor combined with the possibility of disparate failures of material due to undetectable manufacturing defects, the Probability of Failure values used as design targets may not be precisely accurate predictions of the rate of cracking of components in service. The Designer is required to evaluate the effects of cracking of individual Graphite Core Components in the course of the design of the Graphite Core Assembly and ensure that the assembly is damage tolerant.

ASME Section III, Division 5, Subsection $\mathrm{HH}$, Subpart A-3330(b)

(b) arrange the Graphite Core Components comprising the Graphite Core Assembly so that cracking of individual Graphite Core Components does not detrimentally affect the connections between the Graphite Core Components and thus impede the functionality of the Graphite Core Assembly; 
Enclosure 1

September 27, 2011

CCN 225396

Page 40 of 67

ASME Section III, Division 5, Subsection $\mathrm{HH}$, Subpart A-3214.7

The combined stress is the sum of all of the components of stress at a point. In design, it is customary to distinguish between primary and secondary stresses. These are defined as follows:

- Primary stress is any normal stress or a shear stress developed by an imposed loading that is necessary to satisfy the laws of equilibrium of external and internal forces and moments. The basic characteristic of a primary stress is that it is not self-limiting. Primary stresses that considerably exceed the material strength will result in failure. A thermal stress is not classified as a primary stress.

- Secondary stress is a normal stress or a shear stress developed by the constraint of adjacent material or by self-constraint of the structure. The basic characteristic of a secondary stress is that it is self-limiting. Local yielding and minor distortions may satisfy the conditions that cause the stress to occur.

Due to the brittle nature of graphite, no distinction is made between primary and secondary stresses for the purpose of assessment to these rules. Combined stress is thus the combination of primary and secondary stress.

During the next revision of the white paper, Section 3.3.5.2 (page 36) will be revised to provide clarification regarding the ASME Code as follows:

"The code also deviates from the ASME standard practice of defining primary and secondary stresses. Due to the brittle nature of graphite, no distinction is made between primary and secondary stresses for the purpose of assessment to ASME graphite design rules. Combined stress is thus the combination of primary and secondary stresses. Irradiation induced stresses and mechanical stress concentrations are the largest contributors to stresses in graphite core components. These irradiation-induced stresses follow thermal and neutron fast fluence gradients within the block. These stress gradients are the critical stresses in the graphite blocks. Stress concentrations arise from keyways and dowels in the graphite components producing the highest mechanical stresses. Other mechanical stresses (combined membrane, bending and peak stresses) are of lesser magnitude, but are included in the calculation of stresses at a point."

RAI G-27:

Deleted by the NRC.

RAI G-28: It is stated in Section 3.3.5.2 that "the mechanical stresses (primary, secondary, and membrane) do not challenge the graphite core components strength margins." However, it would appear that the geometry and placement of the core components, and the presence of notches, keyways, and dowels could potentially create stress concentration effects different than primary, secondary, and membrane stress. Arguably, these stresses need to be combined with those from the irradiation induced strain and the resulting stresses to arrive at the combined stress on the component. Provide a discussion addressing these considerations. 
Enclosure 1

September 27, 2011

CCN 225396

Page 41 of 67

\section{Response G-28:}

The statement that the mechanical stresses "do not challenge the graphite core components strength margins" was included to highlight the fact that mechanical stresses are typically not governing relative to stresses induced by fluence and thermal effects. Regardless, the term "strength margins" is not congruent with the ASME code.

Per the ASME graphite design rules, all irradiation induced loads as well as all mechanical loads have to be included in determining the stress at a point. The stress state at a point is used in determining the probability of failure (Reference 1 ). This paper identifies the graphite strength margins by providing anticipated stresses in graphite components and graphite strengths in prior HTGR designs.

In the next revision of the white paper, Section 3.3.5.2 (page 36) will be revised as given in the response to RAI G-26.

Reference:

1. B. T. Kelly, 1978, "Radiation Damage in Graphite and Its Relevance to Reactor Design", Progress in Nuclear Energy, v. 2, 1978.

RAI G-29: In Section 3.3.6.1, projected service conditions for the pebble bed reactor has been provided. Provide similar information for a prismatic reactor design.

Response G-29:

Based on work done in 2007 during pre-conceptual design for the NGNP Project, the maximum fast neutron fluence for the prismatic permanent reflector blocks is less than $4 \times 10^{20} \mathrm{n} / \mathrm{cm}^{2}(E>$ $0.18 \mathrm{MeV}$ ). The maximum fast neutron fluence for replaceable reflector blocks (and fuel elements) is less than $4 \times 10^{21} \mathrm{n} / \mathrm{cm}^{2}(E>0.18 \mathrm{MeV})$ as of HTGR conceptual design. During normal operation and LBEs, the maximum graphite temperature in the fuel elements is approximately the same as the maximum fuel temperature. For normal operation, the maximum time-averaged fuel temperature is $<1250^{\circ} \mathrm{C}$. The minimum graphite temperature during normal operation is approximately the same as the coolant inlet temperature.

During depressurized conduction cooldown LBEs, the maximum peak temperature is $\sim 1600^{\circ} \mathrm{C}$ and occurs in a very small region of the core (adjacent to the inner graphite reflector of the annular core and typically in Layers 4 and 5 of the 10 layers of fuel elements) for at most a day or two.

In the next revision of the white paper, Section 3.3.6.1 (page 36) will be revised to provide clarification regarding the service conditions as follows:

The fluence levels and irradiation temperatures seen by the various graphite reflector components are dependent upon both the reactor type and their locations within the reactor. Service conditions seen by graphite components within pebble bed reactors are typically more limiting, because of their longer design lives and the correspondingly higher fluence levels that will be accumulated by some of these components. Normal operating temperatures for the pebble bed graphite reflector range between 250 and $800^{\circ} \mathrm{C}\left(482\right.$ and $\left.1472^{\circ} \mathrm{F}\right)$. The maximum temperatures that would be seen by the 
Enclosure 1

September 27, 2011

CCN 225396

Page 42 of 67

reflector graphite during certain LBEs are less than $1200^{\circ} \mathrm{C}\left(2192^{\circ} \mathrm{F}\right)$. Only components in close proximity to the pebble fuel are subjected to high fluence levels that may limit their lifetime to less than that of the design life of the plant as a whole, this maximum fluence being slightly above $1.1 \times 10^{22}$ n.cm $\mathrm{cm}^{-2}$ EDN (equivalent Dido nickel) (15 dpa). The affected parts of these components do not serve a structural function.

The maximum fast neutron fluence for the prismatic permanent reflector blocks is less than $4 \times 10^{20} \mathrm{n} / \mathrm{cm}^{2}(E>0.18 \mathrm{MeV})$ as of the NGNP pre-conceptual design. The maximum fast neutron fluence for replaceable reflector blocks (and fuel elements) is less than $4 \times 10^{21} \mathrm{n} / \mathrm{cm}^{2}$ ( $E>0.18 \mathrm{MeV}$ ). During normal operation and LBEs, the maximum graphite temperature in the fuel elements is approximately the same as the maximum fuel temperature. For normal operation, the maximum time-averaged fuel temperature is $<1250^{\circ} \mathrm{C}$. The minimum graphite temperature during normal operation is approximately the same as the coolant inlet temperature.

During depressurized conduction cooldown LBEs, the maximum peak temperature is $\sim 1600^{\circ} \mathrm{C}$ and occurs in a very small region of the core (adjacent to the inner graphite reflector of the annular core and typically in Layers 4 and 5 of the 10 layers of fuel elements adjacent to the inner graphite reflector of the annular core) for at most a day or two.

RAI G-30: Section 3.3.6.2 describes properties for baseline characterization, including compressive strength and fatigue strength. However, these properties are not discussed in Section 3.3.6.3 regarding characterization of irradiated graphite. What bases exist to suggest that compressive strength and fatigue strength are not subjected to potential degradation due to irradiation?

Response G-30:

ASME analysis procedures use data from the Material Data Sheets collected by the designer. The conservatism in using nonirradiated test data is explained in the response to RAI G-25. Moreover, see Reference 1 for discussions on fatigue strength from irradiated material and Reference 2 for a discussion on irradiated graphite strength.

References:

1. Price, R. J., "Cyclic Fatigue of Near-Isotropic Graphite: Influence of Stress Cycle and Neutron Irradiation", Carbon, Vol 16, 1978.

2. Kelly, B. T, "Radiation Damage in Graphite and Reactor Design", Progress in Nuclear Energy, Vol 2, 1978.

RAI G-31: In Section 3.3.6.3, it is mentioned that the thermal conductivity of irradiated graphite depends on the fluence and that a secondary reduction in thermal conductivity occurs at high fluence range due to more advanced material degradation. Describe what is meant by "advanced material degradation?" For example, is it "pore generation", as mentioned in Appendix B, page 82 ? The mechanism for vacancy generation by displacement of atoms is understood. What is the mechanism for generation of pores? Is it physically possible to remove material by irradiation to form pores, or are these postulated mechanisms waiting for experimental evidence? If evidence exists in the form of transmission electron microscopy 
Enclosure 1

September 27, 2011

CCN 225396

Page 43 of 67

observation, have they been verified to be consistent across different graphite types? What is the impact of such degradation on the need for removal of graphite blocks either for replacement, or for decommissioning and disposal?

Response G-31:

Advanced material degradation refers to the latter stages of graphite pore generation leading to eventual property degradation (including thermal conductivity) and structural failure in the graphite. The mechanism of pore generation is as follows. Neutron induced displacement damage in the graphite crystal causes simultaneous $\langle c\rangle$-axis growth and $\langle a>$-axis shrinkage. Initially, $\langle c\rangle$-axis expansion is accommodated within aligned cracks (porosity) contained in the graphite (e.g., "Mrozowski" or thermal cracks between graphitic basal layer planes, which form due to the anisotropic thermal shrinkage that occurs on cooling from processing temperatures).

Hence, the polycrystalline graphite exhibits overall volume shrinkage, dominated by the <a>axis shrinkage. With further displacement damage the induced $\langle c\rangle$-axis growth in the polycrystalline graphite fills the available aligned cracks/porosity and the polycrystalline graphite volume and dimensional behavior is increasingly dominated by crystal <c>-axis expansion. The rate of shrinkage of the polycrystalline graphite falls and eventually reaches zero. The polycrystalline graphite thus exhibits a volume "turnaround" phenomenon from bulk dimensional/volume shrinkage into growth. The mismatch of irradiation induced crystal strains causes the formation of local cracks or pores within the graphite structure (pore generation).

Hence, the mechanism of pore generation does not involve removal of material by irradiation. There is some microstructural evidence for induced changes in porosity (recent work at Manchester University, UK). However, much of the evidence for direct pore generation has not been published (German and UK data). Dimensional changes and physical property degradation at very large damage doses are explained by the mechanism of pore generation in graphite. This eventual structural and property degradation is recognized and limited in the ASME core component design code through the imposition of a temperature dependent cohesive life limit fluence (Reference 1 ) as the neutron fluence when $+10 \%$ linear dimensional change (with-grain) has occurred in the components and the component may no longer be considered to provide a contribution to structural performance (HHA-3142.4). Further evidence of "pore generation" will become available through the NGNP Graphite Irradiation Program, where new $X$-ray tomography tools will be utilized to examine the pore structure of irradiated graphite. The mechanism of polycrystalline graphite crack/pore generation during irradiation is expected to be common to all NGNP candidate graphite grades, as is the form of the irradiation induced volume and dimensional change curves. However, the magnitude of the minimum volume shrinkage and the temperature dependent fluence at which the cohesive life limit is attained is expected to be somewhat different for the various candidate grades. Where the reactor design requires the graphite components to operate at high neutron doses and temperatures, data will be required to define the ASME code cohesive life limit for the graphite such that it has sufficient strength for replacement or decommissioning.

Reference:

1. ASME, 2010, "Boiler and Pressure Vessel Code," Sect. III, Division 5, Sub-Section H, article HA 3000. 
Enclosure 1

September 27, 2011

CCN 225396

Page 44 of 67

RAI G-32: In Section 3.3.6.3, it is stated that "From a design perspective, the available strength reserve must be compared against the stress within the graphite component based on the fluence-temperature history of the component." Explain how this concept is handled in the design code. What criteria should be used for comparison and why? Describe the basis for accepting or rejecting a component for further service after such comparison.

Response G-32:

The ASME graphite design rules do not use the concept of "strength reserve" or "strength margins" as a measure of survivability or failure. The ASME graphite design rules define the probability of failure as crack initiation in a finite volume of the graphite component based on the assessment procedures of the ASME graphite design rules.

Crack initiation does not necessary mean imminent component failure. It will be the reactor designer's responsibility during the design activity to evaluate fractures predicted by the probabilistic analysis to exceed probabilistic thresholds as fluence accumulates, and to determine if the functionality of the component is lost or maintained.

Currently, the NGNP Project is developing a document to further elucidate the ASME graphite design rules. The document will provide the background theories used in the ASME design rules and their application in code assessments (e.g., compressive strength requirements, use of tensile strength for determination of probability of failure requirements for various structural reliability classes, how the graphite component lifetime is determined using the design code). The plan is for this document to be an addendum to the updated white paper in the future. If the document becomes available prior to the update to the white paper, it will be provided as a reference material.

During the next revision of the white paper, Section 3.3.6.3 (page 39) will be revised to provide clarification regarding the ASME code rules as follows:

Other design properties important to the evaluation of irradiation induced and mechanical loads and stresses in accordance with the ASME graphite design rules are found in Appendix II of Subsection HHA. ASME graphite design rules define the probability of failure as crack initiation in a finite volume of the graphite component based on the assessment procedures of the ASME graphite design rules. Crack initiation does not necessary mean imminent component failure. It is the designer's responsibility to evaluate fractures predicted by the probabilistic analysis to exceed probabilistic thresholds as fluence accumulates, and to determine if the functionality of the component is lost or maintained.

RAI G-33: In Section 3.3.6.3, it is stated that "Evolution of creep strain with fluence in irradiated graphite (differential strain between stressed and unstressed) specimens is characterized by primary, secondary, and tertiary regimes, much like those observed in metals." However, this statement may not be accurate. While the traditional metallic creep is analyzed by the behavior of creep strain as a function of time at constant temperature and varying applied (tensile) stress or at constant applied (tensile) stress and varying temperature, the irradiation creep is analyzed as the strain as a function of cumulative irradiation dose at mostly constant applied (compressive) stress and temperature. The staff understands that the irradiation dose could be proportional to cumulative time. However, because of the 3-dimensional variation in the 
Enclosure 1

September 27, 2011

CCN 225396

Page 45 of 67

temperature and dose, a brick could potentially experience, the concept may not be applicable. Provide additional justification for the white paper's description of creep strain evolution in graphite.

Response G-33:

Since the 3-dimensional temperature and dose profiles within the graphite components are design specific, the cumulative effect this has on graphite response will be addressed for all material properties once the design has been established. Once the proper conditions have been understood from the design, the variation in stress relief response (i.e., creep) as a function of this 3-dimensional temperature and dose variation can be effectively modeled based upon the results from the graphite irradiation program. The irradiation program will provide irradiation material property changes over a range of dose $(0.5-7 \mathrm{dpa})$ at three nominal temperature levels $\left(600,900\right.$, and $\left.1200^{\circ} \mathrm{C}\right)$ and three different stress levels $(7 \mathrm{MPa}, 14 \mathrm{MPa}$, and $21 \mathrm{MPa}$ ). Using these empirically determined values and an appropriate analytical creep model (currently being developed by the NGNP Graphite Program), the material response over a range of dose, stress, and temperature can be calculated for all positions within the graphite core. As the dose (or temperature) evolves over time the material response can be calculated up to a dose level of $7 \mathrm{dpa}$. Operation times or doses over an accumulated dose of $7 \mathrm{dpa}$ will require additional data to verify the model and calculations

RAI G-34: In Section 3.3.6.3 it is stated that "There is evidence to suggest that the normalized creep strain (normalized to initial elastic strain) is similar for different grades of graphite, lending support to the theory that this creep behavior is not material grade specific. Additional creep data would be useful in supporting this position and extending its application for a broader fluence-temperature range and for a wider variety of nuclear graphite grades. This may help in rationalizing and minimizing the need for costly irradiation creep experiments for current reactor graphite grades or grades that may be developed in the future." Other sections of the white paper suggest that all graphite properties, normalized or not, depend strongly on the type of graphite and the way it is manufactured. While some dependencies can be mathematically cancelled out by "normalization", this does not mean, per se, that the irradiation creep behavior of the different types of graphite will be the same or similar and that irradiation experiments may not be needed for various types of graphite. Why should creep be different purely from the perspective of its microstructure influencing its mechanical behavior? Provide additional discussion and justification for the white paper description of normalized creep strain.

Response G-34:

The actual physical mechanisms controlling irradiation induced creep at an atomic and microstructural level in graphite are not fully understood. This statement merely confirms the limited understanding behind creep phenomenon and proposes that additional creep data be generated to answer some of the seemingly divergent data. The intent behind this statement is that the physics at the crystallite or atomic length scale appear to be similar for all graphite grades implying that the fundamental mechanisms are common to the graphite crystalline structure rather than occurring as a consequence of the fabrication process. However, the macroscopic effect of fabrication processes on creep rates can be significant (change in grain size, final density, extruded or iso-molded, graphitization temperature, etc.). This is assumed to be true for all other graphite material properties as well. New data will help determine what the fundamental mechanisms really are and how the fabrication process can influence the macroscopic response of the graphite under irradiation. Ascertaining the actual mechanisms 
Enclosure 1

September 27, 2011

CCN 225396

Page 46 of 67

and how they can be influenced by the fabrication process will allow the scope of future graphite development and qualification programs to be correspondingly reduced. The desire is that with a better understanding of the actual physical mechanisms only confirmatory studies will be necessary for future graphite development.

The NGNP Graphite Program is investigating the various effects and mechanisms influencing creep (References 1-3). The measured creep rate as a function of dose/fluence and temperature for each major graphite grade is being investigated within the AGC irradiation program. Additionally, determination of the mechanisms responsible for irradiation induced creep is being pursued by the international graphite community (Reference 4). Specific creep data measurements for the NGNP major grades as well as further understanding of the mechanisms will be available from the Graphite Technology Development Program in the future.

References:

1. Analysis of irradiation creep experiments on nuclear reactor graphite Kelly, B.T. ${ }^{1}$; and Burchell, T.D. ${ }^{1}$ Source: Carbon, v 32, n 1, p 119-125, 1994; DOI: 10.1016/0008-6223(94)90017-5; Publisher: Publ by Pergamon Press Inc.

2. Irradiation induced creep behavior of $\mathrm{H}-451$ graphite Burchell, Timothy D. (Materials Science and Technology Division, Oak Ridge National Laboratory, P.O. Box 2008, Oak Ridge, TN 37831-6088, United States) Source: Journal of Nuclear Materials, v 381, n 1 2, p 46-54, October 31, 2008.

3. Irradiation induced creep of graphite Burchell, T.D. (Materials Science and Engineering Division, Oak Ridge National Laboratory, Oak Ridge, United States); Murty, K.L.; Eapen, J. Source: JOM, v 62, n 9, p 93-99, September 2010.

4. IAEA, 2011, www.iaea.org/NuclearPower/Technology/CRP, accessed September 21, 2011.

RAI G-35: In Section 3.3.6.3, it is stated that a program is underway to demonstrate that properties measured on subsize specimens are valid when compared to those obtained on standard specimens. However, the validity of measurements on small samples could still be questionable in representing the "sampling" volume of graphite core component of the reactor. Provide additional justification for the planned use of subsize test specimens.

Response G-35:

The limited irradiation volume available within a nuclear materials test reactor precludes the use of standard sized test samples. Smaller sized sample specimens are thus required to obtain irradiation induced material property data. The issue of sub-sized test specimens is a recognized issue for the NGNP Project, and a number of activities are being conducted to determine any potential bias from utilizing samples with non-standard sizes. These activities include determining the effect of size (i.e., thickness) on thermal diffusivity measurements, the effect of grain size to sample test volume ratio for mechanical testing, the effect of sample size and geometry on fundamental frequency measurements of elastic properties, and sample oxidation rate changes as a function of test specimen size. Other scoping studies are either planned or anticipated in order to verify that the testing standards used for characterization are valid for these non-standard sized specimens. Results from these scoping study activities will be included in the data reports from the NGNP Graphite Technology Development once they are completed. 
Enclosure 1

September 27, 2011

CCN 225396

Page 47 of 67

RAI G-36: Section 3.3.6.4 describes the PBMR Graphite Development Program. However, this program no longer exists. Revise the white paper to reflect the status of this program.

\section{Response G-36:}

The PBMR Program in South Africa has been terminated, and its design team was disbanded by the end of September 2010. All data have been turned over to the South African Government for archiving. The data are not presently available to the NGNP Project.

In the next revision of the white paper, Section 3.3.6.4 (page 40) will be modified as follows to clarify the status of the PBMR program:

\section{PBMR Graphite Development Program}

Prior to its termination in late-2010, the PBMR program in South Africa was working on the development of the Pebble Bed Modular Reactor for electricity and process energy. In support of the proposed PBMR Demonstration Power Plant (DPP), a detailed Materials Qualification Plan (MQP) was developed for NBG-18 graphite and partially implemented. The objectives of the MQP were two-fold:

- To characterize the as-manufactured and irradiated properties of NBG-18 graphite as a basis for confirming its suitability for use in the PBMR and its compliance with the requirements established for the PBMR reflector components.

- To validate the PBMR analytical models for predicting the behavior of irradiated graphite.

The approach taken in the MQP was to utilize the extensive historical database characterizing the irradiated properties of the earlier German ATR-2E and VQMB graphites, since those grades were believed to be similar to NBG-18. The MQP's irradiation test program would then have been used to validate the use of this existing database in developing analytical models for the initial design and structural analysis of the graphite core structures, and to supplement this database in areas where data were sparse or unavailable.

The overall strategy was for the irradiated properties database to be sufficiently complete by initial startup of the DPP to confirm or improve the accuracy of analytical models for graphite design, and to justify operation of the plant over a substantial portion of its life. Thereafter, the remainder of the irradiation test program would substantially lead the actual operation of the initial plants.

By the time of program termination, several batches of pre-production NBG-18 graphite had been acquired and characterized. The characterization of as-manufactured properties was effectively complete. The graphite irradiation tests were in the planning stage, but not started. All data have been turned over to the South African Government for archiving. The data are not presently available to the NGNP Project. 
Enclosure 1

September 27, 2011

CCN 225396

Page 48 of 67

RAI G-37: In Section 3.3.6.4, under the heading "NGNP Graphite Development Program", it is stated that, "respectively, NBG-18 (coarse grain size, pitch coke, vibration molded) and PCEA (medium grain size, petroleum coke, extruded) graphites are considered to be grades most likely to meet the initial pebble-bed and prismatic design requirements." However, in Section 3.3.3, it is stated that "A key requirement in prismatic designs is the need for fine grained graphite, with its correspondingly higher strength, for the fuel elements to ensure an adequate number of grains across the thickness of the graphite webs between the fuel compacts and the coolant holes." Thus, Section 3.3.3 advocates the use of fine-grained iso-molding processing and material derived thereby. Clarify the implications of potentially different materials used for the same purpose. Are these materials interchangeable? Can one be substituted by the other for replacement?

Response G-37:

During the next revision of the white paper, NGNP Section 3.3.3 will be revised to clarify the statement as the following:

A key requirement in prismatic fuel elements is the need for finer grained graphite, with its correspondingly higher strength, to ensure an adequate number of grains across the thickness of the graphite webs between the fuel compacts and the coolant holes.

Also, to clarify this section, the statement that iso-molded graphites need to be used for prismatic designs will be deleted. The only actual requirement is that the grain size be small enough to yield enough grains across the fuel element webs. The intent, of course, is that the graphite grain size must be significantly smaller than the web thickness dimensions to avoid the problem of having only one or two grains bridging the web thickness between fuel and coolant channels in the fuel element. If this basic requirement is met, then the materials can be interchangeable or substituted if they meet core design requirements (also see the responses to RAIs G-13 and G-20).

RAI G-38: In Section 3.3.6.4, it is stated that "Complete properties data need to be developed for the graphite(s) eventually selected for the NGNP. Once the baseline material properties for the selected graphite grade(s) have been established, irradiation induced property changes must then be determined, including the characterization of irradiation induced creep. Determining these properties are important data needed for the design to satisfy the safetyrelated functions identified in Section 3.3.6.1." Describe plans to provide sufficient data and information on the selected graphites for verification and confirmation by the NRC staff in review of the expected NGNP combined license application. If data are not expected to be available when that application is submitted, describe how the application will address this issue so that the NRC staff can conduct an informed evaluation.

\section{Response G-38:}

The NGNP Project plan to provide sufficient data and information on the selected graphite types is outlined in the plan (Reference 1). The NGNP Graphite Technology Development Plan (TDP) outlines the development activities to qualify the major graphite types and provides a timeline of when the data are expected to be available for review. 
Enclosure 1

September 27, 2011

CCN 225396

Page 49 of 67

Reference:

1. PLN-2497, "Graphite Technology Development Plan," Rev 1, Idaho National Laboratory, October 2010.

RAI G-39: Appendix B states that "structural and dimensional changes in polygranular graphites are a function of both the crystallite dimensional changes and the graphite's texture." Describe what is meant by graphite's texture.? If texture is related to the surface structure of graphite, for example roughness, then what role does irradiation play to roughen the surface? Discuss the effect of roughness on coolant flow.

Response G-39:

Graphite texture simply refers to the alignment (or lack of alignment) of the individual crystallite grains in the graphite microstructure. Nuclear grade graphite types possess isotropic or nearisotropic microstructures which correspond to minimal texture. Texture occurs primarily from the green forming process (i.e., extrusion, vibramolding, or isomolding) with extrusion imposing the most texture on the microstructure and isomolding imposing little to no texture.

Graphite roughness is a direct function of the inherent porosity for each graphite type. The larger the pores inside the graphite material the rougher the surface will be when the component is machined. Irradiation should not affect the surface roughness of the graphite component.

Surface roughness of the graphite components does have an effect on the coolant flow and the extent of this effect is being investigated through university lead NEUP research projects.

RAI G-40: Appendix B describes the cohesive life limit. Provide additional definition of this limit. For example, is it a function of cumulative dose? How is the cohesive life limit affected by the temperature, atmosphere (coolant chemistry), and imposed stress? Can the cohesive limit creep-in before the expansion?

Response G-40:

The ASME Section III, Division 5, Subsection HH, Subpart HHA-3142.4 Graphite currently defines cohesive life limit as the following:

A temperature-dependent cohesive life limit fluence is to be defined for the graphite grade used for Graphite Core Components. Material that exceeds this fluence limit is considered to provide no contribution to the structural performance (stiffness and strength) of the Graphite Core Component. This fluence limit shall be set to the fluence at which the material experiences a $+10 \%$ linear dimensional change in the with-grain direction. For full assessment (HHA-3230), this material shall not be included in the volume of the Graphite Core Component assessed.

In addition, the NGNP Project will petition the ASME committee to provide more guidance on the cohesive life limit, taking into account coolant chemistry and irradiation induced creep.

RAI G-41: Appendix B: What difference, if any, exists between the irradiation creep when tensile stress is imposed versus the application of a compressive stress? What type of calculations and/or predictive relationships exist between the volumetric changes, considering 
Enclosure 1

September 27, 2011

CCN 225396

Page 50 of 67

the two types of stresses? If mixed type of stress (e.g., biaxial tension or compression) exists, what would be their effect on irradiation creep and the resulting volumetric change in graphite? Discuss the importance of these factors for the NGNP design.

Response G-41:

Irradiation creep in graphite is more accurately described as "stress relaxation from irradiation induced strain". Since the strain (i.e., creep) is a function of the imposed stress state, the amount and rate of strain within the graphite material will depend closely upon the stresstensile, compression, or biaxial. The most significant stresses imposed upon the components result from irradiation induced dimensional changes and on a smaller scale the compressive forces from stacking the components in the core. Under irradiation, nuclear grade graphite typically experiences macroscopic shrinkage until turnaround, where the material response switches to volumetric expansion. The irradiation induced stresses due to the dimensional changes are therefore primarily compressive in nature at lower doses with gradually increasing induced tensile stress states as the dose increases. These conditions are expected to induce a significantly complex stress state within the graphite ranging from pure tensile to pure compression and fully mixed stress states.

Common observations from previous irradiation creep experiments over the past 50 years have shown little difference in creep rate between loading the test samples in either compression or tension for lower irradiation doses, during dimensional shrinkage. However, the rate can change significantly from the applied stress state once turnaround has been achieved [1]. The tensile creep rate can be accelerated or reduced once turnaround is reached if the test samples are placed under tensile or compressive loading, respectively. The assumption is that these are conservative rate limits, and mixed stress states would tend to be in between these purely tensile loaded and compressive loaded samples.

The NGNP Graphite Program is investigating the various effects and mechanisms influencing creep. Within the AGC irradiation program the measured creep rate as a function of dose/fluence and temperature for each major graphite grade is being investigated for dose levels up to turnaround levels $(0-7 \mathrm{dpa})$. Over this dose range, the samples can be loaded in compression or tension without differences. Dose levels of $\sim 7 \mathrm{dpa}$ are estimated to allow $12-$ 15 years of active service for the graphite components receiving the highest flux levels for the current reactor designs. If the reactor design requires graphite components to receive doses exceeding $7 \mathrm{dpa}$, additional tensile loaded irradiation experiments will be required to measure the creep rate of the major grades of graphite for dose levels past turnaround.

Additional information on this subject can be found in References 1-3.

References:

1. PLN-2497, "Graphite Technology Development Plan," Rev 1, Idaho National Laboratory, October 2010.

2. R.J. Price, 1981, "Irradiation Induced Creep in Graphite: A review," GA-A16402 UC-77, August 1981

3. T.D. Burchell, 2009, "Irradiation Induced Creep in Graphite at High Temperature and Dose - A Revised Model," ORNL/TM-2008/098, February 13, 2009. 
Enclosure 1

September 27, 2011

CCN 225396

Page 51 of 67

\section{RAI G-42:}

Deleted by the NRC.

RAI G-43: Appendix B states that specific heat is rather invariant with graphite type and also is not influenced by irradiation. However, there seem to be observations which indicate that irradiation affects specific heat, at least at low temperature. For example, see : (1) T. Iwata and M. Watanabe, "Increase in specific heat and possible hindered rotation of interstitial C2 molecules in neutron-irradiated graphite" Phys. Rev. B 81, 014105 (2010); (2) W. DeSorbo and W.W. Tyler, "Effect of Irradiation on the Low-Temperature Specific Heat of Graphite", J. Chem. Phys. 26, 244 (1957). Furthermore, different equations have been provided for different types of graphite in General Atomics "Graphite Handbook." In addition, that W. Windes, T. Burchell, and R. Bratton in "Graphite Technology Development Plan", INL/EXT-07-13165, p 23 (2007) state that "changes to the specific heat due to oxidation and/or irradiation will be compared to asreceived values." Provide additional discussion of graphite specific heat characteristics, addressing information given in the references cited.

Response G-43:

As stated, the specific heat values of graphite are not expected to significantly change due to irradiation. The cited references specifically address low temperature irradiation testing where point defect populations and higher subsequent stored energy levels are expected to be significant with little recombination of point defects.

The NGNP Graphite Program will be measuring irradiation induced specific heat changes, if any, during post irradiation examination of the tested grades of graphite. As stated in the Graphite Technology Development Plan, there is minimal change expected from these samples exposed to high temperature irradiation. However, if significant changes are detected from the post irradiation examination (PIE) the graphite program will focus more attention on the measurements and mechanisms.

RAI G-44: Appendix B states that "emissivity of given graphite will depend on its surface condition and the environmental temperature." It is further stated that "The emissivity of nuclear graphite is not expected to change significantly with irradiation." Provide additional justification for the expected irradiation performance, including discussion of irradiation effects on graphite surface structure.

Response G-44:

The surface condition (i.e., roughness and/or deposits) are the only factors that could affect the thermal emissivity for graphite. It is anticipated that any changes to the graphite surface condition which would affect the emissivity will cause minimal changes since if the surface (i.e., material) is removed or altered the surface will still retain a pure black appearance with the same equivalent emissivity levels. The only mechanisms anticipated to affect changes to the emissivity would be exposure to the reactor environment causing surface roughness changes or small oxide deposits from impurities within the graphite or coolant environment forming on the surface. Any changes to the surface condition are chemical (e.g., oxidation of graphite), rather than irradiation induced, and, therefore, irradiation effects are expected to be marginal, if present at all. 
Enclosure 1

September 27, 2011

CCN 225396

Page 52 of 67

Any surface roughness changes will minimally affect emissivity since any new surface exposed will still be graphite in nature and have the same emissivity values. In concept, for those graphite types with higher metallic impurity levels any oxidation from the coolant environment may produce small oxide deposits which would be formed on the outer surface of the graphite components and could affect the emissivity depending upon the purity levels of the graphite and coolant environment. However, nuclear grade graphite and the coolant chemistry in the NGNP core are expected to be very pure, minimizing any oxide deposits on the graphite surfaces even for long periods of time.

NGNP Project is working with various universities within the NEUP research program to measure any possible changes to the emissivity of graphite during exposure to the reactor core environment. If significant changes are discovered to actually occur, the program will perform additional activities to measure the extent of these changes (Reference 1).

Reference:

1. PLN-2497, 2010, "Graphite Technology Development Plan," Rev 1, Idaho National Laboratory, October 2010.

RAI G-45:

Deleted by the NRC.

RAI G-46: Section 3.3.6.4 states that "the prismatic HTGR design assumes that fuel and reflector blocks will be replaced well before turnaround." Clarify what is meant by "well before turnaround". What specific monitoring and inservice inspection will be used to know the dose limit "well before turnaround?"

Response G-46:

"Turnaround" refers to the fast neutron fluence at which the irradiation-induced dimensional change transitions from shrinkage to expansion. The turnaround fluence depends on the particular grade of graphite, the irradiation temperature, and can vary with grain orientation. Turnaround fluences will be determined as a part of the NGNP AGC program for NGNP Project graphite candidates.

The replacement of fuel elements will be governed by the fuel cycle. The replacement of reflector blocks will be guided by the data from the AGC program, supplemented by examination of replaced blocks. Also, see the response to RAI G-29 for projected fluences at replacement.

RAI G-47: In Section 3.3.6.4, it is stated that "test specimens from these grades were irradiated at $750^{\circ} \mathrm{C}\left(1382^{\circ} \mathrm{F}\right)$ up to high fluence (in excess of $20 \mathrm{dpa}$ ), beyond turnaround" in Petten irradiation program. However, results have not been provided in the white paper. Based on the results, describe how these grades compare in their volumetric change due to irradiation.

Particularly for the prismatic design, apparently contradictory statements have been made about the merits of using fine-grained as well as medium-grained graphite for fuel elements. Provide additional information on the dimensional change behavior of these two grades. 
Enclosure 1

September 27, 2011

CCN 225396

Page 53 of 67

\section{Response G-47:}

In the next revision of the white paper, Section 3.3.6.4 (page 43) will be modified to clarify that the Petten experiments were not irradiated to greater than $20 \mathrm{dpa}$. The NGNP AGC program will be producing irradiation data on both fine and medium grained-graphite in the future.

The following change will be made:

Test specimens from these grades were irradiated at $750^{\circ} \mathrm{C}\left(1382^{\circ} \mathrm{F}\right)$ up to fluences of approximately $10 \mathrm{dpa}$. A second phase of irradiation at $950^{\circ} \mathrm{C}\left(1742^{\circ} \mathrm{F}\right)$ up to fluences of between 12 and 14 dpa has been completed. These irradiations at HFR Petten (Netherlands) aim to provide irradiated properties data that can be used to compare irradiation behavior and post-irradiation properties of the different reactor grades available today. When the HFR Petten irradiation data are publically released, NGNP will compare the Petten data with NGNP irradiation data.

RAI G-48: In Section 3.3.6.4, it is stated that "Graphite irradiation tests programs are also planned by China in support of the HTR-PM..." Describe what properties will be determined after irradiation using IG-110 graphite and when these data may become publicly available. Are there attempts to determine the extent of similarity of the Chinese irradiated specimens to those which are being irradiated in AGC program?

\section{Response G-48:}

The NGNP Project is not intending to use the Chinese test data for qualification of graphite materials, nor is the NGNP Project a participant in the Chinese project. Therefore, NGNP Project has no knowledge of the program beyond the fact that it exists. The discussion was provided as reference to future graphite testing that would be performed. The detailed Chinese test data are considered proprietary and are currently not available to the NGNP Project. Therefore, the data will not be used by the NGNP Project.

During the next revision of the white paper, Section 3.3.6.4 (page 43) will be modified to clarify the graphite irradiation program as follows:

Non-NGNP graphite irradiation tests programs are planned by China in support of the HTR-PM, a steam cycle pebble bed concept designed as a commercial follow-on to the HTR-10. The Chinese program is graphite-specific and covers the operating fluence-temperature envelope expected for the HTR-PM. The HTR-PM design is very similar to the German HTR Modul. However, unlike its German predecessor, which employed coarse grain, pitch coke nuclear graphite as reflector material (e.g., ATR-2E, ASR-1RS, PXA2N), the HTR-PM will employ fine-grained, isostatically-molded, petroleum-coke based IG-110 as the reflector graphite. This follows from the use of IG$11 \mathrm{for}$ the HTR-10 graphite reflector. Data from the Chinese program are proprietary and not available to the NGNP Project and, thus, will not be used by the NGNP Project.

RAI G-49: In Section 3.3.7.1 it is stated that "Oxidation of graphite components must also be considered, however, its influence on component strength and, hence, structural integrity is not expected to be significant for events within the design basis." What is the basis for this statement? For example, what evidence is currently available for the effect of simultaneous irradiation-induced graphite degradation and chemical reactivity degradation with the coolant constituents? Are they cumulative (separately additive) in nature? How are tensile, 
Enclosure 1

September 27, 2011

CCN 225396

Page 54 of 67

compressive, and shear strength of graphite affected by the combined degradation mechanisms?

\section{Response G-49:}

The Designer will use the ASME code to account for oxidation in the design of graphite components. ASME Section III, Div. 5, Subsection HH, Subpart HHA 2131 states that the "Design Specification" shall contain the requirements for materials qualification, including envelopes for irradiation and oxidation. Further, HHA 2230 stipulates that data for oxidation effects shall be in the "Materials Data Sheets." Subpart HHA 3000 contains rules for design. HHA 3142 states that graphite shall be considered oxidized when the anticipated weight loss exceeds $1 \%$. Plots are provided for the degradation of strength for several graphite types. HHA 3142 provides rules for designing with irradiated graphite. Changes in strength with irradiation dose are part of the required Materials Data Sheet (HHA Appendix II) but need only be provided if the designer chooses to take account of the increase in strength at low to moderate dose.

In practical terms, the operating specifications for the modular HTGR coolant will preclude the possibility of significant oxidation-related strength degradation during normal operation. In addition, significant degradation would not be expected for events within the design basis.

RAI G-50: In Section 3.3.7.2, "inherent fault tolerance" of the reflector is mentioned in several places. Provide a definition of this term, including discussion of defined engineering margins which are used to support statements in the white paper. Why does this fault tolerance provide safety confidence?

\section{Response G-50:}

Section 3.3.7.2, "Reliability and Integrity Management (RIM) Program and the Outcome Objective for RIM Program," as discussed in Section 5.2 Non-Metallic Materials, will be deleted from the white paper. The plant operational considerations presently discussed in Section 3.3.7.2 will be defined during the final design and licensing application phases.

The term "inherent fault tolerance" is not used in the ASME graphite design rules and, therefore, does not represent any concept of design safety. Its inclusion in the white paper was based on the judgment that the basic characteristics of the design make it tolerant to failures.

RAI G-51: In Section 3.3.7.2, visual inspection has been mentioned as a potential candidate for the RIM program. What are the effects of potential coating of cracks or other flaws by graphite dust and thus compromising possible detection? If flaws or cracks or crack-like defects are observed, what mechanisms are there for evaluating the safety significance of these observed "defects"? How will observance of these defects relate to the concept of "inherent fault tolerance" mentioned in this section?

Response G-51:

As stated in the response to RAI G-50, Section 3.3.7.2, "RIM Program" and the corresponding Outcome Objective, Item 3 in Section 5.2, "Non-Metallic Materials," will be deleted from the white paper.

RAI G-52: In Section 3.3.7.2, it is mentioned that "the designs of prismatic reactor concepts typically provide for the replacement of permanent graphite structures should unanticipated 
Enclosure 1

September 27, 2011

CCN 225396

Page 55 of 67

degradation occur." What is the operational experience in replacing such rather tightly packed columns without potential damage to adjacent components and structures? Discuss how lessons learned from this experience will inform NGNP design and operation.

Response G-52:

Actual operating experience with commercial prismatic reactors is limited to Fort St. Vrain. The response to RAI G-7 addresses normal operation removal and replacement of fuel elements and replaceable reflectors in prism designs. Replacement of permanent reflectors in prism designs or replacement of any reflectors in pebble bed designs would be accomplished after first unloading the core. There is operational experience with initial placement of permanent reflectors; however, there is no operational experience with replacement of permanent reflectors in HTGRs.

As stated in the response to RAI G-50, Section 3.3.7.2, entitled, "RIM Program" and the corresponding Outcome Objective, Item 3 in Section 5.2, "Non-Metallic Materials," will be deleted from the white paper.

RAI G-53: In Section 4.2.1.1, it is stated that "Nuclear graphite has been successfully employed in the construction and operation of gas-cooled reactors, including HTGRs, for over 50 years." However, arguably, no such experience exists to extrapolate information for the expected operational conditions of the NGNP. For example, even though the British AGRs have been operating for a long time, their operational conditions are vastly different than the NGNP HTGR. Additionally, cracking in fuel element channels and control rod channels have been observed in the British AGRs since 2002, while such cracking was not initially expected. It appears that EDF Energy is providing revised safety case documents based on inspection data and the British regulators are continuously reviewing these documents to authorize continued reactor operation. The other HTGRs have not had field experience for such long term operation, including the Japanese HTTR and the Chinese HTR-10. Thus, the statement about "successful operation" is arguable. As has been stated in the white paper, properties information are lacking and are being generated currently for the newer grades of nuclear graphite. Provide additional discussion of the relevance and limitations of applying operating experience for graphite in other gas-cooled reactors to NGNP.

Response G-53:

The NGNP Project uses foreign reactor high temperature reactor program data only as background material and will not use this data for final design or licensing. The NGNP Project cannot comment on technical aspects of other foreign governments' or foreign countries' high temperature gas reactor programs, since these programs and reactors are not under NGNP Project control, nor will they be used to support licensing of the NGNP.

In the next revision of the white paper, Section 4.2.1.1 (page 63) will be modified to clarify ASME code for graphite structures as follows:

Nuclear graphite has been employed in the construction and operation of gas-cooled reactors, including HTGRs, for over 50 years. Up until this time no industrial design code or regulatory basis was in existence to assist in the regulatory approval process concerning graphite core structures. In the U.S., past HTGR designs were licensed as a 
Enclosure 1

September 27, 2011

CCN 225396

Page 56 of 67

DOE demonstration reactors with a Class 104 NRC license. An ASME code for graphite structures is presently being developed as ASME Section III, Division 5, Subsection HHA.

RAI G-54: Section 4.2.1.1 includes a discussion of a test program planned for deployment of the PBMR in South Africa. However, this project no longer exists, so the relevance of those plans to NGNP is questionable. Provide revisions to the white paper to reflect the current status of the PBMR project, including test programs which may not have been completed before the project was terminated.

Response G-54:

The following paragraphs in Section 4.2.1 (page 65) will be deleted in the next revision of the white paper, since, the PBMR program is no longer accessible by the NGNP Project, and the data will not be used by the NGNP Project for graphite qualification.

As an example, Figure 5 illustrates the relationship between the legacy German database and the PBMR Specific Materials Test Reactor Program irradiation conditions that were selected earlier for the proposed PBMR Demonstration Power Plant in South Africa. The solid blue line in the figure represents the projected temperature-fluence envelope at the end of service life for components that serve a structural function (SRC1, as defined in Table 4), whereas the dotted red line denotes a similar envelope for the most highly-irradiated nonstructural components adjacent to the pebble fuel (SRC-2). As shown in Figure 5, the primary and secondary MTR data are designed to both confirm the applicability of the historical data and to supplement that data where required.

Finally, the proposed service life of the graphite components in the PBMR implies the need for a relatively lengthy MTR program. On this basis, the PBMR approach is to acquire MTR data for a significant portion of the service life prior to the start of the lead reactor. The balance of the MTR data would be acquired in such a manner that it substantially leads the actual operation of the reactor.

RAI G-55: In Section 4.2.1.3, it is stated that "The PIRT panel also concluded that theories that can explain graphite behavior have been postulated and, in many cases, shown to represent experimental data well." It is the NRC staff's understanding that phenomenological (curvefitting) relationships developed using MTR data has worked reasonably well to predict graphite behavior, specifically for the British AGRs, but do not reflect operating conditions projected for the NGNP HTGR. Also, the NRC staff is not aware of any tested and proven theories which have explained the graphite behavior for all the graphite properties. British AGRs have experienced cracking in unexpected places, and in cracking modes that were not predicted. There is also some Japanese work which has developed theory for volume change due to irradiation; however, the staff is not aware of any operational experience which has supported such theory. Provide additional discussion of the relevance and limitations of applying current graphite behavior theories to NGNP.

Response G-55:

The graphite behavior theories discussed in the PIRT panel will not be used for final NGNP design or NGNP licensing. The ASME graphite core design rules use empirical mechanical and thermal data collected from qualified providers with known statistical confidence levels. The 


\section{Enclosure 1}

September 27, 2011

CCN 225396

Page 57 of 67

relevance of these graphite behavior theories is moot, since the ASME graphite core design rules will be used.

The second paragraph in Section 4.2.1.3 will be deleted, which includes the statement:

The PIRT panel also concluded that theories that can explain graphite behavior have been postulated and, in many cases, shown to represent experimental data well. 
Enclosure 1

September 27, 2011

CCN 225396

Page 58 of 67

\section{Carbon Composite RAls No. 5899 Revision 0}

The NGNP Project plans to update Sections 3.5 and 4.2.3, Composites Materials, during the next revision of the white paper. Section 4.2.3 "Composites" will be deleted and Section 3.5 will be updated to clarify the purpose of the information being provided for this section. The information provided in this section is presented as background information providing a historical summary of nuclear composite development and manufacturing used in previous U.S. reactor designs as well as foreign reactor programs. The introduction of these foreign high temperature gas-cooled reactors is not intended to represent them as a basis for NGNP core component qualification. The following provides the intended change for Section 3.5:

Currently there has been no application of Carbon Fiber Reinforced Carbon (CFRC) composites in nuclear reactors, including HTGRs. Germany conducted some development work on CFRC components in the past, and the US NGNP program has addressed some current aspects of structural CFRC components for the NGNP design. However, the use of composite components are very design specific, with some reactor designs requiring components made from composite materials but other designs not requiring any composite components. Because specific composite components have not yet been selected for development within the NGNP Project, the project cannot provide specific information on areas for composite research and development.

In addition, there are no established general design codes or standards addressing composite materials for HTGR applications that are analogous to the ASME Code for metallic or graphite components. However, there is a plan within ASME to address this matter through the ASME Subgroup on Graphite Core Components (SGCC). This subgroup has been officially sanctioned by the Board on Nuclear Codes and Standards as part of the BPV Code Section III infrastructure. The SGCC has concentrated its efforts to date on nuclear graphite (see Section 3.3.4); however, high temperature composites are also a part of the subgroup charter. The ASME Code section on nuclear graphite will be issued in 2011 , and the expectation is that the composites code will be addressed thereafter.

Given the current status, the proposed bases for qualification of composite components have not yet been developed. However, general information from past and present research and development programs for composite components is presented herein to provide a background understanding of the general issues that are involved in qualifying composites for use within HTGRs. The specific bases for qualification and regulatory review are to be developed later.

In addition, the NGNP Project plans to update Section 5.2, Outcome Objectives for Nonmetallic Materials, based on above clarification

RAI COMP-1: Information presented in Section 3.5.2.1 is unclear, because the meaning and usage of qualitative adjectives used (i.e., high, low, extremely high, excellent, relative, moderate, etc.) is unclear. The text states such attributes should be "considered." Since these are relative terms, what bases are being used for comparison? Are the properties determination methods the same for these varying attributes, namely for the entire range or the methods could differ for different ranges for these properties? 
Enclosure 1

September 27, 2011

CCN 225396

Page 59 of 67

\section{Response COMP-1:}

See the revised introduction regarding the status of the NGNP design and development of composite materials (i.e., NGNP's General Response for Carbon Composite RAls).

Once a reference design for the NGNP core components have been established quantitative measurements/attributes will be presented in support of the composite components. These measured properties will be compared to the specification requirements established within the reference design criteria.

RAI COMP-2: Section 3.5.4.2: With respect to fatigue resistance, especially for tie-rods, straps, and other functional components, how will the acceptable fatigue limits be determined and applied? What type of modification to currently acceptable fatigue rule will be made?

Response COMP-2:

See the revised introduction regarding the status of the NGNP design and development of composite materials (i.e., NGNP's General Response for Carbon Composite RAls).

However, in general, the topic of composite fatigue has been discussed within the ASME Subgroup on Graphite Core Components (SGCC). The SGCC faces a similar challenge in establishing rules and codes for these components since composites are usually fabricated/manufactured specifically to the requirements for each specific component. This makes development of a generic code for all composite components with different geometries, thermal requirements, mechanical needs, and chemical interactions particularly difficult. Specific requirements such as fatigue resistance will require a careful analysis of the component as well as the conditions the component is expected to experience. The SGCC is determining whether a general methodology can be imposed or whether this analysis should be the responsibility of the applicant.

RAI COMP-3: Section 3.5.4.2: What is the effect of oxidation on the fatigue strength of these composites? What information exists or needed to establish the effects of oxidation corrosion and potential cyclic fatigue of $\mathrm{C}-\mathrm{C}$ and/other ceramic tie rods and functionally-related core internals, such as straps. Describe plans to demonstrate seismic reliability of such components via analytical and/or experimental programs?

\section{Response COMP-3:}

See the revised introduction regarding the status of the NGNP design and development of composite materials (i.e. NGNP's General Response for Carbon Composite RAls).

However, in general, the topic of composite degradation and the effects of degradation on the composite performance are being investigated by the NGNP Project primarily through research grants to university research programs (i.e., the Nuclear Energy University Program [NEUP]). Long term composite degradation mechanisms and effects have been listed as areas of research interest in the NEUP program for a number of years, and some research, both at universities and in national labs, has been undertaken for this issue. In general, the phenomenon of fatigue corrosion in $\mathrm{C}-\mathrm{C}$ composites for nuclear applications has not been specifically addressed to date. It is anticipated that some data will be available from other non- 
Enclosure 1

September 27, 2011

CCN 225396

Page 60 of 67

nuclear applications such as C-C composite airplane braking pad development, composite aerospace applications, and other hi-tech applications utilizing composites.

Note that with the exception of the core outlet connection, which provides the transition between the core outlet plenum and hot gas duct, the identified components of interest would normally see low temperatures associated with the core inlet flow. Elevated temperature conditions associated with conduction cooldown LBEs would be limited in duration and, since there is no flow, would not impact the core outlet connection. The normal operating environment of the helium primary coolant would not be expected to result in significant oxidation.

RAI COMP-4: In Section 3.5.4.2, it is mentioned that fatigue tests were performed with component level tests for tie rods racetrack strap components. At what temperature and environment were these tests conducted, and how do those conditions compare to expected NGNP service conditions? Were such tests conducted with "reference" material to qualify the test?

\section{Response COMP-4:}

See the revised introduction regarding the status of the NGNP design and development of composite materials (i.e. NGNP's General Response for Carbon Composite RAls).

The component-level tests mentioned in Section 3.5.4.2 were conducted by the PBMR Program in South Africa. As noted in the response to RAI G-36, the PBMR Program has been terminated and the specific conditions of these tests are not presently available to the NGNP Project.

\section{COMP-5:}

Deleted by the NRC.

RAI COMP-6: Section 3.5.4.2: How will composite components, such as tie rods and straps, be attached or bonded to other components? What are the structural requirement considerations for these linking or bonding " devices?

Response COMP-6:

See the revised introduction regarding the status of the NGNP design and development of composite materials (i.e. NGNP's General Response for Carbon Composite RAls).

The tie rods and straps are mechanically attached. The specific details of the design were developed by PBMR, (Pty) Ltd., but are not available to the NGNP Project.

\section{COMP-7:}

Deleted by the NRC.

RAI COMP-8: Section 3.5.4.2: Discuss the need for and types of redundancy and/or diversity which will be considered for tie rods and straps.

Response COMP-8:

See the revised introduction regarding the status of the NGNP design and development of composite materials (i.e. NGNP's General Response for Carbon Composite RAls). The specific 


\section{Enclosure 1}

September 27, 2011

CCN 225396

Page 61 of 67

details of the design were developed by PBMR, (Pty) Ltd., but are not available to the NGNP Project. 
Enclosure 1

September 27, 2011

CCN 225396

Page 62 of 67

Ceramic Insulation RAls No. 5900 Revision 0

NGNP's General Response for Composite RAls:

The NGNP Project plans to update Section 3.4, Ceramic Insulation Materials, during the next revision of the white paper. The update will clarify the purpose of the information being provided for this section. The information provided in this section is presented as background information providing a historical summary of nuclear ceramic insulation material development and manufacturing used in previous reactor designs including foreign reactor programs. The introduction of these foreign high temperature gas-cooled reactors is not intended to represent them as a basis for NGNP core component qualification. The following provides the intended change:

Graphite, the principal material used in HTGR core structures, has a relatively high thermal conductivity. The high conductivity of graphite is advantageous in terms of transport of heat from the fuel to the helium coolant during normal operation and via the Reactor Cavity Cooling System during certain LBEs. In some applications, however, it is desirable or necessary to control the flow of heat from the graphite core structures to adjacent metallic components (e.g., core support structure) to avoid excessive temperatures. Ceramic insulation may be used in conjunction with the graphite core structures to achieve this objective. Two classes of ceramic insulation have been used in HTGRs to date, baked carbon and fused or sintered quartz. While quartz-based materials provide a greater degree of insulation, baked carbon is often utilized, where practical, based on economic considerations and the similarity of its properties (e.g., neutronic properties, coefficient of thermal expansion) to those of the adjacent graphite core structures

At present, specific ceramic insulation materials have not yet been selected for development within the NGNP Project.

In addition, there are no established general design codes or standards addressing ceramic insulation materials for HTGR applications that are analogous to the ASME Code for metallic or graphite components. However, there is a plan within ASME to address this shortcoming through the ASME Subgroup on Graphite Core Components (SGCC). This subgroup has been officially sanctioned by the Board on Nuclear Codes and Standards as part of the BPV Code Section III infrastructure. The SGCC has concentrated its efforts to date on nuclear graphite (see Section 3.3.4); however, high temperature composites and manufactured carbon (ceramic insulation) materials are also a part of the subgroup charter. The ASME Code section on nuclear graphite will be issued in 2011, and the expectation is that the composites and manufactured carbon material codes will be addressed thereafter.

Given the current status, the proposed bases for qualification of ceramic insulation components have not yet been developed. However, general information from past and present research and development programs is presented herein to provide a background understanding of the general issues that are involved in qualifying ceramic 
Enclosure 1

September 27, 2011

CCN 225396

Page 63 of 67

insulation components for use in HTGRs. The specific bases for qualification and regulatory review are to be developed later.

In this context, a discussion of baked carbon for use as core insulation is given in this section. In the subsections that follow, additional details are given regarding the manufacturing processes, properties, and prior uses of baked carbon. This is followed by a summary of the approach for the design and structural evaluation, as well as the representative bases for qualification of these insulation components.

In addition, the NGNP Project plans to update Section 5.2, Outcome Objectives for Nonmetallic Materials, based on the above clarification.

RAI INS-1: Table 7 in Section 3.4.2 provides properties data for carbon insulation and nuclear graphite. What ASTM material specification standard exists for carbon insulation materials for nuclear application to state nuclear grade carbon? Considering that the thermal conductivity of carbon insulation is lower than graphite, and thus potentially reducing resistance to thermal shock, what structural integrity requirements are contemplated for carbon insulation? Later, in Section 3.4.4, it is mentioned that Structural Reliability Class (SRC)-3 will be assigned to ceramic insulation components. What information is available on the strength of this insulation after multiple thermal shock loadings, and after irradiation?

\section{Response INS-1:}

See the revised introduction regarding the status of the NGNP design and development of ceramic insulation materials (i.e., NGNP's General Response for Composite RAls).

Note, however, that the transients that would be seen by thermal insulation between the outer edges of the graphite reflector and the core barrel or between the graphite core structures and metallic core support would be comparable to those that would be seen by the graphite core structures, i.e., with rates measured in hours to days. For this reason, thermal shock is not expected to be a significant issue.

RAI INS-2: In Section 3.4.3, "nuclear grade ASR-ORB carbon" is discussed. What is the specification for this "nuclear grade" material? Is NBC-07 also a "nuclear grade" carbon? If so, what specification makes it a "nuclear grade"?

\section{Response INS-2:}

As discussed in the introduction of this section, only general information from past and present research and development programs is presented herein to provide a background understanding of the general issues that are involved in qualifying ceramic insulation components for use within HTGRs. The NGNP Graphite Technology Development Program does not have specifications for ASR-ORB or NBC-07 carbon, nor are the specifications outlined within ASTM standards or the ASME code. Presumably, there was a specification that was accepted by the Japanese regulatory authority for HTTR, but at the present time the NGNP Project is not specifically requiring the use of these materials in the reactor core, and no information is currently available to the NGNP Project.

RAI INS-3: In Section 3.4.3, it is stated that "Shaped carbon blocks are used at various locations in the core structures to insulate selected components from hot gas flow." What type 
Enclosure 1

September 27, 2011

CCN 225396

Page 64 of 67

of thermal (heat transfer) analysis procedures are used to ensure adequate carbon thickness for the "shaped" carbon component to provide the required insulation? Does the thermal conductivity of carbon depend on temperature and neutron dose? If so, how this dependence accounted for in thermal calculations? Are such calculations based on consensus standard procedure?

Response INS-3:

See the revised introduction regarding the status of the NGNP design and development of ceramic insulation materials (i.e., NGNP's General Response for Composite RAls).

However, in general, the location of these components (i.e., outside of the core) will result in minimal radiation dose levels to the material. It is anticipated that minimal property changes will result from this low neutron dose. However, this assumption will be verified through neutron analysis once the core design specifications have been drafted, and appropriate thermal analysis will be conducted.

RAI INS-4: In Section 3.4.3, it is stated that "the carbon blocks around the reflector, at the top of the reflector and the upper insulation layer below the reflector, have $5 \mathrm{wt} \%$ boron carbide added to the carbon to reduce neutron irradiation to the adjacent metallic components in these areas." How does the addition of boron carbide affect the thermal conductivity as a function of temperature? What is the time-dependency of thermal conductivity at temperature for the life time of the carbon component?

Response INS-4:

Section 3.4.3 provides a discussion of past experience with the use of baked carbon insulation in HTGRs, including the HTTR and HTR-10. The information provided in this section is primarily provided for historical purposes and not intended for direct application to the NGNP design.

Past experience, based on thermal measurements taken by manufacturers, has shown that the addition of small amounts of boron carbide to ceramic insulting materials has minimal to no effect on the thermal conductivity of these materials. Additionally, in general, there is no indication that the addition of boron carbide to these materials significantly alters the lifetime thermal diffusivity/conductivity performance.

Further testing and data will be collected for qualifying the material once a baked carbon insulation material type(s) is selected for use.

RAI INS-5: In Section 3.4.3, it is stated that "the carbon insulation blocks were produced by the Lanzhou Carbon Works to ensure low thermal conductivity and good dimensional stability at high temperature." Clarify this statement to clearly identify what component or components are being described (e.g., the insulating block, or metallic structures) Why is dimensional stability important and to what extent? How do you assure that the good dimensional stability is maintained? What inspections would be conducted to assure this expected behavior?

\section{Response INS-5:}

See the revised introduction regarding the status of the NGNP design and development of ceramic insulation materials (i.e., NGNP's General Response for Composite RAls). 
Enclosure 1

September 27, 2011

CCN 225396

Page 65 of 67

However, in this general example the components being described are for insulating blocks at the bottom of the reactor. As such, they require low thermal conductivity/diffusivity properties to thermally protect the adjacent metallic components and high dimensional stability, since the support columns for the entire graphite core rest upon these insulating blocks and they must provide a very stable structure to ensure physical core stability.

RAI INS-6: In Section 3.4.4, it is stated that "the use of ceramic insulation in the CSC is restricted to areas where it is not exposed to significant fast neutron irradiation (e.g., <1018 n.cm-2 EDN) and, consequently, irradiation-induced changes in properties will be negligible." The value given for fast neutron irradiation appears to be misformatted. Is it correct to assume that it should appear as $<10^{18} \mathrm{n} \mathrm{cm}^{-2}$ ? Throughout Section 3.4 , clarify the various operating conditions, the specific materials to be used, and properties required to assure expected design performance.

\section{Response INS-6:}

The comment is correct. The intended value is $10^{18} \mathrm{n} / \mathrm{cm}^{2} \mathrm{EDN}$ (Equivalent DIDO Nickel). This dose corresponds to approximately $0.0013 \mathrm{dpa}$ and illustrates that the fast neutron dose is very small for these components. This formatting error will be corrected, and the conversion will be added to Section 3.4.4 in the next revision of the white paper. The various operating conditions, the specific materials to be used, and properties required to assure expected design performance cannot be provided at this time because they will be determined by the final design.

RAI INS-7: Table 8 in Section 3.4.5, characterizes baked carbon insulation properties. Temperature-dependent friction coefficient in helium between graphite and carbon is one of the properties. This friction property between graphite and baked carbon insulation has not been identified for characterization in Sections 3.3.6.2 or 3.3.6.3 for graphite. Explain this discrepancy.

\section{Response INS-7:}

The friction coefficient between graphite and baked carbon would be required only if baked carbon is used. Thus, it is included in the baked carbon section.

RAI INS-8: In Section 3.4.5, is the PBMR procedure for determining equivalent boron content, mentioned in Table 8, publicly available? Provide a description of the procedure, and discuss any review and approval by a consensus standards organization, such as ASTM?

Response INS-8:

See the revised introduction regarding the status of the NGNP design and development of ceramic insulation materials (i.e., NGNP's General Response for Composite RAls).

However, in general, there are ASTM standards, that specify the maximum boron content levels and how to determine the equivalent boron contents of nuclear materials. It is anticipated that these ASTM standards may be used when the NGNP reference design has been established or a designated designer identifies the specifications for ceramic insulating components. These standards include:

- ASTM D 7219, Standard Specification for Isotropic and Near-isotropic Nuclear Graphites 
Enclosure 1

September 27, 2011

CCN 225396

Page 66 of 67

- ASTM C 1233, Practice for Determining Equivalent Boron Contents of Nuclear Materials.

As noted in the response to RAI G-36, the PBMR Program has been terminated. The PBMR procedure for determining equivalent boron content is not presently available to the NGNP Project.

RAI INS-9: Section 3.4: Cracking and continuously inter-connected porosity is a possibility for ceramic materials. Thus, while insulating characteristics may be functionally adequate, what is the possibility of the coolant flowing through this inter-connected porosity ("thermal streaking") which could potentially lead to hot spots continuously impinged by hot gas on the metallic strictures? If such thermal streaking is possible, then how can the design assure the structural integrity of pressure boundary material?

Response INS-9:

See the revised introduction regarding the status of the NGNP design and development of ceramic insulation materials (i.e., NGNP's General Response for Composite RAls).

However, in general, fracture behavior of manufactured carbon and graphites, which depends greatly upon the defect microstructure, is currently being studied by NGNP graphite program (Reference 1) and the ASTM D02.F0 subcommittee on Manufactured Carbons and Graphite. The general observation is that the defect population within these manufactured carbon/graphite structures is not large or interconnected enough to pose a credible scenario where enough coolant gas flows through to create thermal streaking. The issue of bypass flows associated with fractures is essentially the same as stated for structural graphite components. The designer must demonstrate that coolant flows associated with credible fractures will not result in significant (i.e., sufficient to result in overheating of the metallic components) radial overheating from the active core, where heating is taking place, to the core periphery, where the core barre or core support structure are located. Since heated coolant flows tend to involve cooler inlet helium (which is at higher pressure), it is not likely that this mechanism will pose a significant issue.

Reference:

1. PLN-2497, 2010, "Graphite Technology Development Plan," Rev 1, Idaho National Laboratory, October 2010.

RAI INS-10: Section 3.4 states that ceramic insulation will be adjacent to metallic components. How will reactor operating conditions contribute to thermodynamic and chemical reactions which may occur between these materials? What are the consequences resulting from potential degradation due to such reactions? If there is spalling of insulation refractory materials, as is typical in the case of refractory (thermal protection) use, what are the consequences? How will such degradation be detected and its effects mitigated?

Response INS-10:

See the revised introduction regarding the status of the NGNP design and development of ceramic insulation materials (i.e., NGNP's General Response for Composite RAls). 


\section{Enclosure 1}

September 27, 2011

CCN 225396

Page 67 of 67

Note, however, that the temperature of the metallic components in the protected regions are close to the reactor inlet temperature during normal operation $\left(<300^{\circ} \mathrm{C}\right)$, and, thus, such reactions are unlikely. LBEs involving significantly elevated temperatures would be rare and of limited duration and location. 
Appendix E

NRC Letter, NGNP - Assessment of White Paper on High Temperature Materials, dated May 9, 2012 


\section{Appendix E}

\section{NRC Letter, NGNP - Assessment of White Paper on High Temperature Materials, dated May 9, 2012}

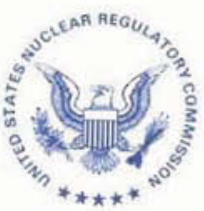

Mr. Jim Kinsey, Director

Regulatory Affairs

Next Generation Nuclear Plant Project

Idaho National Laboratory

P.O. Box 1625

2525 North Fremont Ave

Idaho Falls, ID 83415

\author{
UNITED STATES \\ NUCLEAR REGULATORY COMMISSION \\ WASHINGTON, D.C. 20555-0001
}

May 9,2012

\section{SUBJECT: NEXT GENERATION NUCLEAR PLANT - ASSESSMENT OF WHITE PAPER ON HIGH TEMPERATURE MATERIALS}

Dear Mr. Kinsey:

This letter forwards a report assessing the contents of a white paper submitted by the Next Generation Nuclear Plant (NGNP) Project and the Project's responses to initial requests for additional information (RAls) submitted by the Nuclear Regulatory Commission (NRC) after preliminary review. Specifically, this report assesses the Project's "NGNP High Temperature Materiais White Paper" (ADAMS accession number ML101800221).

The assessment report was developed by a working group composed of the NRC staff from the Office of New Reactors (NRO) and the Office of Nuclear Regulatory Research (RES). Note that this assessment reflects the opinions of the members of the working group and should not be construed as formal staff positions in the context of future licensing activities.

The assessment is necessarily preliminary, consistent with the high level at which the approaches have been presented, the ongoing status of the associated development and testing programs, and the lack of detail on the proposed NGNP design and how its safetyrelated performance will be analyzed for evaluation against appropriate criteria

The working group has noted a number of areas where the proposed approaches could be strengthened and where technical issues and design choices could potentially affect implementation of the approaches. The working group is aware of the related research and development activities led and conducted by Idaho National Laboratory (INL). The working group members have also regularly participated in INL meetings and conferences to provide input to part of the technical knowledge development.

The working group recognizes that the objective of the white paper was not to solicit a regulatory decision. Accordingly, the assessment report does not reach any final conclusions regarding the design and qualification of any NGNP components, materials, or their use in the plant design. Furthermore, the enclosed assessment does not constitute staff endorsement or rejection of any aspect of the ASME Code. Such endorsement is typically made via rulemaking in accordance with NRC's processes. The staff will not provide a final conclusion regarding the 
design and qualification of any NGNP components, materials, or their use in the plant design, until a NGNP combined license or design certification application is received and reviewed.

Many of the issues identified in the assessment can be addressed within the context of the Project's ongoing and planned development activities. It bears noting, however, that some of the more challenging potential issues might be most effectively resolved by conducting prototype-specific programs of operational testing, monitoring, surveillance, and inspection in the NGNP prototype reactor.

Please contact Jeffrey Cruz (Jeffrey.Cruz@nrc.gov, 301-415-0599) or Donald Carlson (Donald.Carlson@nrc.gov, 301-415-0109) if you have questions regarding the enclosed assessment report.

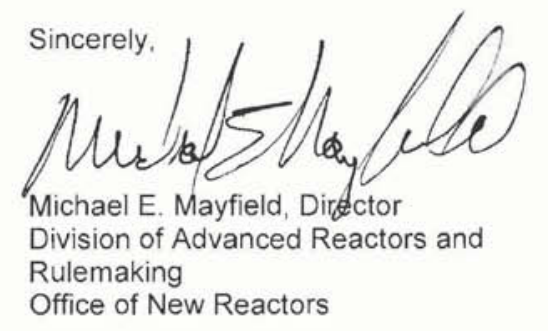

Project No:: 0748

Enclosures:

Assessment of White Paper Submittal on

High Temperature Materials

cc: COL - NGNP Mailing List 
OFFICE OF NEW REACTORS

\section{ASSESSMENT OF WHITE PAPER SUBMITTAL ON HIGH TEMPERATURE MATERIALS}

NEXT GENERATION NUCLEAR PLANT

PROJECT 0748

\section{INTRODUCTION}

The Next Generation Nuclear Plant (NGNP) Project was established by the U.S. Department of Energy (DOE) as required by Congress in Title VI, Subtitle C, of the Energy Policy Act of 2005 (EPAct). The mission of the NGNP Project (i.e., the Project) is to develop, license, build, and operate a prototype high temperature gas cooled reactor (HTGR) plant that generates high temperature process heat for use in hydrogen production and other energy-intensive industries while also generating electric power. To fulfill this mission, the Project is considering a modular HTGR with either a prismatic block or pebble bed core and safety features described as follows: ${ }^{1}$

"To achieve the safety objectives for the NGNP Project, the HTGR relies on inherent and passive safety features. Modular HTGRs use the inherent high temperature characteristics of TRISO-coated fuel particles, graphite moderator, and helium coolant, along with passive heat removal capability of a low-power-density core with a relatively large height-to-diameter ratio within an uninsulated steel reactor vessel to assure sufficient core residual heat removal under loss-of-forced cooling or loss-of-coolant-pressure conditions."

As stipulated by the EPAct, the Project and the Nuclear Regulatory Commission (NRC) have been engaged in pre-licensing interactions on technical and policy issues that could affect design and licensing of the NGNP prototype. Such early interactions are encouraged by the Commission Policy Statement on the Regulation of the Advanced Nuclear Power Plants, which states in part the following:

"During the initial phase of advanced reactor development, the Commission particularly encourages design innovations that enhance safety, reliability, and security... and that generally depend on technology that is either proven or can be demonstrated by a straightforward technology development program. In the absence of a significant history of operating experience on an advanced concept reactor, plans for the innovative use of proven technology and/or new technology development programs should be presented to

\footnotetext{
${ }^{1}$ INL/EXT-11-22708, "Modular HTGR Safety Basis and Approach," NGNP information paper submitted September 6, 2011, Project 0748, ADAMS accession number ML11251A169, excerpt page 8.
} 
the NRC for review as early as possible, so that the NRC can assess how the proposed program might influence regulatory requirements."

DOE's contractor, Idaho National Laboratory (INL), is conducting research and development in support of the Project and has prepared a series of white papers on aspects of the HTGR design and safety basis in order to obtain NRC feedback on design, safety, technical, and/or licensing process issues that could affect NGNP deployment.

On June 25, 2010, the Project submitted a materials white paper (MWP), designated as INL/EXT-09-17187 (ADAMS accession number ML101800221), addressing high temperature materials expected to be part of an eventual NGNP design. The cover letter for that submittal stated that the white paper

...provides the result of reviews of existing policies, regulations and guidance associated with acceptable materials for HTGR reactor applications. It includes development of a process for high-temperature component material selection and evaluation, leading to recommendations for qualification and acceptance of the HTGR reactor components. Metallic and non-metallic materials proposed for high-temperature service within the NGNP are identified and assessed in terms of supporting codes and standards and the existing bases for design and qualification. As part of this assessment, the processes for establishing the expected material performance requirements under operating and accident conditions are also described.

Following NRC Staff review of this paper, and pending resolution of associated follow-on questions or requests for additional information, the NGNP Project requests that NRC (sic) feedback and documentation of its review in a format that will facilitate resolution of key design, safety, and licensing issues in the high temperature materials area, and that can (sic) used as a firm for the preparation of future HTGR license application(s).

Section 5 of the MWP describes a series of "Outcome Objectives." These objectives are divided into two categories for metallic and non-metallic materials. The Project is seeking NRC staff review and feedback on these objectives in order to address materials issues in advance of a license application.

For metallic materials, the MWP requests that the NRC provide feedback on the suitability of the American Society of Mechanical Engineers (ASME) Code for design of reactor components that are expected to operate in conditions outside the envelope of existing power plants. The report describes prospective changes to the ASME Code to address these different operating conditions and the materials that may be used in the NGNP.

The ASME Code is also considering how to address graphite components in HTGRs. The MWP requests NRC feedback on proposed Code changes, along with the experimental 
program to characterize the effects of long term exposure to neutron irradiation and high temperatures on the graphite structures.

The MWP assessment was conducted by a working group composed of NRC personnel from the Office of New Reactors (NRO) and the Office of Nuclear Regulatory Research (RES). On July 25,2011 , the NRC working group provided a set of requests for additional information (RAl) consisting of general questions on the overall materials for NGNP, and questions on each of the materials, namely, high temperature metals and alloys, graphite, carbon-carbon and ceramic composites, and insulation materials (ADAMS accession number ML112030174).

The Project provided responses to the RAl questions on September 27, 2011 (ADAMS accession number ML11272A067). The current assessment addresses the RAI responses.

It should be noted that the NRC will not provide any final conclusions regarding the design and qualification of any NGNP components, materials, or their use in the plant design, until a NGNP combined license or design certification application is received and reviewed.

\section{ASSESSMENT}

The NRC working group has completed its assessment of the MWP and associated RAI responses. This assessment does not provide final regulatory conclusions on any aspect of the NGNP design or the completeness of requirements in technical data for design basis modeling of properties and their specific application to reactor operation. Such conclusions will be provided in the safety evaluation of a future license or design certification submittal. The feedback provided by the working group generally reflects the lack of detailed design information and the preliminary and pre-conceptual nature of limited reactor design information driving the contents of the MWP.

In developing this assessment report, the working group used:

- Information provided in the MWP

- RAI responses provided by the Project

- Follow-up discussions with Project technical staff

Potentially significant issues were identified in interactions outside the context of the RAI questions and responses. These issues concern the planned scope of graphite irradiation testing. The working group is concerned that the Project's testing plans do not presently include graphite irradiation at temperatures in the range of 250 to $600^{\circ} \mathrm{C}$. The working group acknowledges that data needs at the lower end of this irradiation temperature range were not evident for the helium-turbine NGNP conceptual designs that the Project was considering several years ago. However, for steam-turbine NGNP conceptual designs like those presented by the Project in April 2011, irradiation temperatures as low as 250 to $300^{\circ} \mathrm{C}$ would seem to

$$
\text { - } 3 \text { - }
$$


apply to graphite located in the upper core and reflector regions. The working group thus sees potential needs for testing particularly at the lowest graphite irradiation temperatures.

Associated needs for post-irradiation testing may include those for graphite mechanical properties as well as special measurements of graphite irradiation energy storage and release, specific heat, and thermal conductivity as may be needed to support the analysis of NGNP licensing basis events. Resolving this potential issue could necessitate significant additions or modifications to the Project's plans for graphite irradiation testing.

The remainder of this report presents the MWP assessment results under nine headings (I-IX) that categorize the Project's responses to specific RAI questions. The nine headings are explained as follows. Category I is used to classify responses that have provided enough clarifying information to satisfactorily address the technical concerns of the RAI. Category II is assigned when more research is needed to provide the information sought by the RAI. Category III is assigned when more work in the consensus codes and standards bodies (e.g. ASME) is needed to appropriately address the RAI. Category IV is used when the Project's response indicates that the RAI requests vendor-proprietary data or information that is beyond the scope of the white paper. Category $\mathrm{V}$ is assigned to a response that indicates that the information sought by the RAI is unavailable given that the conceptual NGNP design is not yet finalized. Category VI is assigned to responses that indicate that the technical concern of the RAI should be addressed during the actual design of the NGNP reactor. Category VII is used when the Project's response states that it will be revising the contents of the white paper pertaining to the RAI. Category VIII is assigned to responses that indicate the Project will withdraw portions of the white paper based on the RAI concern. Finally, Category IX is assigned to responses that do not adequately address the RAI. There are several cases in which the Project's response is applicable to multiple headings. Therefore, when applicable, the RAI response will be addressed under multiple headings of the report.

The working group notes that the use of the aforementioned categories is not intended to provide a regulatory decision on the acceptability of the white paper or the RAI responses. Given the preliminary and conceptual nature of the NGNP design, the NGNP Project should use the categories as a tool to guide its future efforts toward the resolution of the discussed issues. All RAI questions and responses are fully documented in the RAI response document referenced above (ADAMS accession number ML11272A067), which is duplicated in Appendix $A$ of this report for more convenient reference.

Note: RAI coding schemes are: COMP - Composite materials; G - Graphite; HTM - High Temperature Materials; INS - Insulating Materials; GEN - General.

Category l: The Project's responses have addressed the technical concern of the RAI and there is no additional action needed to address the issue. In cases where further work is needed to implement the plans described in the RAI response, other categories are assigned as needed. 
a. For RAI G-4, the response states that, "an ongoing activity in NGNP Graphite Technology Development Plan (Reference 1) will provide the data to determine the parameters described above and their effects on the rate of oxidation. Further, various university research grants have been awarded in this area with the intent to determine the effects of oxidation on graphite performance, specifically at normal operating conditions. These data will be combined with the programmatic data generated from the NGNP graphite research and development program to ensure an adequate understanding of oxidation mechanisms in all three oxidation regimes." The working group considers this explanation satisfactory.

b. RAI G-8, RAI G-11, RAI G-12, RAI G-23, RAI G-30, and RAI G-49: The response answers in a satisfactory way the objective principle of the working group request for additional information. However, not all planned studies have been completed to date, and some modifications to this white paper could still evolve in the light of the last ongoing study developments, further actions by the ASME Code Committee to refine existing code, etc. These items are further discussed below under different categories.

c. On RAI HTM-3, the working group notes the Project's response that, "the higher pressure is on the outside of the hot gas duct, any leakage would be from outside (cold) to inside (hot)." The working group notes also that, "the thickness selected for the inner liner of the hot gas duct will include an allowance for corrosion and erosion that has not yet been established." This response has also been noted under Category VI.

d. For RAI HTM-8, the Project's response includes the statement, "Cobalt is the alloying element that would be of greatest potential concern for activation if it were carried through the core in the coolant stream. This element is in low concentration in Alloy $800 \mathrm{H}$ and has not been found to be present in significant quantity in the oxide scale. The microchemistry of the oxide scale resulting from environmental interaction with helium containing varying levels of impurities is being characterized in the NGNP Technology Development Program."

e. For RAI HTM-17, the working group considers the clarification provided as partially incomplete. Also, see comment under Category IX for this response.

f. RAls HTM-1, HTM-2, HTM-18, and HTM-19: The Project's response answers in a satisfactory way the objective principle of the working group request for additional information. However, not all planned studies have been completed to date, and some modifications to this white paper could still evolve in the light of the last ongoing study developments, further actions by the ASME Code Committee to refine existing code, etc. These items are further discussed below under different groups.

g. RAI INS-2: The working group has noted the following response from the Project related to RAI INS-2: "The NGNP Graphite Technology Development Program does not have specifications for ASR-ORB or NBC-07 carbon, nor are the specifications outlined within ASTM standards or the ASME code. Presumably, there was a specification that was accepted by the Japanese regulatory authority for HTTR, but at the present time the

$$
\text { - } 5 \text { - }
$$


NGNP Project is not specifically requiring the use of these materials in the reactor core, and no information is currently available to the NGNP Project."

h. RAIs INS-1, INS-7, and INS-10: The Project's response answers in a satisfactory way the objective principle of the working group request for additional information. However, not all planned studies have been completed to date, and some modifications to this white paper could still evolve in the light of the last ongoing study developments, further actions by the ASME Code Committee to refine existing code, etc. These items are further discussed below under different groups.

Category 1I: The Project's responses indicate that more research is being conducted or will be conducted that, when completed, will provide the information sought by the RAI. Essentially, the information sought are not available now and it is expected that the NGNP Project will inform the working group of any new information related to the technical concerns as it becomes available. Other headings are assigned as needed to appropriately categorize the unresolved issue.

i. For RAI GEN-3, the Project states that, "Specific aging issues for the graphite and metallic components are being actively pursued within the Graphite and High Temperature Materials Research \& Development (R\&D) Programs (References 1-3). Specific aging issues include irradiation induced dimensional changes and creep within graphite components, creep-fatigue and creep within metallic components, long-term environmental degradation of metallic and graphite components, and loss of mechanical strength and fracture resistance in graphite due to long term irradiation dose. Information from these NGNP programmatic studies will determine the appropriate mitigation and inspection measures required to assure the safety case of the high temperature gas-cooled reactor (HTGR). The NGNP program is not directly assessing the aging issues of composite systems but is directing work being performed at university programs under the Nuclear Energy University Program (NEUP).

However, specific aging monitoring programs, monitoring methods, periods, and examination areas of components can only be determined once the reference design, technical requirements, components, and material selections have been established. Aging management will be addressed as a part of the future license application process. "This is also noted under Category VI.

j. In responding to RAI GEN-6, the Project has stated that, "In general, the data needs and additional research and development needs identified in the PIRT (phenomena identification and ranking tabulation) reviews are consistent with the plans (Reference 1). Graphite oxidation from a steam incursion is being addressed through oxidation activities in the plan. Dust generation and tribology studies are being performed in university research programs under the NEUP program. The effects or probability of fracture failure leading to spallation of graphite components is being addressed under the multi-axial strength and failure mechanism development sections of the graphite technology development program."

$-6-$ 
On this, the working group will still refer to at least one of the vendor DDNs, for example, General Atomics, which indicates that their design would potentially depend on the outcome of the DOE research. For example, General Atomics DDN states, "... possible strategy is to startup the NGNP without having obtained the complete data base as defined by the above DDNs and use data obtained during the startup phase (either from NGNP operation or ongoing testing at DOE laboratories) to satisfy some elements of these DDNs." (Ref: "Technology Development Road Mapping Report for NGNP with $750^{\circ} \mathrm{C}$ Reactor Outlet Helium Temperature", PC-000586, dated May 11, 2009, and available from INL portal website)

k. For RAI HTM-4, the Project's response includes the following statement: "The NGNP Project is currently investigating the potential loss of load bearing area for $800 \mathrm{H}$ materials under quasi-static environmental conditions to support the quantification of this effect. Quantification of erosion/corrosion effects will be determined later after further design details become known." This response is also noted under Category VI.

I. For RAI HTM-12, the working group notes the Project's response, "The standard atmosphere for generating data incorporated in the Code is laboratory air. Thus, the Code does not address other key requirements of the design of these components, such as the emissivity, corrosion resistance, thermal aging, and irradiation effects. All of these potential influences on the properties are being addressed in the NGNP Technology Development Program."

m. For RAI G-4, the response states that, "An ongoing activity in NGNP Graphite Technology Development Plan (Reference 1) will provide the data to determine the parameters described above and their effects on the rate of oxidation. Further, various university research grants have been awarded in this area with the intent to determine the effects of oxidation on graphite performance, specifically at normal operating conditions. These data will be combined with the programmatic data generated from the NGNP graphite research and development program to ensure an adequate understanding of oxidation mechanisms in all three oxidation regimes."

n. For RAI G-6, the response states that,". However, this initial estimate may change based upon the results from NGNP graphite irradiation experiments, wherein the onset of turnaround will be determined as a function of dose for each graphite grade that has been identified as a potential candidate for NGNP. Inspection of replaceable reflector elements removed from the reactor during refueling operations will provide additional information that will augment the replacement schedule decisions based upon irradiation experiments performed by the NGNP Technology Development Program."

o. For RAI G-14, the response states that, "The NGNP Graphite Technology Development Program will provide data on the behavior of directional orientation material property values for isotropic graphite types (i.e., IG-110, etc.) for the NGNP operating conditions of temperature, fluence, atmosphere (coolant chemistry) and residence time. These data will be generated from the AGC irradiation experiment, and some data will also be obtained from the as-fabricated baseline testing program once it is complete. Additional

$$
\text { - } 7 \text { - }
$$


historical data on isotropic graphite types will be provided, if necessary, once a design has been established and an application is submitted".

p. For RAI G-16, the response states that, "The raw materials used to fabricate the graphite will be different, resulting in possible very small changes to the material properties between different batches. This variation between batches is one of the main research activities for the NGNP graphite program. Billets from different batches (and different raw material sources) will be compared to determine the variation in material properties as a function of batch. In addition, the irradiation testing program will use samples from different batches to ascertain the effects of raw material variation on irradiation induced material property changes. These changes will be determined from the NGNP Graphite Technology Development Program once irradiation testing is completed."

q. For RAI G-31, the response states that, "Further evidence of "pore generation" will become available through the NGNP Graphite Irradiation Program, where new X-ray tomography tools will be utilized to examine the pore structure of irradiated graphite. The mechanism of polycrystalline graphite crack/pore generation during irradiation is expected to be common to all NGNP candidate graphite grades, as is the form of the irradiation induced volume and dimensional change curves. However, the magnitude of the minimum volume shrinkage and the temperature dependent fluence at which the cohesive life limit is attained is expected to be somewhat different for the various candidate grades. Where the reactor design requires the graphite components to operate at high neutron doses and temperatures, data will be required to define the ASME code cohesive life limit for the graphite such that it has sufficient strength for replacement or decommissioning."

r. For RAI G-33, the Project has responded: "Since the 3-dimensional temperature and dose profiles within the graphite components are design specific, the cumulative effect this has on graphite response will be addressed for all material properties once the design has been established. Once the proper conditions have been understood from the design, the variation in stress relief response (i.e., creep) as a function of this 3dimensional temperature and dose variation can be effectively modeled based upon the results from the graphite irradiation program. The irradiation program will provide irradiation material property changes over a range of dose $(0.5-7 \mathrm{dpa})$ at three nominal temperature levels $\left(600,900\right.$, and $\left.1200^{\circ} \mathrm{C}\right)$ and three different stress levels $(7 \mathrm{MPa}, 14$ $\mathrm{MPa}$, and $21 \mathrm{MPa}$ ). Using these empirically determined values and an appropriate analytical creep model (currently being developed by the NGNP Graphite Program), the material response over a range of dose, stress, and temperature can be calculated for all positions within the graphite core. As the dose (or temperature) evolves over time the material response can be calculated up to a dose level of $7 \mathrm{dpa}$. Operation times or doses over an accumulated dose of $7 \mathrm{dpa}$ will require additional data to verify the model and calculations." This response has also been discussed under Category VI.

s. For RAI G-34, the Project's response states that, "The NGNP Graphite Program is investigating the various effects and mechanisms influencing creep (References 1-3). The measured creep rate as a function of dose/fluence and temperature for each major graphite grade is being investigated within the AGC irradiation program. Additionally, 
determination of the mechanisms responsible for irradiation induced creep is being pursued by the international graphite community (Reference 4). Specific creep data measurements for the NGNP major grades as well as further understanding of the mechanisms will be available from the Graphite Technology Development Program in the future."

t. For RAI G-35, the response has been stated as: "The issue of sub-sized test specimens is a recognized issue for the NGNP Project, and a number of activities are being conducted to determine any potential bias from utilizing samples with non-standard sizes. These activities include determining the effect of size (i.e., thickness) on thermal diffusivity measurements, the effect of grain size to sample test volume ratio for mechanical testing, the effect of sample size and geometry on fundamental frequency measurements of elastic properties, and sample oxidation rate changes as a function of test specimen size. Other scoping studies are either planned or anticipated in order to verify that the testing standards used for characterization are valid for these nonstandard sized specimens. Results from these scoping study activities will be included in the data reports from the NGNP Graphite Technology Development once they are completed."

u. For RAI G-38, the response states that "The NGNP Project plan to provide sufficient data and information on the selected graphite types is outlined in the plan (Reference 1). The NGNP Graphite Technology Development Plan (TDP) outlines the development activities to qualify the major graphite types and provides a timeline of when the data are expected to be available for review."

v. For RAI G-39, the response states that, "Surface roughness of the graphite components does have an effect on the coolant flow and the extent of this effect is being investigated through university lead NEUP research projects." The working group has an additional question based on this response. Since surface degradation could potentially occur to graphite during reactor operation due to chemical reactions, such as oxidation, for example, does this imply that variations in coolant flow could potentially occur during reactor normal operation? If so, how will this be addressed in the design of graphite core components?

w. For RAI G-41, the Project's response is: "The NGNP Graphite Program is investigating the various effects and mechanisms influencing creep. Within the AGC irradiation program the measured creep rate as a function of dose/fluence and temperature for each major graphite grade is being investigated for dose levels up to turnaround levels (0-7 dpa). Over this dose range, the samples can be loaded in compression or tension without differences. Dose levels of $\sim 7 \mathrm{dpa}$ are estimated to allow $12-15$ years of active service for the graphite components receiving the highest flux levels for the current reactor designs. If the reactor design requires graphite components to receive doses exceeding $7 \mathrm{dpa}$, additional tensile loaded irradiation experiments will be required to measure the creep rate of the major grades of graphite for dose levels past turnaround." This response is also noted under Category VI. 
x. For RAI G-43, the response states: "The NGNP Graphite Program will be measuring irradiation induced specific heat changes, if any, during post irradiation examination of the tested grades of graphite. As stated in the Graphite Technology Development Plan, there is minimal change expected from these samples exposed to high temperature irradiation. However, if significant changes are detected from the post irradiation examination (PIE) the graphite program will focus more attention on the measurements and mechanisms."

y. For RAI G-44, the response states: "NGNP Project is working with various universities within the NEUP research program to measure any possible changes to the emissivity of graphite during exposure to the reactor core environment. If significant changes are discovered to actually occur, the program will perform additional activities to measure the extent of these changes (Reference 1)."

z. For RAI G-46, the response states that, "The replacement of fuel elements will be governed by the fuel cycle. The replacement of reflector blocks will be guided by the data from the AGC program, supplemented by examination of replaced blocks. Also, see the response to RAI G-29 for projected fluences at replacement." This response is also noted in Category VI.

aa. For RAI-G-47, the response is stated thus: "In the next revision of the white paper, Section 3.3.6.4 (page 43) will be modified to clarify that the Petten experiments were not irradiated to greater than $20 \mathrm{dpa}$. The NGNP AGC program will be producing irradiation data on both fine and medium grained-graphite in the future. The following change will be made: Test specimens from these grades were irradiated at $750^{\circ} \mathrm{C}\left(1382^{\circ} \mathrm{F}\right)$ up to fluences of approximately $10 \mathrm{dpa}$. A second phase of irradiation at $950^{\circ} \mathrm{C}\left(1742^{\circ} \mathrm{F}\right)$ up to fluences of between 12 and $14 \mathrm{dpa}$ has been completed. These irradiations at HFR Petten (Netherlands) aim to provide irradiated properties data that can be used to compare irradiation behavior and post-irradiation properties of the different reactor grades available today. When the HFR Petten irradiation data are publically released, NGNP will compare the Petten data with NGNP irradiation data." This response is also included in Category VII.

bb. For RAI COMP-3, the Project's response is: "...in general, the topic of composite degradation and the effects of degradation on the composite performance are being investigated by the NGNP Project primarily through research grants to university research programs (i.e., the Nuclear Energy University Program [NEUP]). Long term composite degradation mechanisms and effects have been listed as areas of research interest in the NEUP program for a number of years, and some research, both at universities and in national labs, has been undertaken for this issue. In general, the phenomenon of fatigue corrosion in $\mathrm{C}$-C composites for nuclear applications has not been specifically addressed to date. It is anticipated that some data will be available from other non-nuclear applications such as $\mathrm{C}-\mathrm{C}$ composite airplane braking pad development, composite aerospace applications, and other hi-tech applications utilizing composites." 
cc. For RAI INS-4, the response is stated as, "Past experience, based on thermal measurements taken by manufacturers, has shown that the addition of small amounts of boron carbide to ceramic insulating materials has minimal to no effect on the thermal conductivity of these materials. Additionally, in general, there is no indication that the addition of boron carbide to these materials significantly alters the lifetime thermal diffusivity/conductivity performance. Further testing and data will be collected for qualifying the material once a baked carbon insulation material type(s) is selected for use."

Category III: The Project's response indicates that more work needs to be performed in the consensus codes and standards bodies(i.e. ASME) to respond to the RAI. This is really work in progress and it is expected that the NGNP Project will inform the working group of any new information related to the technical concerns as it becomes available.

a. For all RAls related to the high temperature materials section involving potential code application, the Project's responses state in general that, "....specific Code Cases will be modified to acknowledge the anticipated evolution from the present Code Cases to the new Division 5 rules. In the RAI responses below, references to Code Cases N-201-5 and N-499-2 should be understood in the above context. The modification to the white paper will be completed upon resolution of the issues raised in the RAls."

b. For RAI HTM-11, the working group has noted the Project's response, "The Code allowable for design using $800 \mathrm{H}$ will be extended by ASME to a range of $850-900^{\circ} \mathrm{C}$ and up to 500,000 hours in air. This time and temperature will define the design limits for this alloy."

c. For RAI HTM-12, the working group has noted the Project's response, "The standard atmosphere for generating data incorporated in the Code is laboratory air. Thus, the Code does not address other key requirements of the design of these components, such as the emissivity, corrosion resistance, thermal aging, and irradiation effects."

d. For RAI HTM-26, the response states that, "Also, as discussed in Section 3.2.5.4, the Code does not address key requirements of the design components, such as corrosion resistance and thermal aging effects. Therefore, additional research \& development effort will be required." The working group has noted this statement and would consider this during future staff evaluation of the applicable ASME Code case for endorsement with potential conditions.

e. For RAI G-13, the response states that, "The new ASME graphite design code does not currently provide guidance in selecting graphite grades for use in components with thin ligaments. Such features are, therefore, the responsibility of the respective designers. The NGNP Project will petition the ASME Subgroup on Graphite Core Components to include guidance for selection of graphite grades for core components incorporating thin ligaments."

f. For RAI G-20, the response states that, "The new ASME graphite design code does not presently address requirements for designs with thin ligaments. The evaluation of such

$$
-11 \text { - }
$$


features is, therefore, the responsibility of the respective designers. NGNP will petition the ASME Subgroup on Graphite Core Components to address requirements for thin ligaments (also see response to RAI G-13)."

g. For RAI G-40, the response states that, "In addition, the NGNP Project will petition the ASME committee to provide more guidance on the cohesive life limit, taking into account coolant chemistry and irradiation induced creep."

h. For RAI COMP-2, the response states that, "... in general, the topic of composite fatigue has been discussed within the ASME Subgroup on Graphite Core Components (SGCC). The SGCC faces a similar challenge in establishing rules and codes for these components since composites are usually fabricated/manufactured specifically to the requirements for each specific component. This makes development of a generic code for all composite components with different geometries, thermal requirements, mechanical needs, and chemical interactions particularly difficult. Specific requirements such as fatigue resistance will require a careful analysis of the component as well as the conditions the component is expected to experience. The SGCC is determining whether a general methodology can be imposed or whether this analysis should be the responsibility of the applicant."

Category IN: The Project's response indicates that the RAI requests vendor-proprietary data or information that is stated to be beyond the scope of the materials white paper. Information are vendor specific and since the vendor is not finalized, this information cannot be disseminated now. Other headings are assigned as needed to appropriately categorize the unresolved issue.

a. For RAI G-24, the Project's response states that "graphite manufacturing processes are controlled by and proprietary to the manufacturers. The NGNP Project does not have access to this information and therefore cannot comment on manufacturing processes and facilities. Questions regarding the graphite manufacturers' processes and facilities should be directed to the specific graphite manufacturer and issues should be addressed during the design and licensing application phase." This response is also binned in Category VI.

Category V: The Project's response indicates that because the conceptual design of the NGNP is still evolving, the answers to the RAl are not yet available. It is expected that the NGNP Project will inform the working group of any new information that may resolve technical concerns as it becomes available. Other headings are assigned as needed to appropriately categorize the unresolved issue.

a. In RAI GEN-2, it is stated that, "the generation of insulation-derived debris from the hot duct assembly would require a major failure of the internal liner of the hot duct assembly. For the upper plenum shroud, the generation of insulation-derived debris would require major failure of metallic cover plates." The working group comments: "Arguably, other mechanisms could potentially operate as well. For example, hightemperature atmospheric chemical reactions between the insulation and the environment, insulation and the contacting metallic alloy could potentially result in

$$
-12 \text { - }
$$


degradation products, which could be volatiles as well as solids, with an activity coefficient of unity. Unless chemical equilibrium thermodynamics calculations provide contrary information, such chemical reactions should be considered feasible for insulation degradation. See Response HTM-28 also."

Also, a major failure cannot be discounted, per se. Just because it is a major failure, that doesn't mean it can't happen (e.g., Takoma Narrows bridge). Need to look at HTM3 to see what additional basis is provided.

b. For RAI GEN-6, the response states that, "The High Temperature Materials White Paper, as well as all of the other NGNP white papers, was written in a manner to be generic with regard to HTGR technology (i.e., independent of variations among potential reactor suppliers in design details and technology development needs). This approach is appropriate at this stage of the NGNP Project, with no decision having yet been made regarding which reactor supplier will conduct the final design of the NGNP. Accordingly, specific DDNs are not discussed in any of the NGNP white papers."

For RAI GEN-6, the response states that, "the NGNP Project is referring to a future risk informed and performance based regulatory infrastructure." It is not clear that the RIPB framework is comprehensive with regard to engineering requirements for structural integrity. The DID white paper provides only a limited discussion of ASME requirements, for example, with much of the substantial discussion given in a footnote on page 19 of that paper. That footnote states that ISI requirements for the helium pressure boundary are expected to be based on component reliability targets. Given that the Project's NGNP proposal is predicated on very high retention of fission products within the fuel particles, it is not clear how the HPB reliability targets will be conservatively established. At the extreme, one could argue that no ISI is required at all if there is no chance fission products will be released from the fuel.

c. For RAI HTM-4, the response states that, "Quantification of erosion/corrosion effects will be determined later after further design details become known."

d. For RAI G-15, the response states that, "The conceptual design of the HTGR is still underway, and a final decision regarding the HTGR design has not yet been made. Accordingly, the requested comparison cannot be made at this time. The reactor designer will use the key requirements in a design specification to select a graphite grade, considering manufacturability, grain size, and graphite costs, to achieve compliance with the ASME graphite design rules."

e. For RAI INS-3, the response states that, "However, in general, the location of these components (i.e., outside of the core) will result in minimal radiation dose levels to the material. It is anticipated that minimal property changes will result from this low neutron dose. However, this assumption will be verified through neutron analysis once the core design specifications have been drafted, and appropriate thermal analysis will be conducted." 
f. For RAI INS-6, the Project's response includes: "...The various operating conditions, the specific materials to be used, and properties required to assure expected design performance cannot be provided at this time because they will be determined by the final design." This response is also included in Category VI.

Category VI: The Project's response indicates that the technical concern contained in the RAI willshould be addressed during the actual design of the NGNP reactor. It is expected that the NGNP Project will inform the working group of any new information related to the technical concerns as it becomes available. Other headings are assigned as needed to appropriately categorize the unresolved issue.

a. For RAI GEN-3, the response states that, "Aging management will be addressed as a part of the future license application process."

b. For RAI GEN-5, the Project's response does not clearly address the question. The reference to the DID methodology describes the role of the pressure boundary only in terms of a radiological boundary, as opposed to the need for structural integrity.

c. For RAI HTM-2, the response states that, "The actual temperature of the vessel would be still lower by some $25-50^{\circ} \mathrm{C}$, depending upon the details of the design." The working group assessment notes this expectation. If a different temperature range were to be in the actual design, this could potentially affect working group assessment or feedback.

d. For RAI HTM-3, the working group has noted the Project's response: "...the thickness selected for the inner liner of the hot gas duct will include an allowance for corrosion and erosion that has not yet been established." This response has also been included under Category I.

e. For RAI HTM-3, the response states that, "The potential for flow induced vibration and its effects on the hot gas duct liner will be addressed by analysis. The effects of vibration on the insulating properties of the hot gas duct will be characterized by testing." The working group considers these as open items which need to be addressed in a licensing submittal. As written, the working group cannot endorse a vague proposal for future analysis and testing.

f. For RAI HTM-4, the response states that, "Quantification of erosion/corrosion effects will be determined later after further design details become known." This response is also noted under Category II.

g. For RAI HTM-25, the response states that, "The tenacity of this oxide may require experimental verification in either thermal cycling or flow testing if further design information suggests conditions that are significantly outside the base of experience (not expected)." The working group has noted this as a potential follow-up item for the future when the design is finalized.

$-14-$ 
h. For RAI HTM-28, the response states that, "The compatibility of the liner and insulation material will be addressed by testing where data are not presently available. Testing of the insulating characteristics of the liner, including vibration testing and cyclic thermal testing are needed to confirm the expected performance of the insulation system and to identify any potential for insulation degradation resulting from the plant design duty cycle. Details regarding the above will be addressed during detailed design efforts and the future license application process."

i. For RAI G-24, the Project's response states that "graphite manufacturing processes are controlled by and proprietary to the manufacturers. The NGNP Project does not have access to this information and therefore cannot comment on manufacturing processes and facilities. Questions regarding the graphite manufacturers' processes and facilities should be directed to the specific graphite manufacturer and issues should be addressed during the design and licensing application phase." This response is also noted under Category IV.

j. For RAI G-33, the Project's response is: "Since the 3-dimensional temperature and dose profiles within the graphite components are design specific, the cumulative effect this has on graphite response will be addressed for all material properties once the design has been established. Once the proper conditions have been understood from the design, the variation in stress relief response (i.e., creep) as a function of this 3 dimensional temperature and dose variation can be effectively modeled based upon the results from the graphite irradiation program. The irradiation program will provide irradiation material property changes over a range of dose $(0.5-7$ displacements per atom (dpa)) at three nominal temperature levels $\left(600,900\right.$, and $\left.1200^{\circ} \mathrm{C}\right)$ and three different stress levels (7 megapascals (MPa), $14 \mathrm{MPa}$, and $21 \mathrm{MPa}$ ). Using these empirically determined values and an appropriate analytical creep model (currently being developed by the NGNP Graphite Program), the material response over a range of dose, stress, and temperature can be calculated for all positions within the graphite core. As the dose (or temperature) evolves over time the material response can be calculated up to a dose level of $7 \mathrm{dpa}$. Operation times or doses over an accumulated dose of $7 \mathrm{dpa}$ will require additional data to verify the model and calculations." This response is also noted under Category II.

k. For RAI G-41, the response is: ".... If the reactor design requires graphite components to receive doses exceeding $7 \mathrm{dpa}$, additional tensile loaded irradiation experiments will be required to measure the creep rate of the major grades of graphite for dose levels past turnaround." This response is also noted under Category II.

I. For RAI G-46, the response states that, "The replacement of fuel elements will be governed by the fuel cycle. The replacement of reflector blocks will be guided by the data from the AGC program, supplemented by examination of replaced blocks. Also, see the response to RAI G-29 for projected fluences at replacement." This response has also been noted under Category II.

m. For RAI COMP-1, the response states that, "Once a reference design for the NGNP -15 - 
core components have been established quantitative measurements/attributes will be presented in support of the composite components. These measured properties will be compared to the specification requirements established within the reference design criteria."

n. For RAI INS-6, the response states, "The comment is correct. The intended value is $1018 \mathrm{n} / \mathrm{cm} 2$ EDN (Equivalent DIDO Nickel). This dose corresponds to approximately $0.0013 \mathrm{dpa}$ and illustrates that the fast neutron dose is very small for these components. This formatting error will be corrected, and the conversion will be added to Section 3.4.4 in the next revision of the white paper. The various operating conditions, the specific materials to be used, and properties required to assure expected design performance cannot be provided at this time because they will be determined by the final design." This response has also been included in Category VII.

o. For RAI INS-8, the Project's response is: "However, in general, there are ASTM standards, that specify the maximum boron content levels and how to determine the equivalent boron contents of nuclear materials. It is anticipated that these ASTM standards may be used when the NGNP reference design has been established or a designated designer identifies the specifications for ceramic insulating components. These standards include:

- ASTM D 7219, Standard Specification for Isotropic and Near-isotropic Nuclear Graphite

- ASTM C 1233, Practice for Determining Equivalent Boron Contents of Nuclear Materials

Furthermore, the response states that, "As noted in the response to RAI G-36, the PBMR Program has been terminated. The PBMR procedure for determining equivalent boron content is not presently available to the NGNP Project."

p. For RAI INS-9, the response states that, "The issue of bypass flows associated with fractures is essentially the same as stated for structural graphite components. The designer must demonstrate that coolant flows associated with credible fractures will not result in significant (i.e., sufficient to result in overheating of the metallic components) radial overheating from the active core, where heating is taking place, to the core periphery, where the core barrel or core support structure are located. Since heated coolant flows tend to involve cooler inlet helium (which is at higher pressure), it is not likely that this mechanism will pose a significant issue."

Category VII: The Project's response indicates that it will be revising, as stated in the response, the contents of the white paper pertaining to the RAI. Based on the RAI, the white paper will be modified to reflect adequate response to RA/s. It is expected that the NGNP Project will inform the working group of any revisions to the white paper as a result of the technical concerns. Other headings are assigned as needed to appropriately categorize the unresolved issue.

a. For high temperature materials issues related to code, the Project's response states, "....specific Code Cases will be modified to acknowledge the anticipated evolution from 
the present Code Cases to the new Division 5 rules. In the RAI responses below, references to Code Cases N-201-5 and N-499-2 should be understood in the above context. The modification to the white paper will be completed upon resolution of the issues raised in the RAls."

b. For RAI HTM-13, HTM-15, and HTM-16, the response states that, "At this time, the NGNP Project is not considering the use of Alloy X/XR at the current core outlet temperatures. Section 3.2.3 will be deleted from the whitepaper, as will other areas of the whitepaper that address Alloy X/XR."

c. For RAI HTM-17, the response states that, "Section 3.2.4.2 should have listed fatigue as an important consideration for designing components made from modified $9 \mathrm{Cr}-1 \mathrm{Mo}$ alloy. During the next revision, the white paper will be corrected to include fatigue in Section 3.2.4.2."

d. For RAI HTM-21, the response states that, "In the next update of the High Temperature Materials White Paper, the sentence in the second paragraph of Section 3.2.4.3 will be deleted to provide clarification."

e. For RAI HTM-27, the Project's response states that, "A discussion of the potential effect of fatigue should have been provided in Section 3.2.6.2. Therefore, during the next revision of the white paper, Section 3.2.6.2 (page 25) will be revised"

f. For RAI HTM-30, the response states that, "In the next revision of the White Paper, Section 5.1 will be further updated to make it clear that the ASME Code is not proposed as the exclusive basis for qualification. This will be done in conjunction with the changes noted in NGNP's General Response for Metals RAls at the beginning of the Metals RAI section."

g. For RAI G-6, the response states that, "During the next revision of the white paper, Section 3.3 .1 (page 29) will be revised as shown in the response to RAI G-5 to provide clarification regarding the ASME design process."

h. For RAI G-10, the response states that, "During the next revision of the white paper, Section 3.3.2 (page 29) will be revised to provide clarification regarding the graphite grade selection process..."

i. For RAI G-13, the response states that, "During the next revision of the white paper, Section 3.3.3 (pages 30-31) will be revised to provide clarification regarding the ASME design process..."

j. For RAI G-17, the response states that "In the next revision of the white paper, Section 3.3.4 (page 32) will be revised to provide clarification regarding the ASTM standards..."

k. For RAI G-19, the response states that, "Currently, the NGNP Project is developing a document to further elucidate the ASME graphite design rules. The document will

$$
-17-
$$


provide the background theories used in the ASME design rules and their application in code assessments (e.g., compressive strength requirements, use of tensile strength for determination of probability of failure requirements for various structural reliability classes, how the graphite component lifetime is determined using the design code). The plan is for this document to be an addendum to the updated white paper in the future. If the document becomes available prior to the update to the white paper, it will be provided as a reference material."

I. For RAI G-21, the response states that, "In addition, "volatile carbon artifacts" will be replaced with "volatile components" in Section 3.3.4.2."

m. For RAI G-25, the response states that, "Currently, the NGNP Project is developing a document to further elucidate the ASME graphite design rules. The document will provide the background theories used in the ASME design rules and their application in code assessments (e.g., compressive strength requirements, use of tensile strength for determination of probability of failure requirements for various structural reliability classes, how the graphite component lifetime is determined using the design code). The plan is for this document to be an addendum to the updated white paper in the future. If the document becomes available prior to the update to the white paper, it will be provided as a reference material." The response also states that, "In addition, Table 4, Maximum probability of failure for each safety class, will be revised to clarify the maximum probability of failure for the respective structural reliability classes."

n. For RAI G-26, the Project's response states that, "During the next revision of the white paper, Section 3.3.5.2 (page 36) will be revised to provide clarification regarding the ASME Code..."

o. For RAI G-28, the response provided includes the statement, "During the next revision of the white paper, Section 3.3.5.2 (page 36) will be revised to provide clarification regarding the ASME Code."

p. For RAI G-29, the response states that, "In the next revision of the white paper, Section 3.3.6.1 (page 36) will be revised to provide clarification regarding the service conditions..."

q. For RAI G-32, the Project's response is: "Currently, the NGNP Project is developing a document to further elucidate the ASME graphite design rules. The document will provide the background theories used in the ASME design rules and their application in code assessments (e.g., compressive strength requirements, use of tensile strength for determination of probability of failure requirements for various structural reliability classes, how the graphite component lifetime is determined using the design code). The plan is for this document to be an addendum to the updated white paper in the future. If the document becomes available prior to the update to the white paper, it will be provided as a reference material. During the next revision of the white paper, Section 3.3.6.3 (page 39) will be revised to provide clarification regarding the ASME code rules..." 
r. For RAI G-36, the Project's response is: "In the next revision of the white paper, Section 3.3.6.4 (page 40) will be modified .... to clarify the status of the PBMR program."

s. For RAI G-37, the Project's response has been stated as: "During the next revision of the white paper, NGNP Section 3.3.3 will be revised to clarify the statement..." The response also states that, "Also, to clarify this section, the statement that iso-molded graphites need to be used for prismatic designs will be deleted."

t. For RAI G-47, the response states that, "In the next revision of the white paper, Section 3.3.6.4 (page 43) will be modified to clarify that the Petten experiments were not irradiated to greater than $20 \mathrm{dpa}$. The NGNP AGC program will be producing irradiation data on both fine and medium grained-graphite in the future." This response is also noted in category 2 .

u. For RAI G-48, the Project's response is: "During the next revision of the white paper, Section 3.3.6.4 (page 43) will be modified to clarify the graphite irradiation program..."

v. For RAI G-53, the Project's response is: "The NGNP Project uses foreign reactor high temperature reactor program data only as background material and will not use this data for final design or licensing. The NGNP Project cannot comment on technical aspects of other foreign governments' or foreign countries' high temperature gas reactor programs, since these programs and reactors are not under NGNP Project control, nor will they be used to support licensing of the NGNP.

In the next revision of the white paper, Section 4.2.1.1 (page 63) will be modified to clarify ASME code for graphite structures."

w. For RAI INS-1 through 10, the Project has stated in its response thus: "The NGNP Project plans to update Section 3.4, Ceramic Insulation Materials, during the next revision of the white paper. The update will clarify the purpose of the information being provided for this section. The information provided in this section is presented as background information providing a historical summary of nuclear ceramic insulation material development and manufacturing used in previous reactor designs including foreign reactor programs. The introduction of these foreign high temperature gascooled reactors is not intended to represent them as a basis for NGNP core component qualification."

"In addition, the NGNP Project plans to update Section 5.2, Outcome Objectives for Nonmetallic Materials, based on..."

x. For RAI INS-6, the response states, "The comment is correct. The intended value is $1018 \mathrm{n} / \mathrm{cm} 2$ EDN (Equivalent DIDO Nickel). This dose corresponds to approximately $0.0013 \mathrm{dpa}$ and illustrates that the fast neutron dose is very small for these components. This formatting error will be corrected, and the conversion will be added to Section 3.4.4 in the next revision of the white paper. The various operating conditions, the specific materials to be used, and properties required to assure expected design performance cannot be provided at this time because they will be determined by the

$$
-19 \text { - }
$$


final design." This response is also captured in Category VI.

Category VIII: The Project's response indicates that it will withdraw portions of the original white paper text, based on the RAI concern. It is expected that the NGNP Project will inform the working group of any subsequent revisions to the white paper as a result of the technical concerns.

a. In response to RAI G-18, the Project has stated that, "“End-product" specimens will be used in the irradiation program. This paragraph repeats the behavior of isotropic materials previously discussed. It will therefore be deleted in the next revision to the white paper.

The following paragraph in Section 3.3.4 will be deleted to provide clarity to this section.

"It is important to recognize that the degree of isotropy only serves as an initial indicator of the graphite behavior under irradiation. End-product isotropy is influenced by raw material, grain size, forming method, and heat treatment. Graphite billets can be fabricated by extrusion, isostatic molding, or vibration molding. Extrusion tends to yield graphite that are less isotropic and less dimensionally stable under irradiation than molded graphite, although isotropy can be improved remarkably through careful control of raw material and processing. Isostatic-molded graphite is commonly available in smaller sizes than extruded grades, while vibration molding is available for larger block sizes."

b. Regarding RAI G-19, the response states that, "The term "strength reserves" is not a concept used in the ASME code. Therefore, during next revision of the white paper, the use of this term will be deleted."

c. In response to RAI G-50, the response states that, "Section 3.3.7.2, "Reliability and Integrity Management (RIM) Program and the Outcome Objective for RIM Program," as discussed in Section 5.2 Non-Metallic Materials, will be deleted from the white paper. The plant operational considerations presently discussed in Section 3.3.7.2 will be defined during the final design and licensing application phases.

The term "inherent fault tolerance" is not used in the ASME graphite design rules and, therefore, does not represent any concept of design safety. Its inclusion in the white paper was based on the judgment that the basic characteristics of the design make it tolerant to failures."

d. For RAI G-51, the response states that, "As stated in the response to RAI G-50, Section 3.3.7.2, "RIM Program" and the corresponding Outcome Objective, Item 3 in Section 5.2, "Non-Metallic Materials," will be deleted from the white paper."

e. For RAI G-52, the response states that: "There is operational experience with initial placement of permanent reflectors; however, there is no operational experience with replacement of permanent reflectors in HTGRs.

$$
-20 \text { - }
$$


As stated in the response to RAI G-50, Section 3.3.7.2, entitled, "RIM Program" and the corresponding Outcome Objective, Item 3 in Section 5.2, "Non-Metallic Materials," will be deleted from the white paper."

f. In response to RAI G-54, the Project has stated," The following paragraphs in Section 4.2.1 (page 65) will be deleted in the next revision of the white paper, since, the PBMR program is no longer accessible by the NGNP Project, and the data will not be used by the NGNP Project for graphite qualification.

As an example, Figure 5 illustrates the relationship between the legacy German database and the PBMR Specific Materials Test Reactor Program irradiation conditions that were selected earlier for the proposed PBMR Demonstration Power Plant in South Africa. The solid blue line in the figure represents the projected temperature-fluence envelope at the end of service life for components that serve a structural function ( $S R C \neg 1$, as defined in Table 4), whereas the dotted red line denotes a similar envelope for the most highly-irradiated nonstructural components adjacent to the pebble fuel (SRC-2). As shown in Figure 5, the primary and secondary MTR data are designed to both confirm the applicability of the historical data and to supplement that data where required.

Finally, the proposed service life of the graphite components in the PBMR implies the need for a relatively lengthy MTR program. On this basis, the PBMR approach is to acquire MTR data for a significant portion of the service life prior to the start of the lead reactor. The balance of the MTR data would be acquired in such a manner that it substantially leads the actual operation of the reactor."

g. In response to RAI G-55, the Project has stated that, "The graphite behavior theories discussed in the PIRT panel will not be used for final NGNP design or NGNP licensing. The ASME graphite core design rules use empirical mechanical and thermal data collected from qualified providers with known statistical confidence levels. The relevance of these graphite behavior theories is moot, since the ASME graphite core design rules will be used.

The second paragraph in Section 4.2.1.3 will be deleted, which includes the statement: "The PIRT panel also concluded that theories that can explain graphite behavior have been postulated and, in many cases, shown to represent experimental data well."

h. For RAls related to Carbon-Carbon Composites Section of the Materials White Paper, the Project has responded thus: "The NGNP Project plans to update Sections 3.5 and 4.2.3, Composites Materials, during the next revision of the white paper. Section 4.2.3 "Composites" will be deleted and Section 3.5 will be updated to clarify the purpose of the information being provided for this section. The information provided in this section is presented as background information providing a historical summary of nuclear 
composite development and manufacturing used in previous U.S. reactor designs as well as foreign reactor programs. The introduction of these foreign high temperature gas-cooled reactors is not intended to represent them as a basis for NGNP core component qualification. "

"In addition, the NGNP Project plans to update Section 5.2, Outcome Objectives for Nonmetallic Materials, based on above clarification."

Category IX: The Project's response does not adequately address the RAl concern. It is expected that the NGNP Project will inform the working group of any new information related to the technical concerns as it becomes available. Other headings are assigned as needed to appropriately categorize the unresolved issue.

a. For RAI HTM-5, the response states, "Although the NGNP technology and development program is expecting to generate Alloy $800 \mathrm{H}$ crack growth data at a later date, those testing plans are not included in current NGNP Project documentation. Once these test plans have been formalized and documented, that information then can be shared with the NRC." It is not clear if the proposed test plan will address RAI concerns.

The response also states that, "Note that since the hot gas duct liner does not serve a pressure retaining function, extensive cracking would be required to result in major failure of that component." The working group has two comments on this response. (1) This will nevertheless contribute to by-pass flow and potential hot streaking in the cross "vessel", which could potentially lead to excessive creep deformation and failure or heat cracking. See Response HTM-28. (2) This may be true, but the responses also note that there is a pressure differential from the cold to the hot duct. It is unlikely that NRC would accept failure of the hot duct liner.

b. For RAI HTM-7, the response states that, "The liner is not a pressure boundary and, by design, will see minimal loads during normal operation and during other events within the duty cycle." The working group notes that, however, there is a pressure differential across it (compressive, though). It's not obvious that there will be minimal loads. It seems reasonable to anticipate that there may be thermal loads, including possible thermal striping and other transients. The response also states that, "since the main circulator includes a flow-assisted check valve that passively closes when the HTS circulator stops." The working group notes with interest that this design detail is described when so many others are not. The working group further notes that there is a need for an SSC to provide this function. The response states further that "pressurized conduction cool down events are rare events with a correspondingly low number of cycles." However, the working group opines that this is yet to be demonstrated by detailed design.

c. For RAI HTM-10, the response states that, "detailed histories of the heat exchanger operating conditions that would allow direct extrapolation are not presently available 
to the NGNP Project." The working group is still of the opinion that it is not appropriate to claim extensive HTGR operating experience. For example, adverse materials' performance took far longer to manifest itself in some cases for LWRs.

d. In response to RAI HTM-17, it is stated that "this strain range-allowable cycles curve (Fig. T-1420-1E) contains data out to 108 cycles." However, it is not clear to the working group whether the data is applicable to 60 -year operating life. The working group would need additional clarification for an informed review.

e. The response for RAI HTM-20 states that "For these reasons, corrosion is not a particular concern." The working group believes that sufficient information is not available to support this conclusion. On the contrary, published information indicates that internal oxidation could be a potential technical issue. Ref: $\mathrm{C}$. Cabet et al. "High temperature corrosion of two structural nickel base alloys in the primary coolant helium of a VHTR", Paper No: E00000143, Proceedings HTR2006: 3rd International Topical Meeting on High Temperature Reactor Technology, October 1-4, 2006, Johannesburg, South Africa.

f. The response to RAI HTM-21 states that, "there are currently no plans to consider the use of Modified $9 \mathrm{Cr}-1 \mathrm{Mo}$ for the current HTGR steam cycle concept in a pressureretaining application. For most of the core internals and support structures where Modified $9 \mathrm{Cr}-1 \mathrm{Mo}$ is being considered, the fabrication would not be performed on-site. Where onsite fabrication is necessary, it would be performed to the same quality standards as shop fabrication, including heat treatments." The working group considers this as a potential commitment for some future activity under NRC's regulatory authority. The working group's current assessment of the white paper does not provide an NRC staff position on or approval of any aspect of the design, qualification of any NGNP components, materials, or their use in the plant design, or fabrication.

g. For RAI HTM-22, the response states that, "The same requirements (including the requirement to account for the effects of neutron irradiation) are judged to be applicable to the modular HTGR." However, the response does not provide an adequate description on what the requirements are or why they are appropriate. Also, the response states that, "Note also that fracture toughness improves with temperature over the operating range of interest." The working group notes that, besides fracture toughness, an important property is ductility to maintain plastic accommodation for potentially propagating crack. It is not clear whether any potential adverse change in design ductility could potentially occur,

h. For RAI HTM-26, the response states that, "There is currently no intention to utilize HTTR materials operating data to proceed with design work for the NGNP Project." If this statement is true, then, arguably, the references to HTTR operating experience should be removed altogether. (See also working group comment on response to RAI HTM-10. 
i. For RAI HTM-28, the response states that, "the stresses seen by the liner are minimal by design, and the thermal structural characteristics of the liner will be addressed by analysis." Response says stresses "are minimal," but should say "will be minimal" or some similar anticipatory wording. Lacking a design, a judgment on stresses is speculative.

j. The working group considers the response to RAI HTM-29 as being vague, needing further clarification. If KTA rules are not relevant, then inclusion adds to confusion regarding its applicability to ASME design code rule.

k. For RAI G-4, the working group is satisfied with the clarification that more research is underway to address technical concerns contained in the RAI. However, the response to the RAI has generated additional need for clarification. The response states that, "The phenomena that control all three regimes are well understood and models have been developed that seamlessly account for all three regimes. These models have been verified and validated to a limited extent using data from previous experiments." However, it is not clear or apparent that the mentioned reference contains such information. The response also states that, "Oxidation of graphite components must also be considered, however, its influence on component strength and, hence, structural integrity is not expected to be significant for events within the design basis." This is due to the limited time for oxidation during one of these events (seconds to minutes for water ingress; hours to a few days for air ingress), and further mitigated by the limitations on oxidant ingress that are integral to the respective designs."

The working group needs data at the LBE temperatures (and air velocity, for oxidation dynamics) to support this statement. The working group is aware of the limited material loss in the Windscale accident. The working group is also aware of the ambiguity of graphite loss in Chernobyl accident. Furthermore, the working group is aware of literature indicating increased oxidation due to activated metals acting as catalysts for enhanced oxidation at temperatures of interest. Thus, the working group believes that this information should be adequately evaluated to support such statement.

Ref (1) Von E. Stolz und F. L. Werner, Mannheim, "Kohlenstofftransport in den ochtemperaturreaktoren THTR und AVR," atomwirtschaft , pp 99 - 103,Februar 1968. Ref (2) M-L. Pointud, W. Karcher, N. Pollitt, J. Lothe, "Catalytic Influence of Different Metals on Corrosion Rate of Graphite," Dragon Project Report, April 1965.

I. Regarding RAI G-7, the response indicates that Ft. St. Vrain fuel blocks were replaced without any problems. But, specifics are lacking, such as what was the criteria for replacement and how many were replaced and when, etc. The literature citied could not be located via typical web search, including government OSTI site, and DOE's Information bridge site. Where can the working group find this and other documents referenced in the RAI responses? Also, the working group is aware of minor structural issues encountered during refueling outage in Ft. St. Vrain. (Ref: D. A. Copinger, D. L. Moses, "Fort Saint Vrain Gas Cooled Reactor Operational Experience", NUREG/CR-6839; ORNL/TM-2003/223 (2004). 
m. In response to RAI COMP-4, the Project has stated that, "The component-level tests mentioned in Section 3.5.4.2 were conducted by the PBMR Program in South Africa. As noted in the response to RAI G-36, the PBMR Program has been terminated and the specific conditions of these tests are not presently available to the NGNP Project."

n. In response to RAI COMP-6, the Project has stated that, "The tie rods and straps are mechanically attached. The specific details of the design were developed by PBMR, (Pty) Ltd., but are not available to the NGNP Project."

o. For RAI COMP-8, the response is: "The specific details of the design were developed by PBMR, (Pty) Ltd., but are not available to the NGNP Project."

p. For RAI INS-5, the Project's response is: "However, in this general example the components being described are for insulating blocks at the bottom of the reactor. As such, they require low thermal conductivity/diffusivity properties to thermally protect the adjacent metallic components and high dimensional stability, since the support columns for the entire graphite core rest upon these insulating blocks and they must provide a very stable structure to ensure physical core stability." This response has not adequately provided the information sought in the RAI.

\section{Summary and Conclusions}

The working group noted the following challenges in conducting an informed assessment of the Project's responses to working group RAls related to outcome objectives of the MWP:

- The NGNP plant design is still conceptual, with no confirmation of materials used for the reactor pressure vessel and its appurtenances, core support structures, primary system boundary, connecting piping, and other components important to safety and the applicable material specifications, design stress, time and temperature and other environmental conditions. It should also be noted that MWP may still be revised, based on working group $\mathrm{RAI}$ and some other new related information.

- RAls raised technical issues that are planned to be addressed by ongoing or planned research programs of DOE and/or other national or international entities.

- RAls concerning codes and standards (C\&S) for use in NGNP design are either currently being addressed by the $\mathrm{C} \& \mathrm{~S}$ bodies or the Project will be petitioning the $\mathrm{C} \& \mathrm{~S}$ bodies to take on the assignment.

- The white paper may be revised by the Project to address RAls. Also, portions of the original white paper text will be withdrawn based on several RAI concerns.

- The Project also will revise some of the outcome objectives of the MWP, based on working group RAls. 
- Finally, some of the Project's responses did not adequately address the working group's RAI.

The working group understands that the objective of the white paper was not to solicit a regulatory decision but rather to scope out how the working group perceives the provided materials with regard to substantiating the safety case. However, due to lack of detail and preliminary and pre-conceptual reactor design information driving the contents of the white paper, the working group cannot comment on the completeness of requirements of technical data for design basis, modeling of properties and their specific application to reactor operation. These types of comments may only be provided in the safety evaluation of a future combined license or design certification submittal.

The working group further notes that the enclosed assessment does not constitute staff endorsement or rejection of any aspect of the ASME Code. Such endorsement is typically made using NRC's standard practice of reviewing the adequacy and sufficiency of the ASME Code rules through the rulemaking process to incorporate by reference the latest editions and addenda of the ASME Codes and Code cases.

Listed alphabetically below are the NRC working group participants who contributed to this assessment report. Principal contributors are designated with an asterisk.

Donald Carlson, NRO

Amy Hull, RES

Shah Malik, RES

*Neil Ray, NRO

*Makuteswara Srinivasan, RES 


\section{APPENDIX A}

The body of this report refers to specific RAI questions and responses. The RAI response document referenced in the report (ADAMS accession number ML11272A067) fully documents all RAI questions and responses. This Appendix provides a copy of that RAI response document for convenient reference.

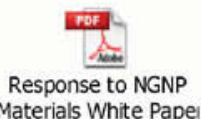

$-27-$ 
cC:

\author{
Mr. Lionel Batty \\ Nuclear Business Team \\ Graftech \\ 12300 Snow Road \\ Parma, OH 44130
}

Ms. Michele Boyd

Legislative Director

Energy Program

Public Citizens Critical Mass Energy

and Environmental Program

215 Pennsylvania Avenue, SE

Washington, DC 20003

Mr. Edward M. Burns

Licensing Manager

U.S. Design Certification

PBMR Pty. Limited

5627 Beacon Street

Pittsburgh, PA 15217-2011

Mr. Eugene S. Grecheck

Vice President

Nuclear Support Services

Dominion Energy, Inc.

5000 Dominion Blvd.

Glen Allen, VA 23060

Michael L. Hammond

Technological Hazards Program Office

Radiological Emergency Preparedness

Program, Region X

U.S. Department of Homeland Security

130 228th Street, SW

Bothell, WA 98021

Mr. Brendan Hoffman

Research Associate on Nuclear Energy

Public Citizens Critical Mass Energy and

Environmental Program

215 Pennsylvania Avenue, SE

Washington, DC 20003
Mr. Hugh Jackson

Public Citizen Critical Mass Energy Project

215 Pennsylvania Avenue, SE

Washington, DC 20003

Beryl Landis

902 Rosier Road

Waynesboro, GA 30830

Mr. Edwin Lyman

Scientific Director

Nuclear Control Institute

1000 Connecticut Ave., NW, Suite 410

Washington, DC 20036

Dieter Matzner

Director, Power Plant Delivery

PBMR Pty. Limited

Lake Buena Vista Building

1267 Gordon Hood Avenue

PO Box 9397

Centurion 0046

Republic of South Africa

Mr. Dobie McArthur

Director, Washington Operations

General Atomics

1899 Pennsylvania Avenue, NW

Suite 300

Washington, DC 20006

Mr. Thomas P. Miller

U.S. Department of Energy

NE-20, Room A286

Headquarters - Germantown

19901 Germantown Road

Germantown, MD 20874-1290

PBMR Pty. Limited

Lake Buena Vista Building

1267 Gordon Hood Avenue

PO Box 9396

Centurion 0046

Republic of South Africa 
COL - NGNP Mailing List

Mr. David Repka

Winston \& Strawn LLP

1700 K. Street, NW

Washington, DC 20006-3817

Mr. Tony Robinson

AREVA NP, Inc.

3315 Old Forest Road

Lynchburg, VA 24501

Dennis R. Spurgeon

Assistant Secretary for Nuclear Energy

U.S. Department of Energy

1000 Independence Avenue, SW

Room 5A-143

Washington, DC 20585

Mr. Robert E. Sweeney

IBEX ESI

4641 Montgomery Avenue

Suite 350

Bethesda, MD 20814

Edward G. Wallace

Sr. General Manager

U.S. Programs

PBMR Pty. Ltd.

PO Box 16789

Chattanooga, TN 37416

Page 2 of 4 


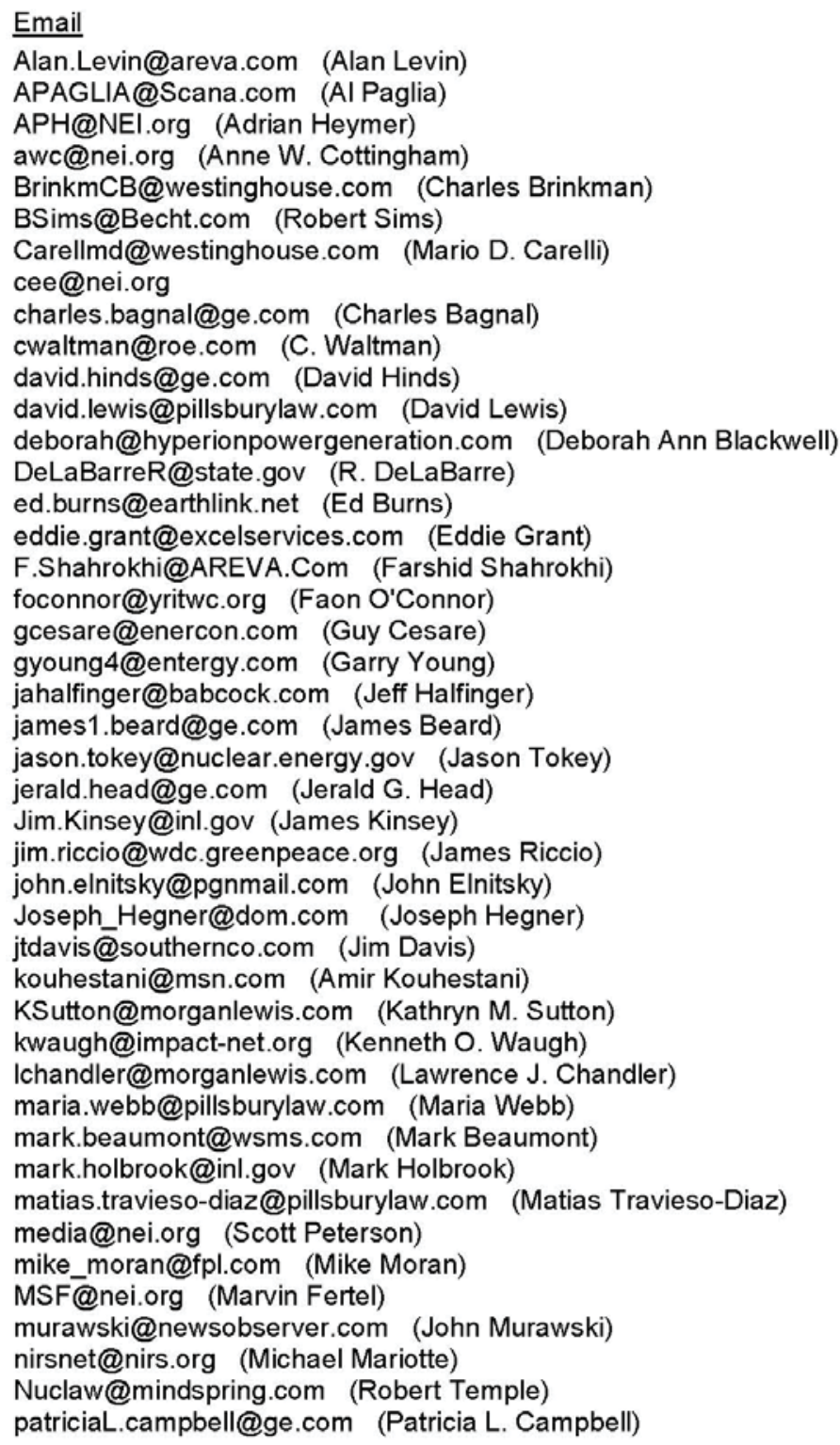


COL - NGNP Mailing List

Paul@beyondnuclear.org (Paul Gunter)

pbessette@morganlewis.com (Paul Bessette)

rbarrett@astminc.com (Richard Barrett)

rclary@scana.com (Ronald Clary)

RJB@NEl.org (Russell Bell)

sabinski@suddenlink.net (Steve A. Bennett)

sandra.sloan@areva.com (Sandra Sloan)

sfrantz@morganlewis.com (Stephen P. Frantz)

shobbs@enercon.com (Sam Hobbs)

stephan.moen@ge.com (Stephan Moen)

Tansel.Selekler@nuclear.energy.gov (Tansel Selekler)

TJKim@babcock.com (T.J. Kim)

tom.miller@hq.doe.gov (Tom Miller)

trsmith@winston.com (Tyson Smith)

Vanessa.quinn@dhs.gov (Vanessa Quinn)

Wanda.K.Marshall@dom.com (Wanda K. Marshall)

whorin@winston.com (W. Horin) 